\title{
Combining Node and Variable Selection Heuristics for Faster MIP Solutions
}

\author{
by \\ Xiaoke Lu
}

A Thesis submitted to the Faculty of Graduate Studies and Research in

Partial fulfillment of the requirements for the degree of

\section{Master of Applied Science (M.A.Sc.) \\ in Electrical and Computer Engineering}

Ottawa-Carleton Institute of Electrical and Computer Engineering Faculty of Engineering

Department of Systems and Computer Engineering

Carleton University

Ottawa, Ontario, K1S 5B6, Canada

January 8,2020

(C) Xiaoke Lu, 2020 


\section{Abstract}

When the branch and bound method is used to solve a mixed-integer linear program (MIP), the Node selection (NS) and variable and direction selection (VDS) heuristics significantly affect the time to find the integer-optimal solution.

Wojtaszek and Chinneck [2010] developed a new node selection heuristic including a modification on the best-projection method, a new backtrack triggering method and the active node search threshold. They suggested that this new node selection heuristic will provide the best branch and bound performance and improve the state of the art when coupled with the variable and direction selection heuristic by Driebeek and Tomlin. An observation in their work also indicated that a feasibilityoriented variable and direction selection method coupled with good node selection method can possibly provide the best MIP problem solution time. There are other works showing that MIP characteristics will influence the branch and bound performance.

In this thesis, various variable and direction selection methods are tested coupled with the node selection heuristic by Wojtaszek and Chinneck. Rules are developed to select VDS / NS configuration depending on MIP characteristics.

Empirical results show a new VDS / NS configuration outperforms the state of the art as well as the VDS / NS configuration found by Wojtaszek and Chinneck. The hypothesis that a feasibility - oriented VDS coupled with a good NS heuristic will provide the fastest MIP solution time is disproved. A new hybrid VDS/NS selection heuristic is developed and shown to provide better results than any individual VDS/NS configuration or the state-of-the-art default configuration. 


\section{Acknowledgements}

I would like to thank my supervisor Professor John W. Chinneck for his insights, patience and professionalism in this research. I benefited greatly from his guidance which I will continue to follow in my career.

I would like to thank my friend Yuan Sun and Chongchong Wu for the

programming help.

Last but not the least, I would like to thank my parents for their support and encouragement. 


\section{Table of Contents}

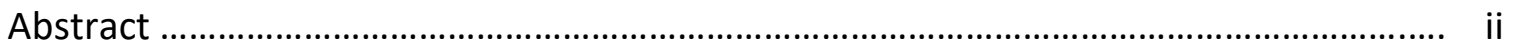

Acknowledgements …………………....................................................................... iii

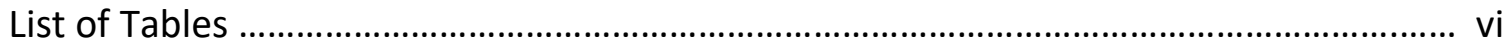

List of Figures .................................................................................................. vii

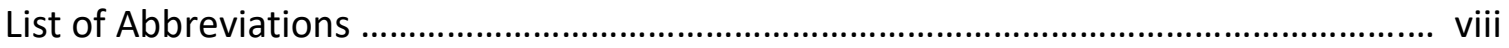

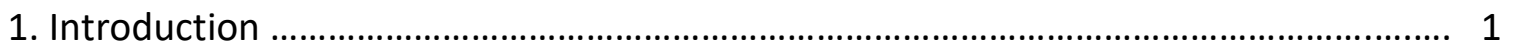

2. A Review of Mixed Integer Linear Programming .......................................................... 4

2.1 Definition of MILP ................................................................................... 4

2.2 The Branch and Bound Method ..................................................................... 5

2.2.1 Node selection and Backtracking ………………………............... 9

2.2.2 Branching Variable and Direction Selection ................................... 10

2.2.3 Example Branch and Bound Solution ........................................... 11

3. State of the Art in Node, Variable and Direction Selection Heuristics .......................... 15

3.1 Node Selection Methods ............................................................................. 15

3.1.1 Basic Node Selection Methods .................................................... 16

3.1.2 Estimation-based Node Selection Heuristics .............................. 17

3.1.3 Distribution Node Selection .......................................................... 21

3.1.4 Backtrack Triggering …………………………………………... 22

3.1.5 Active Node Search Threshold .................................................... 23

3.2 Variable and Direction Selection Methods ……………………………....... 25

3.2.1 Objective-Oriented Variable and Direction Selection ................... 26

3.2.1.1 Pseudo-Cost Based Branching .............................. 26

3.2.1.2 Heuristic by Driebeek and Tomlin ....................... 27

3.2.2 Feasibility-Oriented Variable and Direction Selection ................... 28

3.2.2.1 Active Constraints Variable Selection ................................. 28

3.2.2.2 Probability-Based Branching ............................................. 29 
3.2.2.3 Violation-Based Branching ……………………………... 32

3.3 Branching Direction ............................................................................... 32

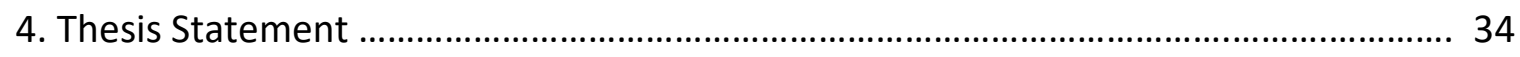

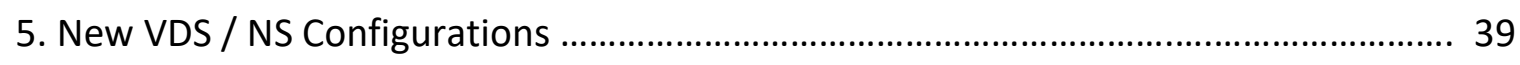

5.1 Node Selection Heuristic ............................................................................. 39

5.2 Variable and Direction Selection Heuristic .................................................... 44

5.3 VDS / NS Configurations ........................................................................... 49

5.4 MIP Characteristics for Rule Development ………………………............... 50

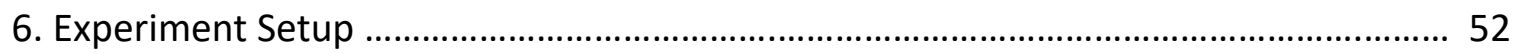

6.1 Hardware and Software......................................................................... 52

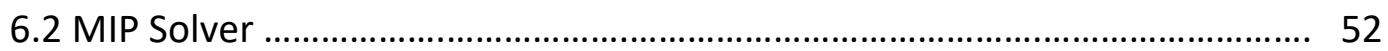

6.3 Performance Measures .................................................................................. 54

6.4 MIP Instances ……………………………………................................. 57

6.5 Experimental Design ................................................................................ 61

6.5.1 Experiment 1: VDS / MBESTP - ASP - ANST Pairings .................. 62

6.5.2 Experiment 2: Identifying the Best VDS / NS Configuration ...... 63

6.5.3 Experiment 3: Rules for Hybrid Configuration ............................. 64

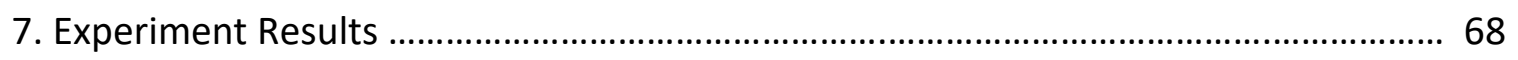

7.1 Experiment 1: VDS / MBESTP - ASP - ANST Pairings …………………….... 68

7.2 Experiment 2: Identifying the Best VDS / NS Configuration ........................... 72

7.3 Experiment 3: Rules for Hybrid Configuration ................................................ 76

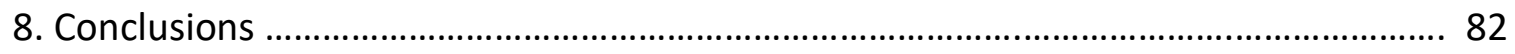

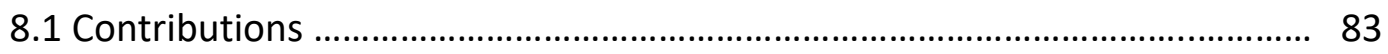

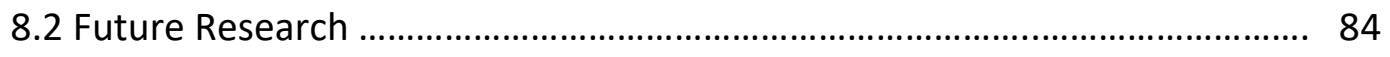

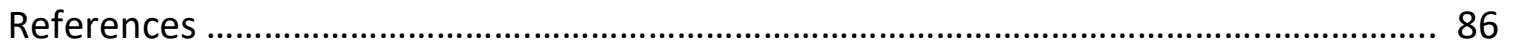

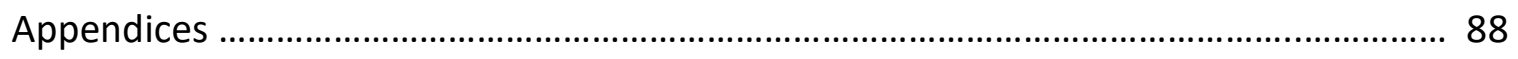




\section{List of Tables}

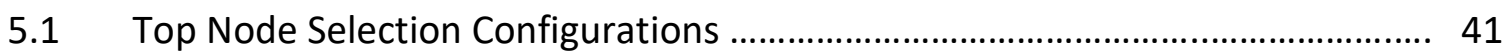

5.2 Performance of 9 Node Selection Configurations ............................................. 42

5.3 VDS methods available in GLPK MIP solver ..................................................... 44

$5.4 \quad$ Testing NS and VDS combinations .................................................................. 50

6.1a Test models - part 1 ...................................................................................... 59

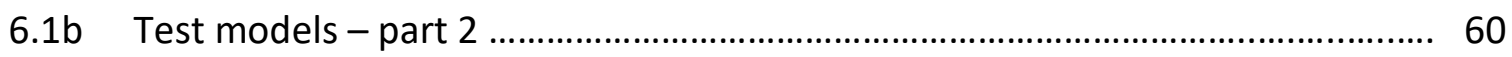

6.2 Groups of VDS - NS configurations to be tested in experiment 1 .................... 62

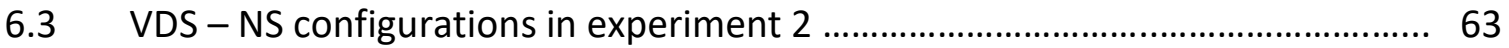

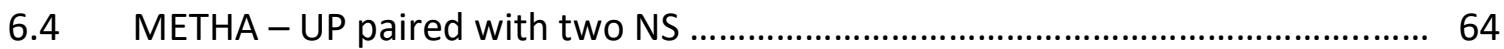

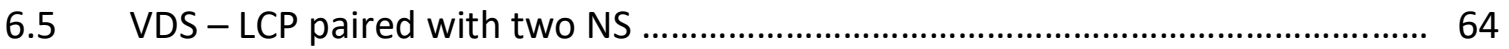

6.6 VDS - D\&t paired with two NS _.................................................................. 64

6.7 Possible MCC, equality, continuous variable categories .................................... 66

6.8 MIP instances in the training set ..................................................................... 67

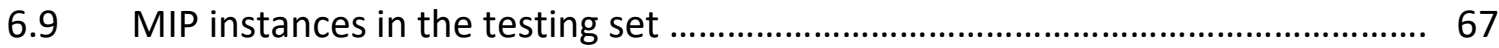

7.1 Number of models solved within certain ratios to best time ……..................... 74

$7.2 \quad$ Analysis of training set ............................................................................... 76

7.3 RULE6: VDS method selection based on MIP characteristics ............................. 77

7.4 Cumulative number of models solved by each method at some ratios to best

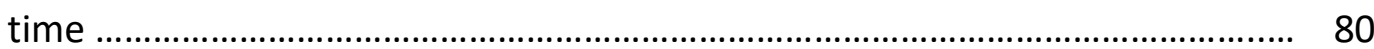

7.5 RULE4: VDS method selection based on all 78 models ...................................... 81

A.1 List of MIP instances taken from MIPLIB2017, MIPLIB2010, MIPLIB2003, MIPLIB3.0, MIPLIB2.0 and Hans Mittelmann's MIP collection with MIP characteristics

B.1 Results of the models solved by at least one VDS / NS configuration................. 95

B.2 Results for models not solved to optimality by any VDS / NS in the time limit, but an incumbent solution was found by at least one VDS / NS configuration ...... 116

B.3 List of MIP instances for which neither an integer-optimal solution nor an integer-feasible solution was found by any VDS / NS configuration ................ 126 


\section{List of Figures}

2.1 Solving MIP problem using LASTF - UP / DEPTH ........................................... 12

2.2 Solving MIP problem using LASTF - UP / BESTB …........................................ 13

2.3 Solving MIP problem using LASTF - DOWN / DEPTH .................................... 14

3.1 Plot of $Z_{i}$ and $Z_{\min }(c)$ vs. $C_{i}$ for all of the nodes in the tree at the completion of the branch and bound process for the $d c m u l t i$ MIP instance. Also shown is the

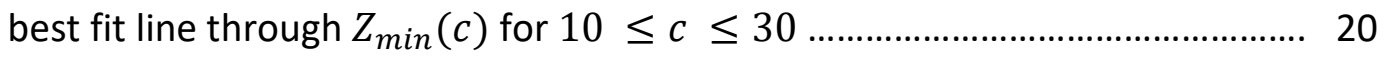

3.2 Gaussian distribution for constraint $g(x)=2 x_{1}+5 x_{2}+x_{3} \leq 10 \ldots \ldots \ldots \ldots \ldots . . . . . . .30$

4.1 A plot of the ratio of depth of a MIP optimal node to the minimum depth over all MIP feasible nodes for a set of MIP instances ................................................. 36

5.1 Performance Profile Comparing the two best configurations with the two state of art GLPK configurations ................................................................................ 43

5.2 Performance Profile for Branching Direction Policy Comparison ..................... 46

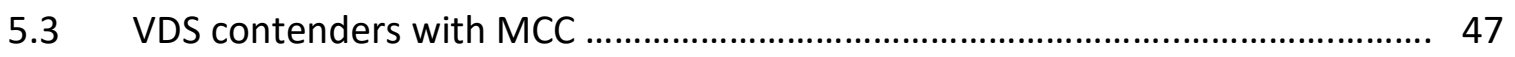

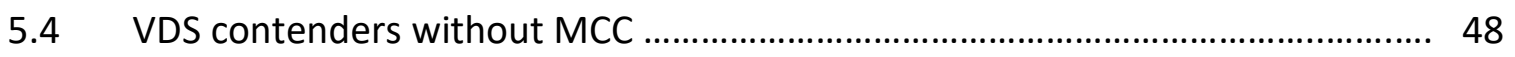

5.5 Performance of simple branching direction policies with equality constraints 49

7.1 VDS - D\&T coupled with different NS heuristics ...................................................... 69

7.2 METHA - UP coupled with different NS heuristics .................................................... 70

7.3 VDS - LCP coupled with different NS heuristics .......................................................... 71

7.4 VDS - PCOST coupled with different NS heuristics .................................................... 71

7.5 Performance Profiles of different VDS coupled with MBESTP - ASP - ANST vs. GLPK default configuration ......................................................................... 73

7.6 Performance profiles of RULE6 and 3 individual VDS - NS configurations on training set

7.7 Performance profiles of RULE6 and 3 individual VDS - NS configurations on

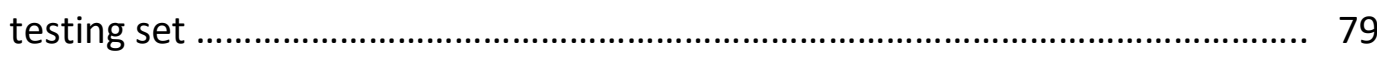

7.8 Performance profiles for RULE4 and individual configurations ....................... 81 


\section{List of Abbreviations}

ANST active node search threshold ...................................................................... 2

ASP aspiration backtrack triggering ……………………................................... 2

B\&B Branch and Bound ................................................................................... 1

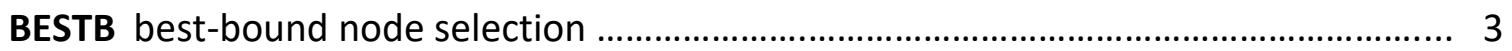

DEPTH depth - first node selection ............................................................................. 9

DIST distribution node selection ...................................................................... 21

FIRSTF first fractional variable selection .................................................................. 10

LASTF last fractional variable selection ……………….......................................... 10

LCP lowest cumulative probability branch direction ................................................ 3

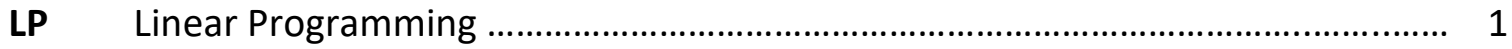

MBESTP modified best-projection node selection ............................................... 2

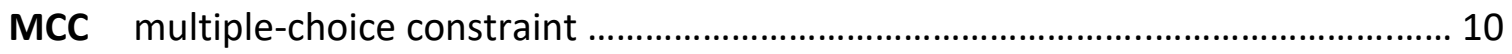

MILP/MIP Mixed-integer Linear Programming …………...................................... 1

MOSTF most fractional variable and node selection ............................................ 10

MVV most violated votes branch direction selection ….......................................... 32

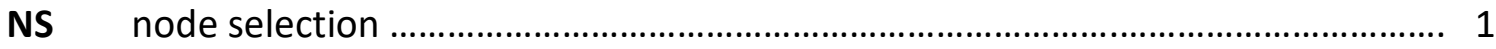

VDS variable and direction selection ............................................................... 1

VDS - D\&T heuristic by Driebeek and Tomlin for variable and direction selection ... 2

VDS - HCP highest cumulative probability branch variable and direction selection 31

VDS - LCP lowest cumulative probability branch variable and direction selection 31 
VDS - MVV most violated votes branch variable and direction selection

VDS - PCOST pseudo-cost variable and direction selection ....................................... 3 


\section{Chapter 1 \\ Introduction}

Mixed-integer Linear Programming (MILP or MIP) is a solution method for optimization problems in diverse fields such as banking, transportation, petroleum, government, military, etc. A MIP problem always aims to maximize or minimize its objective function value. Some or all of the variables need to take on integer or binary values and their values are further restricted by some linear constraints. (Section 2.1)

Branch and bound ( $B$ \& $B$, Section 2.2) in the form of search tree, is the most commonly used method to solve MIP problems. The root node of the branch and bound tree is generated by ignoring the integer restrictions on the original MIP instance and solving the resulting linear programming (LP) relaxation. The child nodes then tighten the bound found from the root node by rounding up or down one of the variables that is supposed to be integral yet has a fractional value in the LP relaxation solution. This repetitive process will lead to an integer-feasible node or to the conclusion that there is no integer-feasible solution. The integer-feasible node with the best objective function value is the integer-optimal node (Section 2.2). Selection of the node, variable and its branching direction are the key factors that significantly affect the amount of time spent solving the MIP problem to optimality. A given MIP instance can be solved within seconds if the variable and direction selection (VDS) method and node selection (NS) method are properly chosen but may take hours otherwise, as these factors will 
determine the shape and size of the branch and bound search tree and the way in which the tree is explored.

A great deal of effort has been put into developing better VDS and NS heuristics (see Chapter 3) in order to speed up the MIP problem solution time. An excellent work among them is Wojtaszek and Chinneck's [2010] node selection heuristic that modified the state of art NS best-projection heuristic [Mitra, 1973] and paired the method with a new aspiration backtrack triggering (ASP) policy and a principle to switch between their modified best-projection (MBESTP) method and the simple depth-first NS method (ANST) for backtracking. This NS heuristic was able to outperform the state of art by a big margin based on their results.

However, their experiments limited the VDS method solely to the heuristic by Driebeek and Tomlin (VDS - D\&T) [Driebeek 1966, Tomlin 1971] that is the default VDS method in the GLPK MIP solver which they used. They did not investigate whether their new MBEST - ASP - ANST node selection heuristic provided improved results when coupled with other VDS methods. Different VDS heuristics have different motivations, so they may give different results when coupled with the same NS heuristic. Feasibilityoriented VDS methods estimate the impact of branching variables and directions on the linear constraints while objective-oriented VDS methods measure the impact of branching variables and directions on the objective function value. In addition, Wotaszek and Chinneck [2010] provided evidence that coupling a good NS heuristic with a feasibility-oriented VDS method can potentially provide the fastest solution time. 
Therefore, the objectives of this thesis are to identify the best VDS / MBESTP ASP - ANST configuration and to determine whether feasibility-oriented VDS methods will give better solution times than objective-oriented VDS methods when coupled with a quality NS method. Last but not the least, an objective of the thesis is to develop rules for selecting the VDS to pair with a quality NS heuristic based on the model characteristics, with the hope that this hybrid method will prove better results than any individual VDS/NS configuration.

The three experiments described in Section 5.4 were conducted to address these objectives. Experiment 1 compares various VDS methods coupled with the NS heuristic of interest MBESTP - ASP - ANST and with the MIP solver default NS method bestbound (BESTB). Experiment 2 compares all configurations having MBESTP - ASP - ANST as the NS setting. Experiment 3 inspects the important characteristics of MIP instances, develops rules from training set problems and verifies them with testing set models.

Empirical results of the experiments are given in Chapter 7. The results show that the NS heuristic MBESTP - ASP - ANST consistently outperformed the MIP solver default NS method when coupled with any VDS method. Consequently, the merit of MBESTP ASP - ANST is universal in the branch and bound method. It provided the overall best performance in conjunction with the objective-oriented VDS method VDS - PCOST. This rejects the hypothesis that the combination of a good NS heuristic and a quality feasibility-oriented VDS method will give the fastest MIP solution time. Rules to select the best VDS / NS configuration were developed and verified: the resulting hybrid VDS/NS outperformed all of the individual VDS/NS configurations tested. 


\section{Chapter 2}

\section{A Review of Mixed Integer Linear Programming}

\subsection{Definition of Mixed Integer Linear Programming}

A MIP problem is comprised of decision variables, bounds on these variables, linear constraints and a linear objective function. The goal is to maximize or minimize the objective function subject to the constraints and variable bounds. Some or all of the decision variables are further restricted to take on integer or binary values. A standard MIP problem looks like:

Objective function:

$$
\text { Minimize } Z=\sum_{j=1}^{n} c_{j} x_{j}
$$

where $x_{j}, j=1,2, \ldots, k$ are integer decision variables and $x_{j}, j=k+1, \ldots, n$ are continuous decision variables and $c_{j}$ are coefficients of the decision variables.

General constraints are of the form:

$$
\sum_{j=1}^{n} a_{i j} x_{j}\{\leq,=, \geq\} b_{m} \text { for } i=1,2, \ldots, m
$$

where $a_{i j}$ are the constraint coefficients and $b_{m}$ is the bound for the $m$ th. constraint. 
Variable bounds:

$$
l_{j} \leq x_{j} \leq u_{j}
$$

where $l_{j}$ and $u_{j}$ are the lower and upper bound of variable $x_{j}$. For the integer decision variables that are explicitly restricted to binary values, the variable bounds are:

$$
0 \leq x_{j} \leq 1
$$

A maximization can be easily transformed into standard minimization problem by multiplying the objective function by -1 .

\subsection{The Branch and Bound Method}

Branch and bound is the most commonly used technique to solve MIP problems [Winston, 2009]. It solves the MIP instance by extensively investigating the nodes in the branch and bound tree. Each node in the decision tree represents a version of the original problem with adjusted variable bounds. The root node represents the original unadjusted problem. The LP relaxation is solved at each node: this simply solves the current problem as though it is a linear programming problem by ignoring the integer restrictions. This provides a lower bound on the best integer-optimum solution obtainable at this node or any descendent node. The subproblems are solved using the simplex method. 
If the solution of the root node LP-relaxation problem has all integer decision variables take on integer values, the search is terminated immediately and the solution is the integer-optimal solution of the MIP. Otherwise two child nodes are generated. Any other node in the branch and bound tree with LP relaxation solution satisfying all integrality constraints is an integer-feasible node. Most of the time, multiple integer feasible nodes will be found before the termination of the branch and bound method. The best integer - feasible node solution after the search completed is the global integer-optimal solution, while the best integer - feasible solution before the search is done is the incumbent solution. The incumbent solution gives the upper bound on the integer-optimal solution and the lowest value of the LP-relaxation solution at any active node gives the current lower bound on the value of the integer-optimum solution. The optimal solution is found when these two bounds converge.

The process to go from parent node to one of the child nodes is called diving. Diving requires branching on a candidate variable that is a decision variable that should be integral and yet is fractional in the parent node LP-relaxation solution. There are two directions to branch, branching up adjusts the bound on the selected variable to be no smaller than the rounded-up integer value of its current fractional value. Branching down adjusts the bound on the selected variable to be no larger than the rounded-down value of its current fractional value. Otherwise the model is the same as in the parent node. The parent and child nodes differ by a single adjusted variable bound, which means that the child node solution is very fast due to the advanced start provided by the parent node solution. 
Diving is a repetitive process until a leaf node is found. Leaf nodes are of three kinds: (i) LP-infeasible, so no integer-feasible solution exists at this node or any descendent; (ii) the LP - relaxation lower bound is worse than the incumbent solution, so the integer - feasible node, if there is one, will have the objective function value worse than the incumbent solution; (iii) integer-feasible. In all three cases, there is no further diving from the node and it is removed from the active list; backtracking is then triggered to select an active node from which to continue the search. In the third case, the objective function value is compared with the incumbent objective function value, and if it is better, then the node solution replaces the incumbent solution.

Other than leaf node backtrack triggering mentioned above, there is another backtrack triggering policy called aspiration backtrack triggering that pre-terminates diving before a leaf node is reached (see Section 3.1.4). The branch and bound process switches back and forth between diving and backtracking until every active node in the branch and bound tree has been explored. Diving counts on the selection of the branching variable and direction while backtracking relies on the node selection and backtrack triggering policy. Therefore, VDS and NS are the most important factors affecting the branch and bound performance. Pseudocode summarizing the branch and bound process is shown in Algorithm 1. 
Input: MIP instance

Initialization:

Incumbent solution $x_{\text {inc }} \leftarrow \varnothing$.

Objective function value of incumbent solution $Z\left(x_{\text {inc }}\right) \leftarrow \infty$.

List of unexplored nodes $L \leftarrow \emptyset$.

Current node node current $\leftarrow \emptyset$.

\section{Procedure:}

1. Add the root node to $L$.

node $_{\text {current }} \leftarrow$ root node.

2. Solve the LP-relaxation of node current.

If the LP-relaxation is infeasible or its lower bound $Z>Z\left(x_{\text {inc }}\right)$ :

Remove node current $_{\text {from } L .}$

node current $\leftarrow \varnothing$.

Go to step 5.

If the LP-relaxation is integer-feasible:

If $Z<Z\left(x_{\text {inc }}\right)$ :

Assign the solution to $x_{\text {inc }}$.

$Z\left(x_{i n c}\right) \leftarrow Z$

Remove node current $_{\text {from } L}$.

node $_{\text {current }} \leftarrow \varnothing$.

Go to step 5.

3. Select a candidate variable from node current $_{\text {for branching. }}$

Generate two child nodes of node $e_{\text {current }}$, add them to $L$.

Remove node current $_{\text {from } L \text {. }}$

4. Select direction: assign one of the newly created child nodes to node current $_{\text {. }}$

Go to step 2.

5. If $L=\emptyset$ :

If $x_{i n c}=\emptyset$, exit with infeasible outcome.

Else exit with $x_{i n c}$ as the MIP optimum solution.

Backtrack: select a node from $L$, assign it to node current $_{\text {. }}$

6. Go to step 2

Algorithm 1: Branch and bound 


\subsubsection{Node Selection and Backtracking}

When the computation of the current node LP relaxation is finished and there are still active nodes unexplored in the branch and bound search tree, a decision has to be made on which node to investigate next. Conventionally, if child nodes of the current node are available, the decision is to solve one of the child nodes next. This node selection method is depth-first (DEPTH) node selection, it dives into deeper levels of the branch and bound tree. The computation of the child node LP subproblem can benefit from depth-first NS method as the parent node LP relaxation solution provides an advanced start to the simplex method. When backtrack is triggered, regardless of whether due to leaf node backtrack triggering or aspiration backtrack triggering, the dive must be terminated and a backtrack node selection method specifies which node to jump to next. This decision can have a huge impact on the performance of branch and bound method since a good selection can avoid the exploration on unpromising nodes.

The backtrack node selection heuristics try to predict which active node is the ancestor of the integer-optimum solution because diving from this node will result in a fast integer-optimal solution. Aspiration backtrack triggering heuristics estimate the final integer-optimal objective value and trigger backtracking when the lower bound of the current node LP solution is worse than the estimate. An ideal estimate can cut the effort of exploring unpromising nodes as well. Advanced node selection heuristics will be covered in depth in Section 3.1. 


\subsubsection{Branching Variable and Direction Selection}

When the solution of a node subproblem has more than one candidate variable, the selection of the variable to be branched on and the corresponding branching direction can have a big impact on the speed of the solution. First fractional (FIRSTF), last fractional (LASTF) and the most fractional (MOSTF) also referred to as the most infeasible, are all basic VDS methods that simply make the decision based on the fractionality of candidate variables. They are reported not to provide good results [Achterberg et al. 2004]. More mature VDS methods are developed differently to serve different purposes. There are objective - oriented VDS heuristics that estimate how much impact each candidate variable has on the MIP objective function before making the choice. When the MIP instance is too difficult to solve in a reasonable time, the goal is to find the first integer-feasible solution quickly. To this extent, feasibility - oriented VDS heuristics are proposed. Methods of this type make decisions mainly based on the impact of candidate variables on the constraints. The state of the art in heuristic variable selection will be covered in next chapter.

Some heuristics select the branching variable and direction simultaneously within the algorithms, some do not. If the selection of branching direction is required after the candidate variable is picked, the mostly commonly used heuristics are to always branch up, always branch down or branch to the closest integer value. When there are multiple - choice constraints (MCC) in the MIP instance, branching up will work extremely well. An MCC constraint is defined as:

$$
\sum x_{i}\{\leq,=\} 1
$$


where $x_{i}$ are binary decision variables.

Branching up on a candidate variable in an MCC constraint will force all other variables to change to 0 . Hence the integrality constraints are satisfied quickly. Such "force to change" principle is exploited to develop other branching direction heuristics that will be reviewed in the next chapter.

Special MIP problem characteristics can influence the performance of VDS methods. More characteristics will be studied in the thesis.

\subsubsection{Example Branch and Bound Solution}

In this section, a simple MIP problem is solved using the branch and bound method. The search trees resulting from different VDS / NS configurations are shown in Figures 2.1 to 2.3 respectively. The MIP problem is:

$$
\begin{gathered}
\text { Minimize } Z=-5 x_{1}-6 x_{2} \\
x_{1}+x_{2} \leq 5 \\
4 x_{1}+7 x_{2} \leq 5 \\
x_{1} \text { and } x_{2} \text { are integer variables and } \\
x_{1}, x_{2} \geq 0
\end{gathered}
$$




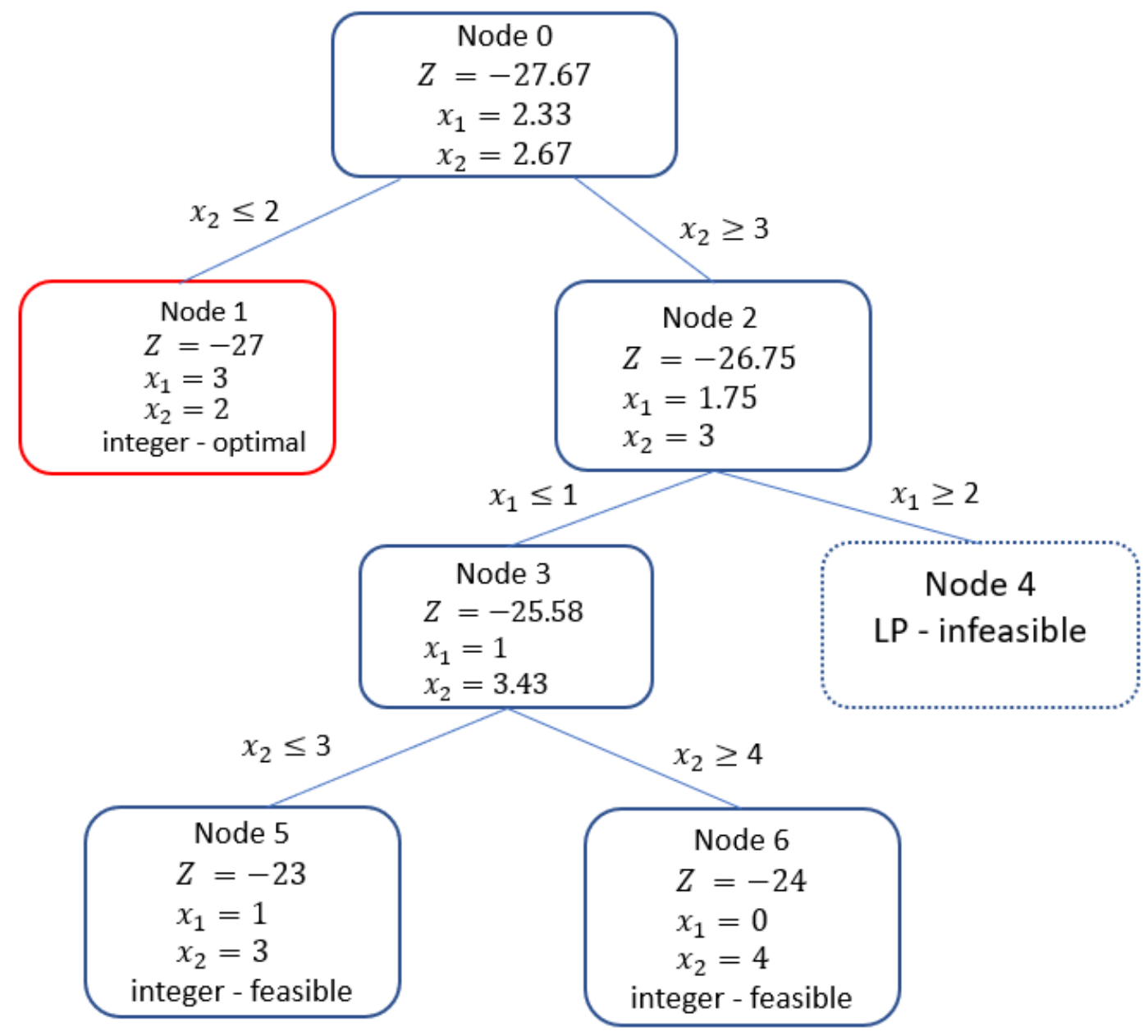

Figure 2.1: Solving MIP problem using LASTF - UP / DEPTH

Each node in the branch and bound tree contains the node LP-relaxation solution and objective value. The line connecting the nodes are labelled with the adjusted bounds on the candidate variable.

If the last fractional variable selection method is chosen, with the candidate variable always branching up and depth - first is the node selection method, then the nodes will be explored in this order: $0->2->4->3->6->5->1$. 
If the VDS method remains the same, but the backtrack node selection is changed to best - bound (BESTB, see Section 3.1.1), the nodes will be explored in this order: 0 -> 2 -> 4 -> 1. Compared to LASTF - UP / DEPTH, the different node selection is made after the leaf node 4 is hit, consequently two less nodes are explored.

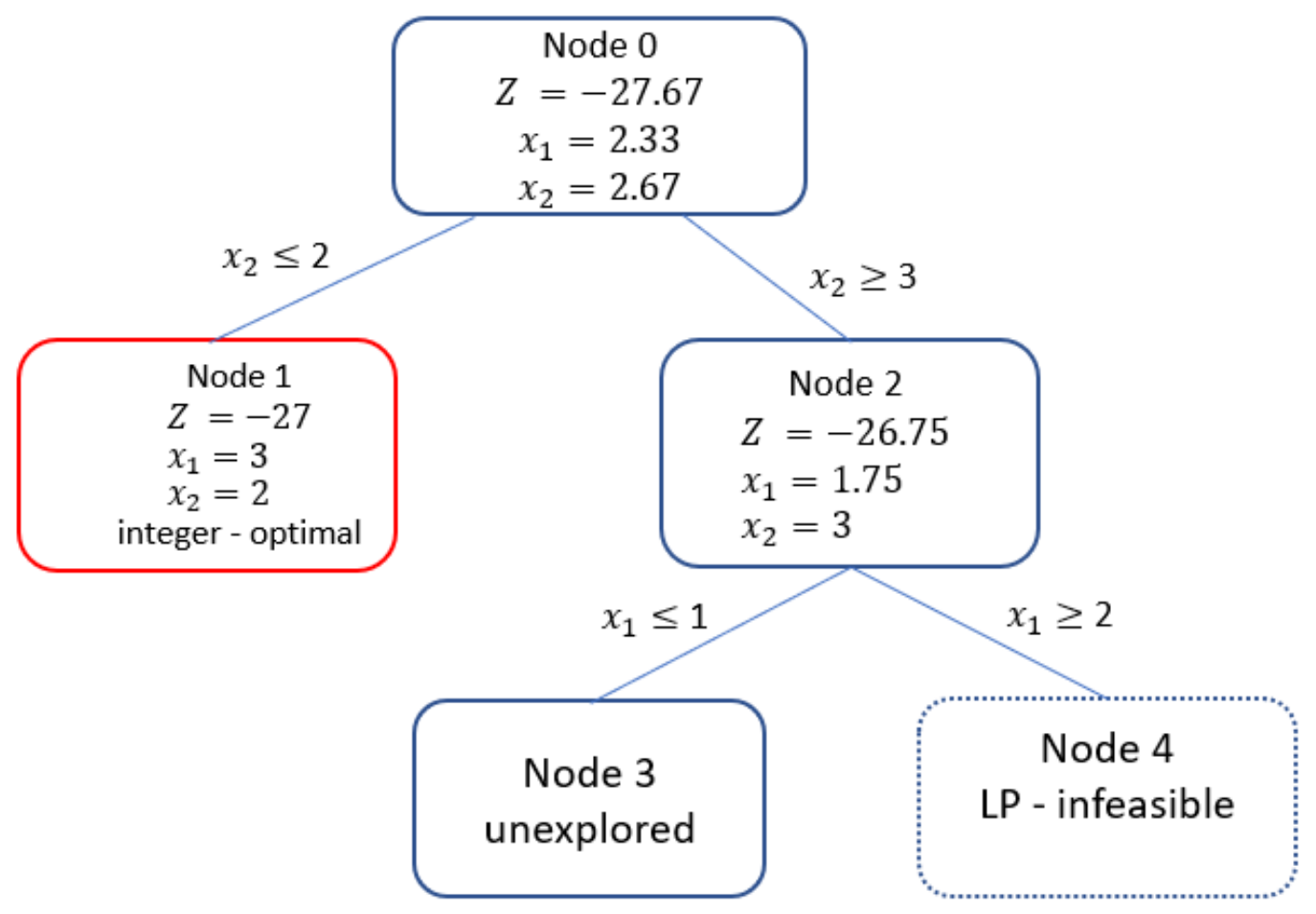

Figure 2.2: Solving MIP problem using LASTF - UP / BESTB

However, choosing the last fractional variable, branching down with depth - first backtracking yields the simple tree shown in Figure 2.3. Only 3 nodes are explored this time in the order of $0->1->2$. 


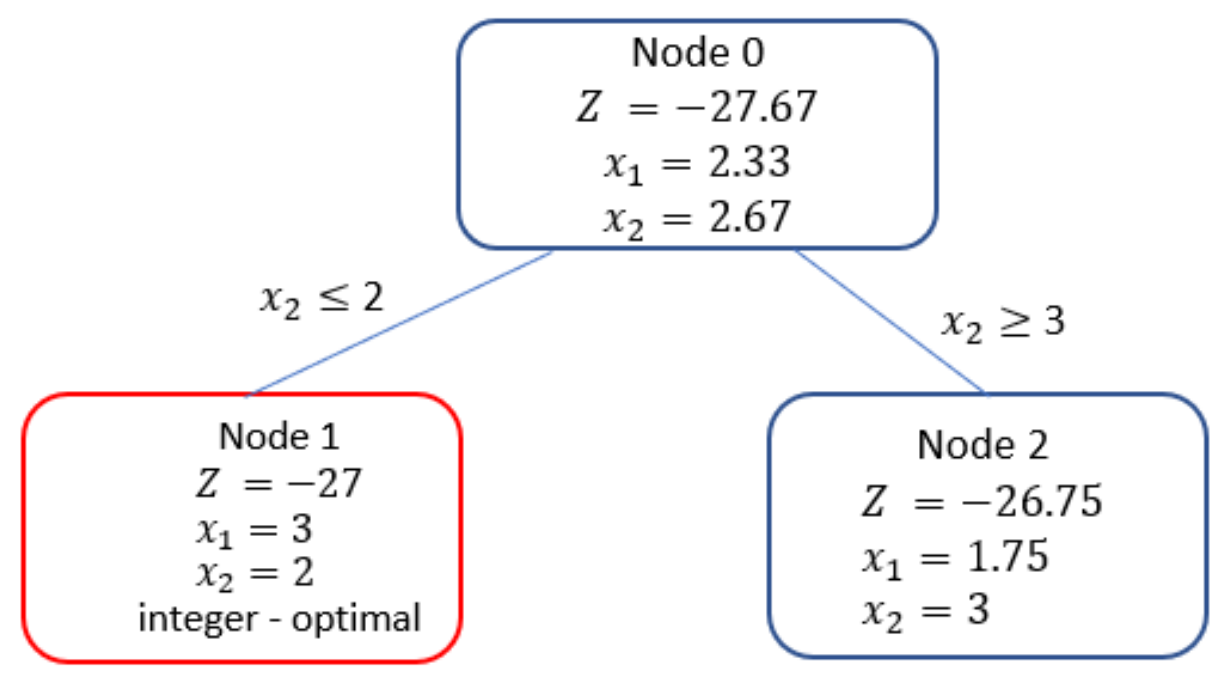

Figure 2.3: Solving MIP problem using LASTF - DOWN / DEPTH

As can be seen, different VDS and NS can produce quite different search trees and therefore result in different MIP problem solution times. 


\section{Chapter 3}

\section{State of the Art in Node, Variable and Direction Selection}

\section{Heuristics}

The heuristics used for selecting the branching variable and direction, for triggering backtrack, and for selecting the node when backtracking determine the size and shape of the branch and bound tree as well as the manner in which it is searched. Good selections of the VDS method and NS heuristics can dramatically cut the effort and time required to solve MIP instances. State of the art VDS and NS heuristics are reviewed in this chapter.

\subsection{Node Selection Methods}

"Node selection" in this thesis refers to backtrack node selection since depth-first node selection is the default mode of operation. The special role of the depth - first heuristic among all NS method is due to the advanced start it is able to provide to the child node LP-relaxation problem which significantly reduces the number of simplex iterations needed to solve the child node subproblem. When the active node upon backtracking is determined, diving from the selected node will start and depth - first search will take control of the node selection method again. 


\subsubsection{Basic Node Selection Methods}

Depth-first search is the default node selection heuristic because of the computational efficiencies provided by the advanced start provided by the parent node solution in solving a child node. When used for backtracking, depth-first search selects the most recently created active node.

The best-bound (BESTB) node selection method, as the name says, determines the node to investigate next by selecting the active node with the best bound (LPrelaxation solution value) which is the smallest lower bound in a minimization problem. This strategy most of the time will end up getting a node not so deep in the branch and bound tree, since the shallower the node is, the fewer variable bounds have been adjusted relative to the very optimistic lower bound of the root node, so the bound provided by the LP relaxation is also quite optimistic. Similarly, there is breadth-first node selection method, which will select the earliest created active node.

The most-feasible node selection method tries to find an integer-feasible solution quickly. It chooses the candidate node with the minimal sum of integer infeasibilities. The computation of the integer infeasibility for a candidate variable is shown below:

$$
f_{i j}=\min \left\{x_{i j}-\left\lfloor x_{i j}\right\rfloor, 1-\left(x_{i j}-\left\lfloor x_{i j}\right\rfloor\right)\right\}
$$

$x_{i j}$ in Equation 3.1 is the value estimated for variable $j$ at node $i$, it is not the actual value of the variable at node $i$, since this node is a potential node to be explored next but has not been solved yet. Hence, this value inherits from its parent node. This 
principle holds true for all node selection methods that use information such as node lower bound, number of candidate variables etc.: the data is taken from the parent node.

\subsubsection{Estimation-based Node Selection Heuristics}

The Best-projection (BESTP) [Mitra, 1973] method takes one step further by investigating the relationship between the integer infeasibility and the local lower bound of nodes in the tree. The integer infeasibility tends to decrease at nodes located deeper in the tree. If this degradation is linearized, the optimal objective value is predictable by obtaining the degradation value from the root node to the current incumbent node using Equation 3.2 and projecting a line with the same slope from a candidate node to the point where the integer infeasibility is zero following Equation 3.3, as a feasible solution would have zero infeasibility. The candidate node with the best projected optimal value will be the node to solve next.

$$
\begin{gathered}
m=\frac{Z_{\text {inc }}-Z_{0}}{S_{0}} \\
\tilde{Z}_{i}^{*}=Z_{i}+m * S_{i}
\end{gathered}
$$

where $m$ is the slope of the degradation line, $Z_{0}$ is the lower bound of the root

node, $Z_{\text {inc }}$ is the objective value of the incumbent solution, $Z_{i}$ is the lower bound of candidate node $i, S_{0}$ the integer infeasibility of the root node, $S_{i}$ the integer infeasibility 
of candidate node $i$ and lastly, $\tilde{Z}_{i}^{*}$ is the optimal objective value estimated from candidate node $i$.

The best-projection method is not applicable until a feasible solution is available. This limitation means that an additional backtrack node selection algorithm must be used before a feasible solution is found.

A modification has been made on the best-projection strategy so that the backtrack node selection will be free of the demand for an incumbent solution. This heuristic modified best-projection (MBESTP) node selection method is inspired by the observation that "There is an approximately linear correlation between $Z_{\min }(c)$ and $c$ for many MIPs." [Wojtaszek and Chinneck, 2010]. $c$ is the number of candidate variables at a node and $Z_{\min }(c)$ is the smallest lower bound among all nodes with $c$ candidate variables.

The obvious drawback of the best-projection method is that it requires an incumbent solution to start with but for a difficult MIP instance with a large number of candidate variables, it would take a long time even to get the first feasible solution. The modified best-projection heuristic, on the contrary, allows the early assessment on the optimal objective value even when there is no incumbent solution.

Take MIP instance dcmulti as an example shown in Figure 3.1 below. The problem has been solved to optimality with all the nodes explored in the tree and number of candidate variables at every node as well as the subproblem lower bounds recorded. Nodes enclosed in boxes have the smallest lower bound among the nodes 
having the same number of candidate variables. Nodes on the vertical axis have no more candidate variables and are thus integer-feasible with the smallest one circled being the optimal. The progression of the $Z_{\min }(c)$ values is relatively linear. This is illustrated in Figure 3.1 by fitting a line to the $Z_{\min }(c)$ values between 10 and 30 candidate variables. Extending this line to the vertical axis provides a good estimate of the MIP-optimum objective function value. The possibility of estimating the final integer-optimal value early is meaningful, since such early precise estimation will dramatically reduce the effort by avoiding exploring many superfluous nodes. The active node with the smallest estimated optimal objective value will be the winner of this node selection strategy. The computation follows the same flow as in the best-projection to first compute the degradation rate and then the best objective value, but has different equations that use the number of candidate variables as the measure of integer infeasibility instead of the sum of the integer infeasibilities:

$$
\begin{gathered}
m=\frac{Z_{\min }\left(C_{\min }\right)-Z_{0}}{C_{0}-C_{\min }} \\
\tilde{Z}_{i}^{*}=Z_{i}+m * C_{i}
\end{gathered}
$$

where $C_{\min }$ is the current minimum number of candidate variables at any active node in the tree, $Z_{\min }\left(C_{\min }\right)$ is the smallest objective value among nodes with $C_{\min }$ candidate variables and $m$ is the slope of the best fit line. $C_{i}$ and $Z_{i}$ are the number of candidate variables for active node $i$ and its lower bound respectively. Finally, $\tilde{Z}_{i}^{*}$ is the optimal objective value estimated from candidate node $i$. 


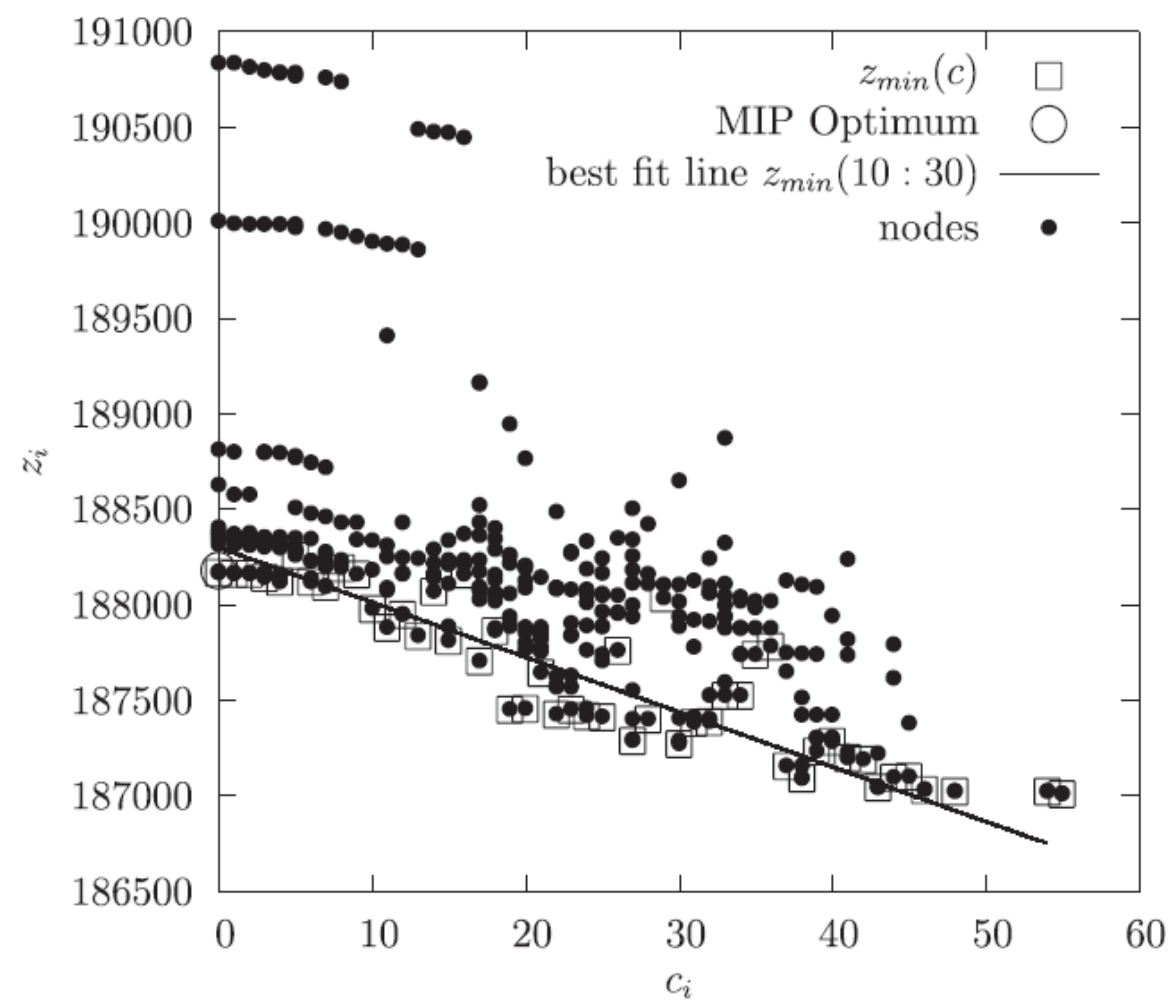

Figure 3.1: Plot of $Z_{i}$ and $Z_{\min }(c)$ vs. $C_{i}$ for all of the nodes in the tree at the completion of the branch and bound process for the dcmulti MIP instance. Also shown is the best fit line through $Z_{\min }(c)$ for $10 \leq c \leq 30$. [Wojtaszek and Chinneck, 2010]

$C_{0}$ should not be the same as $C_{\min }$ in Equation 3.3. Moreover, this modified best-projection method will not work well under the conditions that nodes have very similar values for the number of candidate variables and the lower bounds, which tends to happen at the early phase of the branch and bound search. When the modified best projection method cannot be used, the best-projection method is used if a feasible solution already exists, otherwise the most-feasible backtrack heuristic is used. 


\subsubsection{Distribution Node Selection}

Wojtaszek and Chinneck [2010] proposed a novel method to select the active node upon backtracking by balancing the goals of MIP feasibility and optimality. The motivation is as follows: "(Balancing MIP feasibility and optimality). A characteristic that is typical of many branch and bound trees is that there is a negative correlation between the objective value and the number of candidate variables of a node; i.e. $Z_{i}$ tends to increase with depth while $c_{i}$ tend to decrease with depth", where $Z_{i}$ and $c_{i}$ are the node LP objective function value and number of candidate variables at node $i$ respectively. A small value of $Z_{i}$ indicates that the node is close to MIP optimality while a small value of $c_{i}$ indicate that the node is close to MIP feasibility. Both measures can be modeled using the Normal distribution and Normal cumulative distribution functions. Therefore, this node selection method is called the Distribution node selection (DIST) method. $F_{Z}\left(z_{i}\right)$ estimates the fraction of nodes in the branch and bound tree that have node LP solution objective function value $z \leq z_{i}$. Similarly, $F_{C}\left(c_{i}\right)$ denotes the fraction of nodes whose number of candidate variables is less than or equal to the number in the active node $i$. DIST chooses the active node with the smallest value of $F_{Z C}\left(z_{i}, c_{i}\right)=F_{Z}\left(z_{i}\right) * F_{C}\left(c_{i}\right)$ to be explored next. 


\subsubsection{Backtrack Triggering}

Backtrack triggering aborts the current depth-first search to jump back to an unexplored node in the branch and bound tree. Backtrack requires a node selection heuristic to determine which active node to investigate next.

Backtrack is automatically triggered when a leaf node is reached, that is an LPinfeasible node, or integer-feasible node or the lower bound of the current node is already worse than the incumbent solution, thus diving from this node is pointless in the search for the optimal node.

Backtrack can also be triggered before the leaf node is reached, that is, if an estimated optimal objective function value $\tilde{Z}_{i}^{*}$ (Section 3.1.2) of the MIP problem is available and the lower bound of the current node is worse than the estimated $\tilde{Z}_{i}^{*}$, diving from such node seems to be unpromising. Thus, backtrack is triggered. The value to trigger backtrack in such manner is called an aspiration value. However, the node that has lower bound worse than the aspiration value is not removed from the branch and bound tree, since the aspiration is only an estimation. It is not guaranteed that this lower bound is worse than the actual optimal objective value and the node is still qualified to be explored. The intent of aspiration backtrack is to avoid exploration of unpromising nodes. Therefore, this estimation should be carefully computed. If $\tilde{Z}_{i}^{*}$ is less than the actual optimal objective value $Z_{i}^{*}$ by a big margin, backtrack will be triggered frequently because the estimation is too optimistic. If $\tilde{Z}_{i}^{*}>Z_{i}^{*}$ considerably, the effect 
is the same as leaf node backtrack triggering and the effort to solve the MIP problem is even larger than leaf node triggering due to the computations of the aspiration value.

An effective search strategy switches back and forth between depth-first and other node selection strategies. That is, the search starts by diving from the root node using depth-first, whenever backtrack is triggered, it switches to the desired backtrack node selection method (e.g. any of the state of the art node selection heuristics reviewed above). Once a node is selected, it switches to depth-first to dive from this node.

\subsubsection{Active Node Search Threshold}

Advanced backtrack heuristics are not always a good choice. Wojtaszek and Chinneck [2010] also noticed that "For some MIPs, the amount of time required to perform a given backtrack node selection method can become a significant fraction of the overall amount of time required to solve the problem. This occurs when the number of active nodes in the tree becomes very large."

When this happens, it is pointless to stick with the current backtrack node selection method given the goal is to speed up the branch and bound search. The scheme to decide if the cost of current backtrack node selection outweighs its benefits is proposed by Wojtaszek and Chinneck [2010] in the equation shown below:

$$
R_{t}=\frac{t_{N S}}{t_{B B}-t_{N S}}
$$


where $t_{N S}$ is the total amount of time spent on backtrack node selection while $t_{B B}$ counts the total amount of time performing any operations in branch and bound including variable and direction selection, node selection, simplex iteration etc.

$R_{t}$ computes the ratio of time performing backtrack to any other operations in the branch and bound method. A costly backtrack node selection heuristic leaves less time to solve nodes and perform simplex iterations. Consequently, $R_{t}$ tends to become larger for a costly backtrack compared to the ratio for an efficient one. The $R_{t}$ value is constantly updated after each backtrack node selection process is finished. Once $R_{t}$ reaches the active node search threshold value $q$, changes to the branch and bound parameter settings are made. Major factors that would cause backtrack node selection processing time being too long are a large number of active nodes and backtracking happening too often. The Active Node Search Threshold (ANST) routine will proceed in two phases.

If ANST is triggered and aspiration backtrack triggering is in use, chances are high that the backtrack has been called too frequently. In this case, aspiration backtrack triggering is turned off, and the threshold value $q$ is incremented by a small amount $d q$. This permits the continued used of the backtrack method but without aspiration triggering.

With leaf node backtrack triggering in use, if $R_{t}$ continues to increase and surpasses the new threshold value $q$ again, it implies that the current node selection 
method consumes a great amount of time searching for a node and depth-first will completely take over the backtracking task due to its low computational cost.

\subsection{Variable and Direction Selection Methods}

After a node in the branch and bound tree is explored, a candidate variable and its branching variable have to be decided to continue diving. Simple VDS FIRSTF that chooses the first candidate variable, LASTF that chooses the last candidate variable and MOSTF that chooses the candidate variable with the largest integer infeasibility are known to be ineffective. More mature methods select different candidate variable and branching directions depending on their goals. Objective-oriented diving considers the degradation of the objective function value upon branching on a certain variable. Feasibility diving considers the impact of branching variables on the constraints. Methods for both types of diving are reviewed in the subsections below.

\subsubsection{Objective-Oriented Variable and Direction Selection}

\subsubsection{Pseudo-Cost Based Branching}

The concept of pseudo-cost estimation was first introduced by Benichou et al. [1971]. This VDS predicts the deterioration of the objective function value per unit of change of a branching variable. Each integer variable has two corresponding pseudo-cost values, one for the up branch $P_{j}^{U}$, the other one for the down branch $P_{j}^{D}$. In order to compute the pseudo-cost values, the variable and both branching directions have to have been 
branched on at least once. The change in the lower bound between the parent node and the up branch child node is:

$$
\Delta Z_{j}^{U}=Z_{j}^{U}-Z_{j}^{P}
$$

where $Z_{j}^{U}$ is the lower bound for the up branch node and $Z_{j}^{P}$ is the lower bound of the parent node. Then the pseudo-cost of variable $j$ branching up is defined as:

$$
P_{j}^{U}=\frac{\Delta Z_{j}^{U}}{1-f_{j}}
$$

where $f_{j}$ represents the infeasibility of variable $j$. Similarly, the pseudo-cost value for down branching is:

$$
P_{j}^{D}=\frac{\Delta Z_{j}^{D}}{f_{j}}
$$

Benichou et al. also observed that the pseudo-cost value of a variable branching in a certain direction remains unchanged throughout the branch and bound tree with only a few exceptions. Therefore, the pseudo-cost values of a variable can be used once determined, without recomputing at other nodes.

The pseudo-cost method (VDS - PCOST) is able to select both branching variable and direction within its computation. The candidate variable with the largest pseudocost value is chosen and its branching direction is the one with the smaller pseudo-cost value.

Many extensions to the pseudo-cost idea have been proposed. Gauthier and Ribière [1977] proposed the policy to sort the candidate variables in terms of their 
impact on the objective value degradation and the one with the largest impact in the list will always be chosen. Linderoth and Savelsbergh [1999] suggested to explicitly compute the pseudo-cost value for the candidate variables that have never been branched on before.

\subsubsection{Heuristic by Driebeek and Tomlin}

Another well-known heuristic that chooses branching variable and direction simultaneously is the heuristic proposed by Driebeek [1966] and improved by Tomlin [1971], thus it is often referred to as the Heuristic by Driebeek and Tomlin (VDS - D\&T). This method estimates the potential degradation of the objective function value given the branch variable and direction. The degradation is estimated by performing a dual simplex pivot. Tomlin improved the estimate by explicitly considering the integrality of candidate variables. Therefore, this estimate is both feasibility-oriented and objectiveoriented, which makes the VDS - D\&T a hybrid method. The degradation for upbranching and down-branching are calculated respectively. Similar to the pseudo-cost branching method, the candidate variable with the largest estimated degradation is selected and the direction is chosen based on which one has the smaller absolute value of the degradation. 


\subsubsection{Feasibility-Oriented Variable and Direction Selection}

Some more recently developed variable selection heuristics shifted the focus from the objective function to the problem constraints. Instead of estimating the degradation of objective value upon choosing a certain candidate variable, the impacts of candidate variables on the constraints are investigated.

\subsubsection{Active Constraints Variable Selection}

Patel and Chinneck [2007] recognized that the LP-relaxation optimal solution of a given node is determined by the active constraints at this node. Active constraints are the equality constraints and the inequality constraints that are tight at the current node LP optimum. Due to this reason, they measured the impact each candidate variable has on the active constraints, reasoning that the variable that has the most impact on the active constraints will also have the most impact on the solution point. Various schemes of active constraint variable selection methods are proposed, including method-A that simply counts the number of occurrences of a candidate variable in any active constraints, or method- $H_{M}$ that weighs the impact of candidate variable $j$ on active constraint $i$ by formula $w_{i j}=1 / N_{i}^{F}$, where $N_{i}^{F}$ denotes the number of candidate variables in the active constraint $i, w_{i j}$ will be assigned to 0 if the candidate variable $j$ does not appear in the active constraint $i$. Scheme method- $H_{O}$ further takes the candidate variable coefficient into consideration, for the fact that a candidate variable with a greater coefficient will have a larger impact on the constraint and inversely, more 
candidate variables appearing in an active constraint will weaken the impact for each

candidate variable. Hence the measure here becomes $w_{i j}=\left|c_{i j}\right| / N_{i}^{F}$, with $c_{i j}$ being the coefficient of candidate variable $j$ in constraint $i$. These active constraints heuristics are reported to consistently outperform a commercial MIP solver in the search for the first feasible solution and method-A with candidate variable branching up (METHA - UP) is the best among them [Patel and Chinneck, 2007].

\subsubsection{Probability-Based Branching}

After Pesant and Quimper [2008] developed a solution counting method using the concept of solution density for knapsack constraints which have the form of $\sum a_{k} x_{k} \leq b$, Pryor and Chinneck [2010] extended this to calculate the probability of constraints being satisfied given the ranges of a branching variable in the up branch vs. the down branch. Assume that the branching variable has the coefficient $c_{i}$ and falls in the range of $\left[l_{i}, u_{i}\right]$ where $l_{i}$ is the lower bound of variable $i$ and $u_{i}$ the upper bound. The accumulation of independent random variables tends to be a normal distribution by the Central Limit Theorem [Gorban, 2017], with

$$
\begin{gathered}
\text { mean } \mu=\sum_{i=1}^{n} c_{i} \frac{l_{i}+u_{i}}{2} \\
\text { and variance } \sigma^{2}=\sum_{i=1}^{n} c_{i}^{2} \frac{\left(u_{i}-l_{i}\right)^{2}}{12}
\end{gathered}
$$

Accordingly, the probability of satisfying an inequality constraint given the variable ranges can be computed using the Gaussian distribution with the mean and variance in 
hand. For example, for a constraint $g(x)=2 x_{1}+5 x_{2}+x_{3} \leq 10$, where the variables have the ranges 0 to 5 , the constraint left hand side has a mean of 20 and a variance of 62.5. The probability of satisfying this constraint is shown in red of the probability distribution in Figure 3.2. With the candidate variable fixed with range $\left[l_{i}, u_{i}\right]$ and a fractional LP-relaxation optimal value $\dot{x}_{i}$, down branching on this variable will generate a child node in which the $x_{i}$ has the range $\left[l_{i},\left|\dot{x}_{i}\right|\right]$ while in the up-branch, child node $x_{i}$ will have the range of $\left[\left[\dot{x}_{i}\right], u_{i}\right]$. Therefore, the cumulative probabilities of satisfying the constraints of down-branch and up-branch can be estimated respectively. If the branching variable has not already been determined, it can be chosen based on the up and down branch probabilities over all candidate variables and all affected constraints. For example, you could choose both the variable and direction using the lowest cumulative probability on any single active constraint that includes a branching variable.

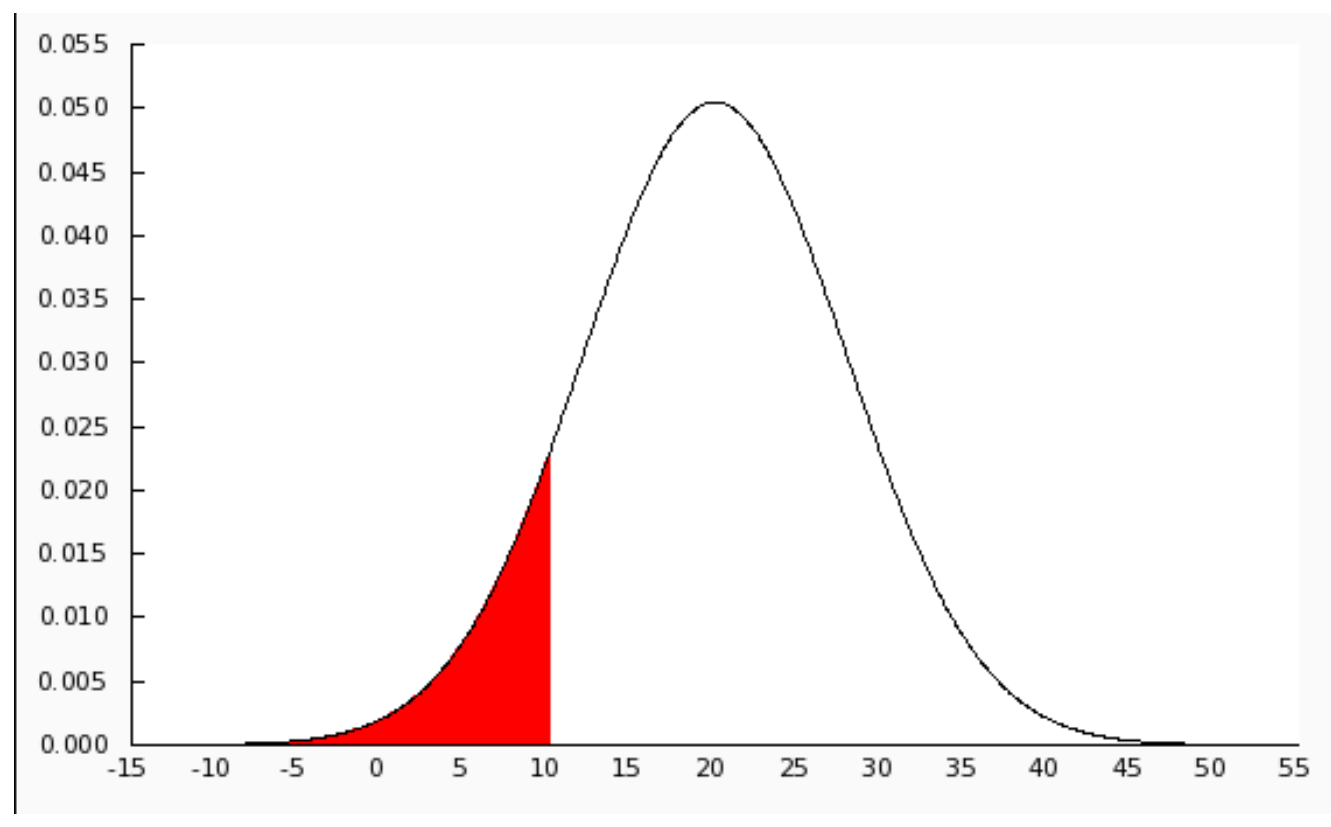

Figure 3.2: Gaussian distribution for constraint $g(x)=2 x_{1}+5 x_{2}+x_{3} \leq 10$ 
Equality constraints are treated in a different fashion as the probability of satisfying an equality constraint exactly is essentially zero. Hence a new measurement of centeredness for equality constraints $g(x)=b$ is introduced as:

$$
\text { Equality Centeredness Measure }=\frac{\min [P(g(x) \leq b), P(g(x) \geq b)]}{\max [P(g(x) \leq b), P(g(x) \geq b)]}
$$

This measurement also has a span from 0 to 1 and a larger number implies a larger likelihood of satisfying the equality constraint thus aligning perfectly with the measure for inequality constraints.

A commonly used policy is to always choose the candidate variable with the lowest probability of satisfying the constraints (centeredness for equalities). This forces other variables to change values as well, with more of the candidate variables potentially taking on integer values. The candidate variable and direction with higher probability of satisfying the constraints will most likely keep other candidate variables unchanged with their fractional values at the current node for the next branch. Due to this nature, the lowest cumulative probability (LCP) heuristic selects the branch direction that has the smallest probability. Also, the variable and direction selection using lowest cumulative probability (VDS-LCP) heuristic chooses the branching variable and direction simultaneously and is experimentally proven to do better than the variable and direction selection using highest cumulative probability (VDS-HCP) strategy [Pryor and Chinneck, 2010]. 


\subsubsection{Violation-Based Branching}

A similar constraint violation-based policy most violated votes (MVV) is suggested to determine the branch direction given the branch variable. This heuristic looks at the active constraints in which the branch variable is present. Whichever branching direction violates the tight constraint will get a vote and the direction with the most votes will be chosen. As for the equality constraints, the direction with a smaller centeredness measure will get the vote, as a smaller centeredness measure indicates a greater likelihood of violating the equality constraint.

In case the branching variable hasn't been determined, this violation voting policy is applicable to choose the variable and direction combination. If $k$ candidate variables are present at the current subproblem, there are $2 k$ variable-direction combinations. A vote is recorded for the most violated direction for each variable in each active constraint, and the variable and direction having the most votes is chosen. Therefore, this method is called variable and direction selection using most violated votes (VDS-MVV).

\subsection{Branching Direction}

For methods that do not select branching variable and direction simultaneously, the most common heuristics for selecting branching direction are to always branch up, always branch down or branch to the closest integer. Branching up is a good branching direction heuristic. Patel and Chinneck [2006] branched up for all active constraints 
heuristics and this turned out to be a good choice. However, there was no definite conclusion about the best branching direction until Pryor and Chinneck [2010] empirically showed that branching up is generally the better choice. They pointed out in special cases such as the presence of multiple-choice constraints (MCC), branching up forces all binary variables to take on integer values simultaneously thus leading to an integer-feasible solution more quickly. In general, branching up forces more candidate variables to change which is more likely to produce integer values than branching in a way that causes few candidates to change their current value. Pryor and Chinneck's new branching direction heuristics LCP (Section 3.2.2.2) and MVV (Section 3.2.2.3) are based on this "force to change" principle. 


\section{Chapter 4}

\section{Thesis Statement}

Wojtaszek and Chinneck [2010] conducted exhaustive experiments on the performance of a variety of NS heuristics and proved that the node selection heuristic MBESTP - ASP - ANST is the best one in terms of speed to the optimum solution. The performance of this NS heuristic will be reviewed in the next chapter. Generally, this NS heuristic consists of a modified best projection backtrack node selection method (MBESTP, see Section 3.1.2.3), an aspirational backtrack triggering policy (ASP, see Section 3.1.3.2) and a principle used to switch the current backtrack NS method to the simple depth-first backtracking when the MBESTP calculations become too time-consuming (ANST, see Section 3.1.4) Their work really shows considerable improvement on the state of art node selection methods.

However, all these experiments were carried out with a single VDS method (the GLPK default Driebeek and Tomlin heuristic VDS - D\&T [Driebeek 1966, Tomlin 1971]), so there is a chance that pairing with a different VDS will provide better results. Recall that the selection of the active node and candidate variable along with its corresponding branching direction are both key factors to the branch and bound method.

All variable and direction selection methods rely on some sort of diving since the LP relaxations in a parent and child node differ by only a single variable bound adjustment, so a simplex warm start is available, which greatly decreases the 
computational effort as compared to restarting the LP solution at some other node. Objective-oriented methods choose the branching variable and direction based on impact on the objective function, such as VDS - PCOST (Section 3.2.1.1), while feasibilityoriented methods like METHA - UP (Section 3.2.2.1) choose the branching variable and direction based on their impact on the constraints, with the goal of reaching an integerfeasible solution quickly. The VDS - D\&T (see Section 3.2.1.2) used by Wojtaszek and Chinneck [2010] is in fact a partial feasibility-oriented VDS method. One could argue that optimum solutions could be achieved even more quickly if the MBESTP-ASP-ANST is coupled with a fully objective-oriented VDS heuristic such as PCOST. In addition, the merits of MBESTP-ASP-ANST as a node selection heuristic are not fully demonstrated until it is shown that it provides speed improvements when paired with any type of VDS, including feasibility-oriented VDS heuristics.

Wojtaszek and Chinneck [2010] observed that "The MIP optimal node in the branch and bound tree tends to be closer to the root node than most other MIP feasible nodes (i.e. less deep than other MIP feasible nodes)." This is basically saying that among all the integer-feasible nodes in the branch and bound tree, the optimal node is prone to be the shallowest or very close to the shallowest integer-feasible node. This makes sense since the LP relaxation of the root node provides the most optimistic bound of any node in the tree, and the LP relaxation in a node that is closer to the root node is more similar to the root node LP relaxation than the LP relaxation in a node that is farther from the root (fewer bound adjustments). It is thus more likely to have an objective function value that is more similar to the very optimistic root node LP relaxation 
objective function value. A figure taken from their work [Wojtaszek and Chinneck, 2010] is shown in Figure 4.1, In 120 MIP models solved to optimality, the integer-optimum node is the shallowest integer-feasible node in about half of them, and the majority of the integer-feasible node are within 1.5 times the depth of the shallowest integerfeasible node.

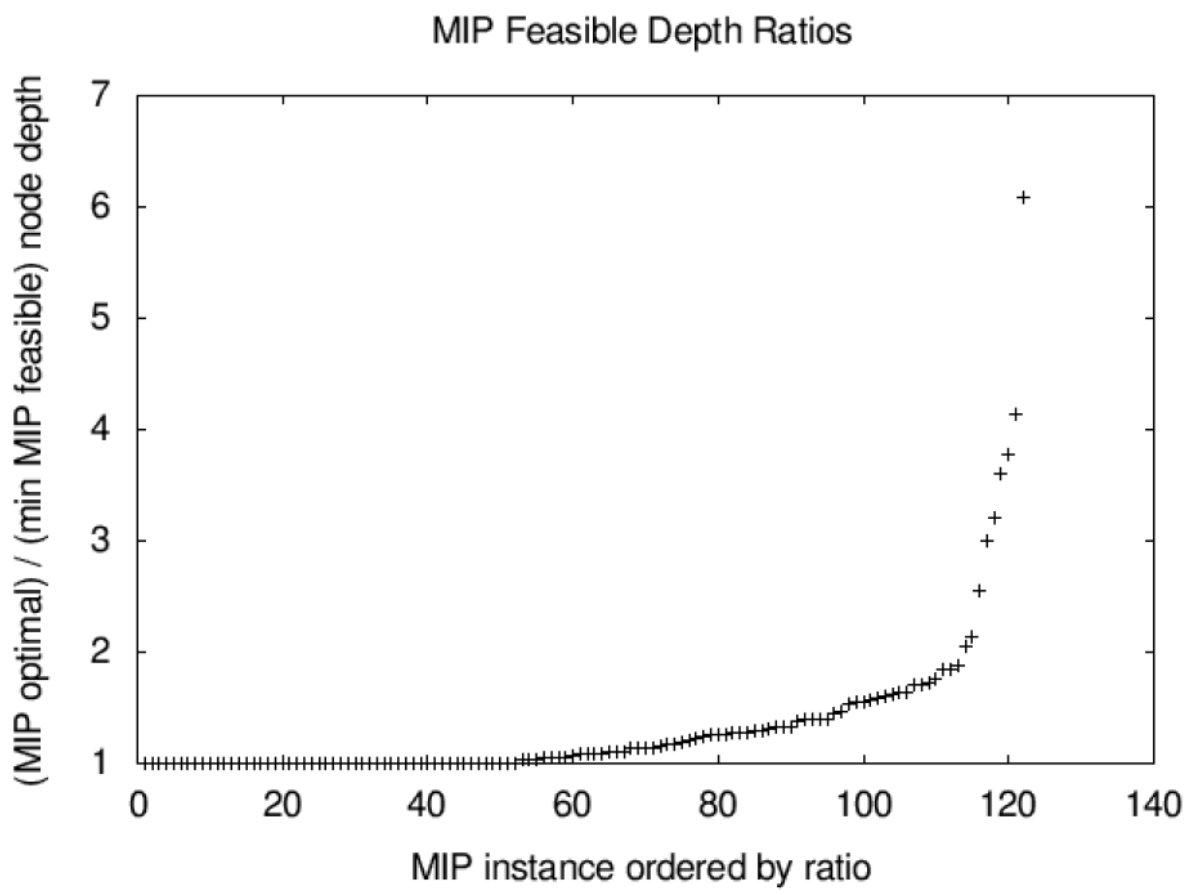

Figure 4.1: A plot of the ratio of depth of a MIP optimal node to the minimum depth over all MIP feasible nodes for a set of MIP instances [Wojtaszek and Chinneck, 2010]

This observation leads to a related but more specific question: Will the coupling of a feasibility diving heuristic with the quality node selection heuristic MBESTP - ASP ANST provide the best solution time? Diving from any node, a feasibility-seeking VDS heuristic will most likely find a shallower integer-feasible node than found by objectiveoriented VDS heuristics thus the progression from the given node to the shallowest integer 
feasible-node below it is most likely the fastest route to an integer-optimum solution, given that the starting node is well chosen.

Of course, the start node must be well chosen: it must be the most likely ancestor node of the integer-optimum solution node, that's exactly what Wojtaszek and Chinneck [2010] stated the NS heuristic MBESTP - ASP - ANST is capable of achieving. Therefore, theoretically speaking, coupling MBESTP - ASP - ANST with an effective feasibility-oriented VDS heuristic will result in a shallow integer-feasible solution, which may be the integer-optimum solution more often than not.

The performance of a single VDS / NS is inconsistent, even the best ones fall short on a small fraction of MIP problems. Different VDS / NS configurations show unique potentials and limitations on different MIP problems. No literature explicitly explains the reason, but most likely the MIP characteristics have a large impact on it since several works express this notion. Therefore, the idea comes to mind that a better way to solve MIP problems is to select the most appropriate VDS / NS configuration depending on the problem characteristics instead of sticking with a single VDS / NS configuration even it has the best general performance.

To sum up, this thesis addresses the following problems:

1. What is the best VDS to pair with the MBESTP-ASP-ANST node selection heuristic? In the course of determining this we will also determine whether MBESTP-ASP-ANST improves the speed to optimality of VDS methods based on 
different approaches such as objective-oriented methods vs. feasibility-oriented methods.

2. Does a feasibility diving VDS coupled with a quality NS heuristic such as MBESTPASP-ANST provide the integer-optimal solution in the shortest time? In the course of investigating this question, determine which feasibility-oriented VDS heuristic provides the best results when paired with MBESTP-ASP-ANST.

3. Are there rules for selecting the best VDS/NS configuration based on the MIP model characteristics that provide faster solutions than any individual VDS/NS configuration? 


\section{Chapter 5}

\section{New VDS / NS Configurations}

As mentioned in section 2.2, the major factors that should be taken into consideration when conducting the branch and bound method are the node selection strategy, the variable selection strategy and the branching direction selection. This section evaluates and selects the options for these heuristics.

\subsection{Node Selection Heuristics}

The node selection configuration not only refers to the main algorithm to select an active node to solve next upon backtracking, but also the backtrack triggering policy and whether or not to utilize the measure of the benefit and cost of a certain node selection method, namely, the Active Node Search Threshold (ANST).

Wojtaszek and Chinneck [2010] tested the top 8 heuristics along with the GLPK 4.28 state of the art heuristic $B P P_{0}-L f-N$ at the time, from a preliminary test of 79 total configurations after adding several state-of-the-art methods into GLPK. The added methods provided $3 \times 6 \times 2=36$ new NS configurations by choosing different backtrack node selection methods, backtrack triggering methods and whether or not to use ANST. Wojtaszek and Chinneck [2010] narrowed them down to the 8 most promising configurations. The test also included the GLPK default node selection 
configuration for reference. These configurations are listed in table 5.1. The abbreviations in the table are as follows:

- Backtrack node selection methods:

○ BPro: best projection (GLPK default)

- $B \operatorname{Pr}_{1}$ : modified best projection (new)

○ Dist: distribution (new)

- Backtrack triggering methods:

- E: backtrack triggered after each node (added)

$\circ \quad L f$ : leaf node triggering

- $B \operatorname{Pr} A_{0}$ : best projection aspiration (added)

- $B P r A_{1}$ : modified best projection aspiration (new)

○ PCA: pseudo-cost (best-estimate) aspiration (added)

- DExA: depth extrapolation aspiration (new)

- Active Node Search Threshold (ANST):
- Y: use ANST (new)
- $N$ : do not use ANST 


\begin{tabular}{|c|c|}
\hline & NS heuristic \\
\hline 1 & $B P r_{0}-L f-N$ \\
\hline 2 & $B P r_{0}-B P r A_{0}-N$ \\
\hline 3 & $B P r_{1}-B P r A_{1}-Y$ \\
\hline 4 & $B P r_{1}-B P r A_{1}-N$ \\
\hline 5 & $B P r_{1}-P C A-Y$ \\
\hline 6 & Dist-E-N \\
\hline 7 & Dist-BPrA $A_{1}-Y$ \\
\hline 8 & $B P r_{1}-P C A-N$ \\
\hline 9 & $B P r_{1}-D E x A-Y$ \\
\hline
\end{tabular}

Table 5.1: Top Node Selection Configurations

A set of 272 MIP instances were tested, each run under all 9 node selection configurations. 109 of them were solved with at least one test configuration, 130 instances were not solved to optimality but an integer-feasible solution was found with at least one configuration. For the other 33 instances, neither an optimal solution nor an integer-feasible solution was found. The detailed results are summarized in the table below. 


\begin{tabular}{|c|c|c|c|}
\hline \multirow[t]{2}{*}{ Configuration } & \multicolumn{3}{|c|}{ Solved MIPs } \\
\hline & FAIL & TOTTM & MRATE \\
\hline$B P r_{1}-B P r A_{1}-Y$ & 6 & 86653.72 & 1.33 \\
\hline Dist-BPrA 1 -Y & 6 & 86654.38 & 1.37 \\
\hline$B P r_{1}-P C A-Y$ & 6 & 88560.12 & 1.34 \\
\hline$B P r_{1}-D E x A-Y$ & 6 & 91509.11 & 1.4 \\
\hline Dist-E-N & 15 & 97340.26 & 1.34 \\
\hline$B P r_{1}-B P r A_{1}-N$ & 13 & 99798.67 & 1.43 \\
\hline$B P r_{1}-P C A-N$ & 12 & 100752.39 & 1.5 \\
\hline$B P r_{0}-B P r A_{0}-N$ & 14 & 109239.58 & 1.75 \\
\hline$B P r_{0}-L f-N$ & 15 & 109579.06 & 1.78 \\
\hline
\end{tabular}

Table 5.2: Performance of 9 Node Selection Configurations [Wojtaszek and Chinneck, 2010]

Configurations $B \operatorname{Pr}_{1}-B P \operatorname{PA}_{1}-Y$, Dist-BPrA $A_{1}-Y, B P r_{1}-P C A-Y$ and $B \operatorname{Pr}_{1}-D E x A-Y$ top the charts with only 6 failures each. Furthermore, the configuration $B \operatorname{Pr}_{1}-B \operatorname{PrA}_{1}-Y$ stands out among these 4 configuration with the smallest "TOTTM" and "MRATE" which stands for the total solution time for the whole set of 109 solved MIPs and the average ratio of solution time to the best solution time for each instance respectively. Dist-BPrA $-Y$ is slightly behind with almost the same total finish time. The conclusions can be drawn more easily with the graphical illustration of the performance profile shown in Figure 5.1 below. 


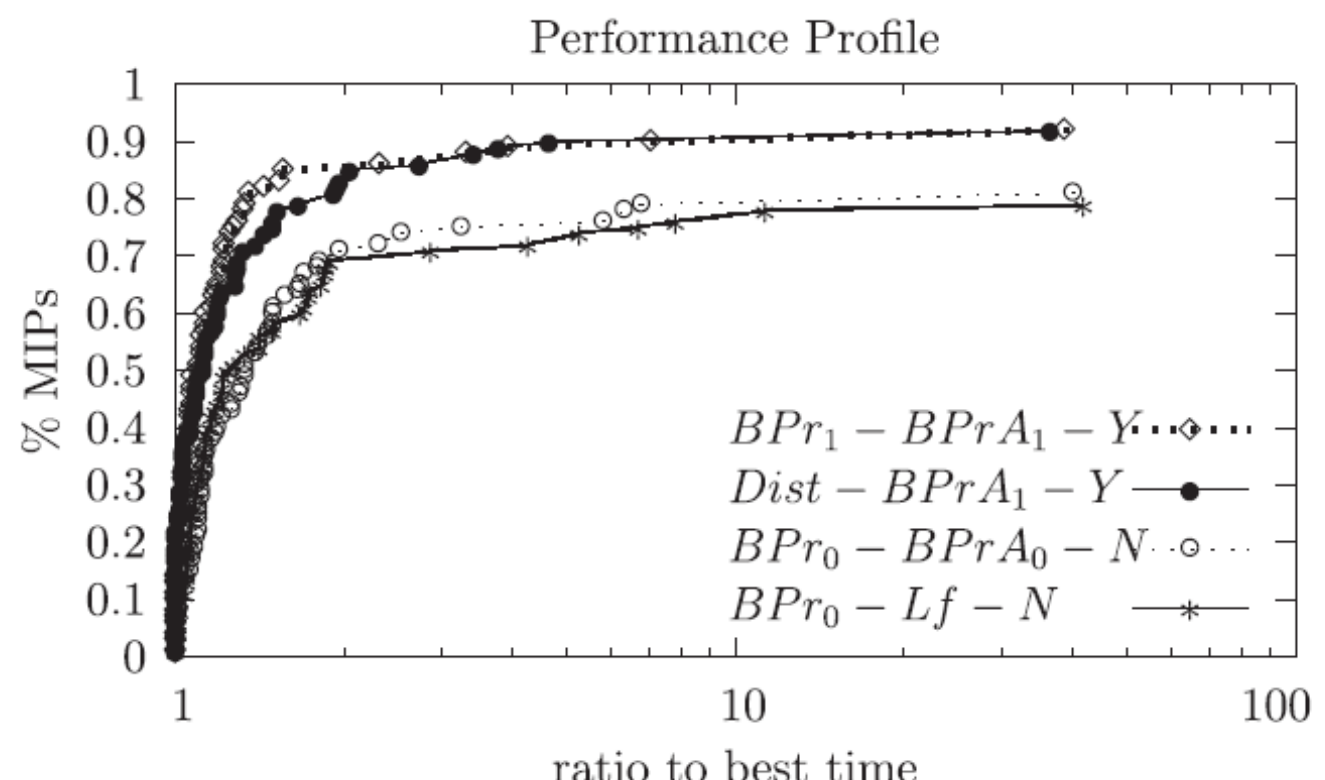

Figure 5.1: Performance Profile Comparing the two best configurations with the two state of art GLPK configurations [Wojtaszek and Chinneck, 2010]

Obviously, $B \operatorname{Pr}_{1}-B P r A_{1}-Y$ and Dist-BPrA $A_{1}-Y$ beat the two state-of-the-art GLPK configurations $B \operatorname{Pr}_{0}-B P A_{0^{-}} N$ and $B P r_{0}-L f-N$ by a big margin. The traces of these two configurations have similar starts and ends. The gap between these two methods around inflection points indicate that $B \operatorname{Pr}_{1}-B \operatorname{Pr}_{1}-Y$ is able to solve roughly $17 \%(0.87-$ 0.7) of the test models in less time.

Conclusively, $B \operatorname{Pr}_{1}-B P r A_{1}-Y$ aka the modified best projection node selection method triggered by modified best projection aspiration with ANST turned on is the best node selection heuristic identified by Wojtaszek and Chinneck. Labelled MBESTP - ASP - 
ANST in this thesis, it will be paired with various VDS in later experiments. The GLPK default best - bound (BESTB) NS will also be tested.

\subsection{Variable and Direction Selection Heuristics}

The VDS methods available in the GLPK MIP solver (Section 6.2) are shown in Table 5.3 below.

\begin{tabular}{|c|c|}
\hline & VDS method \\
\hline 1 & FIRSTF \\
\hline 2 & LASTF \\
\hline 3 & MOSTF \\
\hline 4 & VDS -D\&T \\
\hline 5 & VDS - PCOST \\
\hline
\end{tabular}

Table 5.3: VDS methods available in GLPK MIP solver [Makhorin, 2001]

The VDS heuristics to choose the first (FIRSTF) or last (LASTF) fractional candidate variables and the most fractional candidate variable (MOSTF) are known to be poor methods according to Achterberg et al. [2005], hence they will be omitted. VDS - D\&T and VDS - PCOST are both well-known VDS methods. VDS - PCOST is a pure objective oriented method and VDS - D\&T is a partial feasibility-oriented VDS method.

The variable and direction selection method not only includes the choice of the candidate variable to branch on next, but also the corresponding branching direction 
associated with the variable. Some state-of-the-art variable selection methods determine the branching direction within its algorithm such as VDS - PCOST and VDS D\&T stated above, while the others do not. Hence, it is necessary to predetermine a consistent branching direction policy before branching. Even for the variable and direction selection methods that select the variable and direction simultaneously, the algorithm can be dissected to couple the variable selection with different branching direction policies and the distinction would be noticeable. The conventional branching direction policies include (i) branch up always, (ii) branch down always, and (iii) branch in the direction of the closest integer. To assess the performance of branching direction policies, Pryor and Chinneck [2010] set up an experiment to test speed to first integer feasible solution by running through a set of 142 models with the 3 branching policies mentioned above as well as the GLPK default branching direction policy. GLPK uses the heuristic by Driebeek and Tomlin as default method [Makhorin, 2001], which is a combined method for variable and direction selection. The results are reflected in the performance profile shown in the figure below. 


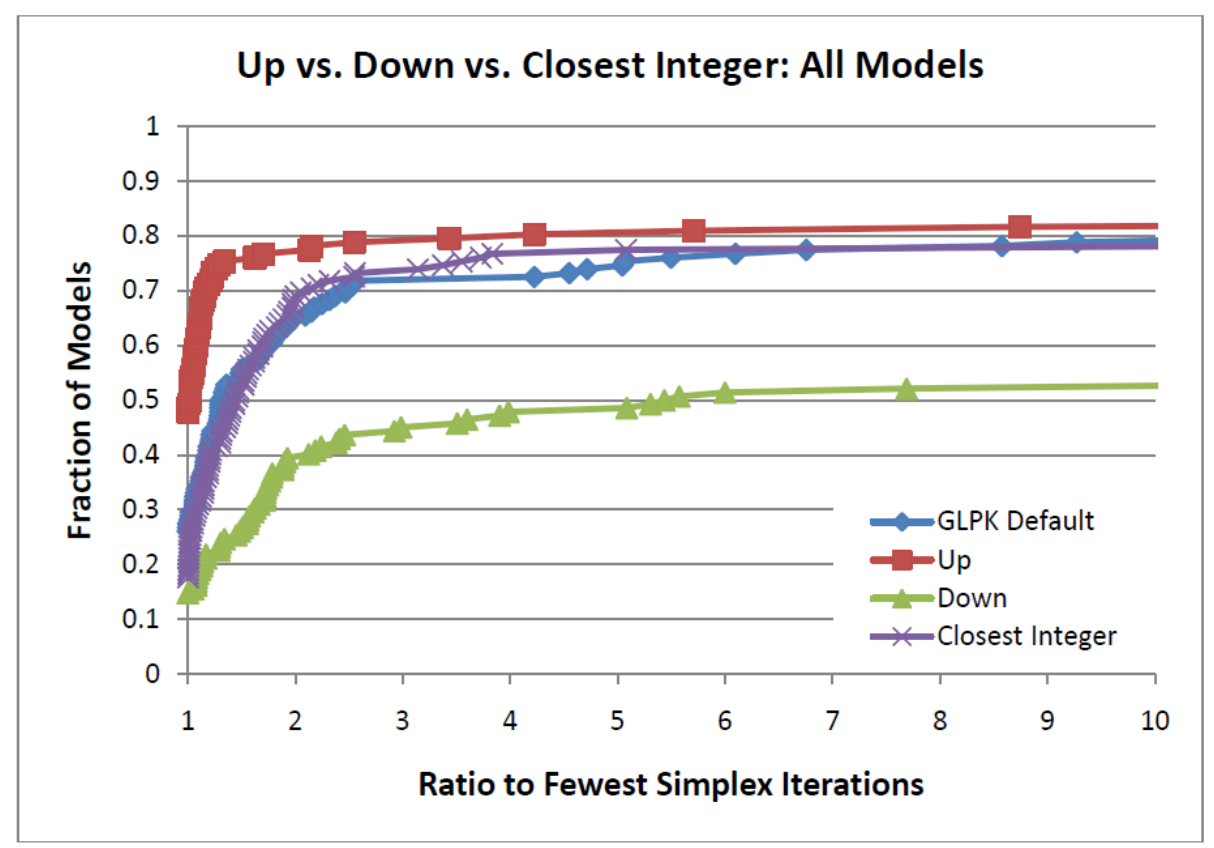

Figure 5.2: Performance Profile for Branching Direction Policy Comparison [Pryor and Chinneck, 2010]

Here, branching up is dominant as its trace is entirely above the other three meaning that the branching up policy reached the first integer - feasible solution faster and was able to solve more instances within the same amount of time. Accordingly, when pairing the variable selection method with branching direction policy, branching up should be given priority. Consequently, for method A that chooses only the branching variable within the algorithm, an option is to combine it with branching up. Other contenders could be the combinations of method A with probability or violation based branching direction policies. Last but not the least, the feasibility - oriented heuristic VDS-LCP is included in the experiment. 
Pryor and Chinneck [2010] examined the performance of various VDS on sets of models with and without multiple choice constraints (MCC), since these have a large impact on solution speed.

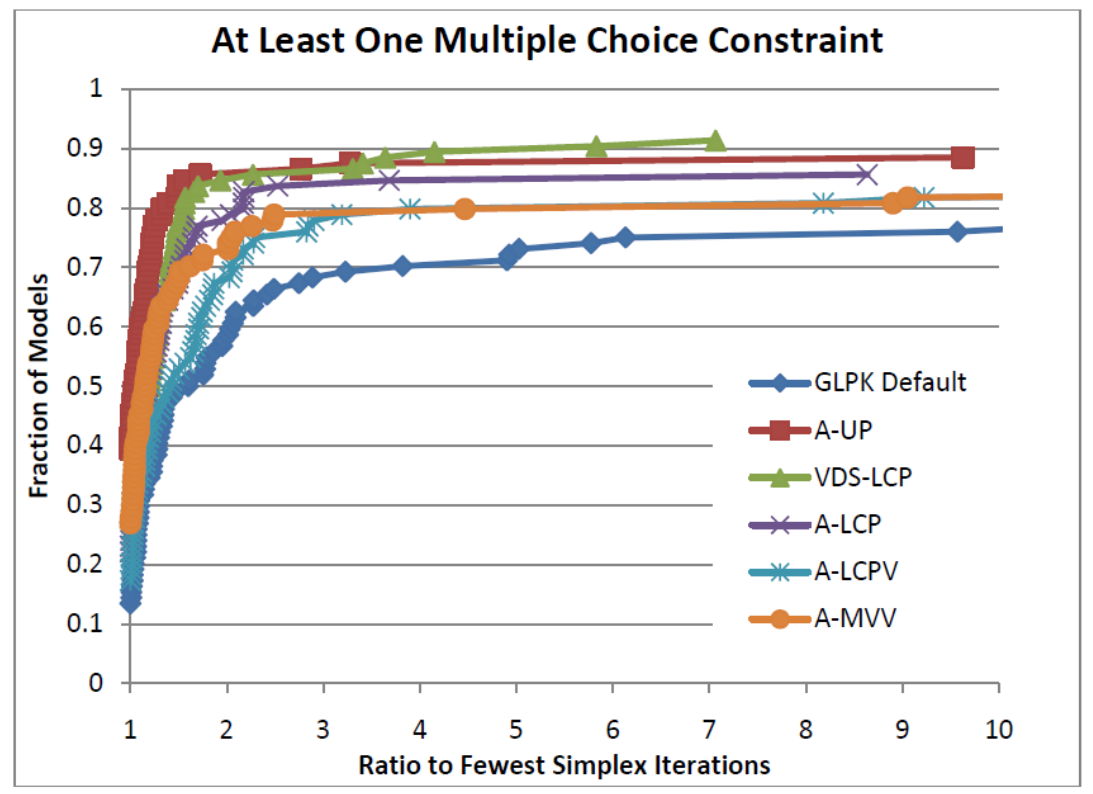

Figure 5.3: VDS contenders with MCC [Pryor and Chinneck, 2010]

METHA - Up is generally the fastest to the first feasible solution and VDS - LCP was slightly behind with longer finish time but was able to solve more MIP instances. Without MCCs as shown in Figure 5.4, METHA - Up was not dominant anymore but still managed to be one of the leaders. In general, METHA - Up is the best one among all the VDS combinations involving method A. VDS - LCP is also a promising candidate. Another candidate that should be taken into consideration is the GLPK default, namely, the heuristic by Driebeek and Tomlin. In spite of its poor performance compared to other contenders in terms of speed to first integer - feasible solution, it shows potential to solve problems having equality constraints. As shown in Figure 5.5, the branching 
direction strategy developed in the heuristic by Driebeek and Tomlin managed to solve the most MIP instances when the model has at least one equality constraint, compared to other methods for choosing the branching direction.

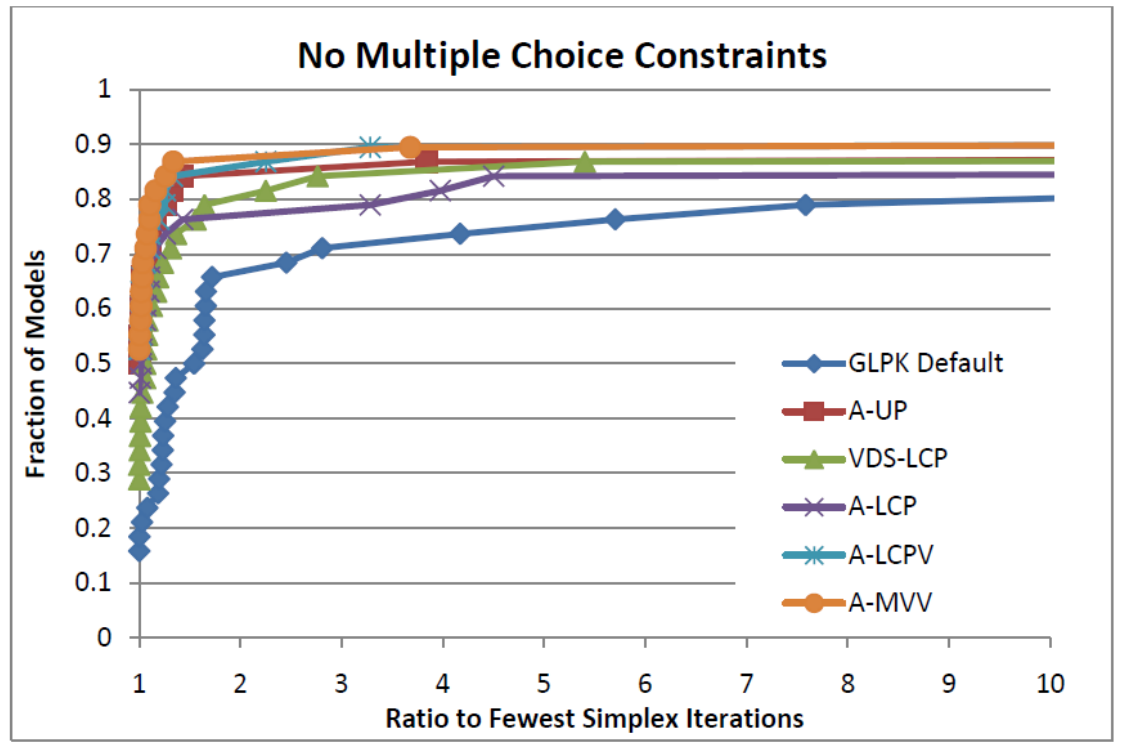

Figure 5.4: VDS contenders without MCC [Pryor and Chinneck, 2010] 


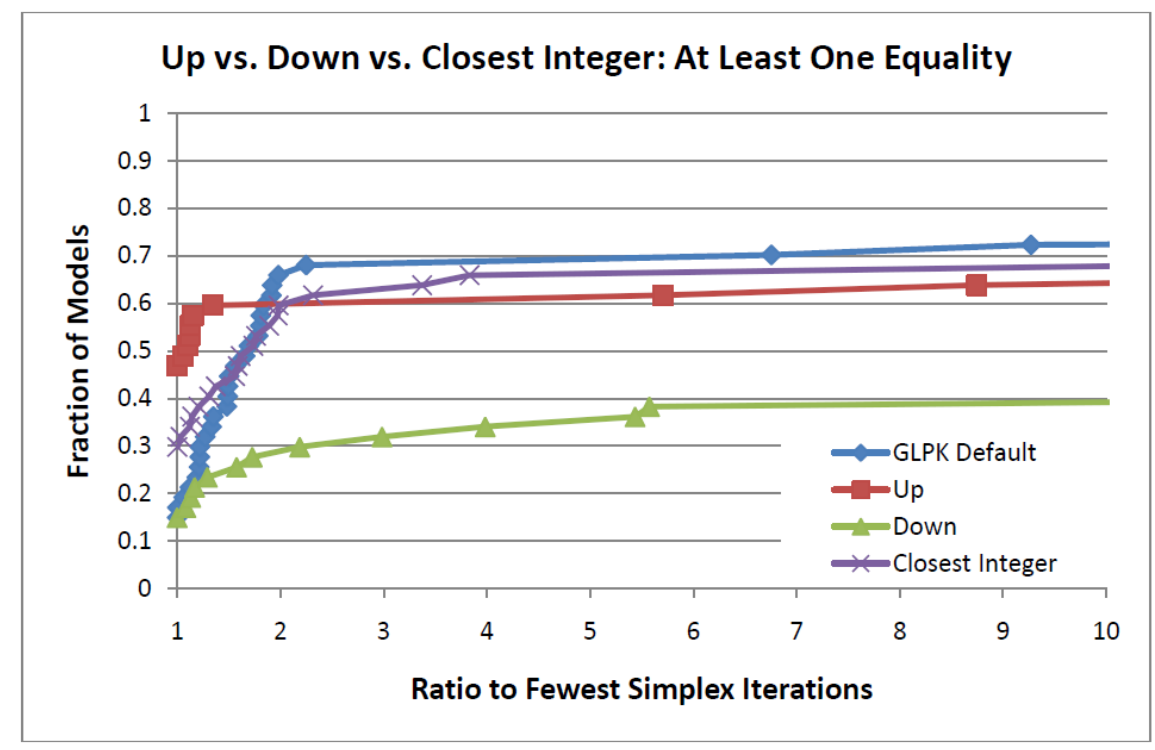

Figure 5.5: Performance of simple branching direction policies with equality constraints [Pryor and Chinneck, 2010]

To sum up, the selections of VDS heuristic in the thesis are VDS - PCOST, a pure objective - oriented VDS method; METHA - UP and VDS - LCP, both feasibility oriented VDS methods; and VDS - D\&T, a hybrid VDS method. The NS heuristic MBEST ASP - ASP will be tested coupled with selected VDS methods of each type.

\subsection{VDS / NS Configurations}

VDS and NS heuristics that show promise (as explained above) are combined into VDS/NS configurations. The VDS / NS configurations that will be tested in this thesis are summarized in Table 5.4 . 


\begin{tabular}{|c|c|c|}
\hline $\begin{array}{c}\text { Configuration } \\
\text { Number }\end{array}$ & VDS method & NS method \\
\hline 1. & VDS - D\&T & BESTB (default) \\
\hline 2. & VDS - D\&T & MBESTP - ASP - ANST \\
\hline 3. & METHA - UP & BESTB \\
\hline 4. & METHA - UP & MBESTP - ASP - ANST \\
\hline 5. & VDS - LCP & BESTB \\
\hline 6. & VDS - LCP & MBESTP - ASP - ANST \\
\hline 7. & VDS - PCOST & BESTB \\
\hline 8. & VDS - PCOST & MBESTP - ASP - ANST \\
\hline
\end{tabular}

Table 5.4 Testing NS and VDS combinations

\subsection{MIP Characteristics for Rule Development}

The performance of a single VDS / NS is inconsistent, even the best VDS / NS configuration falls short on a small fraction of MIP problems. Although there is no definite conclusion in the literature as to which is the best VDS / NS, several VDS / NS configurations show some potentials and limitations on different MIP problems. Which configuration is the best for a particular MIP is likely influenced by the model characteristics. Some existing work has identified model characteristics that impact the effectiveness of different VDS and NS methods. Some important model characteristics are: 
1. Presence or absence of MCC: Pryor and Chinneck [2010] pointed out that the performances of feasibility diving methods METHA - UP and VDS - LCP are affected by the presence of multiple-choice constraints. Since branching up always performs well on MCC, METHA - UP directly chooses to branch up and VDS - LCP gets lower cumulative probability on branching up, thus chooses to branch up as well.

2. Presence or absence of equality constraints: Pryor and Chinneck [2010] also identified that the presence of equality constraints worsens the performance of VDS methods especially METHA - UP, which counts all equality constraints as active constraints, thus influencing the METHA figure of merit.

3. Number of continuous variables: Driebeek [1966] stated that his method was developed to solve primarily problems containing a large number of continuous variables. So VDS - D\&T (proposed by Driebeek and modified by Tomlin [1970]) should have similar behavior. Besides, Gauthier and Ribière [1977] also mentioned that their VDS heuristic that is a variation of VDS - PCOST, should apply generally on problems having a low percentage of integer variables.

Therefore, the development of rules for selecting a VDS / NS configuration will take these characteristics into account. 


\section{Chapter 6}

\section{Experiment Setup}

This chapter specifies the conditions under which all the experiments were conducted including the hardware and software details, the MIP solver parameter settings, the MIP instances, and the metrics used to evaluate the performances of various methods.

\subsection{Hardware and Software}

CPU: Intel Core i7-2600@ @ $3.4 \mathrm{GHz}$ (with no other user tasks running at the same time as the MIP solver).

RAM: $15.6 \mathrm{~GB}$

OS: Linux 5.2.9-200 Fedora 30, 64-bit

Compiler: GNU GCC 9.2.1 (Red Hat 9.2.1-1)

\subsection{MIP solver}

The GLPK (GNU Linear Programming Kit) MIP solver version 4.64 [GLPK, 2018] was used in all the experiments for the following reasons:

1. GLPK is a free open-source MIP solver with detailed user manual. Hence, the original GLPK routines are easily modified and the user-defined routines can be 
added to the GLPK program for research purposes. In this case, NS and VDS heuristics not included in GLPK were added (see below).

2. GLPK uses the branch-and-cut method to solve MIP problems. The branch-andcut method is mainly branch-and-bound based with cutting planes heuristics integrated to eliminate fractional solutions of the LP relaxation early in order to speed up the whole process. Thus it fits well with the goal of this thesis to evaluate the performance of several branch and bound methods.

3. Some heavily used node selection heuristics and VDS methods in this thesis were Previously implemented in GLPK 4.64, making it easier to port them to the current version of GLPK. The ported heuristics included NS by MBESTP - ASP ANST (Section 3.1) and VDS by METHA-UP (Section 3.2.2.1) and VDS-LCP (Section 3.2.2).

4. GLPK is a reasonably competitive non-commercial solver according to Mittelmann's MILP Benchmark [Mittelmann, 2019].

GLPK allows user control of various parameter settings. Unless otherwise specified, all the parameters were set to their default values except for the parameter tmlim, which refers to the time limit in seconds for each GLPK solution. In this thesis, this parameter was set to 3600 for all MIP instances, that is to terminate the program after 1 hour if the MIP problem hasn't been solved yet. 


\subsection{Performance Measures}

The possible outcomes of GLPK working on MIP instances are:

- Optimal solution found within time limit

- Time out with an incumbent solution found

- Time out without an incumbent solution

- Error, meaning that GLPK fails to process the MIP instance

For a MIP instance successfully solved by all contenders within the limit, the most important measure is the integer-optimal solution time, as it reflects the efficiency of a competing method most directly. A method having a solution time within $5 \%$ of the best solution time of the instance will be considered as a tie due to the tolerance on the machine timing measurements. For models with short solution time within 10 seconds, the tolerance is a fixed $0.5 \mathrm{~s}$. That is the method with solution time no more than 0.5 seconds longer than the best solution time in 10 s will be marked as a winner as well.

The number of simplex iterations and the number of nodes solved are also recorded. These are less meaningful than solution time because the number of simplex iterations captures only the LP work and ignores the work done in variable, branching direction, and node selection, while the number of nodes often has no correlation with solution time.

Not all MIP instances are solved to optimality within the 1-hour time limit. For those more difficult instances, the incumbent solution is a measure to be considered. 
That is, the method with the smallest incumbent solution will be regarded as the best method for this MIP problem. This measure does not always accurately reflect the winner if more time is given and the instance is solved to optimality. However, for instances that are unlikely to be solved without an impractical amount of time, a better incumbent solution is desirable. For many instances, the incumbent solution at the time limit is already the final optimal solution but is not yet recognized as the optimal solution since there are still unexplored, but promising nodes in the branch and bound searching tree. This measure can be useful in the experiment thus captured for all models tested in the experiments.

For some models, GLPK either fails, or is unable to find an incumbent solution by any methods within the time limit. These models are excluded from consideration in these cases since they do not provide useful information for evaluation purposes. Since some of the VDS methods used in this thesis are feasibility-oriented like METHA UP and VDS - LCP, the time to reach the first integer-feasible solution as well as the number of integer-feasible solution found within time limit could give some insights into the performance of feasibility- oriented VDS method in conjunction with quality node selection heuristic. So they are recorded in case they can be useful.

To sum up, a complete MIP instance computation record contains the following data:

- VDS: variable and direction selection method used in the branch and bound method.

- NS: node selection heuristic used in the branch and bound method 
- Model: name of the model fed to the GLPL MIP solver

- \# simplex it.: number of simplex iterations till the exit of MIP instance run.

- Incu. Sol.: incumbent solution of MIP on exit (optimum solution, failure, timeout). If the instance is solved to optimality, this incumbent solution is in fact the optimal solution.

- \# nodes: number of nodes visited in the branch and bound tree when time limit is reached.

- $\mathbf{1}^{\text {st }}$ fea. Time: time to reach the first integer-feasible solution.

- \# fea. Nodes: total number of integer-feasible solutions found within the time limit.

- Exit code: status of MIP instance upon exit, they are "INTEGER OPTIMAL SOLUTION FOUND"; "TIME LIMIT EXCEEDED" indicating 1-hour computation time has elapsed but the integer-optimal solution is not found; "FAIL" meaning GLPK solver failed to compute the problem with current VDS / NS configuration.

- Time: time (in seconds) spent to find the optimal solution or the time limit of 3600s if optimal solution is not found.

- Memory: total amount, in bytes, of allocated memory blocks upon exit [Makhorin 2001].

It is very unlikely that a single competing configuration will win every test instance and it has never been reported in the literature that any VDS or NS heuristic 
has achieved this. Each contender is expected to perform well on some models in the test set while doing poorly on some other instances. Better configurations are able to solve more models to integer-optimality in less time, on average. The "best" configuration is thus determined empirically via testing on a set of representative MIP models. The summary statistics are visualized via performance profiles [Dolan and Moré, 2002]. A solution time performance profile provides a graphical visualization of the fraction of models a competing method is able to solve within some ratio to the smallest time used by any method for the model. A method able to finish a higher fraction of models within a smaller ratio of time is recognized as the best method. The curves for the best method will normally be above the other curves.

\subsection{MIP Instances}

A relatively large set of MIP instances is needed in order to evaluate the performance of the methods objectively. The selection of the MIP instances is unbiased, 164 MIP models have been collected from MIPLIB 2017 [Gleixner et al., 2019], MIPLIB 2010 [Gamrath, 2019], MIPLIB 3.0 [Bixby el at., 1998], MIPLIB 2.0 [MIPLIB, 1996] and H. Mittelmann's MIP collection [Mittelmann, 2009]. The selected instances are expected to be easy enough to be solved to optimality within the time limit so the primary performance measure could be applied. For this reason, the models were chosen based on their solution times using the GLPK MIP solver in Mittlemann's benchmark

[Mittlemann, 2019] and Wojtaszek's [2008] experiment results without regard to their 
VDS / NS configurations. Some of the MIPLIB 2017 models were also chosen simply based on their size as measured by the number of nonzeros in the constraint matrix. Thus, no VDS / NS configuration is favored in the experiments. The complete set of models is summarized in Tables 6.1a and 6.1b. The MIP instance source and characteristics are shown in Table A.1. 


\begin{tabular}{|c|c|c|c|}
\hline 22433 & csched008 & gr4x6 & modglob \\
\hline 23588 & csched010 & graphdraw-domain & momentum2 \\
\hline \multirow[t]{2}{*}{ 10teams } & & graphdraw- & \\
\hline & cvs08r139-94 & gemcutter & mtest4ma \\
\hline $50 v-10$ & cvs16r70-62 & gsvm2rl3 & mzzv11 \\
\hline aflow30a & dano3_3 & gt2 & neos-1112782 \\
\hline air04 & dano3_4 & h80x6320d & neos-1112787 \\
\hline air05 & dano3_5 & haprp & neos-1122047 \\
\hline aligninq & danoint & ic97_potential & neos-1171448 \\
\hline app2-2 & dcmulti & $\operatorname{irp}$ & neos-1396125 \\
\hline assign1-5-8 & dsbmip & $k 16 \times 240 b$ & neos-1430701 \\
\hline beasleyC1 & egout & khb05250 & neos-1582420 \\
\hline beavma & eil33-2 & I152lav & neos16 \\
\hline berlin_5_8_0 & enigma & leo2 & neos17 \\
\hline bienst1 & enlight_hard & lotsize & neos-3072252-nete \\
\hline bienst2 & ex9 & Iseu & neos-3083819-nubu \\
\hline \multirow{2}{*}{ binkar10_1 } & exp-1-500-5- & & \\
\hline & 5 & markshare_4_0 & neos-3118745-obra \\
\hline \multirow[t]{2}{*}{ blend2 } & & & neos-3381206- \\
\hline & f2gap201600 & markshare1 & awhea \\
\hline bm23 & fiber & mas76 & neos-3421095-cinca \\
\hline bppc4-08 & fixnet6 & mc11 & neos-3530903-gauja \\
\hline bppc8-02 & flugpl & mcsched & neos-3610040-iskar \\
\hline cap6000 & g200x740 & mik-250-1-100-1 & neos-3610051-istra \\
\hline $\begin{array}{c}\text { chromaticindex32- } \\
8\end{array}$ & gen-ip021 & $\operatorname{misc03}$ & neos-3610173-itata \\
\hline cmflsp50-24-8-8 & gen-ip054 & $\operatorname{misc06}$ & neos-3611447-jijia \\
\hline comp07-2idx & germanrr & $\operatorname{misc07}$ & neos-3611689-kaihu \\
\hline control30-3-2-3 & gmu-35-40 & mod008 & neos-3627168-kasai \\
\hline
\end{tabular}

Table 6.1a: Test models - part 1 


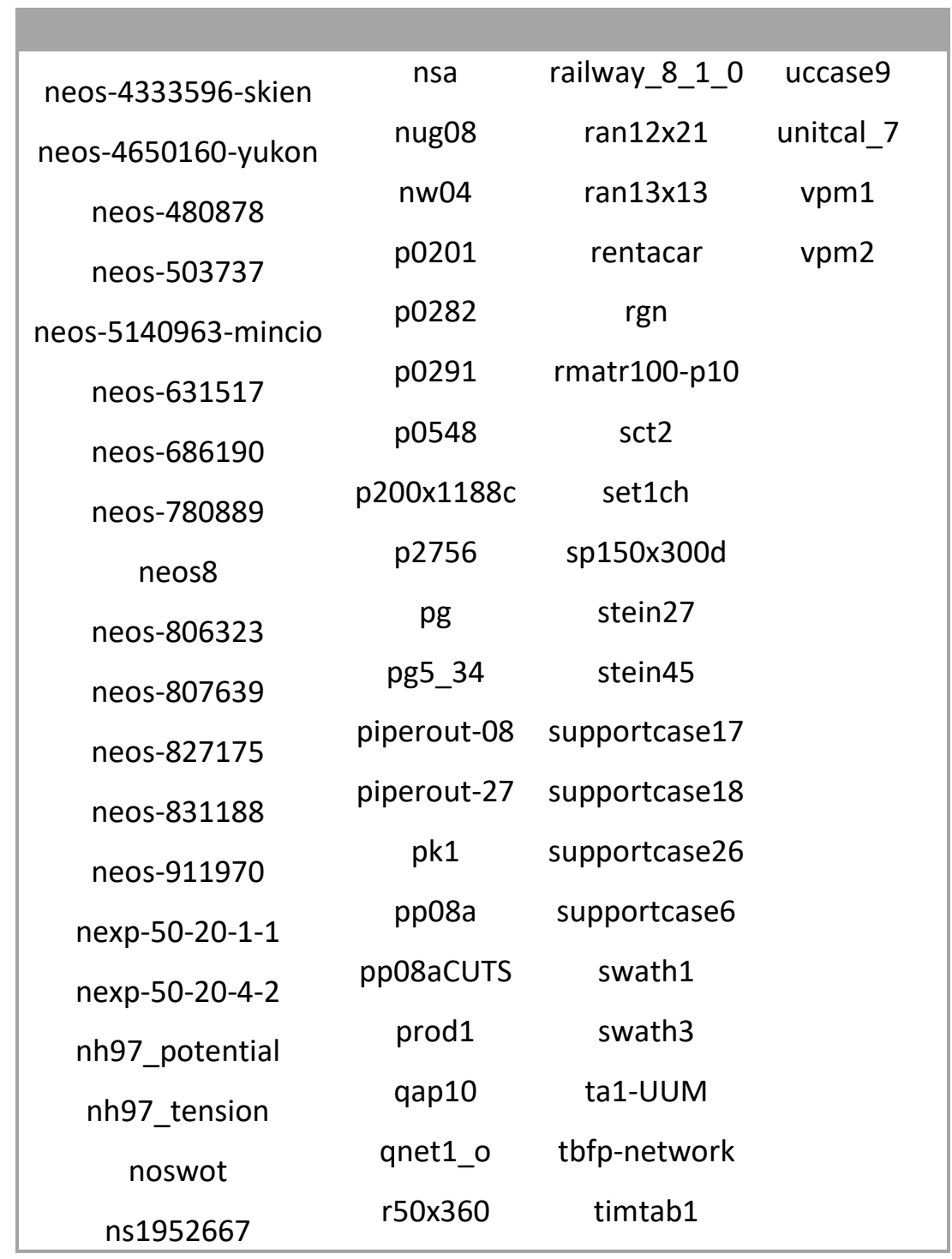

Table 6.1b: Test models - part 2. 


\subsection{Experimental Design}

The objectives in this thesis include (i) evaluating the effect of pairing NS heuristic MBESTP - ASP - ANST with different VDS heuristics, (ii) identifying the best individual VDS/NS configuration, and (ii) developing an improved hybrid combination of methods. Three corresponding experiments were carried out.

All node selection heuristics and variable and direction selection methods used in the experiments are shown below.

- Variable and direction selection configuration:

VDS - PCOST: Pseudo-cost variable and direction selection method (Section 3.2.1)

VDS - D\&T: Heuristic by Driebeek and Tomlin for variable and direction selection (GLPK default, Section 3.2.2)

METHA - UP: Method - A, branching up (Section 3.3.1)

VDS - LCP: Lowest cumulative probability heuristic for variable and node selection (Section 3.3.2)

- Backtrack node selection heuristics:

BESTB: Best-bound (GLPK default, see section 3.1.1)

MBESTP - ASP - ANST: Modified best-projection (section 3.1.2) with aspiration backtrack (section 3.1.4) and active node search threshold (section 3.1.5) 


\subsubsection{Experiment 1: VDS / MBESTP - ASP - ANST Pairings}

All VDS heuristics considered in this thesis are tested on the entire problem set in conjunction with MBESTP - ASP - ANST and the results are compared to their performances when coupled with the GLPK default NS method BESTB. Since 4 VDS methods were selected in Chapter 5, 4 groups of comparison will made. They are shown in Table 6.1.

\begin{tabular}{|ccc|}
$\begin{array}{c}\text { Group } \\
\text { Number }\end{array}$ & VDS method & NS method \\
\hline 1. & VDS - D\&T & BESTB (GLPK default) \\
& VDS - D\&T & MBESTP - ASP - ANST \\
2. & METHA - UP & BESTB (GLPK default) \\
& METHA - UP & MBESTP - ASP - ANST \\
3. & VDS - LCP & BESTB (GLPK default) \\
& VDS - LCP & MBESTP - ASP - ANST \\
4. & VDS - PCOST & BESTB (GLPK default) \\
& VDS - PCOST & MBESTP - ASP - ANST \\
\hline
\end{tabular}

Table 6.2: Groups of VDS - NS configurations to be tested in experiment 1

If all groups favor the VDS / NS configuration with MBESTP - ASP - ANST, the conclusion can be drawn that MBESTP - ASP - ANST is capable of improving the branch and bound performance no matter which VDS method it is coupled with, no matter if it is feasibility - oriented or objective - oriented. 


\subsubsection{Experiment 2: Identifying the Best VDS / NS Configuration}

With the results obtained from experiment 1, the most promising VDS / NS

configuration will be identified in experiment 2. Wojtaszek and Chinneck [2010] verified that VDS - D\&T / MBESTP - ASP - ANST outperformed the state of art GLPK branch and bound method VDS - D\&T / BESTB, so the best methods from Table 6.2 will be compared with it. The VDS / NS configurations of interest are shown in Table 6.3 along with GLPK state of art method VDS - D\&T / BESTB as the bottom line.

\begin{tabular}{|ccc|} 
& VDS method & NS method \\
\hline 1. & VDS - D\&T & MBESTP - ASP - ANST \\
2. & METHA - UP & MBESTP - ASP - ANST \\
3. & VDS - LCP & MBESTP - ASP - ANST \\
4. & VDS - PCOST & MBESTP - ASP - ANST \\
5. & VDS - D\&T & BESTB (default) \\
\hline
\end{tabular}

Table 6.3: VDS - NS configurations in experiment 2

The subproblem stated in Chapter 4 will also be studied here. MBESTP-ASP-ANST paired with the feasibility- oriented VDS heuristics METHA-UP and VDS-LCP, and partial feasibility-oriented VDS - D\&T, is compared with coupling those VDS with the GLPK default NS heuristic BESTB, as well as with the complete GLPK default (VDS D\&T/BESTB). This analysis will answer the question as to whether coupling a good NS method with a feasibility- oriented VDS provides faster MIP solutions. 


\begin{tabular}{|cc|}
\hline VDS method & NS method \\
\hline METHA - UP & MBESTP - ASP - ANST \\
PCOST & MBESTP - ASP - ANST \\
METHA - UP & BESTB (default) \\
\hline
\end{tabular}

Table 6.4: METHA - UP paired with two NS

\begin{tabular}{|cc|}
\hline VDS method & NS method \\
\hline VDS - LCP & MBESTP - ASP - ANST \\
PCOST & MBESTP - ASP - ANST \\
VDS - LCP & BESTB (default) \\
\hline
\end{tabular}

Table 6.5: VDS - LCP paired with two NS

\begin{tabular}{|cc|}
\hline VDS method & NS method \\
\hline VDS - D\&T & MBESTP - ASP - ANST \\
PCOST & MBESTP - ASP - ANST \\
VDS - D\&T & BESTB (default) \\
\hline
\end{tabular}

Table 6.6: VDS - D\&T paired with two NS

\subsubsection{Experiment 3: Rules for Hybrid Configuration}

As discussed in Section 5.4, various characteristics of the MIP model affect the performance of the VDS and NS heuristics. The following characteristics were recorded for each model: 
- MCC: number of multiple-choice constraints (MCC)

- eq: number of equality constraints in the problem

- ineq: number of inequality constraints in the problem

- eq. frac.: the fraction of equality constraints vs. the total number of constraints in the problem

- int. var.: number of integer variables (binaries excluded) in the problem

- bin.: number of binary variables in the problem

- con.: number of continuous variables in the problem

- con. frac.: the fraction of continuous variables vs. the total number of variables in the problem.

The general procedure to identify a rule is to study the outcomes when each characteristic (MCC, eq, con) is present or absent. Combining 3 characteristics together gives 8 possible categories as summarized in Table 6.7. If a cluster of models in the same category are solved faster by a particular VDS/NS configuration in the training set, then this is identified as a rule. 


\begin{tabular}{|cccc|}
\hline & $\begin{array}{c}\text { \# } \\
\text { MCC }\end{array}$ & $\begin{array}{c}\text { \# Equality } \\
\text { Constraints }\end{array}$ & $\begin{array}{c}\text { \# Continuous } \\
\text { Variables }\end{array}$ \\
\hline 1. & 0 & 0 & 0 \\
2. & 0 & 0 & $1+$ \\
3. & 0 & $1+$ & 0 \\
4. & 0 & $1+$ & $1+$ \\
5. & $1+$ & 0 & 0 \\
6. & $1+$ & 0 & $1+$ \\
7. & $1+$ & $1+$ & 0 \\
8. & $1+$ & $1+$ & $1+$ \\
\hline
\end{tabular}

Table 6.7: Possible MCC, equality, continuous variable categories

78 of the 85 MIP instances that were solved to optimality by at least one VDS / NS configuration from Experiment 1 are studied. The 7 omitted models were all solved within $0.5 \mathrm{sec}$ for all configurations and hence will not help in distinguishing between configurations. The 78 MIP instances were randomly split into 2 sets, that is 39 of them were selected for rule development (training set), and the other 39 instances were used to validate the rule (testing set). More specifically, each set has half of the models in each category, this assures the rule developed from a certain category in the training set can be applied and tested to models in the same category in the testing set. The lists of MIP problems for training and testing sets are shown in Tables 6.8 and 6.9. 


\begin{tabular}{|ccccc|}
\hline 22433 & fixnet6 & neos-1430701 & neos-807639 & prod1 \\
23588 & irp & neos-1582420 & neos-831188 & ran13x13 \\
dano3_5 & I152lav & neos-3083819-nubu & nug08 & rentacar \\
danoint & mas76 & neos-3610051-istra & nw04 & rmatr100-p10 \\
dsbmip & mcsched & neos-3611447-jijia & p0201 & stein45 \\
eil33-2 & misc06 & neos-4333596-skien & piperout-08 & supportcase26 \\
enigma & misc07 & neos-686190 & pk1 & vpm2 \\
fiber & mod008 & neos8 & pp08aCUTS & \\
\hline
\end{tabular}

Table 6.8: MIP instances in the training set

\begin{tabular}{|ccccc|}
\hline aflow30a & bppc8-02 & neos-1122047 & neos-806323 & qnet1_o \\
air04 & cap6000 & neos-1171448 & neos-827175 & rgn \\
air05 & dano3_3 & neos-1396125 & ns1952667 & stein27 \\
aligninq & dano3_4 & neos-3610040-iskar & p0282 & supportcase6 \\
beasleyC1 & dcmulti & neos-3610173-itata & p0548 & swath1 \\
bienst1 & f2gap201600 & neos-3611689-kaihu & p200x1188c & tbfp-network \\
bienst2 & khb05250 & neos-503737 & piperout-27 & vpm1 \\
blend2 & markshare_4_0 & neos-780889 & qap10 & \\
\hline
\end{tabular}

Table 6.9: MIP instances in the testing set 


\section{Chapter 7}

\section{Experiment Results}

The goal of this section is to find the answers to the problems stated in Chapter 4 by analyzing the results from a series of experiments and to develop and verify the rules for choosing the most efficient methods to solve MIP instances given the specific problem characteristics.

\subsection{Experiment 1: VDS/MBESTP-ASP-ANST Pairings}

The purpose of this experiment is to identify whether all VDS methods will function better when paired with MBESTP-ASP-ANST than when paired with the GLPK default backtrack node selection method BESTB.

All 8 VDS - NS configurations listed in Table 6.2 were tested on the set of 164 MIP instances with a solution time limit of 1 hour applied to each run.

- 85 MIP instances were solved to optimality by at least one of the methods. These MIP instances are listed in table B.1.

- 70 MIP instances were not solved to optimality within the time limit, but an incumbent solution which is integer-feasible was attained by at least one of the methods. These MIP instances are listed in table B.2. 
- For 9 MIP instances, neither an optimal solution nor an incumbent solution was found within 1 hour. These MIP instances are listed in table B.3

The performance profiles for each group are shown in Figures 7.1 to 7.4 respectively.

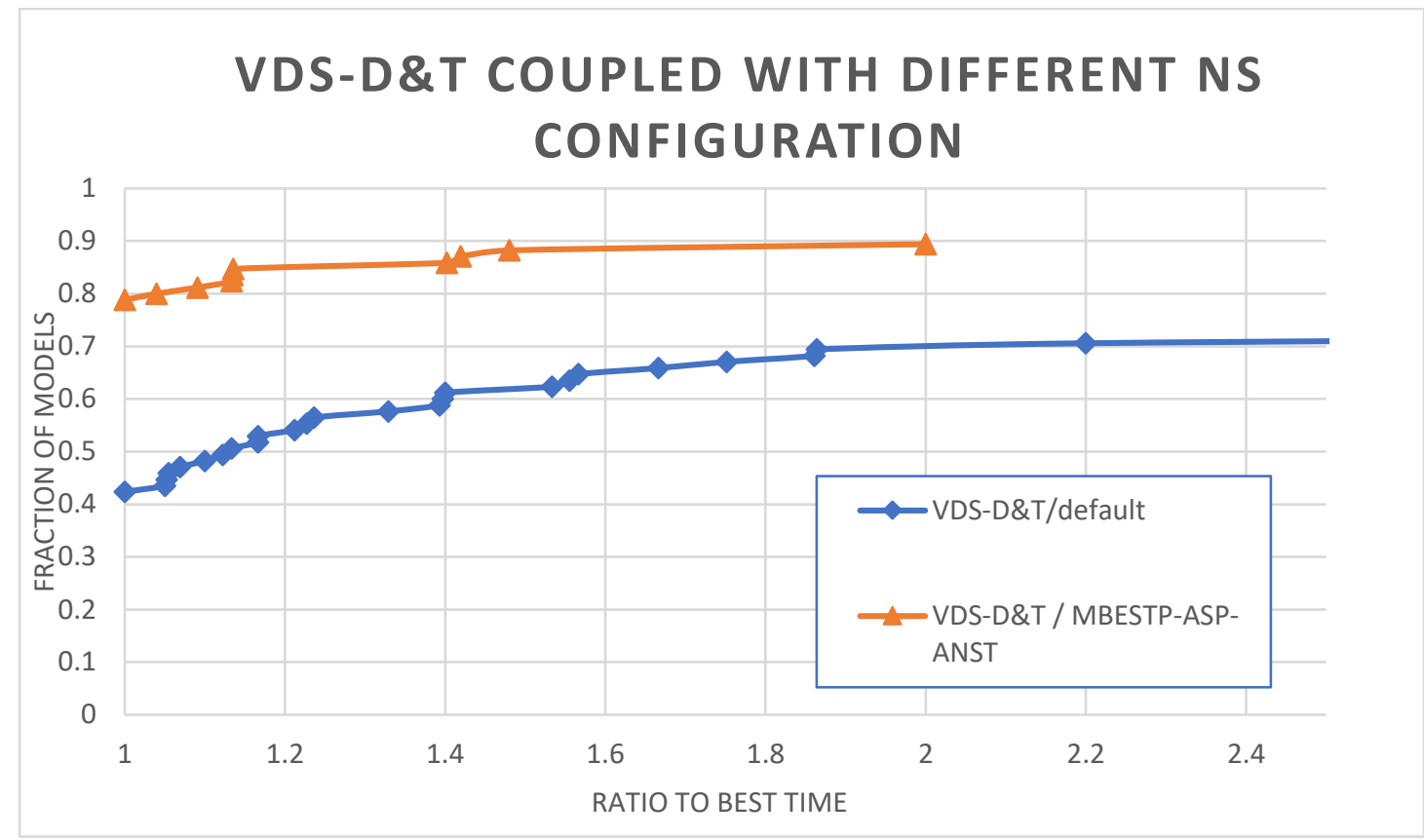

Figure 7.1: VDS - D\&T coupled with different NS heuristics

For the partial feasibility-oriented VDS method D\&T, pairing with MBESTP+ASP+ANST managed to solve $79 \%$ of the models with the best time and solved $89 \%$ of the models within the time limit, these values dropped to $42 \%$ and $80 \%$ when coupling with the GLPK default NS method BESTB. 


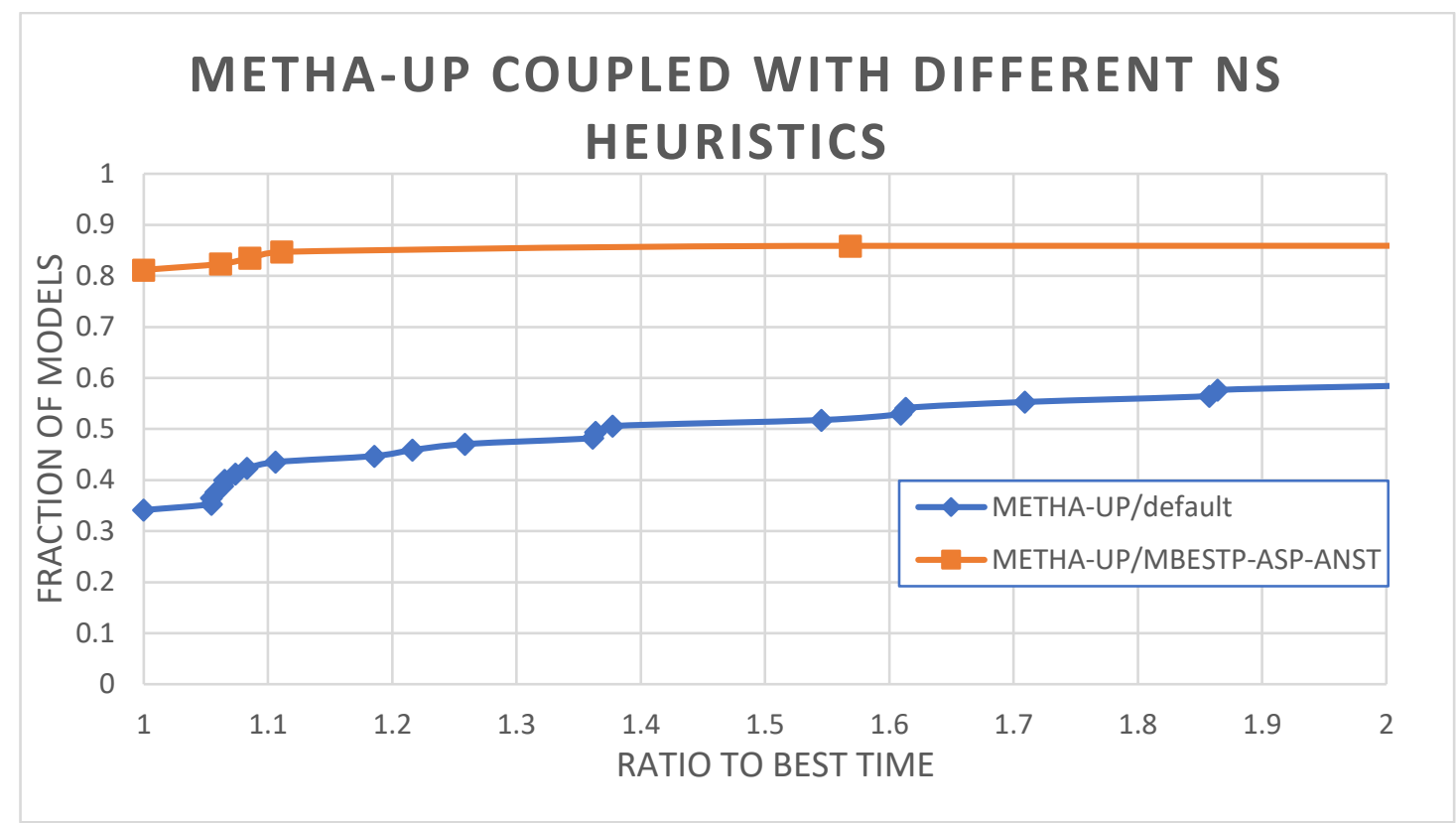

Figure 7.2: METHA - UP coupled with different NS heuristics

The improvement of number of models solved with the best time was substantial for METHA - UP when paired with MBESTP-ASP-ANST: the number went up from $34 \%$ to $81 \%$. A total number of 74 models were solved within 1 hour with MBESTP - ASP - ANST, but only 64 for GLPK default. 


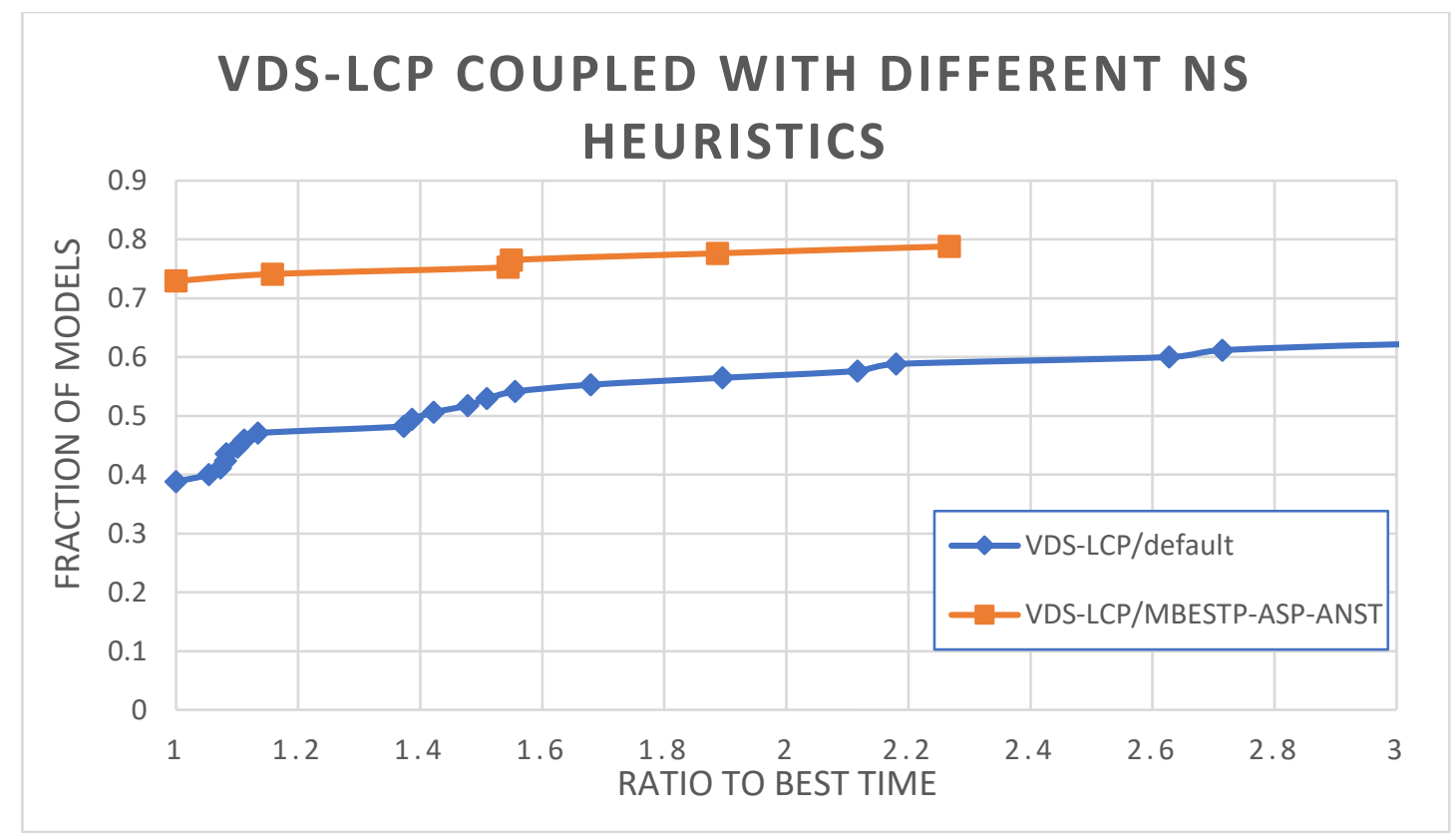

Figure 7.3: VDS - LCP coupled with different NS heuristics

VDS-LCP/default solved 33 models fastest, but VDS-LCP/MBESTP-ASP-ANST

almost doubled that, solving 62 models fastest. VDS-LCP/MBESTP-ASP-ANST also solved 8 more models to optimality within the time limit.

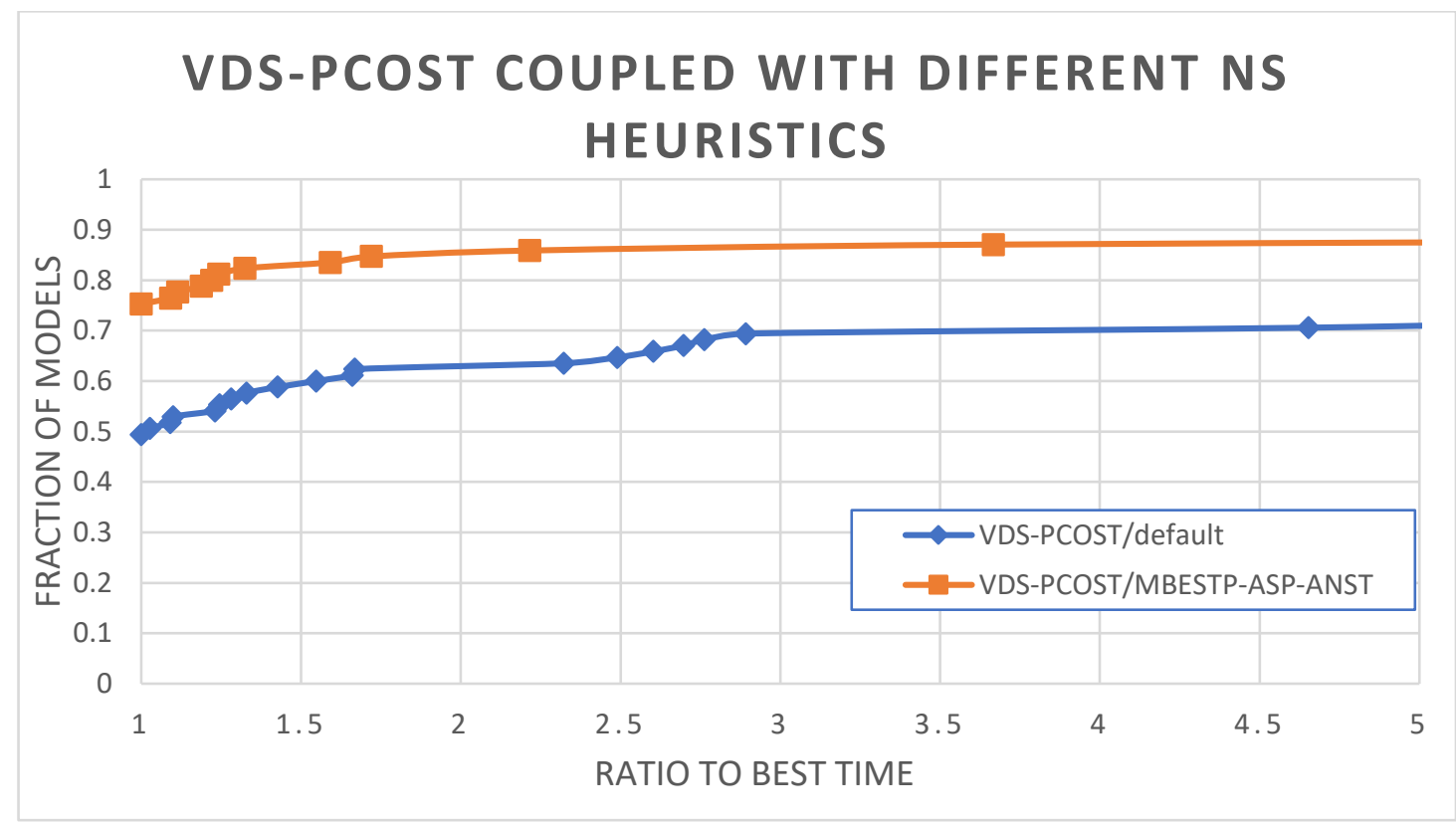

Figure 7.4: VDS - PCOST coupled with different NS heuristics 
As an objective-oriented VDS method, VDS - PCOST / default was able to solve 42 models to optimality fastest, which is the most among the 4 configurations using the GLPK default NS method. This value still increased by 24 when coupling with MBESTP ASP - ANST. 9 more models with optimal solution were found when coupled with MBESTP - ASP - ANST.

Every figure shows the dominant performance of MBESTP - ASP - ANST backtrack NS heuristic over default backtrack NS method BESTB as the utilization of MBESTP - ASP - ANST not only raised the fraction of models solved with the best time but the total number of models solved within the 1-hour time limit.

The backtrack NS heuristic MBESTP-ASP-ANST improves all of the VDS methods coupled with it in this experiment, whether they are objective or feasibility-oriented. MBESTP-ASP-ANST dramatically outperforms the GLPK default BESTB node selection heuristic.

\subsection{Experiment 2: Identifying the Best VDS/NS Configuration}

This experiment aims to identify the most efficient VDS - NS configuration, more precisely which VDS method will have the best performance when coupled with MBESTP - ASP - ANST since Experiment 1 showed that MBESTP-ASP-ANST improves over GLPK default BESTB when paired with all VDS heuristics tested. The default configuration in GLPK is presumably the best configuration identified by the GLPK team, so the best 
VDS/NS configuration found in this experiment may represent an improvement over the GLPK state-of-the-art.

The VDS / NS configurations in Table 6.2 were evaluated on the entire set of MIP instances. The results are summarized in Figure 7.5. GLPK default configuration (VDS $D \& T$ / BESTB) is also included in the figure. The numbers of models solved within the range of 1.5 times to the best time are presented in Table 7.1. The purpose of all these branch and bound methods is to find the optimal solution as fast as possible, and time ratios closer to 1 reflect the performance of the methods in terms of speed. The numbers of models solved to optimality by each configuration are also recorded. The best numbers in each row are highlighted in yellow.

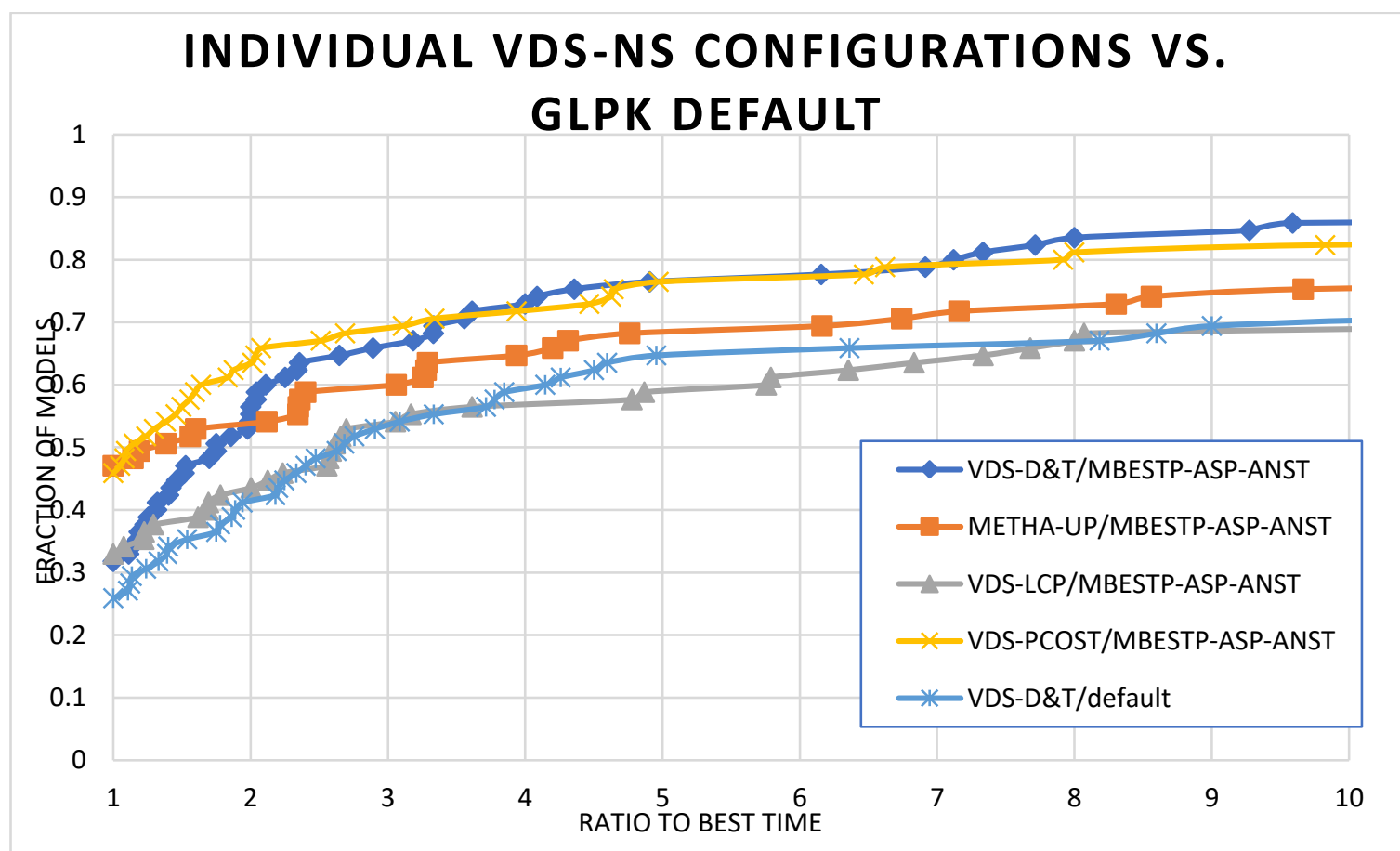

Figure 7.5: Performance Profiles of different VDS coupled with MBESTP - ASP - ANST vs. GLPK default configuration 


\begin{tabular}{ccc|ccc|}
$\begin{array}{c}\text { ratio to } \\
\text { best } \\
\text { time }\end{array}$ & $\begin{array}{c}\text { VDS- } \\
\text { D\&T/MBEST } \\
\text { P-ASP-ANST }\end{array}$ & $\begin{array}{c}\text { METHA- } \\
\text { UP/MBESTP- } \\
\text { ASP-ANST }\end{array}$ & $\begin{array}{c}\text { VDS- } \\
\text { LCP/MBEST } \\
\text { P-ASP-ANST }\end{array}$ & $\begin{array}{c}\text { VDS- } \\
\text { PCOST/MBESTP- } \\
\text { ASP-ANST }\end{array}$ & $\begin{array}{c}\text { VDS- } \\
\text { D\&T(default)/ } \\
\text { default }\end{array}$ \\
$=1$ & 30 & 40 & 28 & 39 & 22 \\
$<=1.1$ & 30 & 40 & 29 & 42 & 22 \\
$<=1.2$ & 33 & 42 & 30 & 43 & 25 \\
$<=1.3$ & 35 & 42 & 32 & 46 & 26 \\
$<=1.4$ & 37 & 43 & 32 & 46 & 29 \\
$<=1.5$ & 39 & 43 & 32 & 48 & 68 \\
time & 76 & 73 & 67 & 75 & \\
limit & & & & & 29 \\
\hline
\end{tabular}

Table 7.1: Number of models solved within certain ratios to best time

An easy conclusion to draw from the results is that the VDS - LCP / MBESTP ASP - ANST is the least promising VDS / NS configuration among the 4 new configurations, as its trace is always beneath the other 3 new configurations. VDS - D\&T / MBESTP - ASP - ANST, METHA - UP / MBESTP - ASP - ANST and VDS - PCOST / MBESTP - ASP - ANST all completely beat the GLPK default method while VDS - LCP / MBESTP - ASP - ANST can barely outperform the GLPK default method as the performance profiles of these two twist around each other in Figure 7.5. In addition, VDS - LCP / MBESTP - ASP - ANST solved 67 out of 85 MIP instances within the solution time limit which is even 1 model less than the number of models solved by GLPK default method. In other words, VDS - LCP / MBESTP - ASP - ANST does not seem to be a promising configuration. 
METHA - UP / MBESTP - ASP - ANST started strong with the most models solved in the best time but is surpassed by VDS - D\&T / MBESTP - ASP - ANST and VDS PCOST / MBESTP - ASP - ANST as the ratio to best time grows larger.

VDS - PCOST / MBESTP - ASP - ANST solves one fewer model than METHAUP/MBESTP-ASP-ANST in the fastest time but leads the chart thereafter. It is reflected in Figure 7.5 as well until VDS - D\&T / MBESTP - ASP - ANST catches up when the ratio to best time is close to 4 .

Overall, VDS - PCOST / MBESTP - ASP - ANST is the best VDS - NS configuration while VDS - LCP / MBESTP - ASP - ANST is the worst new VDS / NS configuration. With VDS - PCOST being an objective-oriented variable and direction selection method, we have an answer to the subproblem stated in Chapter 4: pairing a good NS method with a feasibility-oriented VDS does not provide the fastest MIP solver configuration. All feasibility-oriented VDS / MBESTP - ASP - ANST configurations are outperformed by VDS-PCOST/MBESTP-ASP-ANST. Pryor and Chinneck [2010] identified VDS - LCP as a top method in their experiments, but it is here outperformed by the GLPK default VDS D\&T, even when paired with MBESTP - ASP - ANST. 


\subsection{Experiment 3: Rules for Hybrid Configuration}

Following the method stated in Section 6.5.3, the complete analysis of the training set models is shown in Table 7.2. MBESTP - ASP - ANST is always the selection for NS heuristic. Each cell contains the average ratio to best/number of successes (defined as ratio to best of less than 1.1)/number of failures. The most important measure is the number of successes; the average ratio to best can be influenced by a single large ratio, especially when the number of models in the category is small. The VDS selected for each category is shown in boldface: this defines the hybrid method rules (designated RULE6), as summarized in Table 7.3.

\begin{tabular}{|c|c|c|c|c|c|c|c|}
\hline MCC & $\begin{array}{c}\text { \# Eq. } \\
\text { cons. }\end{array}$ & $\begin{array}{c}\text { \# Cont. } \\
\text { var. }\end{array}$ & $\begin{array}{c}\text { \# of } \\
\text { models }\end{array}$ & $\begin{array}{c}\text { VDS - } \\
\text { D\&T }\end{array}$ & $\begin{array}{c}\text { METHA- } \\
\text { UP }\end{array}$ & VDS - LCP & $\begin{array}{c}\text { VDS - } \\
\text { PCOST }\end{array}$ \\
\hline 0 & 0 & 0 & 2 & $\mathbf{1 . 2 3 / 1 / 0}$ & $1.7 / 1 / 0$ & $1.35 / 1 / 0$ & $1.55 / 1 / 1$ \\
\hline 0 & 0 & $1+$ & 3 & $1.13 / 0 / 2$ & $\mathbf{1 . 7 6 / 2 / 0}$ & $1.62 / 0 / 2$ & $1 / 1 / 2$ \\
\hline 0 & 1 & 0 & 1 & $\mathbf{1 / 1 / 0}$ & $6.16 / 1 / 0$ & fail/0/1 & $2.51 / 0 / 0$ \\
\hline 0 & 1 & 1 & 15 & $2.38 / 5 / 1$ & $2.47 / 5 / 3$ & $3.54 / 6 / 1$ & $\mathbf{1 . 4 6 / 7 / 1}$ \\
\hline 1 & 0 & 0 & 1 & $4 / 0 / 0$ & $1.5 / 0 / 0$ & $1.5 / 0 / 0$ & $\mathbf{1 / 1 / 0}$ \\
\hline 1 & 0 & 1 & 0 & $\mathrm{~N} / \mathrm{A}$ & $\mathrm{N} / \mathrm{A}$ & $\mathrm{N} / \mathrm{A}$ & $\mathrm{N} / \mathrm{A}$ \\
\hline 1 & 1 & 0 & 7 & $2.37 / 2 / 1$ & $\mathbf{2 . 7 6 / 5 / 0}$ & $8.98 / 0 / 1$ & $5.83 / 0 / 1$ \\
\hline 1 & 1 & 1 & 10 & $3.64 / 2 / 2$ & $\mathbf{1 . 1 0 / 6 / 2}$ & $2.74 / 1 / 5$ & $7.21 / 3 / 2$ \\
\hline
\end{tabular}

Table 7.2: Analysis of training set 


$\begin{array}{cccc}\text { \# MCC } & \text { \# Equality Constraints } & \text { \# Continous Variables } & \text { Best VDS method } \\ 0 & 0 & 0 & \text { VDS - D\&T } \\ 0 & 0 & 1+ & \text { METHA - UP } \\ 0 & 1+ & 0 & \text { VDS - D\&T } \\ 0 & 1+ & 1+ & \text { VDS - PCOST } \\ 1+ & 0 & 0 & \text { VDS - PCOST } \\ 1+ & 0 & 1+ & \text { N/A } \\ 1+ & 1+ & 0 & \text { METHA - UP } \\ 1+ & 1+ & 1+ & \text { METHA - UP }\end{array}$

Table 7.3: RULE6: VDS method selection based on MIP characteristics

It is worth noticing that there was no model in the training set having at least one MCC, no equality constraint and at least one continuous variable due to the limited sample size and completely random selection of the test models, thus no definite rule can be identified for this case. Since this case is most similar to the case having at least one MCC and no equality constraints, at this point the VDS-PCOST/MBESTP-ASP-ANST configuration is recommended. A more definite recommendation is left for future research with a larger number of models to be tested.

Figure 7.6 shows the performance profile of RULE6 and the three other best configurations with MBESTP - ASP - ANST on the training set models. 


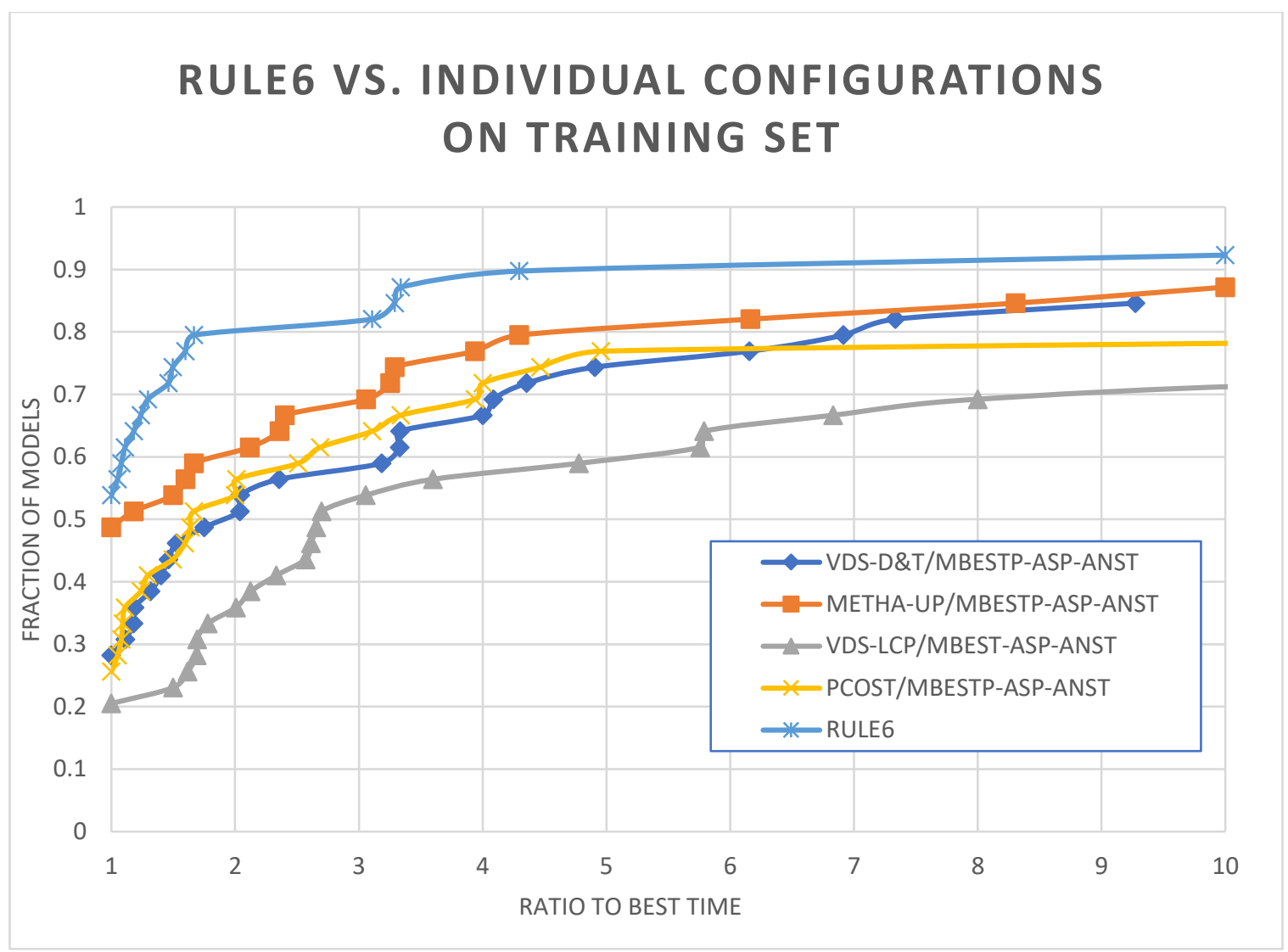

Figure 7.6: Performance profiles of RULE6 and 3 individual VDS - NS configurations on training set

RULE6 dominates the individual configurations on the training set. In the testing set, all configurations are less robust due to the random selection of the models. But RULE6 still has better performance than the other configurations as can be seen in Figure 7.7. RULE6 tops the best individual configuration VDS - PCOST / MBESTP - ASP ANST early and for most of the time. It also completely outperforms the GLPK state of the art VDS / NS configuration. 


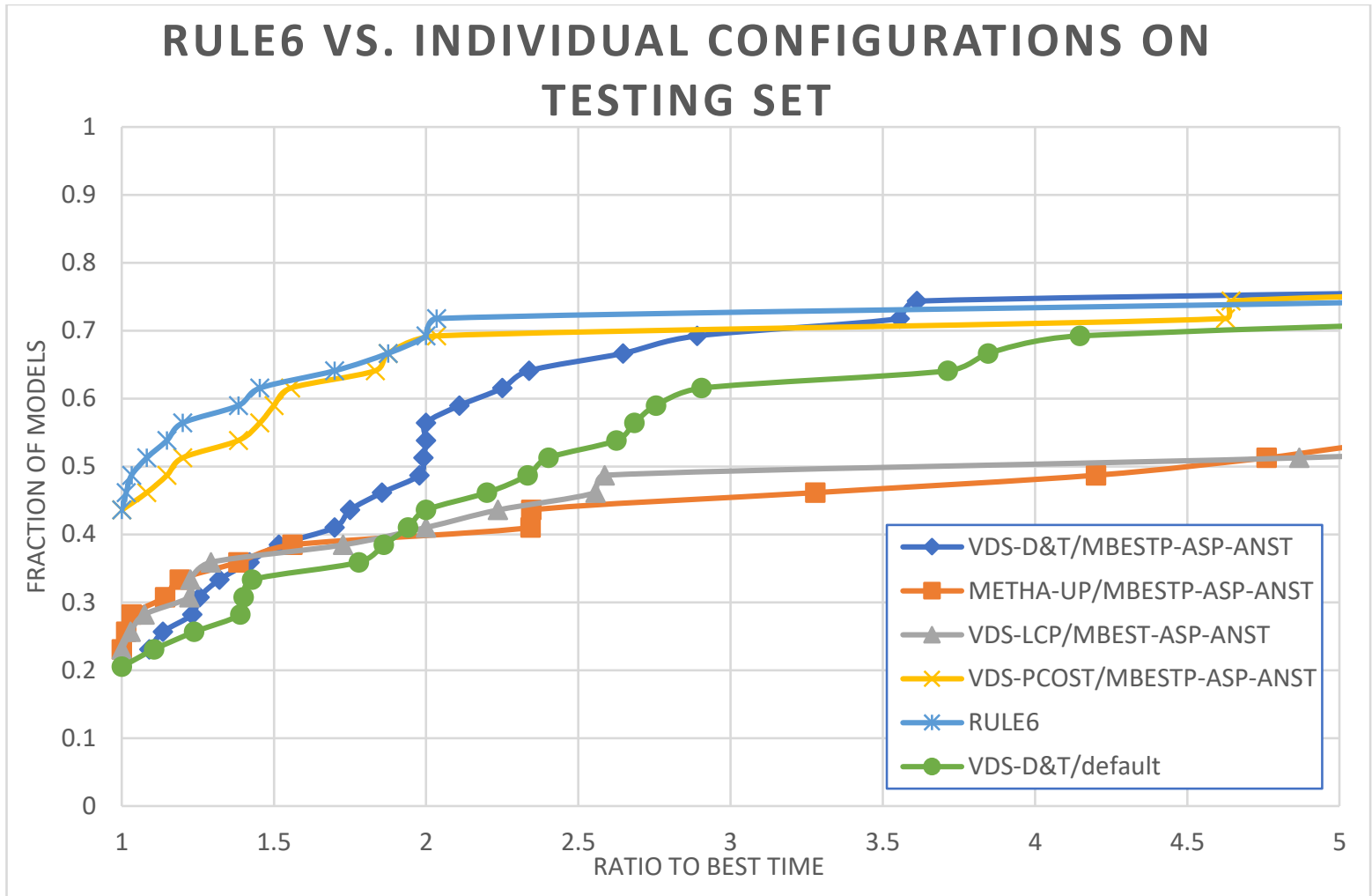

Figure 7.7: Performance profiles of RULE6 and 3 individual VDS - NS configurations on testing set

On the testing set MIP instances, RULE6 and VDS - PCOST / MBESTP - ASP ANST both manage to solve 17 out of 39 models in the best time. After that, the trace of RULE6 ascends quickly and beats the individual configurations especially up to a ratio to best time of 2 , which is the range of interest for fast optimal solution. The number of models that were solved within a specific ratio to the best time by each method are summarized in Table 7.4. 


\begin{tabular}{|ccccccc|}
$\begin{array}{c}\text { ratio to } \\
\text { best time }\end{array}$ & $\begin{array}{c}\text { VDS - } \\
\text { D\&T/MBEST } \\
\text { P-ASP-ANST }\end{array}$ & $\begin{array}{c}\text { METHA - } \\
\text { UP/MBESTP- } \\
\text { ASP-ANST }\end{array}$ & $\begin{array}{c}\text { VDS- } \\
\text { LCP/MBESTP } \\
\text {-ASP-ANST }\end{array}$ & $\begin{array}{c}\text { VDS- } \\
\text { PCOST/MBESTP } \\
\text {-ASP-ANST }\end{array}$ & $\begin{array}{c}\text { RULE6 } \\
\text { VDS- } \\
\text {-A \&T(defau } \\
\text { It)/default }\end{array}$ \\
$<=1.1$ & 7 & 9 & 9 & 17 & 17 & 8 \\
$<=1.5$ & 14 & 11 & 11 & 18 & 20 & 8 \\
$<=2$ & 22 & 14 & 14 & 23 & 24 & 13 \\
Time limit & 36 & 32 & 16 & 26 & 27 & 17 \\
\hline
\end{tabular}

Table 7.4: Cumulative number of models solved by each method at some ratios to best time on the testing set

As an illustration of how well this approach to developing hybrid rules based on the model characteristics can work, the whole set of 78 MIP instances was used as training data. While overfitting to the data, it indicates the potential of this approach when larger sets of training and testing models are available. This results in a different rule (denoted as RULE4), summarized in Table 7.5. When there are no MCC, equality constraints or continuous variables, RULE4 selects VDS - PCOST instead of VDS - D\&T as in RULE6, and when there is at least one MCC, at least one equality constraint and no continuous variables, RULE4 chooses VDS - D\&T instead of METHA - UP as in RULE6. The performance profile for RULE4 (Figure 7.8) is similar to that for RULE6 (Figure 7.6). 


$\begin{array}{cccc}\text { \# MCC } & \text { \# Equality Constraints } & \text { \# Continous Variables } & \text { Best VDS method } \\ 0 & 0 & 0 & \text { VDS - PCOST } \\ 0 & 0 & 1+ & \text { METHA - UP } \\ 0 & 1+ & 0 & \text { VDS - D\&T } \\ 0 & 1+ & 1+ & \text { VDS - PCOST } \\ 1+ & 0 & 0 & \text { VDS - PCOST } \\ 1+ & 0 & 1+ & \text { N/A } \\ 1+ & 1+ & 0 & \text { VDS - D \&T } \\ 1+ & 1+ & 1+ & \text { METHA - UP }\end{array}$

Table 7.5: RULE4: VDS method selection based on all 78 models

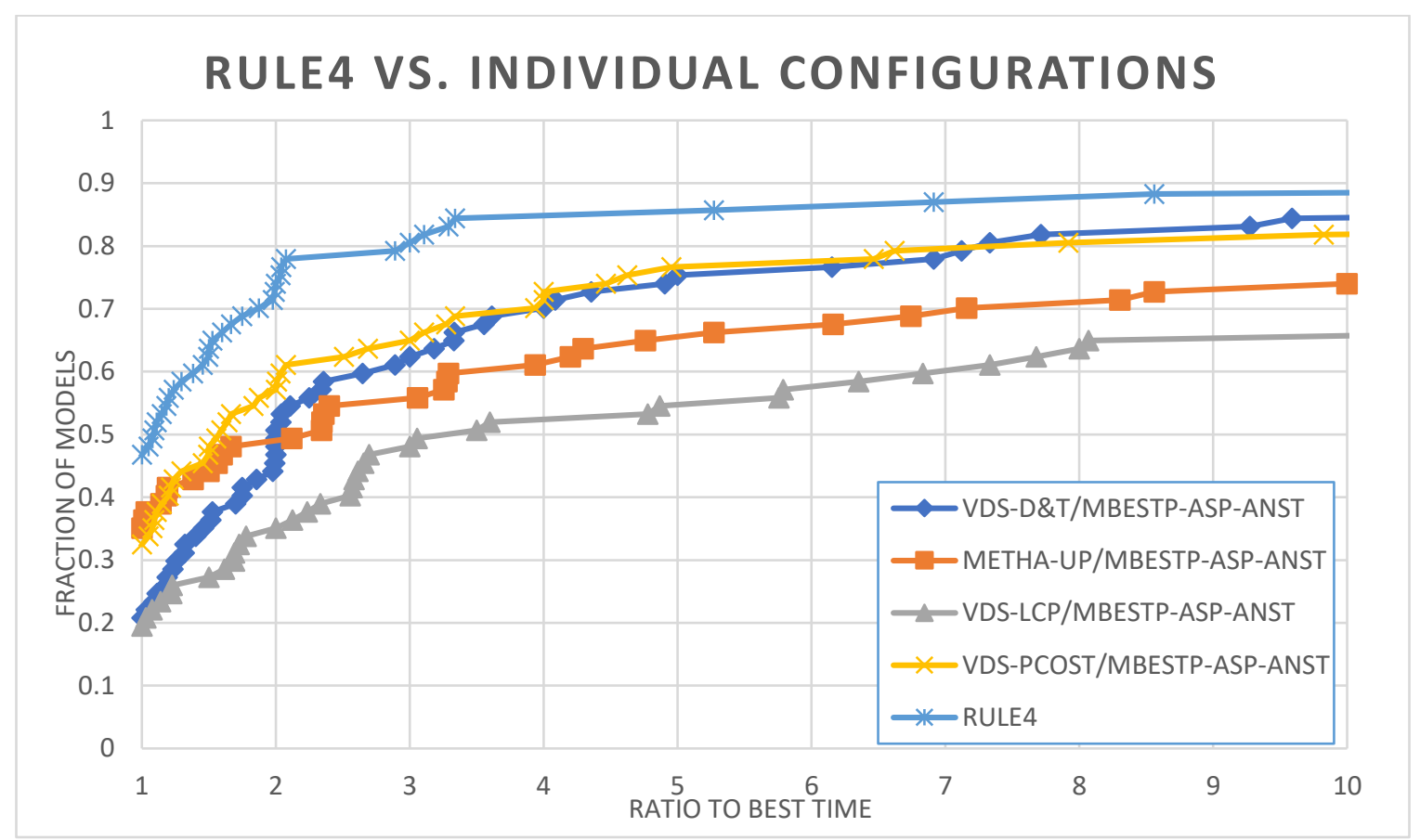

Figure 7.8: Performance profiles for RULE4 and individual configurations

Given the potential shown by RULE4, future research should investigate the development of hybrid rules based on larger training and testing sets. At present, RULE6 is reliable and clearly shows improvement over individual VDS / NS configurations and the GLPK state of the art. 


\section{Chapter 8}

\section{Conclusions}

1. In the branch and bound method, backtrack node selection dominates the VDS in improving speed to optimality as a good backtrack NS heuristic such as MBESTP - ASP - ANST was able to improve the performances by a great margin when coupled with any VDS method. This is shown in Section 7.1.

2. Coupling the objective-oriented method VDS - PCOST with the good backtrack NS heuristic MBESTP - ASP - ANST has the best performance among any individual VDS / NS configurations tested in the thesis. METHA - UP / MBESTP ASP - ANST and VDS - D\&T are slower but are still faster than the GLPK default method. VDS - LCP / MBESTP - ASP - ANST is not a promising VDS / NS configuration as it provides similar performance to the GLPK default. These results are shown in Section 7.2.

3. A feasibility-oriented VDS method is not necessarily the best type of VDS method to combine with the backtrack NS heuristic MBESTP - ASP - ANST since it was outperformed by VDS - PCOST / MBESTP - ASP - ANST as shown in Section 7.2, where VDS - PCOST is a pure objective-oriented VDS method. 
4. Branch and bound solutions are sensitive to the characteristics of the MIP models. RULE6 developed and validated in Section 7.3 shows a way to determine the best VDS / NS configurations for each situation, thereby providing a method that significantly outperforms the default configuration for a representative solver and also outperforms the better individual configurations developed in this thesis.

\subsection{Contributions}

1. Identified VDS / NS configurations that improve the speed of the branch and bound method for solving MIP problems. They are: VDS - PCOST / MBESTP ASP - ANST, VDS - D\&T / MBESTP - ASP - ANST and METHA - UP / MBESTP ASP - ANST .

2. Identified a VDS/MBESTP-ASP-ANST configuration: VDS - PCOST / MBESTP ASP - ANST outperformed the best configuration found by Wojtaszek and

Chinneck [2010] and outperformed the default configuration VDS - D\&T / BESTB in the GLPK solver.

3. Developed rules for selecting the best VDS / NS configuration based on the model characteristics. This improved the speed of the branch and bound method compared to any individual VDS / NS configuration and is significantly faster than the default configuration in the GLPK solver. This is an improvement in the state of the art. 
4. Disproved the conjecture that coupling a feasibility - oriented VDS heuristic with a good NS heuristic will give the fastest speed to optimality.

\subsection{Future Research}

1. The GLPK solver adds cutting planes during the branch and bound process. It is hard to know how this interacts with the VDS/NS heuristics. It would be worthwhile to re-run the experiments with the cutting planes turned off.

2. RULE6 in Section 7.3 was developed using a relatively small number of training instances and is entirely missing examples in one of the 8 MIP characteristic categories. It will be worthwhile to see whether and how the rule changes if a much larger training set is used. RULE4 indicates good potential for this idea.

3. Along with the other model characteristics, the root node solution might be helpful in deriving a rule to select the best VDS/NS configuration because it has information from the first LP relaxation solution, including the initial MIP lower bound and the list of candidate variables for branching. This merits investigation.

4. Right now, the method to use to solve the MIP problem is determined before the start and is fixed in the whole process. It could be helpful to switch methods depending on the status of the solution process at a given node. For example, at some node in the tree, all of the variables in all MCCs in the model may be fixed at integer values, so perhaps we should switch to a 
method that is suitable for models having no MCCs. Dynamic rules such as this should be investigated. 


\section{References}

Benichou, M., J. M. Gauthier, P. Girodet, G. Hentges, G. Ribiere, and O. Vincent. 1971. "Experiments in Mixed-Integer Linear Programming." Mathematical Programming 1 (1): 76-94. https://doi.org/10.1007/BF01584074.

Bixby, Robert E., Sebastian Ceria, Cassandra M. McZeal, and Martin W. P. Savelsbergh, eds. 1998. "MIPLIB Problem Set." MIPLIB 3.0.

http://miplib2010.zib.de/miplib3/miplib3.html (last accessed on December 8, 2019).

Dolan, E.D., and J. More. 2002. "Benchmarking Optimization Software with

Performance Profiles", Mathematical Programming, Series A, Volume 91, pp. 201-213.

Driebeek, Norman J. 1966. "An Algorithm for the Solution of Mixed Intege

Programming Problems Author ( s ): Norman J . Driebeek Source : Management

Science, Vol . 12, No . 7 , Series A, Sciences ( Mar ., 1966 ), Pp . 576-587 Published

by : INFORMS Stable URL : Http://Www.Jstor.” 12 (7): 576-87.

Gamrath, Gerald, ed. 2019. "Complete Problem Set.” MIPLIB 2010.

http://miplib2010.zib.de/miplib2010.php (last accessed on December 8, 2019).

Gauthier, J. M., and G. Ribière. 1977. "Experiments in Mixed-Integer Linear

Programming Using Pseudo-Costs." Mathematical Programming 12 (1): 26-47. https://doi.org/10.1007/BF01593767.

Gleixner, Ambros, Gregor Hendel, Gerald Gamrath, Tobias Achterberg, Michael Bastubbe, Timo Berthold, Philipp M. Christophel, et al. 2019.“MIPLIB 2017: Data Driven Compilation of the 6th Mixed-Integer Programming Library.”, Berlin: Zuse Institute, Berlin.

Gorban, Igor I. 2017. “The Central Limit Theorem.” In The Statistical Stability Phenomenon, pp. 261-70. Springer, Cham.

Linderoth, J. T., and M. W. P. Savelsbergh. 1999. "A Computational Study of Search Strategies for Mixed Integer Programming." INFORMS Journal on Computing 11 (2): 173-87. https://doi.org/10.1287/ijoc.11.2.173.

Makhorin, Andrew. 2001. "GNU Linear Programming Kit.” Moscow Aviation Institute 45 (December).

Mittelmann, Hans. 2019. "MILP Benchmark - MIPLIB2017.”. http://plato.asu.edu/ftp/milp_tables/1thread.res (last accessed on December 8, 2019).

Mittelmann, Hans, ed. "Hans Mittelmann's MIP collection”. http://plato.asu.edu/ftp/milp/, August 11, 2009 (last accessed on December 8, 2019). 
Mitra, G. 1973. "Investigation of some Branch and Bound Strategies for the Solution of Mixed Integer Linear Programs ”, Mathematical Programming 4: 155-70.

Patel, Jagat, and John W. Chinneck. 2007. "Active-Constraint Variable Ordering for Faster Feasibility of Mixed Integer Linear Programs." Mathematical Programming 110 (3): 445-74. https://doi.org/10.1007/s10107-006-0009-0.

Pesant, G., and C.G. Quimper. 2008, "Counting Solutions of Knapsack Constraints", CPAIOR 2008, Lecture Notes in Computer Science 5015:203-217.

Pryor, Jennifer, and John W. Chinneck. 2011. "Faster Integer-Feasibility in Mixed Integer Linear Programs by Branching to Force Change." Computers and Operations Research 38 (8): 1143-52. https://doi.org/10.1016/j.cor.2010.10.025.

Achterberg, Tobias, Thorsten Koch, and Alexander Martin. 2005. "Branching rules revisited." Operations Research Letters 33.1: 42-54.

Tomlin, J.A. (1971), “An Improved Branch-and-Bound Method for Integer Programming", Operations Research 19:1070-1075.

Winston, Wayne L. "Integer Programming." In Operations Research: Applications and Algorithms, 4th. ed., pp. 475-539. Belmont, CA: Brooks/Cole, Cengage Learning, 2009.

Wojtaszek, Daniel T. 2008. "Faster MIP Solutions via New Node Selection Rules." PhD thesis, Systems and Computer Engineering, Carleton University.

Wojtaszek, Daniel T., and John W. Chinneck. 2010. "Faster MIP Solutions via New Node Selection Rules." Computers and Operations Research 37 (9): 1544-56. https://doi.org/10.1016/j.cor.2009.11.011.

"GLPK Versions." 2018. http://ftp.gnu.org/gnu/glpk/ (last accessed on December 8, 2019).

"MIPLIB 2.0 Problem Set." Previous Version of MIPLIB. Accessed December 9, 2019.http://miplib2010.zib.de/miplib2/miplib2.html (last accessed on December 8, 2019). 


\section{Appendix A}

\section{MIP Instances}

Table A.1 shows the MIP instances used in the GLPK MIP solver in this thesis along with some of the instance information and characteristics that are described below.

model: The name of the MIP model.

source: Where the model is chosen from.

MCC: The number of multiple-choice constraints (MCC) of the problem.

eq.: The number of equality constraints.

ineq.: The number of inequality constraints.

int.: The number of integer variables.

bin.: The number of binary variables.

cont.: The number of continuous variables.

Table A.1: List of MIP instances taken from MIPLIB2017, MIPLIB2010, MIPLIB2003, MIPLIB3.0, MIPLIB2.0 and Hans Mittelmann's MIP collection with MIP characteristics.

\begin{tabular}{|l|l|r|r|r|r|r|r|}
\hline model & source & MCC & eq. & ineq. & int. & bin. & cont. \\
\hline 22433 & MIPLIB2017 & 0 & 198 & 0 & 0 & 231 & 198 \\
\hline 23588 & MIPLIB2017 & 0 & 137 & 0 & 0 & 231 & 137 \\
\hline 10 teams & MIPLIB2017 & 120 & 80 & 150 & 0 & 1800 & 225 \\
\hline $50 v-10$ & MIPLIB2017 & 0 & 50 & 183 & 183 & 1464 & 366 \\
\hline aflow30a & MIPLIB2017 & 29 & 58 & 421 & 0 & 421 & 421 \\
\hline air04 & MIPLIB2017 & 821 & 823 & 0 & 0 & 8904 & 0 \\
\hline air05 & MIPLIB2017 & 426 & 426 & 0 & 0 & 7195 & 0 \\
\hline aligninq & MIPLIB2017 & 0 & 1 & 339 & 0 & 1830 & 1 \\
\hline app2-2 & MIPLIB2017 & 12 & 0 & 335 & 0 & 1226 & 0 \\
\hline
\end{tabular}




\begin{tabular}{|c|c|c|c|c|c|c|c|}
\hline model & source & MCC & eq. & ineq. & int. & bin. & cont. \\
\hline assign1-5-8 & MIPLIB2017 & 26 & 31 & 130 & 0 & 130 & 26 \\
\hline beasleyC1 & MIPLIB2017 & 0 & 500 & 1250 & 0 & 1250 & 1250 \\
\hline beavma & MIPLIB2017 & 23 & 89 & 283 & 0 & 195 & 195 \\
\hline berlin_5_8_0 & MIPLIB2017 & 0 & 0 & 1532 & 0 & 794 & 289 \\
\hline bienst1 & MIPLIB2017 & 0 & 128 & 448 & 0 & 28 & 477 \\
\hline bienst2 & MIPLIB2017 & 0 & 128 & 448 & 0 & 35 & 470 \\
\hline binkar10_1 & MIPLIB2017 & 0 & 1016 & 10 & 0 & 170 & 2128 \\
\hline blend2 & MIPLIB2017 & 0 & 89 & 185 & 33 & 231 & 89 \\
\hline bm23 & MIPLIB 2.0 & 0 & 0 & 27 & 0 & 27 & 0 \\
\hline ьррс4-08 & MIPLIB2017 & 20 & 20 & 91 & 0 & 1454 & 2 \\
\hline ьррс8-02 & MIPLIB2017 & 17 & 20 & 39 & 1 & 229 & 2 \\
\hline cap6000 & MIPLIB2017 & 1871 & 123 & 2053 & 0 & 6000 & 0 \\
\hline $\begin{array}{l}\text { chromaticindex32- } \\
8\end{array}$ & MIPLIB2017 & 2111 & 575 & 1536 & 0 & 2304 & 0 \\
\hline cmflsp50-24-8-8 & MIPLIB2017 & 0 & 1096 & 2424 & 0 & 1392 & 15000 \\
\hline comp07-2idx & MIPLIB2017 & 0 & 131 & 21104 & 109 & 17155 & 0 \\
\hline control30-3-2-3 & MIPLIB2017 & 30 & 152 & 360 & 0 & 90 & 242 \\
\hline csched008 & MIPLIB2017 & 50 & 60 & 290 & 0 & 1284 & 252 \\
\hline csched010 & MIPLIB2017 & 50 & 52 & 299 & 0 & 1457 & 301 \\
\hline cvs08r139-94 & MIPLIB2017 & 94 & 0 & 2398 & 0 & 1864 & 2398 \\
\hline cvs16r70-62 & MIPLIB2017 & 62 & 0 & 3278 & 0 & 2112 & 0 \\
\hline dano3_3 & MIPLIB2017 & 0 & 1224 & 1978 & 0 & 69 & 13804 \\
\hline dano3_4 & $\begin{array}{l}\text { Mittelmann } \\
\mathrm{H} \text {. }\end{array}$ & 0 & 1224 & 1978 & 0 & 92 & 13781 \\
\hline dano3_5 & MIPLIB2017 & 0 & 1224 & 1978 & 0 & 115 & 13758 \\
\hline danoint & MIPLIB2017 & 0 & 144 & 520 & 0 & 56 & 465 \\
\hline demulti & MIPLIB2017 & 5 & 78 & 212 & 0 & 75 & 473 \\
\hline dsbmip & MIPLIB2017 & 40 & 392 & 847 & 0 & 192 & 1694 \\
\hline egout & MIPLIB3.0 & 0 & 43 & 55 & 0 & 55 & 86 \\
\hline eil33-2 & MIPLIB2017 & 32 & 32 & 0 & 0 & 4516 & 0 \\
\hline enigma & MIPLIB3.0 & 20 & 21 & 0 & 0 & 100 & 0 \\
\hline enlight_hard & MIPLIB2017 & 0 & 100 & 0 & 100 & 100 & 0 \\
\hline ex9 & MIPLIB2017 & 0 & 162 & 40800 & 10404 & 0 & 0 \\
\hline exp-1-500-5-5 & MIPLIB2017 & 50 & 250 & 300 & 0 & 250 & 740 \\
\hline f2gap201600 & MIPLIB2017 & 0 & 0 & 20 & 0 & 1600 & 0 \\
\hline fiber & MIPLIB2017 & 23 & 363 & 0 & 0 & 1254 & 44 \\
\hline fixnet6 & MIPLIB2003 & 0 & 100 & 378 & 0 & 378 & 500 \\
\hline flugpl & MIPLIB2017 & 0 & 6 & 12 & 11 & 0 & 7 \\
\hline g200x740 & MIPLIB2017 & 0 & 0 & 940 & 0 & 740 & 740 \\
\hline gen-ip021 & MIPLIB2017 & 0 & 0 & 28 & 35 & 0 & 0 \\
\hline gen-ip054 & MIPLIB2017 & 0 & 0 & 27 & 30 & 0 & 0 \\
\hline
\end{tabular}




\begin{tabular}{|c|c|c|c|c|c|c|c|}
\hline model & source & MCC & eq. & ineq. & int. & bin. & cont. \\
\hline germanrr & MIPLIB2017 & 0 & 239 & 10540 & 5251 & 5323 & 239 \\
\hline gmu-35-40 & MIPLIB2017 & 379 & 0 & 424 & 0 & 1200 & 5 \\
\hline $\operatorname{gr} 4 \times 6$ & MIPLIB2017 & 24 & 10 & 24 & 0 & 24 & 24 \\
\hline graphdraw-domain & MIPLIB2017 & 45 & 45 & 820 & 20 & 180 & 54 \\
\hline $\begin{array}{l}\text { graphdraw- } \\
\text { gemcutter }\end{array}$ & MIPLIB2017 & 28 & 28 & 446 & 16 & 112 & 38 \\
\hline gsvm2rl3 & MIPLIB2017 & 0 & 0 & 180 & 0 & 60 & 181 \\
\hline gt2 & MIPLIB2017 & 2 & 0 & 29 & 164 & 24 & 29 \\
\hline h80x6320d & MIPLIB2017 & 79 & 227 & 6331 & 0 & 6320 & 6320 \\
\hline haprp & MIPLIB2017 & 0 & 288 & 756 & 1828 & 0 & 0 \\
\hline ic97_potential & MIPLIB2017 & 0 & 0 & 1046 & 73 & 450 & 205 \\
\hline irp & MIPLIB2017 & 39 & 39 & 0 & 0 & 20315 & 0 \\
\hline $\mathrm{k} 16 \times 240 \mathrm{~b}$ & MIPLIB2017 & 0 & 16 & 240 & 0 & 240 & 240 \\
\hline khb05250 & MIPLIB2017 & 0 & 77 & 24 & 0 & 24 & 1326 \\
\hline I152lav & MIPLIB3.0 & 95 & 96 & 1 & 0 & 1989 & 0 \\
\hline leo2 & MIPLIB2017 & 428 & 1 & 592 & 0 & 11099 & 1 \\
\hline lotsize & MIPLIB2017 & 120 & 0 & 1920 & 0 & 1195 & 1790 \\
\hline Iseu & MIPLIB3.0 & 17 & 0 & 28 & 0 & 89 & 0 \\
\hline markshare_4_0 & MIPLIB2017 & 0 & 4 & 0 & 0 & 30 & 4 \\
\hline markshare1 & MIPLIB2017 & 0 & 0 & 6 & 0 & 50 & 12 \\
\hline mas76 & MIPLIB2017 & 0 & 0 & 12 & 0 & 150 & 1 \\
\hline mc11 & MIPLIB2017 & 0 & 0 & 1920 & 0 & 1520 & 1520 \\
\hline mcsched & MIPLIB2017 & 505 & 202 & 1905 & 0 & 1745 & 2 \\
\hline mik-250-1-100-1 & MIPLIB2010 & 0 & 0 & 151 & 150 & 100 & 1 \\
\hline $\operatorname{misc03}$ & MIPLIB3.0 & 3 & 27 & 69 & 0 & 159 & 1 \\
\hline misc06 & MIPLIB3.0 & 0 & 250 & 570 & 0 & 112 & 1696 \\
\hline $\operatorname{misc07}$ & MIPLIB2017 & 10 & 35 & 177 & 0 & 259 & 1 \\
\hline mod008 & MIPLIB3.0 & 0 & 0 & 6 & 0 & 319 & 0 \\
\hline modglob & MIPLIB2003 & 0 & 95 & 196 & 0 & 98 & 324 \\
\hline momentum2 & MIPLIB2010 & 54 & 220 & 24017 & 1 & 1808 & 1923 \\
\hline mtest4ma & MIPLIB2017 & 99 & 99 & 1075 & 0 & 975 & 975 \\
\hline mzzv11 & MIPLIB2017 & 5783 & 3372 & 6127 & 251 & 9989 & 0 \\
\hline neos-1112782 & MIPLIB2017 & 0 & 0 & 2115 & 0 & 2070 & 2070 \\
\hline neos-1112787 & MIPLIB2017 & 0 & 0 & 1680 & 0 & 1640 & 1640 \\
\hline neos-1122047 & MIPLIB2017 & 0 & 0 & 57791 & 0 & 100 & 5000 \\
\hline neos-1171448 & MIPLIB2017 & 0 & 0 & 13206 & 0 & 2457 & 13206 \\
\hline neos-1396125 & MIPLIB2017 & 9 & 417 & 1077 & 0 & 129 & 1032 \\
\hline neos-1430701 & MIPLIB2017 & 0 & 0 & 668 & 0 & 156 & 156 \\
\hline neos-1582420 & MIPLIB2017 & 0 & 1 & 10179 & 100 & 10000 & 10180 \\
\hline neos16 & MIPLIB2017 & 0 & 0 & 1027 & 41 & 336 & 0 \\
\hline neos17 & MIPLIB2017 & 0 & 0 & 486 & 0 & 300 & 235 \\
\hline
\end{tabular}




\begin{tabular}{|c|c|c|c|c|c|c|c|}
\hline model & source & MCC & eq. & ineq. & int. & bin. & cont. \\
\hline neos-3072252-nete & MIPLIB2017 & 0 & 143 & 289 & 0 & 144 & 432 \\
\hline $\begin{array}{l}\text { neos-3083819- } \\
\text { nubu }\end{array}$ & MIPLIB2017 & 0 & 4719 & 6 & 8644 & 0 & 0 \\
\hline neos-3118745-obra & MIPLIB2017 & 113 & 0 & 144 & 0 & 1130 & 144 \\
\hline $\begin{array}{l}\text { neos-3381206- } \\
\text { awhea }\end{array}$ & MIPLIB2017 & 0 & 0 & 483 & 1900 & 475 & 0 \\
\hline $\begin{array}{l}\text { neos-3421095- } \\
\text { cinca }\end{array}$ & MIPLIB2017 & 45 & 24 & 1194 & 42 & 117 & 737 \\
\hline $\begin{array}{l}\text { neos-3530903- } \\
\text { gauja }\end{array}$ & MIPLIB2017 & 0 & 0 & 220 & 1890 & 420 & 0 \\
\hline neos-3610040-iskar & MIPLIB2017 & 0 & 1 & 334 & 0 & 85 & 345 \\
\hline neos-3610051-istra & MIPLIB2017 & 0 & 1 & 708 & 0 & 76 & 729 \\
\hline neos-3610173-itata & MIPLIB2017 & 0 & 1 & 746 & 0 & 77 & 767 \\
\hline neos-3611447-jijia & MIPLIB2017 & 0 & 1 & 376 & 0 & 85 & 387 \\
\hline $\begin{array}{l}\text { neos-3611689- } \\
\text { kaihu }\end{array}$ & MIPLIB2017 & 0 & 1 & 322 & 0 & 88 & 333 \\
\hline $\begin{array}{l}\text { neos-3627168- } \\
\text { kasai }\end{array}$ & MIPLIB2017 & 0 & 0 & 1655 & 0 & 535 & 927 \\
\hline $\begin{array}{l}\text { neos-4333596- } \\
\text { skien }\end{array}$ & MIPLIB2017 & 5 & 225 & 587 & 0 & 460 & 545 \\
\hline $\begin{array}{l}\text { neos-4650160- } \\
\text { yukon }\end{array}$ & MIPLIB2017 & 0 & 316 & 1653 & 0 & 624 & 1969 \\
\hline neos-480878 & MIPLIB2017 & 24 & 36 & 1285 & 0 & 189 & 345 \\
\hline neos-503737 & MIPLIB2017 & 150 & 150 & 350 & 0 & 2500 & 350 \\
\hline $\begin{array}{l}\text { neos-5140963- } \\
\text { mincio }\end{array}$ & MIPLIB2017 & 28 & 28 & 156 & 0 & 183 & 13 \\
\hline neos-631517 & MIPLIB2017 & 160 & 167 & 184 & 0 & 859 & 231 \\
\hline neos- 686190 & MIPLIB2017 & 120 & 121 & 3543 & 60 & 3600 & 3664 \\
\hline neos-780889 & MIPLIB2017 & 579 & 73560 & 350 & 0 & 182700 & 0 \\
\hline neos8 & MIPLIB2017 & 4 & 12 & 46312 & 4 & 23224 & 46324 \\
\hline neos- 806323 & MIPLIB2010 & 20 & 850 & 691 & 0 & 14725 & 0 \\
\hline neos-807639 & MIPLIB2017 & 20 & 850 & 691 & 0 & 80 & 950 \\
\hline neos-827175 & MIPLIB2017 & 28 & 10512 & 3675 & 0 & 21350 & 11154 \\
\hline neos-831188 & MIPLIB2017 & 1038 & 1126 & 1059 & 0 & 4612 & 0 \\
\hline neos-911970 & MIPLIB2017 & 35 & 35 & 72 & 0 & 840 & 48 \\
\hline nexp-50-20-1-1 & MIPLIB2017 & 0 & 18 & 522 & 0 & 245 & 245 \\
\hline nexp-50-20-4-2 & MIPLIB2017 & 245 & 0 & 540 & 0 & 980 & 245 \\
\hline nh97_potential & MIPLIB2017 & 0 & 0 & 1916 & 328 & 630 & 222 \\
\hline nh97_tension & MIPLIB2017 & 0 & 0 & 737 & 361 & 257 & 958 \\
\hline noswot & MIPLIB2017 & 0 & 0 & 182 & 25 & 75 & 28 \\
\hline ns1952667 & MIPLIB2017 & 0 & 41 & 0 & 13264 & 0 & 0 \\
\hline nsa & MIPLIB2017 & 0 & 36 & 1261 & 0 & 36 & 352 \\
\hline
\end{tabular}




\begin{tabular}{|c|c|c|c|c|c|c|c|}
\hline model & source & MCC & eq. & ineq. & int. & bin. & cont. \\
\hline nug08 & $\begin{array}{l}\text { Mittelmann } \\
\text { H. }\end{array}$ & 16 & 912 & 0 & 1632 & 0 & 0 \\
\hline nw04 & MIPLIB2017 & 36 & 36 & 0 & 0 & 87482 & 0 \\
\hline p0201 & MIPLIB2017 & 26 & 0 & 133 & 0 & 201 & 0 \\
\hline p0282 & MIPLIB3.0 & 177 & 0 & 241 & 0 & 282 & 0 \\
\hline p0291 & MIPLIB2.0 & 168 & 0 & 252 & 0 & 0 & 291 \\
\hline p0548 & MIPLIB3.0 & 30 & 0 & 176 & 0 & 548 & 0 \\
\hline p200x1188c & MIPLIB2017 & 0 & 200 & 1188 & 0 & 1188 & 1188 \\
\hline p2756 & MIPLIB3.0 & 717 & 0 & 755 & 0 & 2756 & 0 \\
\hline $\mathrm{pg}$ & MIPLIB2017 & 0 & 0 & 125 & 0 & 100 & 2600 \\
\hline pg5_34 & MIPLIB2017 & 0 & 0 & 225 & 0 & 100 & 2500 \\
\hline piperout-08 & MIPLIB2017 & 65 & 166 & 14423 & 130 & 10245 & 24 \\
\hline piperout-27 & MIPLIB2017 & 65 & 158 & 18284 & 121 & 11514 & 24 \\
\hline pk1 & MIPLIB2017 & 0 & 15 & 30 & 0 & 55 & 31 \\
\hline pp08a & MIPLIB2003 & 0 & 64 & 72 & 0 & 64 & 176 \\
\hline pp08aCUTS & MIPLIB2003 & 0 & 64 & 182 & 0 & 64 & 176 \\
\hline prod1 & MIPLIB2017 & 7 & 8 & 200 & 0 & 149 & 101 \\
\hline qap10 & MIPLIB2017 & 1820 & 1820 & 0 & 4150 & 0 & 0 \\
\hline qnet1_o & MIPLIB2017 & 48 & 332 & 124 & 129 & 1288 & 124 \\
\hline r50×360 & MIPLIB2017 & 0 & 50 & 360 & 0 & 360 & 360 \\
\hline railway_8_1_0 & MIPLIB2017 & 0 & 0 & 2527 & 0 & 1177 & 619 \\
\hline $\operatorname{ran} 12 \times 21$ & MIPLIB2017 & 0 & 33 & 252 & 0 & 252 & 252 \\
\hline $\operatorname{ran} 13 \times 13$ & MIPLIB2017 & 0 & 26 & 169 & 0 & 169 & 169 \\
\hline rentacar & MIPLIB2017 & 0 & 6292 & 513 & 0 & 55 & 9502 \\
\hline rgn & MIPLIB3.0 & 4 & 20 & 4 & 0 & 100 & 80 \\
\hline rmatr100-p10 & MIPLIB2017 & 0 & 1 & 7259 & 0 & 100 & 7259 \\
\hline sct2 & MIPLIB2017 & 0 & 360 & 1791 & 0 & 2872 & 3013 \\
\hline set1ch & MIPLIB2003 & 0 & 240 & 252 & 0 & 240 & 472 \\
\hline sp150x300d & MIPLIB2017 & 0 & 150 & 300 & 0 & 300 & 300 \\
\hline stein27 & MIPLIB3.0 & 0 & 0 & 118 & 0 & 27 & 0 \\
\hline stein45 & MIPLIB3.0 & 0 & 0 & 331 & 0 & 45 & 0 \\
\hline supportcase17 & MIPLIB2017 & 4 & 652 & 1456 & 235 & 732 & 414 \\
\hline supportcase18 & MIPLIB2017 & 120 & 120 & 120 & 0 & 13410 & 0 \\
\hline supportcase26 & MIPLIB2017 & 0 & 0 & 870 & 0 & 396 & 40 \\
\hline supportcase6 & MIPLIB2017 & 57 & 771 & 0 & 1 & 130051 & 0 \\
\hline swath1 & MIPLIB2017 & 0 & 540 & 380 & 0 & 2306 & 4499 \\
\hline swath3 & MIPLIB2017 & 0 & 504 & 380 & 0 & 2706 & 4099 \\
\hline ta1-UUM & MIPLIB2017 & 0 & 2 & 437 & 605 & 0 & 1683 \\
\hline tbfp-network & MIPLIB2017 & 42 & 2436 & 0 & 0 & 72747 & 0 \\
\hline timtab1 & MIPLIB2017 & 0 & 0 & 171 & 94 & 77 & 226 \\
\hline uccase9 & MIPLIB2017 & 0 & 11879 & 37686 & 0 & 8064 & 25178 \\
\hline
\end{tabular}




\begin{tabular}{|l|l|r|r|r|r|r|r|}
\hline model & source & MCC & eq. & ineq. & int. & bin. & cont. \\
\hline unitcal_7 & MIPLIB2017 & 0 & 2907 & 46032 & 0 & 2856 & 22899 \\
\hline vpm1 & MIPLIB3.0 & 24 & 42 & 192 & 0 & 168 & 210 \\
\hline vpm2 & MIPLIB2003 & 0 & 42 & 192 & 0 & 168 & 210 \\
\hline
\end{tabular}




\section{Appendix B}

\section{Experimental Results}

Tables B.1 to B. 3 show the tested results of 8 VDS / NS configurations running on the set of 164 tested MIP problems. Table B.1 has 85 MIP models whose integer-optimal solution was found by at least one VDS / NS configuration. Table B.2 has 70 MIP models, none of which was solved to optimality within the time limit by any VDS / NS configuration, but an incumbent solution was found by at least one VDS / NS configuration. Table B.3 has 9 models for which neither the integer-optimal solution nor an incumbent solution was found by any VDS / NS configurations.

The following codes are used:

VDS: $\quad D:$ VDS - D\&T, A: METHA - UP, P: VDS - PCOST, L: VDS - LCP

NS: $\quad$ M: MBESTP - ASP - ANST, B: BESTB (GLPK default)

Incu. Sol.: $\quad N$ : Not yet found

Exit code: $\quad I$ : Integer-optimal solution found

$T:$ Time limit exceeded

F: Fail 
Table B.1: Results of the models solved by at least one VDS / NS configuration.

\begin{tabular}{|c|c|c|c|c|c|c|c|c|c|c|}
\hline VDS & NS & model & $\begin{array}{r}\text { simplex } \\
\text { it. }\end{array}$ & incu. Sol. & nodes & $\begin{array}{r}\text { 1st fea. } \\
\text { Time }\end{array}$ & $\begin{array}{r}\text { fea. } \\
\text { nodes }\end{array}$ & $\begin{array}{l}\text { exit } \\
\text { code }\end{array}$ & time & memory \\
\hline D & B & aligning & $4.35 \mathrm{E}+05$ & $2.71 \mathrm{E}+03$ & $3.03 E+04$ & $2.55 \mathrm{E}+02$ & $1.00 \mathrm{E}+00$ & I & $3.00 \mathrm{E}+02$ & $6.58 \mathrm{E}+07$ \\
\hline$A$ & $M$ & aligninq & $1.93 \mathrm{E}+05$ & $2.71 E+03$ & $1.12 \mathrm{E}+04$ & $5.37 E+00$ & $2.00 E+00$ & I & $2.46 \mathrm{E}+01$ & $2.33 E+07$ \\
\hline D & $\mathrm{M}$ & aligninq & $2.65 \mathrm{E}+05$ & $2.71 E+03$ & $1.51 \mathrm{E}+04$ & $5.03 E+01$ & $2.00 \mathrm{E}+00$ & 1 & $1.54 \mathrm{E}+02$ & $2.64 \mathrm{E}+07$ \\
\hline $\mathrm{A}$ & $\mathrm{B}$ & aligninq & $2.01 \mathrm{E}+05$ & $2.71 \mathrm{E}+03$ & $1.06 \mathrm{E}+04$ & $0.00 \mathrm{E}+00$ & $0.00 \mathrm{E}+00$ & 1 & $2.57 E+01$ & $2.74 \mathrm{E}+07$ \\
\hline $\mathrm{L}$ & $M$ & aligninq & $4.94 \mathrm{E}+05$ & $2.71 E+03$ & $2.91 \mathrm{E}+04$ & $4.98 \mathrm{E}+01$ & $2.00 \mathrm{E}+00$ & 1 & $2.17 E+02$ & $5.52 E+07$ \\
\hline $\mathrm{L}$ & B & aligninq & $4.96 \mathrm{E}+05$ & $2.71 E+03$ & $2.91 \mathrm{E}+04$ & $0.00 \mathrm{E}+00$ & $0.00 \mathrm{E}+00$ & 1 & $2.39 E+02$ & $8.12 \mathrm{E}+07$ \\
\hline$P$ & $M$ & aligning & $5.65 E+04$ & $2.71 E+03$ & $4.98 \mathrm{E}+03$ & $2.37 E+00$ & $1.00 E+00$ & I & $1.05 E+01$ & $1.20 E+07$ \\
\hline $\mathrm{P}$ & $\mathrm{B}$ & aligninq & $4.20 \mathrm{E}+04$ & $2.71 E+03$ & $4.30 \mathrm{E}+03$ & $2.45 \mathrm{E}+00$ & $1.00 \mathrm{E}+00$ & 1 & $8.60 E+00$ & $8.57 E+06$ \\
\hline D & $\mathrm{B}$ & cap6000 & $1.30 \mathrm{E}+04$ & $-2.45 E+06$ & $4.28 \mathrm{E}+03$ & $0.00 \mathrm{E}+00$ & $0.00 \mathrm{E}+00$ & 1 & $1.33 \mathrm{E}+01$ & $1.15 \mathrm{E}+07$ \\
\hline A & $M$ & cap6000 & $2.80 \mathrm{E}+05$ & $-2.45 E+06$ & $1.22 \mathrm{E}+05$ & $1.07 \mathrm{E}+01$ & $1.00 \mathrm{E}+00$ & 1 & $3.63 E+02$ & $2.29 E+07$ \\
\hline D & $M$ & cap6000 & $1.51 \mathrm{E}+04$ & $-2.45 E+06$ & $4.90 \mathrm{E}+03$ & $0.00 \mathrm{E}+00$ & $0.00 \mathrm{E}+00$ & 1 & $1.51 \mathrm{E}+01$ & $1.11 \mathrm{E}+07$ \\
\hline A & B & cap6000 & $2.81 \mathrm{E}+05$ & $-2.45 E+06$ & $1.49 \mathrm{E}+05$ & $0.00 E+00$ & $0.00 E+00$ & I & $4.31 E+02$ & $6.53 E+07$ \\
\hline $\mathrm{L}$ & $\mathrm{M}$ & cap6000 & $1.73 \mathrm{E}+04$ & $-2.45 E+06$ & $5.53 E+03$ & $0.00 \mathrm{E}+00$ & $0.00 \mathrm{E}+00$ & 1 & $1.72 \mathrm{E}+01$ & $1.22 \mathrm{E}+07$ \\
\hline $\mathrm{L}$ & B & cap6000 & $1.66 \mathrm{E}+04$ & $-2.45 E+06$ & $6.26 \mathrm{E}+03$ & $0.00 \mathrm{E}+00$ & $0.00 \mathrm{E}+00$ & 1 & $1.74 \mathrm{E}+01$ & $1.31 \mathrm{E}+07$ \\
\hline $\mathrm{P}$ & $\mathrm{M}$ & cap6000 & $1.86 \mathrm{E}+04$ & $-2.45 \mathrm{E}+06$ & $7.10 \mathrm{E}+03$ & $0.00 \mathrm{E}+00$ & $0.00 \mathrm{E}+00$ & 1 & $1.84 \mathrm{E}+01$ & $1.46 \mathrm{E}+07$ \\
\hline $\mathrm{P}$ & B & cap6000 & $9.36 \mathrm{E}+03$ & $-2.45 E+06$ & $2.84 \mathrm{E}+03$ & $1.32 \mathrm{E}+00$ & $1.00 \mathrm{E}+00$ & 1 & $8.30 \mathrm{E}+00$ & $1.42 \mathrm{E}+07$ \\
\hline D & B & $\bmod 008$ & $7.87 E+03$ & $3.07 E+02$ & $2.05 E+03$ & $0.00 E+00$ & $0.00 E+00$ & I & $5.00 \mathrm{E}-01$ & $9.44 E+05$ \\
\hline $\mathrm{A}$ & $\mathrm{M}$ & $\bmod 008$ & $1.81 \mathrm{E}+04$ & $3.07 E+02$ & $9.71 \mathrm{E}+03$ & $0.00 \mathrm{E}+00$ & $0.00 \mathrm{E}+00$ & 1 & $1.20 \mathrm{E}+00$ & $1.26 \mathrm{E}+06$ \\
\hline D & $\mathrm{M}$ & $\bmod 008$ & $7.86 \mathrm{E}+03$ & $3.07 E+02$ & $2.05 E+03$ & $0.00 \mathrm{E}+00$ & $0.00 \mathrm{E}+00$ & I & 5.00E-01 & $6.48 \mathrm{E}+05$ \\
\hline A & B & $\bmod 008$ & $1.81 \mathrm{E}+04$ & $3.07 \mathrm{E}+02$ & $9.71 \mathrm{E}+03$ & $0.00 \mathrm{E}+00$ & $0.00 \mathrm{E}+00$ & I & $1.30 \mathrm{E}+00$ & $3.11 E+06$ \\
\hline $\mathrm{L}$ & $\mathrm{M}$ & $\bmod 008$ & $8.12 \mathrm{E}+03$ & $3.07 E+02$ & $3.94 \mathrm{E}+03$ & $0.00 \mathrm{E}+00$ & $0.00 \mathrm{E}+00$ & 1 & 5.00E-01 & $1.07 \mathrm{E}+06$ \\
\hline $\mathrm{L}$ & B & $\bmod 008$ & $8.12 E+03$ & $3.07 E+02$ & $3.94 \mathrm{E}+03$ & $0.00 E+00$ & $0.00 E+00$ & I & 6.00E-01 & $1.71 E+06$ \\
\hline $\mathrm{P}$ & $M$ & $\bmod 008$ & $1.57 \mathrm{E}+04$ & $3.07 E+02$ & $7.58 \mathrm{E}+03$ & $0.00 \mathrm{E}+00$ & $0.00 \mathrm{E}+00$ & 1 & $1.00 E+00$ & $1.02 E+06$ \\
\hline$P$ & B & $\bmod 008$ & $1.79 \mathrm{E}+04$ & $3.07 E+02$ & $7.72 E+03$ & $0.00 \mathrm{E}+00$ & $0.00 \mathrm{E}+00$ & 1 & $1.10 \mathrm{E}+00$ & $2.26 \mathrm{E}+06$ \\
\hline D & B & $\begin{array}{c}\text { neos- } \\
503737\end{array}$ & $3.07 E+06$ & $5.00 \mathrm{E}+01$ & $1.04 \mathrm{E}+05$ & $1.79 \mathrm{E}+00$ & $7.00 \mathrm{E}+00$ & 1 & $1.06 \mathrm{E}+03$ & $1.53 \mathrm{E}+08$ \\
\hline A & $M$ & $\begin{array}{c}\text { neos- } \\
503737\end{array}$ & $2.46 \mathrm{E}+04$ & $5.00 \mathrm{E}+01$ & $6.61 \mathrm{E}+02$ & $1.67 \mathrm{E}+00$ & $1.00 E+00$ & I & $1.70 E+00$ & $5.11 E+06$ \\
\hline D & $M$ & $\begin{array}{c}\text { neos- } \\
503737\end{array}$ & $7.35 E+04$ & $5.00 \mathrm{E}+01$ & $1.54 \mathrm{E}+03$ & $1.62 \mathrm{E}+01$ & $1.00 \mathrm{E}+00$ & I & $1.63 E+01$ & $6.60 E+06$ \\
\hline A & B & $\begin{array}{l}\text { neos- } \\
503737\end{array}$ & $8.97 E+04$ & $5.00 \mathrm{E}+01$ & $2.03 E+03$ & 1.90E-01 & $7.00 \mathrm{E}+00$ & I & $6.10 E+00$ & $8.03 E+06$ \\
\hline $\mathrm{L}$ & $\mathrm{M}$ & $\begin{array}{c}\text { neos- } \\
503737\end{array}$ & $4.93 E+04$ & $5.00 \mathrm{E}+01$ & $8.27 \mathrm{E}+02$ & $3.71 E+00$ & $1.00 \mathrm{E}+00$ & 1 & $3.80 E+00$ & $5.69 E+06$ \\
\hline $\mathrm{L}$ & B & $\begin{array}{c}\text { neos- } \\
503737\end{array}$ & $2.52 \mathrm{E}+06$ & $5.00 \mathrm{E}+01$ & $3.89 E+04$ & $2.30 \mathrm{E}-01$ & $6.00 \mathrm{E}+00$ & 1 & $1.91 E+02$ & $1.25 \mathrm{E}+08$ \\
\hline $\mathrm{P}$ & $\mathrm{M}$ & $\begin{array}{c}\text { neos- } \\
503737\end{array}$ & $1.57 \mathrm{E}+07$ & $5.20 \mathrm{E}+01$ & $7.24 \mathrm{E}+05$ & $1.53 \mathrm{E}+01$ & $2.00 \mathrm{E}+00$ & $\mathrm{~T}$ & $3.60 E+03$ & $3.09 E+08$ \\
\hline $\mathrm{P}$ & B & $\begin{array}{c}\text { neos- } \\
503737\end{array}$ & $1.70 \mathrm{E}+07$ & $5.20 \mathrm{E}+01$ & $1.41 \mathrm{E}+06$ & $6.96 \mathrm{E}+00$ & $3.00 \mathrm{E}+00$ & $\mathrm{~T}$ & $3.60 E+03$ & $1.13 \mathrm{E}+09$ \\
\hline D & B & nug08 & $7.14 \mathrm{E}+03$ & $2.14 \mathrm{E}+02$ & $2.30 \mathrm{E}+01$ & $6.50 \mathrm{E}-01$ & $1.00 \mathrm{E}+00$ & I & $1.40 \mathrm{E}+00$ & $3.33 E+06$ \\
\hline A & $M$ & nug08 & $5.90 \mathrm{E}+03$ & $2.14 \mathrm{E}+02$ & $1.30 \mathrm{E}+01$ & $5.00 \mathrm{E}-02$ & $2.00 E+00$ & 1 & $8.00 \mathrm{E}-01$ & $3.34 \mathrm{E}+06$ \\
\hline
\end{tabular}




\begin{tabular}{|c|c|c|c|c|c|c|c|c|c|c|}
\hline VDS & NS & model & $\begin{array}{r}\text { implex } \\
\text { it. }\end{array}$ & incu. Sol. & nodes & $\begin{array}{r}\text { 1st fea. } \\
\text { Time }\end{array}$ & $\begin{array}{r}\text { fea. } \\
\text { nodes }\end{array}$ & $\begin{array}{c}\text { exit } \\
\text { code }\end{array}$ & time & memory \\
\hline D & $M$ & nug08 & $4 \mathrm{E}+03$ & $E+02$ & $30 E+01$ & $6.50 \mathrm{E}-01$ & $00 E+00$ & I & $.40 \mathrm{E}+00$ & $3.34 \mathrm{E}+06$ \\
\hline A & B & nug08 & $E+03$ & $4 \mathrm{E}+02$ & $.30 E+01$ & $5.00 \mathrm{E}-02$ & $2.00 \mathrm{E}+00$ & I & $8.00 \mathrm{E}-01$ & $3.33 \mathrm{E}+06$ \\
\hline $\mathrm{L}$ & $\mathrm{M}$ & nug08 & $E+04$ & $2.14 E+02$ & $53 \mathrm{E}+02$ & $2.00 \mathrm{E}-02$ & $.00 \mathrm{E}+00$ & 1 & $70 E+00$ & $3.35 \mathrm{E}+06$ \\
\hline $\mathrm{L}$ & B & nug08 & $E+04$ & $2.14 E+02$ & $.53 \mathrm{E}+02$ & 2.00E-02 & $4.00 \mathrm{E}+00$ & $\mathrm{I}$ & $1.70 \mathrm{E}+00$ & $3.35 \mathrm{E}+06$ \\
\hline $\mathrm{P}$ & $M$ & nug08 & $1.56 \mathrm{E}+04$ & $2.14 \mathrm{E}+02$ & $8.43 E+02$ & $1.22 \mathrm{E}+01$ & $2.00 \mathrm{E}+00$ & 1 & $1.38 \mathrm{E}+01$ & 4.87E+06 \\
\hline $\mathrm{P}$ & B & nug08 & $1.56 \mathrm{E}+04$ & $2.14 E+02$ & $8.43 E+02$ & $1.21 \mathrm{E}+01$ & $1.00 \mathrm{E}+00$ & 1 & $1.38 \mathrm{E}+01$ & $4.87 \mathrm{E}+06$ \\
\hline D & B & p0201 & $1.59 \mathrm{E}+04$ & $7.62 \mathrm{E}+03$ & $2.10 \mathrm{E}+03$ & $1.00 \mathrm{E}-02$ & $7.00 \mathrm{E}+00$ & I & $9.00 \mathrm{E}-01$ & $1.79 \mathrm{E}+06$ \\
\hline A & $M$ & p0201 & $8.42 \mathrm{E}+03$ & $7.62 \mathrm{E}+03$ & $1.09 \mathrm{E}+03$ & $2.00 \mathrm{E}-02$ & $1.00 \mathrm{E}+00$ & I & $3.00 \mathrm{E}-01$ & $8.08 \mathrm{E}+05$ \\
\hline D & $M$ & p0201 & $1.37 \mathrm{E}+04$ & $7.62 \mathrm{E}+03$ & $1.62 \mathrm{E}+03$ & $1.00 \mathrm{E}-02$ & $6.00 \mathrm{E}+00$ & 1 & 8.00E-01 & $7.52 \mathrm{E}+05$ \\
\hline A & B & p0201 & $1.59 \mathrm{E}+04$ & $7.62 E+03$ & $2.11 E+03$ & $0.00 E+00$ & $5.00 E+00$ & I & $6.00 \mathrm{E}-01$ & $1.87 \mathrm{E}+06$ \\
\hline $\mathrm{L}$ & $\mathrm{M}$ & p0201 & $5.29 \mathrm{E}+03$ & $7.62 \mathrm{E}+03$ & $7.67 \mathrm{E}+02$ & $1.00 \mathrm{E}-02$ & $4.00 \mathrm{E}+00$ & 1 & $3.00 \mathrm{E}-01$ & $6.46 \mathrm{E}+05$ \\
\hline $\mathrm{L}$ & B & p0201 & $1.23 \mathrm{E}+04$ & $7.62 E+03$ & $1.56 \mathrm{E}+03$ & 1.00E-02 & $3.00 \mathrm{E}+00$ & 1 & $4.00 \mathrm{E}-01$ & $1.23 \mathrm{E}+06$ \\
\hline $\mathrm{P}$ & $\mathrm{M}$ & p0201 & $2.38 \mathrm{E}+03$ & $7.62 E+03$ & $2.69 \mathrm{E}+02$ & 8.00E-02 & $2.00 \mathrm{E}+00$ & 1 & $2.00 \mathrm{E}-01$ & $8.49 \mathrm{E}+05$ \\
\hline $\mathrm{P}$ & B & p0201 & $77 E+03$ & $7.62 E+03$ & $3.77 E+02$ & $7.00 \mathrm{E}-02$ & $2.00 E+00$ & 1 & OOE-01 & $9.83 \mathrm{E}+05$ \\
\hline D & $\mathrm{B}$ & p0282 & $1.49 \mathrm{E}+03$ & $2.58 \mathrm{E}+05$ & $6.31 \mathrm{E}+02$ & $1.00 \mathrm{E}-02$ & $1.00 \mathrm{E}+01$ & 1 & OOE-01 & $7.01 \mathrm{E}+05$ \\
\hline A & $\mathrm{M}$ & p0282 & $2.52 \mathrm{E}+05$ & $2.58 \mathrm{E}+05$ & $1.37 \mathrm{E}+05$ & OE-02 & $1.10 \mathrm{E}+01$ & 1 & $2.56 \mathrm{E}+01$ & $1.37 \mathrm{E}+07$ \\
\hline D & $\mathrm{M}$ & p0282 & $9.80 \mathrm{E}+02$ & $2.58 \mathrm{E}+05$ & $3.35 \mathrm{E}+02$ & $2.00 \mathrm{E}-02$ & $8.00 \mathrm{E}+00$ & I & $1.00 \mathrm{E}-01$ & $6.69 \mathrm{E}+05$ \\
\hline A & B & p0282 & $3.23 \mathrm{E}+05$ & $2.58 \mathrm{E}+05$ & $1.64 \mathrm{E}+05$ & $2.00 \mathrm{E}-02$ & $9.00 \mathrm{E}+00$ & 1 & $8.74 \mathrm{E}+01$ & $4.54 \mathrm{E}+07$ \\
\hline L & $M$ & p0282 & $2.40 \mathrm{E}+03$ & $2.58 \mathrm{E}+05$ & $7.79 \mathrm{E}+02$ & $3.00 \mathrm{E}-02$ & $2.60 \mathrm{E}+01$ & I & $1.00 \mathrm{E}-01$ & $6.85 E+05$ \\
\hline L & B & p0282 & $7.40 \mathrm{E}+03$ & $2.58 \mathrm{E}+05$ & $2.33 E+03$ & 4.00E-02 & $1.20 \mathrm{E}+01$ & I & 4.00E-01 & $1.30 \mathrm{E}+06$ \\
\hline $\mathrm{P}$ & $M$ & p0282 & $8.88 \mathrm{E}+02$ & $2.58 \mathrm{E}+05$ & $2.85 \mathrm{E}+02$ & 4.00E-02 & $5.00 \mathrm{E}+00$ & 1 & $1.00 \mathrm{E}-01$ & $8.58 \mathrm{E}+05$ \\
\hline$P$ & $\mathrm{~B}$ & p0282 & $9.56 \mathrm{E}+02$ & $2.58 \mathrm{E}+05$ & $4.15 \mathrm{E}+02$ & $5.00 \mathrm{E}-02$ & $4.00 \mathrm{E}+00$ & 1 & $.00 \mathrm{E}-01$ & $9.01 \mathrm{E}+05$ \\
\hline D & B & p0548 & $1.00 \mathrm{E}+05$ & $8.69 \mathrm{E}+03$ & $6.47 \mathrm{E}+04$ & $6.54 \mathrm{E}+00$ & $7.00 \mathrm{E}+00$ & 1 & $1.81 \mathrm{E}+01$ & $1.01 \mathrm{E}+07$ \\
\hline A & $N$ & p0548 & $0 \mathrm{E}+07$ & $9.32 \mathrm{E}+03$ & $6.07 E+06$ & $2.42 \mathrm{E}+03$ & $9.00 \mathrm{E}+00$ & $\mathrm{~T}$ & $3.60 \mathrm{E}+03$ & $1.92 \mathrm{E}+07$ \\
\hline D & $\mathrm{N}$ & p0548 & $E+04$ & 8.65 & $8.54 \mathrm{E}+03$ & 10E-01 & $70 E+01$ & I & $3.20 \mathrm{E}+00$ & $1.55 \mathrm{E}+06$ \\
\hline A & B & p0548 & $3.66 \mathrm{E}+06$ & $\cdots$ & $1.07 \mathrm{E}+06$ & $0.00 \mathrm{E}+00$ & $.00 \mathrm{E}+00$ & 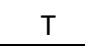 & $3.60 \mathrm{E}+03$ & 2.99E+08 \\
\hline $\mathrm{L}$ & $\mathrm{M}$ & p0548 & $1.26 \mathrm{E}+07$ & $2.77 \mathrm{E}+04$ & $8.36 \mathrm{E}+06$ & $1.75 \mathrm{E}+01$ & $1.44 \mathrm{E}+02$ & 1 & $3.60 \mathrm{E}+03$ & $3.63 \mathrm{E}+07$ \\
\hline $\mathrm{L}$ & B & p0548 & $7.14 \mathrm{E}+06$ & $\mathrm{~N}$ & $9.34 \mathrm{E}+05$ & $0.00 E+00$ & $0.00 \mathrm{E}+00$ & $\mathrm{~T}$ & $3.60 \mathrm{E}+03$ & $5.00 \mathrm{E}+08$ \\
\hline$P$ & $\mathrm{M}$ & p0548 & $6.06 \mathrm{E}+03$ & $8.69 \mathrm{E}+03$ & $3.67 \mathrm{E}+03$ & $8.10 \mathrm{E}-01$ & $1.00 \mathrm{E}+00$ & 1 & $9.00 \mathrm{E}-01$ & $1.04 \mathrm{E}+06$ \\
\hline $\mathrm{P}$ & B & p0548 & $6.37 \mathrm{E}+03$ & $8.69 \mathrm{E}+03$ & $4.25 \mathrm{E}+03$ & 8.70E-01 & $2.00 \mathrm{E}+00$ & 1 & $9.00 \mathrm{E}-01$ & $2.39 \mathrm{E}+06$ \\
\hline D & B & rentacar & $6.46 \mathrm{E}+03$ & $3.04 \mathrm{E}+07$ & $1.37 \mathrm{E}+02$ & $7.80 \mathrm{E}-01$ & $1.00 \mathrm{E}+00$ & 1 & $1.00 \mathrm{E}+00$ & $1.08 \mathrm{E}+07$ \\
\hline A & $M$ & rentacar & $1.96 \mathrm{E}+03$ & $3.04 \mathrm{E}+07$ & $2.10 \mathrm{E}+01$ & $1.10 \mathrm{E}-01$ & $2.00 \mathrm{E}+00$ & 1 & $3.00 \mathrm{E}-01$ & $1.08 \mathrm{E}+07$ \\
\hline D & $M$ & rentacar & $3.88 \mathrm{E}+03$ & $3.04 \mathrm{E}+07$ & $7.90 \mathrm{E}+01$ & $1.90 \mathrm{E}-01$ & $3.00 \mathrm{E}+00$ & 1 & $6.00 \mathrm{E}-01$ & $1.08 \mathrm{E}+07$ \\
\hline A & $D$ & rentacar & $5.76 \mathrm{E}+03$ & $3.04 \mathrm{E}+07$ & $1.17 \mathrm{E}+02$ & 1.10E-01 & $3.00 \mathrm{E}+00$ & 1 & $9.00 \mathrm{E}-01$ & $1.08 \mathrm{E}+07$ \\
\hline $\mathrm{L}$ & $\mathrm{M}$ & rentacar & $2.55 \mathrm{E}+04$ & $3.04 \mathrm{E}+07$ & $4.43 E+02$ & 3.10E-01 & $7.00 \mathrm{E}+00$ & 1 & $3.40 \mathrm{E}+00$ & $1.14 \mathrm{E}+07$ \\
\hline L & B & rentacar & $1.07 \mathrm{E}+04$ & $3.04 \mathrm{E}+07$ & $1.87 \mathrm{E}+02$ & 3.10E-01 & $6.00 \mathrm{E}+00$ & 1 & $1.50 \mathrm{E}+00$ & $1.08 \mathrm{E}+07$ \\
\hline $\mathrm{P}$ & M & $\operatorname{ar}$ & $2.13 E+03$ & $3.04 \mathrm{E}+07$ & $3.50 \mathrm{E}+01$ & 01 & $00 \mathrm{E}+00$ & 1 & 01 & $.13 E+07$ \\
\hline $\mathrm{P}$ & B & re & $E+03$ & $4 \mathrm{E}+07$ & $9.90 \mathrm{E}+01$ & -01 & $00 \mathrm{E}+00$ & 1 & $9.00 \mathrm{E}-01$ & $1.15 \mathrm{E}+07$ \\
\hline D & $\mathrm{B}$ & rgn & $2.72 \mathrm{E}+04$ & $8.22 \mathrm{E}+01$ & $5.56 \mathrm{E}+03$ & $0.00 \mathrm{E}+00$ & $3.00 \mathrm{E}+00$ & 1 & $.00 \mathrm{E}-01$ & $2.02 \mathrm{E}+06$ \\
\hline A & M & rgn & $5.19 \mathrm{E}+03$ & $8.22 \mathrm{E}+01$ & $1.90 \mathrm{E}+03$ & $0.00 E+00$ & $2.00 E+00$ & 1 & 2.00E-01 & $3.03 E+05$ \\
\hline
\end{tabular}




\begin{tabular}{|c|c|c|c|c|c|c|c|c|c|c|}
\hline VDS & NS & model & $\begin{array}{r}\text { simplex } \\
\text { it. }\end{array}$ & incu. Sol. & nodes & $\begin{array}{r}\text { 1st fea. } \\
\text { Time }\end{array}$ & $\begin{array}{r}\text { fea. } \\
\text { nodes }\end{array}$ & $\begin{array}{l}\text { exit } \\
\text { code }\end{array}$ & time & memory \\
\hline D & $M$ & $\mathrm{rgn}$ & $2.69 \mathrm{E}+04$ & $8.22 E+01$ & $5.57 \mathrm{E}+03$ & $0.00 \mathrm{E}+00$ & $2.00 \mathrm{E}+00$ & 1 & $6.00 \mathrm{E}-01$ & $6.80 \mathrm{E}+05$ \\
\hline$A$ & $\mathrm{~B}$ & $\mathrm{rgn}$ & $5.31 \mathrm{E}+03$ & $8.22 \mathrm{E}+01$ & $1.90 \mathrm{E}+03$ & $0.00 E+00$ & $2.00 \mathrm{E}+00$ & 1 & $2.00 \mathrm{E}-01$ & $7.43 E+05$ \\
\hline $\mathrm{L}$ & $M$ & $\mathrm{rgn}$ & $3.77 \mathrm{E}+04$ & $8.22 E+01$ & $8.27 E+03$ & $0.00 E+00$ & $1.00 \mathrm{E}+00$ & 1 & $7.00 \mathrm{E}-01$ & $8.71 \mathrm{E}+05$ \\
\hline $\mathrm{L}$ & $\mathrm{B}$ & $\mathrm{rgn}$ & $3.77 \mathrm{E}+04$ & $8.22 \mathrm{E}+01$ & $8.27 E+03$ & $0.00 \mathrm{E}+00$ & $1.00 \mathrm{E}+00$ & 1 & 8.00E-01 & $2.60 \mathrm{E}+06$ \\
\hline $\mathrm{P}$ & $\mathrm{M}$ & $\mathrm{rgn}$ & $8.02 \mathrm{E}+03$ & $8.22 \mathrm{E}+01$ & $2.72 \mathrm{E}+03$ & $5.00 \mathrm{E}-02$ & $1.00 \mathrm{E}+00$ & 1 & $2.00 \mathrm{E}-01$ & $6.45 \mathrm{E}+05$ \\
\hline$P$ & $\mathrm{~B}$ & $\mathrm{rgn}$ & $8.04 \mathrm{E}+03$ & $8.22 \mathrm{E}+01$ & $2.45 \mathrm{E}+03$ & $2.00 \mathrm{E}-02$ & $1.00 \mathrm{E}+00$ & 1 & $2.00 \mathrm{E}-01$ & $1.04 \mathrm{E}+06$ \\
\hline $\mathrm{D}$ & $\mathrm{B}$ & stein27 & $1.32 \mathrm{E}+04$ & $1.80 \mathrm{E}+01$ & $2.42 E+03$ & $0.00 \mathrm{E}+00$ & $2.00 \mathrm{E}+00$ & 1 & 3.00E-01 & $9.39 \mathrm{E}+05$ \\
\hline A & $M$ & stein27 & $1.14 \mathrm{E}+04$ & $1.80 \mathrm{E}+01$ & $2.34 \mathrm{E}+03$ & $0.00 \mathrm{E}+00$ & $2.00 \mathrm{E}+00$ & 1 & 2.00E-01 & $6.83 \mathrm{E}+05$ \\
\hline $\mathrm{D}$ & $M$ & stein27 & $1.33 \mathrm{E}+04$ & $1.80 \mathrm{E}+01$ & $2.47 E+03$ & $0.00 \mathrm{E}+00$ & $2.00 \mathrm{E}+00$ & 1 & $4.00 \mathrm{E}-01$ & $7.92 \mathrm{E}+05$ \\
\hline A & $\mathrm{B}$ & stein27 & $1.14 \mathrm{E}+04$ & $1.80 \mathrm{E}+01$ & $2.34 \mathrm{E}+03$ & $0.00 \mathrm{E}+00$ & $2.00 \mathrm{E}+00$ & 1 & 2.00E-01 & $9.91 \mathrm{E}+05$ \\
\hline $\mathrm{L}$ & $\mathrm{M}$ & stein27 & $1.53 \mathrm{E}+04$ & $1.80 \mathrm{E}+01$ & $3.79 \mathrm{E}+03$ & $0.00 \mathrm{E}+00$ & $2.00 \mathrm{E}+00$ & 1 & 4.00E-01 & $9.13 \mathrm{E}+05$ \\
\hline $\mathrm{L}$ & $\mathrm{B}$ & stein27 & $1.53 \mathrm{E}+04$ & $1.80 \mathrm{E}+01$ & $3.79 \mathrm{E}+03$ & $0.00 \mathrm{E}+00$ & $2.00 \mathrm{E}+00$ & I & 4.00E-01 & $1.40 \mathrm{E}+06$ \\
\hline $\mathrm{P}$ & $M$ & stein27 & $1.37 E+04$ & $1.80 \mathrm{E}+01$ & $3.20 \mathrm{E}+03$ & $2.00 \mathrm{E}-02$ & $1.00 \mathrm{E}+00$ & 1 & 3.00E-01 & $7.63 E+05$ \\
\hline $\mathrm{P}$ & $\mathrm{B}$ & stein27 & $1.39 \mathrm{E}+04$ & $1.80 \mathrm{E}+01$ & $3.30 \mathrm{E}+03$ & $1.00 \mathrm{E}-02$ & $1.00 \mathrm{E}+00$ & 1 & $3.00 \mathrm{E}-01$ & $1.08 \mathrm{E}+06$ \\
\hline$D$ & $\mathrm{~B}$ & enigma & $5.24 \mathrm{E}+03$ & $0.00 \mathrm{E}+00$ & $2.37 E+03$ & $1.20 \mathrm{E}-01$ & $1.00 \mathrm{E}+00$ & 1 & $.00 \mathrm{E}-01$ & $7.42 \mathrm{E}+05$ \\
\hline A & $\mathrm{M}$ & enigma & $9.44 \mathrm{E}+04$ & $0.00 \mathrm{E}+00$ & $4.48 \mathrm{E}+04$ & $1.94 \mathrm{E}+00$ & $2.00 \mathrm{E}+00$ & 1 & $2.00 \mathrm{E}+00$ & $5.27 \mathrm{E}+05$ \\
\hline $\mathrm{D}$ & $\mathrm{M}$ & enigma & $7.78 \mathrm{E}+03$ & $0.00 \mathrm{E}+00$ & $3.26 \mathrm{E}+03$ & $1.90 \mathrm{E}-01$ & $1.00 \mathrm{E}+00$ & 1 & $2.00 \mathrm{E}-01$ & $4.81 \mathrm{E}+05$ \\
\hline$A$ & $\mathrm{~B}$ & enigma & $5.08 \mathrm{E}+04$ & $0.00 \mathrm{E}+00$ & $1.89 \mathrm{E}+04$ & $9.40 \mathrm{E}-01$ & $1.00 \mathrm{E}+00$ & 1 & $9.00 \mathrm{E}-01$ & $5.12 \mathrm{E}+06$ \\
\hline $\mathrm{L}$ & $M$ & enigma & $2.50 \mathrm{E}+05$ & $9.99 \mathrm{E}-16$ & $1.74 \mathrm{E}+05$ & $7.32 \mathrm{E}+00$ & $2.00 \mathrm{E}+00$ & 1 & $8.10 \mathrm{E}+00$ & $2.13 \mathrm{E}+06$ \\
\hline L & $\mathrm{B}$ & enigma & $1.98 \mathrm{E}+05$ & $-2.00 \mathrm{E}-15$ & $1.34 \mathrm{E}+05$ & $5.06 \mathrm{E}+00$ & $2.00 \mathrm{E}+00$ & 1 & $1.36 \mathrm{E}+01$ & $1.38 \mathrm{E}+07$ \\
\hline $\mathrm{P}$ & $M$ & enigma & $3.72 E+04$ & $0.00 \mathrm{E}+00$ & 1.55E+04 & $7.10 \mathrm{E}-01$ & $2.00 \mathrm{E}+00$ & 1 & $8.00 \mathrm{E}-01$ & $7.13 \mathrm{E}+05$ \\
\hline$P$ & $\mathrm{~B}$ & enigma & $5.33 \mathrm{E}+03$ & $0.00 \mathrm{E}+00$ & $1.93 \mathrm{E}+03$ & $1.20 \mathrm{E}-01$ & $1.00 \mathrm{E}+00$ & 1 & $1.00 \mathrm{E}-01$ & $5.77 \mathrm{E}+05$ \\
\hline $\mathrm{D}$ & $\mathrm{B}$ & khb05250 & $1.83 \mathrm{E}+04$ & $1.07 \mathrm{E}+08$ & $4.25 \mathrm{E}+03$ & $1.00 \mathrm{E}-02$ & $7.00 \mathrm{E}+00$ & 1 & $2.10 \mathrm{E}+00$ & $4.37 \mathrm{E}+06$ \\
\hline A & $M$ & khb05250 & $1.45 \mathrm{E}+05$ & $1.07 \mathrm{E}+08$ & $2.08 \mathrm{E}+04$ & $2.00 \mathrm{E}-02$ & $8.00 \mathrm{E}+00$ & 1 & $1.11 \mathrm{E}+01$ & $7.24 \mathrm{E}+06$ \\
\hline D & $M$ & khb05250 & $1.49 \mathrm{E}+04$ & $1.07 \mathrm{E}+08$ & $3.02 E+03$ & $2.00 \mathrm{E}-02$ & $8.00 \mathrm{E}+00$ & 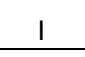 & $1.80 \mathrm{E}+00$ & $2.06 \mathrm{E}+06$ \\
\hline A & $\mathrm{B}$ & khb05250 & $1.61 \mathrm{E}+05$ & $1.07 \mathrm{E}+08$ & $2.67 E+04$ & $1.00 \mathrm{E}-02$ & $1.30 \mathrm{E}+01$ & 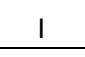 & $1.35 \mathrm{E}+01$ & $2.10 \mathrm{E}+07$ \\
\hline $\mathrm{L}$ & $\mathrm{M}$ & khb05250 & $1.45 \mathrm{E}+05$ & $1.07 \mathrm{E}+08$ & $2.06 \mathrm{E}+04$ & $1.00 \mathrm{E}-02$ & $1.00 \mathrm{E}+01$ & 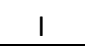 & $1.13 \mathrm{E}+01$ & $9.07 E+06$ \\
\hline $\mathrm{L}$ & $\mathrm{B}$ & khb05250 & $2.08 \mathrm{E}+05$ & $1.07 \mathrm{E}+08$ & $3.52 E+04$ & $1.00 \mathrm{E}-02$ & $1.50 \mathrm{E}+01$ & 1 & $1.67 \mathrm{E}+01$ & $3.40 \mathrm{E}+07$ \\
\hline$P$ & $\mathrm{M}$ & khb05250 & $9.02 \mathrm{E}+03$ & $1.07 \mathrm{E}+08$ & $1.67 \mathrm{E}+03$ & $3.00 \mathrm{E}-02$ & $3.00 \mathrm{E}+00$ & 1 & $8.00 \mathrm{E}-01$ & $2.07 \mathrm{E}+06$ \\
\hline $\mathrm{P}$ & $\mathrm{B}$ & khb05250 & $1.34 \mathrm{E}+04$ & $1.07 \mathrm{E}+08$ & $3.13 E+03$ & $2.00 \mathrm{E}-02$ & $7.00 \mathrm{E}+00$ & I & $1.10 \mathrm{E}+00$ & $3.80 \mathrm{E}+06$ \\
\hline D & $\mathrm{B}$ & $\begin{array}{c}\text { neos- } \\
1430701 \\
\end{array}$ & 07 & 01 & +05 & $=-02$ & $E+00$ & $\mathrm{~T}$ & $50 E+03$ & $.01 \mathrm{E}+08$ \\
\hline A & M & & $E+07$ & $-7.70 \mathrm{E}+01$ & $4.06 \mathrm{E}+06$ & 4.83 & $00 \mathrm{E}+00$ & 1 & $E+03$ & $5.71 \mathrm{E}+07$ \\
\hline $\mathrm{D}$ & $\mathrm{M}$ & & $3.33 \mathrm{E}+07$ & $-7.60 E+01$ & $1.79 \mathrm{E}+06$ & $5.00 \mathrm{E}-01$ & $.00 \mathrm{E}+00$ & $\mathrm{~T}$ & $3.60 \mathrm{E}+03$ & $6.28 \mathrm{E}+07$ \\
\hline A & $\mathrm{B}$ & & $1.33 \mathrm{E}+07$ & $-7.70 \mathrm{E}+01$ & $6.92 \mathrm{E}+05$ & $4.00 E-02$ & $8.00 \mathrm{E}+00$ & $\mathrm{~T}$ & $3.60 \mathrm{E}+03$ & $4.04 \mathrm{E}+08$ \\
\hline $\mathrm{L}$ & $\mathrm{M}$ & $\begin{array}{l}\text { neos- } \\
1430701\end{array}$ & $5.90 \mathrm{E}+07$ & $-7.70 \mathrm{E}+01$ & $4.14 \mathrm{E}+06$ & $9.00 \mathrm{E}-02$ & $3.00 \mathrm{E}+00$ & $\mathrm{~T}$ & $3.60 \mathrm{E}+03$ & $5.13 \mathrm{E}+07$ \\
\hline $\mathrm{L}$ & $B$ & $\begin{array}{l}\text { neos- } \\
1430701 \\
\end{array}$ & $1.24 \mathrm{E}+07$ & $-7.70 \mathrm{E}+01$ & $7.25 \mathrm{E}+05$ & $3.00 \mathrm{E}-02$ & $8.00 \mathrm{E}+00$ & $\mathrm{~T}$ & $3.60 \mathrm{E}+03$ & $3.93 \mathrm{E}+08$ \\
\hline $\mathrm{P}$ & M & \multicolumn{2}{|c|}{ neos-1430701 } & & & & & $\mathrm{F}$ & & \\
\hline
\end{tabular}




\begin{tabular}{|c|c|c|c|c|c|c|c|c|c|c|}
\hline VDS & NS & model & $\begin{array}{r}\text { simplex } \\
\text { it. }\end{array}$ & incu. Sol. & nodes & $\begin{array}{r}\text { 1st fea. } \\
\text { Time }\end{array}$ & $\begin{array}{r}\text { fea. } \\
\text { nodes }\end{array}$ & $\begin{array}{l}\text { exit } \\
\text { code }\end{array}$ & time & memory \\
\hline$P$ & B & $\begin{array}{l}\text { neos- } \\
1430701\end{array}$ & $1.12 \mathrm{E}+07$ & $-7.70 \mathrm{E}+01$ & $8.16 \mathrm{E}+05$ & $2.20 \mathrm{E}-01$ & $5.00 \mathrm{E}+00$ & $\mathrm{~T}$ & $3.60 \mathrm{E}+03$ & $4.11 E+08$ \\
\hline D & B & $\begin{array}{l}\text { f2gap201 } \\
600\end{array}$ & $1.81 \mathrm{E}+05$ & $7.65 \mathrm{E}+04$ & $3.16 \mathrm{E}+04$ & $0.00 \mathrm{E}+00$ & $0.00 \mathrm{E}+00$ & 1 & $4.50 \mathrm{E}+01$ & $3.40 \mathrm{E}+07$ \\
\hline A & $\mathrm{M}$ & $\begin{array}{l}\text { f2gap201 } \\
600\end{array}$ & $4.04 \mathrm{E}+07$ & $7.65 E+04$ & $5.46 \mathrm{E}+06$ & $0.00 \mathrm{E}+00$ & $0.00 \mathrm{E}+00$ & $\mathrm{~T}$ & $3.60 \mathrm{E}+03$ & $1.85 \mathrm{E}+08$ \\
\hline D & $\mathrm{M}$ & $\begin{array}{l}\text { f2gap201 } \\
600\end{array}$ & $1.81 \mathrm{E}+05$ & $7.65 E+04$ & $3.16 \mathrm{E}+04$ & $0.00 \mathrm{E}+00$ & $0.00 \mathrm{E}+00$ & $\mathrm{I}$ & $4.30 \mathrm{E}+01$ & $2.12 \mathrm{E}+07$ \\
\hline A & $\mathrm{B}$ & $\begin{array}{l}\text { f2gap201 } \\
600\end{array}$ & $3.11 \mathrm{E}+06$ & $7.65 E+04$ & $1.07 \mathrm{E}+06$ & $0.00 \mathrm{E}+00$ & $0.00 \mathrm{E}+00$ & $\mathrm{~T}$ & $3.60 \mathrm{E}+03$ & $1.82 \mathrm{E}+09$ \\
\hline $\mathrm{L}$ & $\mathrm{M}$ & $\begin{array}{l}\text { f2gap201 } \\
600\end{array}$ & $2.67 \mathrm{E}+07$ & $7.65 \mathrm{E}+04$ & $5.06 \mathrm{E}+06$ & $0.00 \mathrm{E}+00$ & $0.00 \mathrm{E}+00$ & $\mathrm{~T}$ & $3.60 \mathrm{E}+03$ & $4.65 \mathrm{E}+08$ \\
\hline $\mathrm{L}$ & B & $\begin{array}{l}\text { f2gap201 } \\
600\end{array}$ & $6.57 \mathrm{E}+06$ & $7.65 \mathrm{E}+04$ & $8.03 E+05$ & $0.00 \mathrm{E}+00$ & $0.00 \mathrm{E}+00$ & $\mathrm{~T}$ & $3.60 \mathrm{E}+03$ & $2.27 E+09$ \\
\hline $\mathrm{P}$ & $\mathrm{M}$ & $\begin{array}{l}\text { f2gap201 } \\
600\end{array}$ & $2.09 \mathrm{E}+05$ & $7.65 E+04$ & $3.90 \mathrm{E}+04$ & $0.00 \mathrm{E}+00$ & $0.00 \mathrm{E}+00$ & $\mathrm{I}$ & $2.53 E+01$ & $2.19 \mathrm{E}+07$ \\
\hline$P$ & $\mathrm{~B}$ & $\begin{array}{l}\text { f2gap201 } \\
600\end{array}$ & $2.09 E+05$ & $7.65 E+04$ & $3.82 E+04$ & $0.00 \mathrm{E}+00$ & $0.00 \mathrm{E}+00$ & I & $2.76 \mathrm{E}+01$ & 4.27E+07 \\
\hline D & $\mathrm{B}$ & danoint & $1.62 \mathrm{E}+07$ & $6.57 \mathrm{E}+01$ & $6.91 \mathrm{E}+05$ & $3.70 \mathrm{E}-01$ & $5.00 \mathrm{E}+00$ & $\mathrm{~T}$ & $3.60 \mathrm{E}+03$ & $8.37 E+08$ \\
\hline A & $\mathrm{M}$ & danoint & $3.93 \mathrm{E}+07$ & $6.57 \mathrm{E}+01$ & $1.20 \mathrm{E}+06$ & $8.46 \mathrm{E}+00$ & $1.10 \mathrm{E}+01$ & $\mathrm{~T}$ & $3.60 \mathrm{E}+03$ & $3.22 \mathrm{E}+08$ \\
\hline $\mathrm{D}$ & $\mathrm{M}$ & danoint & $4.68 \mathrm{E}+07$ & $6.57 \mathrm{E}+01$ & $1.35 \mathrm{E}+06$ & $2.50 \mathrm{E}-01$ & $1.30 \mathrm{E}+01$ & $\mathrm{~T}$ & $3.60 \mathrm{E}+03$ & $1.86 \mathrm{E}+08$ \\
\hline A & $\mathrm{B}$ & danoint & $2.24 \mathrm{E}+07$ & $6.70 \mathrm{E}+01$ & $5.67 \mathrm{E}+05$ & $3.65 E+00$ & $7.00 \mathrm{E}+00$ & $\mathrm{~T}$ & $3.60 E+03$ & $9.28 \mathrm{E}+08$ \\
\hline $\mathrm{L}$ & $\mathrm{M}$ & danoint & $3.63 \mathrm{E}+07$ & $6.57 \mathrm{E}+01$ & $1.34 \mathrm{E}+06$ & $9.20 \mathrm{E}-01$ & $1.10 \mathrm{E}+01$ & I & $2.45 \mathrm{E}+03$ & $2.00 \mathrm{E}+08$ \\
\hline $\mathrm{L}$ & $\mathrm{B}$ & danoint & $1.71 \mathrm{E}+07$ & $6.63 \mathrm{E}+01$ & $5.94 \mathrm{E}+05$ & $4.18 \mathrm{E}+00$ & $6.00 E+00$ & $\mathrm{~T}$ & $3.60 E+03$ & $8.50 E+08$ \\
\hline $\mathrm{P}$ & $\mathrm{M}$ & danoint & $4.75 \mathrm{E}+07$ & $6.57 \mathrm{E}+01$ & $1.58 \mathrm{E}+06$ & $8.20 \mathrm{E}-01$ & $7.00 \mathrm{E}+00$ & 1 & $3.03 E+03$ & $1.56 \mathrm{E}+08$ \\
\hline $\mathrm{P}$ & $\mathrm{B}$ & danoint & $1.86 \mathrm{E}+07$ & $6.57 \mathrm{E}+01$ & $7.42 \mathrm{E}+05$ & $1.88 \mathrm{E}+00$ & $5.00 \mathrm{E}+00$ & $\mathrm{~T}$ & $3.60 \mathrm{E}+03$ & $1.00 \mathrm{E}+09$ \\
\hline D & $\mathrm{B}$ & 22433 & $1.46 \mathrm{E}+03$ & $2.15 E+04$ & $7.70 \mathrm{E}+01$ & $1.00 \mathrm{E}-01$ & $1.00 \mathrm{E}+00$ & I & $1.00 \mathrm{E}-01$ & $1.08 \mathrm{E}+06$ \\
\hline A & $\mathrm{M}$ & 22433 & $1.32 \mathrm{E}+03$ & $2.15 \mathrm{E}+04$ & $4.30 \mathrm{E}+01$ & $0.00 \mathrm{E}+00$ & $0.00 \mathrm{E}+00$ & I & $1.00 \mathrm{E}-01$ & $1.06 \mathrm{E}+06$ \\
\hline D & $\mathrm{M}$ & 22433 & $2.50 E+03$ & $2.15 E+04$ & $1.25 \mathrm{E}+02$ & $1.90 \mathrm{E}-01$ & $1.00 \mathrm{E}+00$ & 1 & $2.00 \mathrm{E}-01$ & $1.08 \mathrm{E}+06$ \\
\hline A & $\mathrm{B}$ & 22433 & $1.54 \mathrm{E}+03$ & $2.15 \mathrm{E}+04$ & $5.30 \mathrm{E}+01$ & $0.00 \mathrm{E}+00$ & $0.00 \mathrm{E}+00$ & 1 & $1.00 \mathrm{E}-01$ & $1.07 \mathrm{E}+06$ \\
\hline $\mathrm{L}$ & $\mathrm{M}$ & 22433 & $3.46 \mathrm{E}+03$ & $2.15 E+04$ & $1.45 \mathrm{E}+02$ & $0.00 \mathrm{E}+00$ & $0.00 \mathrm{E}+00$ & 1 & $3.00 \mathrm{E}-01$ & $1.08 \mathrm{E}+06$ \\
\hline $\mathrm{L}$ & $\mathrm{B}$ & 22433 & $3.53 \mathrm{E}+03$ & $2.15 \mathrm{E}+04$ & $1.35 \mathrm{E}+02$ & $0.00 \mathrm{E}+00$ & $0.00 \mathrm{E}+00$ & 1 & $3.00 \mathrm{E}-01$ & $1.09 \mathrm{E}+06$ \\
\hline $\mathrm{P}$ & $\mathrm{M}$ & 22433 & $1.07 \mathrm{E}+03$ & $2.15 E+04$ & $5.10 \mathrm{E}+01$ & $0.00 \mathrm{E}+00$ & $0.00 \mathrm{E}+00$ & 1 & $3.00 \mathrm{E}-01$ & $1.43 \mathrm{E}+06$ \\
\hline $\mathrm{P}$ & B & 22433 & $1.07 \mathrm{E}+03$ & $2.15 \mathrm{E}+04$ & $5.10 \mathrm{E}+01$ & $0.00 \mathrm{E}+00$ & $0.00 \mathrm{E}+00$ & 1 & $3.00 \mathrm{E}-01$ & $1.43 \mathrm{E}+06$ \\
\hline$D$ & $\mathrm{~B}$ & 23588 & $3.41 \mathrm{E}+04$ & $8.09 E+03$ & $3.42 \mathrm{E}+03$ & $1.40 \mathrm{E}-01$ & $3.00 \mathrm{E}+00$ & I & $3.40 \mathrm{E}+00$ & $2.63 E+06$ \\
\hline $\mathrm{A}$ & $\mathrm{M}$ & 23588 & $1.70 \mathrm{E}+04$ & $8.09 \mathrm{E}+03$ & $1.67 \mathrm{E}+03$ & $2.00 \mathrm{E}-02$ & $9.00 \mathrm{E}+00$ & 1 & $9.00 \mathrm{E}-01$ & $1.39 \mathrm{E}+06$ \\
\hline D & $\mathrm{M}$ & 23588 & $2.98 \mathrm{E}+04$ & $8.09 E+03$ & $2.77 \mathrm{E}+03$ & $5.30 \mathrm{E}-01$ & $6.00 \mathrm{E}+00$ & 1 & $3.00 \mathrm{E}+00$ & $1.82 \mathrm{E}+06$ \\
\hline A & B & 23588 & $2.01 \mathrm{E}+04$ & $8.09 \mathrm{E}+03$ & $2.05 \mathrm{E}+03$ & $3.00 \mathrm{E}-02$ & $4.00 \mathrm{E}+00$ & 1 & $1.00 \mathrm{E}+00$ & $2.03 E+06$ \\
\hline $\mathrm{L}$ & $\mathrm{M}$ & 23588 & $4.23 E+04$ & $8.09 E+03$ & $4.07 E+03$ & $1.20 \mathrm{E}-01$ & $6.00 E+00$ & 1 & $4.30 \mathrm{E}+00$ & $1.95 E+06$ \\
\hline $\mathrm{L}$ & $\mathrm{B}$ & 23588 & $4.68 \mathrm{E}+04$ & $8.09 \mathrm{E}+03$ & $4.26 \mathrm{E}+03$ & $1.00 \mathrm{E}-01$ & $4.00 \mathrm{E}+00$ & I & $4.60 \mathrm{E}+00$ & $3.03 E+06$ \\
\hline $\mathrm{P}$ & $\mathrm{M}$ & 23588 & $1.51 \mathrm{E}+04$ & $8.09 \mathrm{E}+03$ & $1.83 \mathrm{E}+03$ & $0.00 \mathrm{E}+00$ & $0.00 \mathrm{E}+00$ & 1 & $1.00 \mathrm{E}+00$ & $1.81 \mathrm{E}+06$ \\
\hline $\mathrm{P}$ & $\mathrm{B}$ & 23588 & $1.66 \mathrm{E}+04$ & $8.09 \mathrm{E}+03$ & $1.99 \mathrm{E}+03$ & $1.70 \mathrm{E}-01$ & $2.00 \mathrm{E}+00$ & I & $1.10 \mathrm{E}+00$ & $2.24 \mathrm{E}+06$ \\
\hline D & B & qnet1_o & $1.88 \mathrm{E}+04$ & $1.60 \mathrm{E}+04$ & $9.11 \mathrm{E}+02$ & $1.50 \mathrm{E}-01$ & $3.00 \mathrm{E}+00$ & 1 & $1.40 \mathrm{E}+00$ & $2.37 \mathrm{E}+06$ \\
\hline $\mathrm{A}$ & $\mathrm{M}$ & qnet1_o & $1.45 \mathrm{E}+06$ & $1.60 \mathrm{E}+04$ & $7.45 \mathrm{E}+04$ & $1.00 \mathrm{E}-01$ & $9.00 \mathrm{E}+00$ & 1 & $9.44 \mathrm{E}+01$ & $1.42 \mathrm{E}+07$ \\
\hline D & $\mathrm{M}$ & qnet1_o & $1.67 \mathrm{E}+04$ & $1.60 \mathrm{E}+04$ & $7.81 \mathrm{E}+02$ & $3.40 \mathrm{E}-01$ & $4.00 \mathrm{E}+00$ & I & $1.20 \mathrm{E}+00$ & $2.26 \mathrm{E}+06$ \\
\hline
\end{tabular}




\begin{tabular}{|c|c|c|c|c|c|c|c|c|c|c|}
\hline VDS & NS & model & $\begin{array}{r}\text { implex } \\
\text { it. }\end{array}$ & incu. Sol. & nodes & $\begin{array}{r}\text { 1st fea. } \\
\text { Time }\end{array}$ & $\begin{array}{r}\text { fea. } \\
\text { nodes }\end{array}$ & $\begin{array}{l}\text { exit } \\
\text { code }\end{array}$ & time & memory \\
\hline A & B & net1_o & $8 E+06$ & $1.60 \mathrm{E}+04$ & $99 \mathrm{E}+05$ & $1.00 \mathrm{E}-01$ & $70 E+01$ & 1 & $27 E+02$ & $.96 E+08$ \\
\hline L & M & net1_o & $E+04$ & 1.60E+04 & $3.75 E+03$ & $6.00 \mathrm{E}-02$ & $00 E+C$ & 1 & $40 \mathrm{E}+00$ & $.19 E+06$ \\
\hline $\mathrm{L}$ & D & qnet1_o & $E+04$ & $1.60 \mathrm{E}+04$ & $28 \mathrm{E}+03$ & $3.30 \mathrm{E}-01$ & $00 \mathrm{E}+00$ & 1 & $3.80 \mathrm{E}+00$ & $.56 \mathrm{E}+06$ \\
\hline $\mathrm{P}$ & $\mathrm{M}$ & qnet1_o & $1 \mathrm{E}+03$ & $1.60 \mathrm{E}+04$ & $2.83 \mathrm{E}+02$ & $1.60 \mathrm{E}-01$ & $.00 \mathrm{E}+00$ & 1 & $6.00 \mathrm{E}-01$ & $2.67 \mathrm{E}+06$ \\
\hline$P$ & B & qnet1_o & $6.89 \mathrm{E}+03$ & $1.60 \mathrm{E}+04$ & $2.87 \mathrm{E}+02$ & $1.60 \mathrm{E}-01$ & $1.00 \mathrm{E}+00$ & 1 & $6.00 \mathrm{E}-01$ & $2.63 \mathrm{E}+06$ \\
\hline D & B & bppc8-02 & $4.35 \mathrm{E}+06$ & $5.07 \mathrm{E}+02$ & $6.09 \mathrm{E}+05$ & $2.00 \mathrm{E}-02$ & $8.00 \mathrm{E}+00$ & $\mathrm{~T}$ & $3.60 E+03$ & $1.45 \mathrm{E}+08$ \\
\hline A & $M$ & bppc8-02 & $4.55 \mathrm{E}+06$ & $5.07 \mathrm{E}+02$ & $7.12 \mathrm{E}+05$ & $1.00 \mathrm{E}-02$ & $1.00 \mathrm{E}+01$ & I & $4.19 \mathrm{E}+02$ & $2.45 \mathrm{E}+07$ \\
\hline D & $M$ & bppc8-02 & $6.32 \mathrm{E}+06$ & $5.07 \mathrm{E}+02$ & $8.95 \mathrm{E}+05$ & $2.00 \mathrm{E}-02$ & $1.30 \mathrm{E}+01$ & 1 & $8.50 \mathrm{E}+02$ & $3.06 \mathrm{E}+07$ \\
\hline A & $\mathrm{B}$ & bppc8-02 & $4.60 \mathrm{E}+06$ & $5.07 \mathrm{E}+02$ & $7.18 \mathrm{E}+05$ & $1.00 \mathrm{E}-02$ & $3.70 \mathrm{E}+01$ & I & $7.78 \mathrm{E}+02$ & $1.03 \mathrm{E}+08$ \\
\hline L & M & bppc8-02 & $9.73 E+05$ & $5.07 \mathrm{E}+02$ & $2.30 \mathrm{E}+05$ & $1.00 \mathrm{E}-02$ & $1.10 \mathrm{E}+01$ & 1 & $1.46 \mathrm{E}+02$ & $1.17 \mathrm{E}+07$ \\
\hline $\mathrm{L}$ & $B$ & bppc8-02 & $5.45 \mathrm{E}+05$ & $5.07 \mathrm{E}+02$ & $1.19 \mathrm{E}+05$ & $1.00 \mathrm{E}-02$ & $2.80 \mathrm{E}+01$ & 1 & $7.71 \mathrm{E}+01$ & $1.38 \mathrm{E}+07$ \\
\hline$P$ & $\mathrm{M}$ & ьррс8-02 & $2.02 \mathrm{E}+05$ & $5.07 \mathrm{E}+02$ & $4.64 \mathrm{E}+04$ & $2.20 \mathrm{E}-01$ & $3.00 \mathrm{E}+00$ & 1 & $29 \mathrm{E}+01$ & $2.91 \mathrm{E}+06$ \\
\hline $\mathrm{P}$ & $B$ & bppc8-02 & $E+05$ & $5.07 \mathrm{E}+02$ & $6.53 \mathrm{E}+04$ & $1.20 \mathrm{E}-01$ & $7.00 \mathrm{E}+00$ & 1 & $3.27 \mathrm{E}+01$ & $6.98 \mathrm{E}+06$ \\
\hline$D$ & $\mathrm{~B}$ & beasleyC1 & $4 \mathrm{E}+05$ & $8.50 \mathrm{E}+01$ & $1.94 \mathrm{E}+04$ & $6.00 \mathrm{E}-01$ & $8.00 \mathrm{E}+00$ & $\mathrm{I}$ & $5.26 \mathrm{E}+01$ & $1.17 \mathrm{E}+08$ \\
\hline A & $M$ & beasleyC1 & $1.75 \mathrm{E}+07$ & $8.50 \mathrm{E}+01$ & $1.18 \mathrm{E}+06$ & 3.80E-01 & $.00 \mathrm{E}+00$ & T & $3.60 \mathrm{E}+03$ & $9.72 \mathrm{E}+08$ \\
\hline D & $\mathrm{M}$ & beasleyC1 & $1.88 \mathrm{E}+05$ & $8.50 \mathrm{E}+01$ & $1.15 \mathrm{E}+04$ & $8.00 \mathrm{E}-01$ & $5.00 \mathrm{E}+00$ & 1 & $3.43 \mathrm{E}+01$ & $3.06 \mathrm{E}+07$ \\
\hline A & $B$ & beasley $\mathrm{C} 1$ & $9.76 \mathrm{E}+06$ & $8.80 \mathrm{E}+01$ & $6.35 \mathrm{E}+05$ & $7.20 \mathrm{E}+01$ & $3.00 \mathrm{E}+00$ & $\mathrm{~T}$ & $3.60 \mathrm{E}+03$ & $3.28 \mathrm{E}+09$ \\
\hline $\mathrm{L}$ & $\mathrm{M}$ & beasleyC1 & $1.84 \mathrm{E}+07$ & $8.50 \mathrm{E}+01$ & $1.23 \mathrm{E}+06$ & $1.69 E+00$ & $4.00 \mathrm{E}+00$ & $\mathrm{~T}$ & $3.60 \mathrm{E}+03$ & $6.09 \mathrm{E}+08$ \\
\hline $\mathrm{L}$ & $\mathrm{B}$ & beasleyC1 & $1.46 \mathrm{E}+07$ & $\mathrm{~N}$ & $1.50 \mathrm{E}+06$ & $0.00 \mathrm{E}+00$ & $0.00 \mathrm{E}+00$ & $\mathrm{~T}$ & $3.60 \mathrm{E}+03$ & $7.85 \mathrm{E}+08$ \\
\hline $\mathrm{P}$ & $\mathrm{M}$ & beasleyC1 & $1.29 \mathrm{E}+05$ & $8.50 \mathrm{E}+01$ & $7.60 \mathrm{E}+03$ & $1.87 \mathrm{E}+00$ & $3.00 \mathrm{E}+00$ & 1 & $1.96 \mathrm{E}+01$ & $2.78 \mathrm{E}+07$ \\
\hline $\mathrm{P}$ & $\mathrm{B}$ & beasleyC1 & $1.13 \mathrm{E}+06$ & $8.50 \mathrm{E}+01$ & $1.54 \mathrm{E}+05$ & $1.07 \mathrm{E}+02$ & $3.00 \mathrm{E}+00$ & 1 & $1.80 \mathrm{E}+02$ & $7.92 \mathrm{E}+07$ \\
\hline D & $\mathrm{B}$ & prod1 & $4.99 \mathrm{E}+06$ & $-5.60 \mathrm{E}+01$ & $5.76 \mathrm{E}+05$ & $2.06 \mathrm{E}+00$ & $3.00 \mathrm{E}+00$ & 1 & $1.84 \mathrm{E}+03$ & $1.10 \mathrm{E}+08$ \\
\hline A & $\mathrm{M}$ & od1 & $1 \mathrm{E}+07$ & $-5.60 \mathrm{E}+01$ & $2.15 \mathrm{E}+06$ & $1.00 \mathrm{E}-02$ & $6.00 \mathrm{E}+00$ & 1 & $6.89 \mathrm{E}+02$ & $3.88 \mathrm{E}+07$ \\
\hline D & $M$ & prod1 & $E+06$ & $-5.60 E+01$ & $5.58 \mathrm{E}+05$ & $1.50 \mathrm{E}+01$ & $00 \mathrm{E}+00$ & I & $5.12 \mathrm{E}+02$ & $3.89 \mathrm{E}+07$ \\
\hline A & $B$ & pr & $E+06$ & $-5.60 \mathrm{E}+01$ & $6.58 \mathrm{E}+05$ & $1.00 \mathrm{E}-02$ & $00 \mathrm{E}+00$ & T & $50 \mathrm{E}+03$ & $4.31 \mathrm{E}+08$ \\
\hline $\mathrm{L}$ & $M$ & prod1 & $9.81 \mathrm{E}+06$ & $-5.60 \mathrm{E}+01$ & $2.00 \mathrm{E}+06$ & $1.00 \mathrm{E}-02$ & $7.00 \mathrm{E}+00$ & 1 & $7.29 E+02$ & $5.63 \mathrm{E}+07$ \\
\hline L & $\mathrm{B}$ & prod1 & 4.67E+06 & $-5.60 \mathrm{E}+01$ & $6.45 \mathrm{E}+05$ & $1.00 \mathrm{E}-02$ & $8.00 \mathrm{E}+00$ & $\mathrm{~T}$ & $3.60 \mathrm{E}+03$ & $4.10 \mathrm{E}+08$ \\
\hline$P$ & $\mathrm{M}$ & prod1 & $6.07 \mathrm{E}+06$ & $-5.60 \mathrm{E}+01$ & $7.42 \mathrm{E}+05$ & $1.28 \mathrm{E}+01$ & $2.00 \mathrm{E}+00$ & 1 & $4.31 \mathrm{E}+02$ & $2.01 \mathrm{E}+07$ \\
\hline$P$ & $\mathrm{~B}$ & prod1 & $6 \mathrm{E}+06$ & $-5.60 E+01$ & $50 \mathrm{E}+05$ & $61 E+02$ & $.00 E+00$ & $T$ & +03 & $69 \mathrm{E}+08$ \\
\hline D & $\mathrm{B}$ & $\begin{array}{l}\text { neos- } \\
1396125\end{array}$ & $5 \mathrm{E}+07$ & $00 \mathrm{E}+03$ & $4.78 \mathrm{E}+05$ & $4.22 \mathrm{E}+02$ & $.00 \mathrm{E}+00$ & $\mathrm{~T}$ & $60 \mathrm{E}+03$ & $7.29 \mathrm{E}+08$ \\
\hline A & M & & -06 & $00 \mathrm{E}+03$ & $6.48 \mathrm{E}+04$ & & $00 \mathrm{E}+00$ & 1 & $30 \mathrm{E}+02$ & $.83 \mathrm{E}+07$ \\
\hline D & $\mathrm{M}$ & & +07 & $0 \mathrm{E}+03$ & $4.06 \mathrm{E}+05$ & $2.60 \mathrm{E}+03$ & $6.00 \mathrm{E}+00$ & $\mathrm{~T}$ & $3.60 \mathrm{E}+03$ & $6.65 \mathrm{E}+08$ \\
\hline A & $\mathrm{B}$ & & $4 \mathrm{E}+06$ & $3.00 \mathrm{E}+03$ & $1.00 \mathrm{E}+05$ & $8.23 \mathrm{E}+01$ & $1.20 \mathrm{E}+01$ & 1 & $3.93 E+02$ & $1.53 \mathrm{E}+08$ \\
\hline L & M & & $E+07$ & $\mathrm{OOE}+03$ & $6.98 \mathrm{E}+05$ & $1.92 \mathrm{E}+01$ & $00 \mathrm{E}+00$ & 1 & $02 E+03$ & $1.94 \mathrm{E}+08$ \\
\hline $\mathrm{L}$ & B & $\begin{array}{c}\text { neos- } \\
1396125 \\
\end{array}$ & $3 E+07$ & $00 \mathrm{E}+03$ & $5.16 \mathrm{E}+05$ & $2.05 E+02$ & $6.00 \mathrm{E}+00$ & $\mathrm{~T}$ & $3.60 \mathrm{E}+03$ & $8.73 \mathrm{E}+08$ \\
\hline $\mathrm{P}$ & $\mathrm{M}$ & $\begin{array}{l}\text { neos- } \\
1396125\end{array}$ & $2.55 \mathrm{E}+07$ & $3.00 \mathrm{E}+03$ & $7.10 \mathrm{E}+05$ & $8.18 \mathrm{E}+02$ & $3.00 \mathrm{E}+00$ & $\mathrm{~T}$ & $3.60 \mathrm{E}+03$ & $3.35 \mathrm{E}+08$ \\
\hline
\end{tabular}




\begin{tabular}{|c|c|c|c|c|c|c|c|c|c|c|}
\hline VDS & NS & model & $\begin{array}{r}\text { simplex } \\
\text { it. }\end{array}$ & incu. Sol. & nodes & $\begin{array}{r}\text { 1st fea. } \\
\text { Time }\end{array}$ & $\begin{array}{r}\text { fea. } \\
\text { nodes }\end{array}$ & $\begin{array}{l}\text { exit } \\
\text { code }\end{array}$ & time & memory \\
\hline $\mathrm{P}$ & $\mathrm{B}$ & $\begin{array}{l}\text { neos- } \\
1396125\end{array}$ & $2.23 \mathrm{E}+07$ & $3.80 \mathrm{E}+03$ & $8.35 E+05$ & $7.30 \mathrm{E}+02$ & $5.00 \mathrm{E}+00$ & $\mathrm{~T}$ & $3.60 \mathrm{E}+03$ & $9.54 \mathrm{E}+08$ \\
\hline $\mathrm{D}$ & $\mathrm{B}$ & $\begin{array}{l}\text { neos- } \\
4333596- \\
\text { skien } \\
\end{array}$ & $1.89 \mathrm{E}+06$ & $-1.46 \mathrm{E}+07$ & $1.39 \mathrm{E}+05$ & $9.80 \mathrm{E}-01$ & $1.10 \mathrm{E}+01$ & 1 & $3.23 E+02$ & $1.33 \mathrm{E}+08$ \\
\hline A & $M$ & \multicolumn{2}{|c|}{ neos-4333596-skien } & & & & & $\mathrm{F}$ & & \\
\hline D & $\mathrm{M}$ & $\begin{array}{l}\text { neos- } \\
4333596- \\
\text { skien }\end{array}$ & $1.83 \mathrm{E}+06$ & $-1.46 \mathrm{E}+07$ & $1.31 \mathrm{E}+05$ & $9.10 \mathrm{E}-01$ & $7.00 \mathrm{E}+00$ & 1 & $2.87 \mathrm{E}+02$ & $1.71 \mathrm{E}+07$ \\
\hline $\mathrm{A}$ & $\mathrm{B}$ & $\begin{array}{l}\text { neos- } \\
4333596- \\
\text { skien }\end{array}$ & $3.94 \mathrm{E}+06$ & $\mathrm{~N}$ & $5.54 \mathrm{E}+05$ & $0.00 \mathrm{E}+00$ & $0.00 E+00$ & $\mathrm{~T}$ & $3.60 E+03$ & $2.93 E+08$ \\
\hline $\mathrm{L}$ & $M$ & $\begin{array}{l}\text { neos- } \\
4333596- \\
\text { skien }\end{array}$ & $3.08 \mathrm{E}+07$ & $\mathrm{~N}$ & $3.54 \mathrm{E}+06$ & $0.00 E+00$ & $0.00 E+00$ & $\mathrm{~T}$ & $3.60 \mathrm{E}+03$ & $3.31 E+07$ \\
\hline $\mathrm{L}$ & $\mathrm{B}$ & $\begin{array}{l}\text { neos- } \\
4333596- \\
\text { skien }\end{array}$ & $5.73 E+06$ & $\mathrm{~N}$ & $7.76 \mathrm{E}+05$ & $0.00 \mathrm{E}+00$ & $0.00 \mathrm{E}+00$ & $\mathrm{~T}$ & $3.60 \mathrm{E}+03$ & $2.97 \mathrm{E}+08$ \\
\hline $\mathrm{P}$ & $M$ & \multicolumn{2}{|c|}{ neos-4333596-skien } & & & & & $\mathrm{F}$ & & \\
\hline $\mathrm{P}$ & $\mathrm{B}$ & $\begin{array}{l}\text { neos- } \\
4333596- \\
\text { skien }\end{array}$ & $5.24 \mathrm{E}+06$ & $\mathrm{~N}$ & $8.89 E+05$ & $0.00 \mathrm{E}+00$ & $0.00 \mathrm{E}+00$ & $\mathrm{~T}$ & $3.60 \mathrm{E}+03$ & $2.96 \mathrm{E}+08$ \\
\hline $\mathrm{D}$ & $\mathrm{B}$ & dsbmip & $3.17 E+03$ & $-3.05 E+02$ & $2.91 \mathrm{E}+02$ & 1.50E-01 & $6.00 \mathrm{E}+00$ & $\mathrm{I}$ & $6.00 \mathrm{E}-01$ & $3.34 \mathrm{E}+06$ \\
\hline $\mathrm{A}$ & $M$ & dsbmip & $8.41 \mathrm{E}+02$ & $-3.05 E+02$ & $6.10 \mathrm{E}+01$ & $5.00 \mathrm{E}-02$ & $1.00 \mathrm{E}+00$ & I & $1.00 \mathrm{E}-01$ & $3.06 \mathrm{E}+06$ \\
\hline $\mathrm{D}$ & $\mathrm{M}$ & dsbmip & $3.69 \mathrm{E}+03$ & $-3.05 E+02$ & $2.69 \mathrm{E}+02$ & 4.90E-01 & $1.00 \mathrm{E}+00$ & I & $5.00 \mathrm{E}-01$ & $3.24 \mathrm{E}+06$ \\
\hline A & $\mathrm{B}$ & dsbmip & $8.68 \mathrm{E}+02$ & $-3.05 E+02$ & $6.70 \mathrm{E}+01$ & 4.00E-02 & $2.00 \mathrm{E}+00$ & $\mathrm{I}$ & $1.00 \mathrm{E}-01$ & $3.08 \mathrm{E}+06$ \\
\hline $\mathrm{L}$ & $\mathrm{M}$ & dsbmip & $4.04 \mathrm{E}+03$ & $-3.05 E+02$ & $2.83 \mathrm{E}+02$ & $3.60 \mathrm{E}-01$ & $1.00 \mathrm{E}+00$ & $\mathrm{~F}$ & & \\
\hline $\mathrm{L}$ & $\mathrm{B}$ & dsbmip & $3.81 \mathrm{E}+03$ & $-3.05 E+02$ & $3.31 \mathrm{E}+02$ & 3.60E-01 & $1.00 \mathrm{E}+00$ & 1 & 4.00E-01 & $3.46 \mathrm{E}+06$ \\
\hline $\mathrm{P}$ & $M$ & dsbmip & $1.11 \mathrm{E}+03$ & $-3.05 E+02$ & $8.90 \mathrm{E}+01$ & 3.60E-01 & $1.00 \mathrm{E}+00$ & 1 & $4.00 \mathrm{E}-01$ & $4.26 \mathrm{E}+06$ \\
\hline $\mathrm{P}$ & $\mathrm{B}$ & dsbmip & $1.29 \mathrm{E}+03$ & $-3.05 E+02$ & $1.15 \mathrm{E}+02$ & 3.70E-01 & $2.00 \mathrm{E}+00$ & 1 & $4.00 \mathrm{E}-01$ & $4.28 \mathrm{E}+06$ \\
\hline $\mathrm{D}$ & $\mathrm{B}$ & mcsched & $4.06 \mathrm{E}+06$ & $2.12 E+05$ & $1.49 \mathrm{E}+05$ & $2.67 E+00$ & $1.50 \mathrm{E}+01$ & $\mathrm{~T}$ & $3.60 \mathrm{E}+03$ & $1.70 \mathrm{E}+08$ \\
\hline A & $\mathrm{M}$ & mcsched & $4.57 \mathrm{E}+05$ & $2.12 \mathrm{E}+05$ & $1.09 \mathrm{E}+04$ & 7.50E-01 & $4.00 \mathrm{E}+00$ & 1 & $6.18 \mathrm{E}+01$ & $1.52 \mathrm{E}+07$ \\
\hline $\mathrm{D}$ & $\mathrm{M}$ & mcsched & $4.33 E+06$ & $2.12 \mathrm{E}+05$ & $1.58 \mathrm{E}+05$ & $3.18 \mathrm{E}+00$ & $6.00 \mathrm{E}+00$ & $\mathrm{~T}$ & $3.60 \mathrm{E}+03$ & $1.94 \mathrm{E}+08$ \\
\hline $\mathrm{A}$ & $\mathrm{B}$ & mcsched & $4.57 \mathrm{E}+05$ & $2.12 E+05$ & $1.08 \mathrm{E}+04$ & $1.30 \mathrm{E}-01$ & $4.00 \mathrm{E}+00$ & 1 & $6.16 \mathrm{E}+01$ & $2.20 \mathrm{E}+07$ \\
\hline $\mathrm{L}$ & $\mathrm{M}$ & mcsched & $1.80 \mathrm{E}+07$ & $2.12 \mathrm{E}+05$ & $4.22 \mathrm{E}+05$ & $2.84 \mathrm{E}+00$ & $7.00 \mathrm{E}+00$ & $\mathrm{~T}$ & $3.60 \mathrm{E}+03$ & $7.14 \mathrm{E}+08$ \\
\hline $\mathrm{L}$ & $\mathrm{B}$ & mcsched & $2.04 \mathrm{E}+07$ & $2.13 E+05$ & $4.08 \mathrm{E}+05$ & 1.40E-01 & $6.00 \mathrm{E}+00$ & $\mathrm{~T}$ & $3.60 \mathrm{E}+03$ & $9.24 \mathrm{E}+08$ \\
\hline $\mathrm{P}$ & $\mathrm{M}$ & mcsched & $9.78 \mathrm{E}+06$ & $2.12 E+05$ & $3.24 \mathrm{E}+05$ & $1.61 \mathrm{E}+01$ & $6.00 \mathrm{E}+00$ & 1 & $1.96 \mathrm{E}+03$ & $2.16 \mathrm{E}+08$ \\
\hline$P$ & B & mcsched & $1.02 \mathrm{E}+07$ & $2.12 \mathrm{E}+05$ & $4.26 \mathrm{E}+05$ & $1.56 \mathrm{E}+01$ & $9.00 E+00$ & $\mathrm{~T}$ & $3.60 E+03$ & $4.00 E+08$ \\
\hline D & $\mathrm{B}$ & $\begin{array}{l}\text { pp08aCUT } \\
\text { S }\end{array}$ & $3.09 E+06$ & $7.44 \mathrm{E}+03$ & $1.19 \mathrm{E}+06$ & $3.00 \mathrm{E}-02$ & $9.00 E+00$ & $T$ & $3.60 \mathrm{E}+03$ & $1.16 \mathrm{E}+09$ \\
\hline A & $\mathrm{M}$ & $\begin{array}{l}\text { pp08aCUT } \\
\mathrm{S}\end{array}$ & $5.62 \mathrm{E}+07$ & $7.40 \mathrm{E}+03$ & $1.04 \mathrm{E}+07$ & $3.60 \mathrm{E}-01$ & $1.80 \mathrm{E}+01$ & $\mathrm{~T}$ & $3.60 E+03$ & $6.89 E+07$ \\
\hline $\mathrm{D}$ & $\mathrm{M}$ & $\begin{array}{l}\text { pp08aCUT } \\
\mathrm{S}\end{array}$ & $2.58 \mathrm{E}+07$ & $7.35 E+03$ & $4.42 E+06$ & $1.80 \mathrm{E}-01$ & $8.00 E+00$ & 1 & $2.92 \mathrm{E}+03$ & $6.31 E+07$ \\
\hline A & B & $\begin{array}{l}\text { pp08aCUT } \\
\mathrm{S}\end{array}$ & $5.02 E+06$ & $8.12 \mathrm{E}+03$ & $1.35 \mathrm{E}+06$ & $1.00 \mathrm{E}-02$ & $1.20 \mathrm{E}+01$ & T & $3.60 \mathrm{E}+03$ & $2.70 \mathrm{E}+09$ \\
\hline $\mathrm{L}$ & $M$ & $\begin{array}{l}\text { pp08aCUT } \\
\text { S }\end{array}$ & $5.51 \mathrm{E}+07$ & $7.43 E+03$ & $1.02 \mathrm{E}+07$ & $4.30 E+00$ & $5.00 E+00$ & $T$ & $3.60 E+03$ & $2.48 \mathrm{E}+07$ \\
\hline
\end{tabular}




\begin{tabular}{|c|c|c|c|c|c|c|c|c|c|c|}
\hline VDS & NS & model & $\begin{array}{r}\text { mplex } \\
\text { it. }\end{array}$ & cu. Sol. & nodes & $\begin{array}{r}\text { st fea. } \\
\text { Time }\end{array}$ & $\begin{array}{r}\text { fea. } \\
\text { nodes }\end{array}$ & $\begin{array}{l}\text { exit } \\
\text { code }\end{array}$ & time & memory \\
\hline $\mathrm{L}$ & B & & $9 \mathrm{E}+06$ & $27 \mathrm{E}+03$ & $68 \mathrm{E}+06$ & $2.78 \mathrm{E}+01$ & $00 \mathrm{E}+00$ & $\mathrm{~T}$ & $60 \mathrm{E}+03$ & $.20 \mathrm{E}+09$ \\
\hline $\mathrm{P}$ & $\mathrm{M}$ & & +07 & $5 E+03$ & $8 E+06$ & $0 \mathrm{E}-01$ & $00 \mathrm{E}+00$ & 1 & $2.22 \mathrm{E}+03$ & $5.46 \mathrm{E}+07$ \\
\hline $\mathrm{P}$ & B & $\begin{array}{l}\text { pp08aCUT } \\
\mathrm{S}\end{array}$ & $E+06$ & $\mathrm{E}+03$ & $1.18 \mathrm{E}+06$ & $0 \mathrm{E}-02$ & $1.00 \mathrm{E}+01$ & $\mathrm{~T}$ & $\mathrm{O} \mathrm{E}+03$ & $1.44 \mathrm{E}+09$ \\
\hline D & B & vpm2 & $1.83 \mathrm{E}+06$ & $1.38 \mathrm{E}+01$ & $8.29 \mathrm{E}+05$ & $9.00 \mathrm{E}-02$ & $1.00 \mathrm{E}+01$ & $\mathrm{~T}$ & $3.60 \mathrm{E}+03$ & $5.15 \mathrm{E}+08$ \\
\hline A & $M$ & vpm2 & $5.18 \mathrm{E}+07$ & $1.45 \mathrm{E}+01$ & $1.54 \mathrm{E}+07$ & 3.60E-01 & $5.00 \mathrm{E}+00$ & $\mathrm{~T}$ & $3.60 \mathrm{E}+03$ & $2.66 \mathrm{E}+07$ \\
\hline $\mathrm{D}$ & $M$ & vpm2 & $4.85 \mathrm{E}+06$ & $1.38 \mathrm{E}+01$ & $1.31 \mathrm{E}+06$ & 4.90E-01 & $3.00 \mathrm{E}+00$ & 1 & $5.01 \mathrm{E}+02$ & $1.96 \mathrm{E}+07$ \\
\hline A & B & vpm2 & $2.41 \mathrm{E}+06$ & $1.45 \mathrm{E}+01$ & $1.30 \mathrm{E}+06$ & $1.00 \mathrm{E}-02$ & $1.40 \mathrm{E}+01$ & $\mathrm{~T}$ & $3.60 \mathrm{E}+03$ & $6.83 \mathrm{E}+08$ \\
\hline $\mathrm{L}$ & $\mathrm{M}$ & vpm2 & $\mathrm{E}+07$ & $1.38 \mathrm{E}+01$ & $3.82 \mathrm{E}+06$ & 4.00E-02 & $4.00 \mathrm{E}+00$ & 1 & $8.66 \mathrm{E}+02$ & $2.42 \mathrm{E}+07$ \\
\hline $\mathrm{L}$ & B & vpm2 & $4 \mathrm{E}+06$ & $\mathrm{~N}$ & $1.29 \mathrm{E}+06$ & $0.00 \mathrm{E}+00$ & $0.00 \mathrm{E}+00$ & $\mathrm{~T}$ & $3.60 \mathrm{E}+03$ & $3.85 \mathrm{E}+08$ \\
\hline$P$ & $\mathrm{M}$ & vpm2 & $E+06$ & $E+01$ & $6.47 \mathrm{E}+05$ & $4.00 \mathrm{E}-02$ & $4.00 \mathrm{E}+00$ & 1 & $1.51 \mathrm{E}+02$ & $2.73 \mathrm{E}+07$ \\
\hline $\mathrm{P}$ & B & vpm2 & $1.94 \mathrm{E}+06$ & $1.38 \mathrm{E}+01$ & $5.61 \mathrm{E}+05$ & $3.50 \mathrm{E}-01$ & $7.00 \mathrm{E}+00$ & T & $3.60 \mathrm{E}+03$ & $4.46 \mathrm{E}+08$ \\
\hline $\mathrm{D}$ & B & fixnet6 & $3.66 \mathrm{E}+04$ & $3.98 \mathrm{E}+03$ & $3.61 \mathrm{E}+03$ & $7.00 \mathrm{E}-02$ & $9.00 \mathrm{E}+00$ & 1 & $2.70 \mathrm{E}+00$ & $5.35 \mathrm{E}+06$ \\
\hline A & $M$ & fixnet6 & $6.29 \mathrm{E}+03$ & $3.98 \mathrm{E}+03$ & $8.97 \mathrm{E}+02$ & $1.00 \mathrm{E}-02$ & $5.00 \mathrm{E}+00$ & 1 & $5.00 \mathrm{E}-01$ & $2.31 \mathrm{E}+06$ \\
\hline $\mathrm{D}$ & $\mathrm{M}$ & fixnet6 & $2.81 \mathrm{E}+04$ & $3.98 \mathrm{E}+03$ & $2.68 \mathrm{E}+03$ & $6.00 \mathrm{E}-02$ & $1.10 \mathrm{E}+01$ & 1 & $2.20 \mathrm{E}+00$ & $2.53 \mathrm{E}+06$ \\
\hline $\mathrm{A}$ & B & fixnet6 & $1.22 \mathrm{E}+04$ & $3.98 \mathrm{E}+03$ & $1.94 \mathrm{E}+03$ & $1.00 \mathrm{E}-02$ & $1.20 \mathrm{E}+01$ & 1 & $1.10 \mathrm{E}+00$ & $3.83 \mathrm{E}+06$ \\
\hline $\mathrm{L}$ & $\mathrm{M}$ & et6 & $51 \mathrm{E}+03$ & $3.98 \mathrm{E}+03$ & $1.31 \mathrm{E}+03$ & $1.30 \mathrm{E}-01$ & $5.00 \mathrm{E}+00$ & 1 & OOE-01 & $2.52 \mathrm{E}+06$ \\
\hline L & B & fix & $2.55 \mathrm{E}+04$ & $3.98 \mathrm{E}+03$ & $4.64 \mathrm{E}+03$ & 70E-01 & $4.00 \mathrm{E}+00$ & 1 & $1.90 \mathrm{E}+00$ & $5.02 \mathrm{E}+06$ \\
\hline$P$ & $M$ & & $2 E+03$ & $3.98 \mathrm{E}+03$ & $4.71 \mathrm{E}+02$ & 02 & $3.00 \mathrm{E}+00$ & 1 & -01 & $1.93 \mathrm{E}+06$ \\
\hline $\mathrm{P}$ & B & fixnet6 & $6.87 \mathrm{E}+03$ & $3.98 \mathrm{E}+03$ & $6.89 \mathrm{E}+02$ & $9.00 \mathrm{E}-02$ & $5.00 \mathrm{E}+00$ & 1 & OOE-01 & $2.98 \mathrm{E}+06$ \\
\hline D & B & fiber & $3.94 \mathrm{E}+05$ & $4.06 \mathrm{E}+05$ & $5.31 \mathrm{E}+04$ & 40E-01 & $5.00 \mathrm{E}+00$ & - & $6.71 \mathrm{E}+01$ & $6.62 \mathrm{E}+07$ \\
\hline A & $\mathrm{M}$ & fiber & $2.01 \mathrm{E}+07$ & 4.17E+05 & $3.85 \mathrm{E}+06$ & $1.19 \mathrm{E}+01$ & $3.60 \mathrm{E}+01$ & T & $3.60 \mathrm{E}+03$ & $1.52 \mathrm{E}+07$ \\
\hline D & $M$ & fiber & $4.18 \mathrm{E}+05$ & $4.06 \mathrm{E}+05$ & $5.39 \mathrm{E}+04$ & $1.40 \mathrm{E}-01$ & $6.00 \mathrm{E}+00$ & 1 & $6.36 \mathrm{E}+01$ & $1.76 \mathrm{E}+07$ \\
\hline A & B & fiber & $6.70 \mathrm{E}+06$ & $1.06 \mathrm{E}+06$ & $1.24 \mathrm{E}+06$ & $2.00 \mathrm{E}-02$ & $2.80 \mathrm{E}+01$ & $\mathrm{~T}$ & $3.60 \mathrm{E}+03$ & $5.98 \mathrm{E}+08$ \\
\hline $\mathrm{L}$ & $M$ & fiber & $2.05 \mathrm{E}+07$ & $4.18 \mathrm{E}+05$ & $4.05 E+06$ & $4.82 \mathrm{E}+01$ & $5.00 \mathrm{E}+00$ & $\mathrm{~T}$ & $3.60 \mathrm{E}+03$ & $2.51 \mathrm{E}+07$ \\
\hline $\mathrm{L}$ & B & fiber & $4.65 \mathrm{E}+06$ & $5.54 \mathrm{E}+05$ & $1.92 \mathrm{E}+06$ & $5.00 \mathrm{E}-02$ & $3.00 \mathrm{E}+00$ & $\mathrm{~T}$ & $3.60 \mathrm{E}+03$ & $9.40 \mathrm{E}+08$ \\
\hline$P$ & $\mathrm{M}$ & fiber & $1.58 \mathrm{E}+05$ & $4.06 \mathrm{E}+05$ & $1.99 \mathrm{E}+04$ & $2.22 \mathrm{E}+00$ & $1.60 \mathrm{E}+01$ & 1 & $1.46 \mathrm{E}+01$ & $1.81 \mathrm{E}+07$ \\
\hline$P$ & $\mathrm{~B}$ & fib & $2.23 \mathrm{E}+05$ & $4.06 \mathrm{E}+05$ & $3.47 \mathrm{E}+04$ & $6.27 \mathrm{E}+00$ & $3.00 \mathrm{E}+00$ & 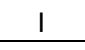 & $26 \mathrm{E}+01$ & $5.16 \mathrm{E}+07$ \\
\hline D & B & & $7 \mathrm{E}+02$ & $1.20 \mathrm{E}+06$ & $3.85 \mathrm{E}+02$ & OOE-02 & $1.00 \mathrm{E}+00$ & 1 & $0.00 \mathrm{E}+00$ & 1. $30 \mathrm{E}+05$ \\
\hline A & $\mathrm{M}$ & flugpl & $1.67 \mathrm{E}+02$ & $1.20 \mathrm{E}+06$ & $2.59 \mathrm{E}+02$ & $0.00 \mathrm{E}+00$ & $5.00 \mathrm{E}+00$ & 1 & $0.00 \mathrm{E}+00$ & $8.66 \mathrm{E}+04$ \\
\hline D & M & flugpl & $2.72 \mathrm{E}+02$ & $1.20 \mathrm{E}+06$ & $4.43 \mathrm{E}+02$ & $1.00 \mathrm{E}-02$ & $2.00 \mathrm{E}+00$ & 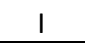 & $0.00 \mathrm{E}+00$ & $8.74 E+04$ \\
\hline A & $\mathrm{B}$ & flugpl & $1.71 \mathrm{E}+02$ & $1.20 \mathrm{E}+06$ & $2.51 \mathrm{E}+02$ & $0.00 \mathrm{E}+00$ & $2.00 \mathrm{E}+00$ & 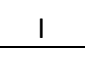 & $0.00 \mathrm{E}+00$ & $1.04 \mathrm{E}+05$ \\
\hline $\mathrm{L}$ & $M$ & flugpl & $2.77 \mathrm{E}+02$ & $1.20 \mathrm{E}+06$ & 4.17E+02 & $0.00 \mathrm{E}+00$ & $3.00 \mathrm{E}+00$ & 1 & $0.00 \mathrm{E}+00$ & $9.67 E+04$ \\
\hline $\mathrm{L}$ & B & flugpl & $2.78 \mathrm{E}+02$ & $1.20 \mathrm{E}+06$ & $4.43 \mathrm{E}+02$ & $1.00 \mathrm{E}-02$ & $2.00 \mathrm{E}+00$ & 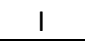 & $0.00 \mathrm{E}+00$ & $1.39 \mathrm{E}+05$ \\
\hline $\mathrm{P}$ & $\mathrm{M}$ & flugpl & $1.86 \mathrm{E}+02$ & $1.20 \mathrm{E}+06$ & $3.65 \mathrm{E}+02$ & $1.00 \mathrm{E}-02$ & $4.00 \mathrm{E}+00$ & 1 & $0.00 \mathrm{E}+00$ & $9.61 E+04$ \\
\hline $\mathrm{P}$ & B & flugpl & $2.37 E+02$ & $1.20 \mathrm{E}+06$ & $3.51 \mathrm{E}+02$ & $1.00 \mathrm{E}-02$ & $6.00 \mathrm{E}+00$ & 1 & $0.00 \mathrm{E}+00$ & $1.39 \mathrm{E}+05$ \\
\hline D & $\mathrm{B}$ & $\operatorname{gr} 4 \times 6$ & $2.18 \mathrm{E}+02$ & $2.02 \mathrm{E}+02$ & $9.10 \mathrm{E}+01$ & $0.00 \mathrm{E}+00$ & $4.00 \mathrm{E}+00$ & 1 & $0.00 \mathrm{E}+00$ & $1.10 \mathrm{E}+05$ \\
\hline A & $M$ & $\operatorname{gr} 4 \times 6$ & $1.67 \mathrm{E}+02$ & $2.02 \mathrm{E}+02$ & $5.30 \mathrm{E}+01$ & $0.00 \mathrm{E}+00$ & $4.00 \mathrm{E}+00$ & 1 & $0.00 \mathrm{E}+00$ & $1.02 \mathrm{E}+05$ \\
\hline D & $\mathrm{M}$ & $\operatorname{gr} 4 \times 6$ & $1.67 \mathrm{E}+02$ & $2.02 \mathrm{E}+02$ & $4.90 \mathrm{E}+01$ & $0.00 \mathrm{E}+00$ & $3.00 \mathrm{E}+00$ & 1 & $0.00 \mathrm{E}+00$ & $1.02 \mathrm{E}+05$ \\
\hline
\end{tabular}




\begin{tabular}{|c|c|c|c|c|c|c|c|c|c|c|}
\hline VDS & NS & model & $\begin{array}{r}\text { implex } \\
\text { it. }\end{array}$ & incu. Sol. & nodes & $\begin{array}{r}\text { 1st fea. } \\
\text { Time }\end{array}$ & $\begin{array}{r}\text { fea. } \\
\text { nodes }\end{array}$ & $\begin{array}{l}\text { exit } \\
\text { code }\end{array}$ & time & memory \\
\hline A & $\mathrm{B}$ & $r 4 \times 6$ & $1.63 \mathrm{E}+02$ & $2.02 E+02$ & $5.10 \mathrm{E}+01$ & $0.00 \mathrm{E}+00$ & $3.00 \mathrm{E}+00$ & 1 & $0.00 \mathrm{E}+00$ & $1.02 \mathrm{E}+05$ \\
\hline $\mathrm{L}$ & $\mathrm{M}$ & $\operatorname{gr} 4 \times 6$ & $=02$ & $2 E+02$ & $5.10 \mathrm{E}+01$ & $0.00 \mathrm{E}+00$ & $0 \mathrm{EE}+00$ & 1 & $00 E+00$ & $9.38 \mathrm{E}+04$ \\
\hline $\mathrm{L}$ & $\mathrm{B}$ & $\operatorname{gr} 4 \times 6$ & $\mathrm{E}+02$ & $2.02 E+02$ & $4.90 \mathrm{E}+01$ & $0.00 \mathrm{E}+00$ & $5.00 \mathrm{E}+00$ & I & $0.00 \mathrm{E}+00$ & $1.02 \mathrm{E}+05$ \\
\hline$P$ & $M$ & $\operatorname{gr} 4 \times 6$ & $1.80 \mathrm{E}+02$ & $2.02 E+02$ & $4.10 \mathrm{E}+01$ & $0.00 \mathrm{E}+00$ & $1.00 \mathrm{E}+00$ & 1 & $0.00 \mathrm{E}+00$ & $1.28 \mathrm{E}+05$ \\
\hline $\mathrm{P}$ & $\mathrm{B}$ & $\operatorname{gr} 4 \times 6$ & $1.80 \mathrm{E}+02$ & $2.02 E+02$ & $4.10 \mathrm{E}+01$ & $0.00 \mathrm{E}+00$ & $1.00 \mathrm{E}+00$ & 1 & $0.00 \mathrm{E}+00$ & $1.28 \mathrm{E}+05$ \\
\hline D & $\mathrm{B}$ & |152lav & $2.29 \mathrm{E}+04$ & $4.72 E+03$ & $2.22 \mathrm{E}+03$ & 4.00E-01 & $1.00 \mathrm{E}+00$ & 1 & $6.80 \mathrm{E}+00$ & $6.31 \mathrm{E}+06$ \\
\hline $\mathrm{A}$ & $M$ & I152lav & $2.63 \mathrm{E}+04$ & $4.72 \mathrm{E}+03$ & $3.14 \mathrm{E}+03$ & $3.00 \mathrm{E}-02$ & $2.00 \mathrm{E}+00$ & 1 & $3.60 \mathrm{E}+00$ & $4.64 \mathrm{E}+06$ \\
\hline $\mathrm{D}$ & $M$ & I152lav & $1.92 \mathrm{E}+04$ & $4.72 \mathrm{E}+03$ & $1.80 \mathrm{E}+03$ & $1.66 \mathrm{E}+00$ & $1.00 \mathrm{E}+00$ & 1 & $5.50 \mathrm{E}+00$ & $4.73 \mathrm{E}+06$ \\
\hline $\mathrm{A}$ & $\mathrm{B}$ & I152lav & $2.61 \mathrm{E}+04$ & $4.72 \mathrm{E}+03$ & $3.03 E+03$ & $1.00 \mathrm{E}-02$ & $3.00 \mathrm{E}+00$ & 1 & $3.50 \mathrm{E}+00$ & $5.66 \mathrm{E}+06$ \\
\hline $\mathrm{L}$ & $\mathrm{M}$ & |152lav & $6.26 \mathrm{E}+04$ & $4.72 \mathrm{E}+03$ & $7.43 \mathrm{E}+03$ & $4.00 \mathrm{E}-02$ & $8.00 \mathrm{E}+00$ & 1 & $1.10 \mathrm{E}+01$ & $8.10 \mathrm{E}+06$ \\
\hline $\mathrm{L}$ & $\mathrm{B}$ & I152lav & $4.21 \mathrm{E}+04$ & $4.72 \mathrm{E}+03$ & $4.52 \mathrm{E}+03$ & $7.00 \mathrm{E}-02$ & $3.00 \mathrm{E}+00$ & 1 & $7.10 \mathrm{E}+00$ & $1.07 \mathrm{E}+07$ \\
\hline$P$ & $\mathrm{M}$ & I152lav & 3.33E+04 & $4.72 \mathrm{E}+03$ & $3.74 \mathrm{E}+03$ & $1.62 \mathrm{E}+00$ & $5.00 \mathrm{E}+00$ & 1 & $5.90 \mathrm{E}+00$ & $6.70 \mathrm{E}+06$ \\
\hline $\mathrm{P}$ & $\mathrm{B}$ & I152lav & $8.70 \mathrm{E}+04$ & $4.72 E+03$ & $1.29 \mathrm{E}+04$ & $2.60 \mathrm{E}+00$ & $2.00 \mathrm{E}+00$ & 1 & $1.63 \mathrm{E}+01$ & $1.66 \mathrm{E}+07$ \\
\hline D & $\mathrm{B}$ & Iseu & 1.62E+04 & $1.12 \mathrm{E}+03$ & $6.47 \mathrm{E}+03$ & $1.20 \mathrm{E}-01$ & $2.00 \mathrm{E}+00$ & 1 & 00E-01 & $1.71 \mathrm{E}+06$ \\
\hline $\mathrm{A}$ & $M$ & Iseu & $1.68 \mathrm{E}+04$ & $1.12 \mathrm{E}+03$ & $8.16 \mathrm{E}+03$ & $E-01$ & $1.00 \mathrm{E}+00$ & 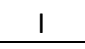 & $E-01$ & $6.32 \mathrm{E}+05$ \\
\hline D & $\mathrm{M}$ & Iseu & $1.76 \mathrm{E}+04$ & $1.12 \mathrm{E}+03$ & $6.89 \mathrm{E}+03$ & $2.00 \mathrm{E}-01$ & $3.00 \mathrm{E}+00$ & I & OOE-01 & $9.10 \mathrm{E}+05$ \\
\hline $\mathrm{A}$ & $\mathrm{B}$ & Iseu & $1.81 \mathrm{E}+04$ & $1.12 \mathrm{E}+03$ & $8.75 E+03$ & 3.30E-01 & $1.00 \mathrm{E}+00$ & 1 & $6.00 \mathrm{E}-01$ & $2.79 \mathrm{E}+06$ \\
\hline $\mathrm{L}$ & $\mathrm{M}$ & Iseu & $2.24 \mathrm{E}+04$ & $1.12 \mathrm{E}+03$ & $1.04 \mathrm{E}+04$ & $3.20 \mathrm{E}-01$ & $1.00 \mathrm{E}+00$ & 1 & $7.00 \mathrm{E}-01$ & $6.58 \mathrm{E}+05$ \\
\hline L & $\mathrm{B}$ & Iseu & $2.31 \mathrm{E}+04$ & $1.12 \mathrm{E}+03$ & $1.08 \mathrm{E}+04$ & $6.50 \mathrm{E}-01$ & $1.00 \mathrm{E}+00$ & 1 & $9.00 \mathrm{E}-01$ & $3.17 E+06$ \\
\hline $\mathrm{P}$ & $M$ & Iseu & $2.16 \mathrm{E}+04$ & $1.12 \mathrm{E}+03$ & $9.80 \mathrm{E}+03$ & $3.00 \mathrm{E}-02$ & $3.00 \mathrm{E}+00$ & 1 & $6.00 \mathrm{E}-01$ & $1.07 \mathrm{E}+06$ \\
\hline $\mathrm{P}$ & $\mathrm{B}$ & Iseu & $2.89 \mathrm{E}+04$ & $1.12 \mathrm{E}+03$ & $1.33 E+04$ & $5.00 \mathrm{E}-02$ & $1.00 \mathrm{E}+00$ & 1 & $1.10 \mathrm{E}+00$ & $3.31 \mathrm{E}+06$ \\
\hline D & $\mathrm{B}$ & misc03 & $\mathrm{BE}+03$ & $3.36 \mathrm{E}+03$ & $8.93 \mathrm{E}+02$ & $.00 \mathrm{E}-02$ & $1.00 \mathrm{E}+00$ & 1 & OOE-01 & $9.33 \mathrm{E}+05$ \\
\hline A & $\mathrm{M}$ & misc03 & $5.28 \mathrm{E}+03$ & $3.36 \mathrm{E}+03$ & $5.97 \mathrm{E}+02$ & $0.00 \mathrm{E}+00$ & $0.00 \mathrm{E}+00$ & 1 & OOE-01 & $5.98 \mathrm{E}+05$ \\
\hline D & $M$ & 3 & $E+03$ & $3.36 \mathrm{E}+03$ & $8.65 \mathrm{E}+02$ & -00 & $0.00 \mathrm{E}+00$ & $i_{-}$ & E-01 & $7.16 \mathrm{E}+05$ \\
\hline $\mathrm{A}$ & $\mathrm{B}$ & misc03 & $8 \mathrm{E}+03$ & $3.36 \mathrm{E}+03$ & $5.45 E+02$ & $2.00 \mathrm{E}-02$ & $1.00 \mathrm{E}+00$ & I & $0 \mathrm{E}-01$ & $8.05 \mathrm{E}+05$ \\
\hline $\mathrm{L}$ & $M$ & misc03 & $6.08 \mathrm{E}+03$ & $3.36 \mathrm{E}+03$ & $8.17 \mathrm{E}+02$ & $0.00 \mathrm{E}+00$ & $.00 \mathrm{E}+00$ & 1 & -01 & $6.47 \mathrm{E}+05$ \\
\hline $\mathrm{L}$ & $\mathrm{B}$ & misc03 & $6.08 \mathrm{E}+03$ & $3.36 \mathrm{E}+03$ & $8.17 E+02$ & $0.00 \mathrm{E}+00$ & $0.00 \mathrm{E}+00$ & 1 & $.00 \mathrm{E}-01$ & $8.72 \mathrm{E}+05$ \\
\hline $\mathrm{P}$ & $\mathrm{M}$ & misc03 & 7.37E+03 & $3.36 \mathrm{E}+03$ & $1.02 \mathrm{E}+03$ & $0.00 \mathrm{E}+00$ & $0.00 \mathrm{E}+00$ & I & $3.00 \mathrm{E}-01$ & $1.08 \mathrm{E}+06$ \\
\hline$P$ & $\mathrm{~B}$ & misc03 & $7.54 \mathrm{E}+03$ & $3.36 \mathrm{E}+03$ & $1.04 \mathrm{E}+03$ & $0.00 \mathrm{E}+00$ & $0.00 \mathrm{E}+00$ & 1 & $3.00 \mathrm{E}-01$ & $1.15 \mathrm{E}+06$ \\
\hline D & $\mathrm{B}$ & misc06 & $1.60 \mathrm{E}+03$ & $1.29 \mathrm{E}+04$ & $3.53 \mathrm{E}+02$ & $1.00 \mathrm{E}-02$ & $7.00 \mathrm{E}+00$ & 1 & $2.00 \mathrm{E}-01$ & $2.56 \mathrm{E}+06$ \\
\hline A & $\mathrm{M}$ & misc06 & $1.13 \mathrm{E}+03$ & $1.29 \mathrm{E}+04$ & $1.29 \mathrm{E}+02$ & $2.00 \mathrm{E}-02$ & $1.00 \mathrm{E}+00$ & 1 & $1.00 \mathrm{E}-01$ & $1.98 \mathrm{E}+06$ \\
\hline D & $M$ & $\operatorname{misc06}$ & $1.16 \mathrm{E}+03$ & $1.29 E+04$ & $1.57 E+02$ & $2.00 \mathrm{E}-02$ & $3.00 \mathrm{E}+00$ & I & $1.00 \mathrm{E}-01$ & $2.02 \mathrm{E}+06$ \\
\hline A & $\mathrm{B}$ & misc06 & $1.09 \mathrm{E}+03$ & $1.29 \mathrm{E}+04$ & $1.35 \mathrm{E}+02$ & $1.00 \mathrm{E}-02$ & $2.00 \mathrm{E}+00$ & 1 & $1.00 \mathrm{E}-01$ & $2.15 \mathrm{E}+06$ \\
\hline L & $\mathrm{M}$ & misc06 & $4.61 \mathrm{E}+03$ & $1.29 \mathrm{E}+04$ & $1.40 \mathrm{E}+03$ & $8.00 \mathrm{E}-02$ & $7.00 \mathrm{E}+00$ & I & $.00 \mathrm{E}-01$ & $2.65 \mathrm{E}+06$ \\
\hline $\mathrm{L}$ & $\mathrm{B}$ & misc06 & $2.01 E+04$ & $1.29 E+04$ & $7.58 \mathrm{E}+03$ & $4.00 \mathrm{E}-02$ & $2.00 \mathrm{E}+01$ & 1 & $3.30 \mathrm{E}+00$ & $7.25 \mathrm{E}+06$ \\
\hline $\mathrm{P}$ & $M$ & $\operatorname{misc06}$ & $1.00 \mathrm{E}+03$ & $1.29 E+04$ & $1.13 E+02$ & $.00 \mathrm{E}-02$ & $1.00 \mathrm{E}+00$ & 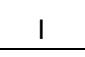 & -01 & $2.50 \mathrm{E}+06$ \\
\hline $\mathrm{P}$ & $\mathrm{B}$ & misc06 & $9.61 \mathrm{E}+02$ & $.29 \mathrm{E}+04$ & $7.90 \mathrm{E}+01$ & OOE-02 & $.00 \mathrm{E}+00$ & 1 & -01 & $2.56 \mathrm{E}+06$ \\
\hline D & $\mathrm{B}$ & & $3 \mathrm{E}+05$ & $73 \mathrm{E}+03$ & $1.70 \mathrm{E}+04$ & $9.60 \mathrm{E}-01$ & $7.00 \mathrm{E}+00$ & 1 & $1.67 \mathrm{E}+02$ & $9.99 \mathrm{E}+07$ \\
\hline A & M & $\begin{array}{l}\text { neos- } \\
686190\end{array}$ & $6.83 \mathrm{E}+04$ & $6.73 E+03$ & $4.88 \mathrm{E}+03$ & $6.16 \mathrm{E}+00$ & $3.00 \mathrm{E}+00$ & I & $1.94 \mathrm{E}+01$ & $2.59 \mathrm{E}+07$ \\
\hline
\end{tabular}




\begin{tabular}{|c|c|c|c|c|c|c|c|c|c|c|}
\hline VDS & NS & model & $\begin{array}{r}\text { simplex } \\
\text { it. }\end{array}$ & cu. Sol. & nodes & $\begin{array}{r}\text { 1st fea. } \\
\text { Time }\end{array}$ & $\begin{array}{r}\text { fea. } \\
\text { nodes }\end{array}$ & $\begin{array}{c}\text { exit } \\
\text { code }\end{array}$ & time & memory \\
\hline D & M & $\begin{array}{l}\text { neos- } \\
686190\end{array}$ & $1 \mathrm{E}+05$ & $73 E+03$ & $1.20 \mathrm{E}+04$ & $6.70 E+00$ & $9.00 \mathrm{E}+00$ & I & $1.19 E+02$ & $4.26 \mathrm{E}+07$ \\
\hline A & B & $\begin{array}{c}\text { neos- } \\
686190 \\
\end{array}$ & $3 \mathrm{E}+05$ & $3 E+03$ & $2.13 E+04$ & $3.14 \mathrm{E}+01$ & $00 \mathrm{E}+00$ & 1 & $7.49 \mathrm{E}+01$ & $9.12 \mathrm{E}+07$ \\
\hline $\mathrm{L}$ & $M$ & $\begin{array}{c}\text { neos- } \\
686190 \\
\end{array}$ & $8 \mathrm{E}+05$ & $73 \mathrm{E}+03$ & $2.45 \mathrm{E}+04$ & $40 \mathrm{E}+00$ & $8.00 \mathrm{E}+00$ & 1 & $1.12 \mathrm{E}+02$ & $7.88 \mathrm{E}+07$ \\
\hline $\mathrm{P}$ & M & $\begin{array}{c}\text { neos- } \\
686190\end{array}$ & $44 \mathrm{E}+05$ & $73 E+03$ & $7.43 \mathrm{E}+04$ & $5.81 \mathrm{E}+01$ & $4.00 \mathrm{E}+00$ & $\mathrm{I}$ & $3.00 E+02$ & $2.11 \mathrm{E}+08$ \\
\hline $\mathrm{L}$ & B & & 05 & 03 & 04 & +00 & $E+00$ & 1 & $70 E+02$ & $2.30 \mathrm{E}+08$ \\
\hline$P$ & B & $\begin{array}{c}\text { neos- } \\
686190 \\
\end{array}$ & $2.61 \mathrm{E}+06$ & $6.73 \mathrm{E}+03$ & $9.97 \mathrm{E}+05$ & $9.33 \mathrm{E}+01$ & $4.00 \mathrm{E}+00$ & 1 & $1.92 \mathrm{E}+03$ & $4.49 \mathrm{E}+08$ \\
\hline D & B & egout & $2.34 \mathrm{E}+02$ & $5.68 \mathrm{E}+02$ & $1.29 \mathrm{E}+02$ & $0.00 \mathrm{E}+00$ & $3.00 \mathrm{E}+00$ & 1 & $0.00 \mathrm{E}+00$ & $2.01 \mathrm{E}+05$ \\
\hline$A$ & $M$ & egout & $2.59 \mathrm{E}+02$ & $5.68 \mathrm{E}+02$ & $9.10 \mathrm{E}+01$ & $0.00 \mathrm{E}+00$ & $5.00 \mathrm{E}+00$ & 1 & $0.00 \mathrm{E}+00$ & $1.92 \mathrm{E}+05$ \\
\hline D & $M$ & egout & $2.26 \mathrm{E}+02$ & $5.68 \mathrm{E}+02$ & $1.03 E+02$ & $0.00 \mathrm{E}+00$ & $5.00 \mathrm{E}+00$ & I & $0.00 \mathrm{E}+00$ & $1.92 \mathrm{E}+05$ \\
\hline$A$ & B & egout & $3.14 \mathrm{E}+02$ & $5.68 \mathrm{E}+02$ & $1.39 \mathrm{E}+02$ & $0.00 \mathrm{E}+00$ & $5.00 \mathrm{E}+00$ & 1 & $0.00 \mathrm{E}+00$ & $2.09 \mathrm{E}+05$ \\
\hline L & $M$ & egout & $4.11 \mathrm{E}+02$ & $5.68 \mathrm{E}+02$ & $2.05 \mathrm{E}+02$ & $0.00 \mathrm{E}+00$ & $1.30 \mathrm{E}+01$ & 1 & $0.00 \mathrm{E}+00$ & $1.92 \mathrm{E}+05$ \\
\hline $\mathrm{L}$ & B & egout & $2.94 \mathrm{E}+02$ & $5.68 \mathrm{E}+02$ & $1.65 \mathrm{E}+02$ & $1.00 \mathrm{E}-02$ & $2.00 \mathrm{E}+00$ & 1 & $0.00 \mathrm{E}+00$ & $2.17 \mathrm{E}+05$ \\
\hline$P$ & $M$ & egout & $2.31 \mathrm{E}+02$ & $5.68 \mathrm{E}+02$ & $1.15 \mathrm{E}+02$ & $0.00 \mathrm{E}+00$ & $5.00 \mathrm{E}+00$ & 1 & $0.00 \mathrm{E}+00$ & $2.54 \mathrm{E}+05$ \\
\hline $\mathrm{P}$ & $\mathrm{B}$ & egout & $2.15 \mathrm{E}+02$ & $5.68 \mathrm{E}+02$ & $1.33 \mathrm{E}+02$ & $1.00 \mathrm{E}-02$ & $2.00 \mathrm{E}+00$ & 1 & $0.00 \mathrm{E}+00$ & $2.63 \mathrm{E}+05$ \\
\hline D & B & bm23 & $6.35 \mathrm{E}+02$ & $3.40 \mathrm{E}+01$ & $2.05 \mathrm{E}+02$ & $2.00 \mathrm{E}-02$ & $1.00 \mathrm{E}+00$ & 1 & $0.00 \mathrm{E}+00$ & $1.79 \mathrm{E}+05$ \\
\hline A & $M$ & bm23 & $1.44 \mathrm{E}+03$ & $3.40 E+01$ & $5.41 \mathrm{E}+02$ & $2.00 \mathrm{E}-02$ & $2.00 \mathrm{E}+00$ & 1 & $0.00 \mathrm{E}+00$ & $2.00 \mathrm{E}+05$ \\
\hline D & $M$ & $\mathrm{bm} 23$ & $6.63 E+02$ & $3.40 \mathrm{E}+01$ & $2.07 E+02$ & $2.00 \mathrm{E}-02$ & $1.00 \mathrm{E}+00$ & 1 & $0.00 \mathrm{E}+00$ & $1.73 \mathrm{E}+05$ \\
\hline A & $\mathrm{B}$ & $\mathrm{bm} 23$ & $8.31 \mathrm{E}+02$ & $3.40 \mathrm{E}+01$ & $2.69 \mathrm{E}+02$ & $1.00 \mathrm{E}-02$ & $2.00 \mathrm{E}+00$ & 1 & $0.00 \mathrm{E}+00$ & $1.81 \mathrm{E}+05$ \\
\hline $\mathrm{L}$ & $\mathrm{M}$ & bm23 & $.29 \mathrm{E}+02$ & $3.40 \mathrm{E}+01$ & $3.07 \mathrm{E}+02$ & $1.00 \mathrm{E}-02$ & $3.00 \mathrm{E}+00$ & 1 & $0.00 \mathrm{E}+00$ & $1.82 \mathrm{E}+05$ \\
\hline L & B & $\mathrm{bm} 23$ & $5 \mathrm{E}+03$ & $3.40 \mathrm{E}+01$ & $4.05 E+02$ & $.00 \mathrm{E}-02$ & $1.00 \mathrm{E}+00$ & 1 & $0.00 \mathrm{E}+00$ & $2.15 \mathrm{E}+05$ \\
\hline $\mathrm{P}$ & $M$ & bm23 & $6.79 \mathrm{E}+02$ & $3.40 E+01$ & $2.93 E+02$ & $1.00 \mathrm{E}-02$ & $2.00 \mathrm{E}+00$ & 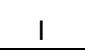 & $0.00 \mathrm{E}+00$ & $2.03 E+05$ \\
\hline $\mathrm{P}$ & B & $\mathrm{bm} 23$ & $\mathrm{DE}+02$ & $3.40 E+01$ & $71 E+02$ & 00E-02 & $.00 E+00$ & 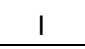 & $00 E+00$ & $2.41 \mathrm{E}+05$ \\
\hline D & B & & 84 & & 02 & 02 & +00 & 1 & $E+02$ & $2.09 \mathrm{E}+08$ \\
\hline A & M & & +04 & $2 E+06$ & $10 \mathrm{E}+01$ & $71 E+01$ & $00 E+00$ & I & $50 \mathrm{E}+02$ & $.09 \mathrm{E}+08$ \\
\hline D & $M$ & & & & $3 \mathrm{E}+02$ & $96 \mathrm{E}+02$ & $00 \mathrm{E}+00$ & 1 & $19 \mathrm{E}+02$ & $2.09 \mathrm{E}+08$ \\
\hline A & B & & & & $E+01$ & +01 & $E+00$ & 1 & $50 \mathrm{E}+02$ & $2.09 \mathrm{E}+08$ \\
\hline $\mathrm{L}$ & M & & +04 & +06 & $0 \mathrm{E}+01$ & $E+01$ & $O O E+00$ & I & $45 E+02$ & $.09 \mathrm{E}+08$ \\
\hline $\mathrm{L}$ & B & $\begin{array}{c}\text { neos- } \\
780889\end{array}$ & -04 & 06 & $0 \mathrm{E}+01$ & $27 \mathrm{E}+01$ & +00 & I & +02 & $2.09 \mathrm{E}+08$ \\
\hline $\mathrm{P}$ & M & & $E+04$ & $2 \mathrm{E}+06$ & $.03 E+02$ & $8.37 E+02$ & $00 \mathrm{E}+00$ & 1 & $9.61 E+02$ & $2.96 \mathrm{E}+08$ \\
\hline $\mathrm{P}$ & $\mathrm{B}$ & & 4.36E+04 & $3.42 E+06$ & $1.03 \mathrm{E}+02$ & $8.36 \mathrm{E}+02$ & $1.00 \mathrm{E}+00$ & 1 & $9.59 \mathrm{E}+02$ & $2.96 \mathrm{E}+08$ \\
\hline D & $\mathrm{B}$ & p0291 & $1.81 E+02$ & $5.22 \mathrm{E}+03$ & $7.70 \mathrm{E}+01$ & $1.00 \mathrm{E}-02$ & $1.00 \mathrm{E}+00$ & I & $0.00 \mathrm{E}+00$ & $5.67 E+05$ \\
\hline$A$ & $M$ & p0291 & $5.64 \mathrm{E}+02$ & $5.22 \mathrm{E}+03$ & $2.03 E+02$ & $1.00 \mathrm{E}-02$ & $3.00 \mathrm{E}+00$ & I & $0.00 \mathrm{E}+00$ & $5.90 \mathrm{E}+05$ \\
\hline D & $M$ & p0291 & $2.01 \mathrm{E}+02$ & $5.22 \mathrm{E}+03$ & $7.10 \mathrm{E}+01$ & $1.00 \mathrm{E}-02$ & $2.00 \mathrm{E}+00$ & 1 & $0.00 \mathrm{E}+00$ & $5.53 \mathrm{E}+05$ \\
\hline 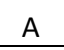 & B & p0291 & $1.34 \mathrm{E}+03$ & $5.22 \mathrm{E}+03$ & $3.87 \mathrm{E}+02$ & 4.00E-02 & $3.00 \mathrm{E}+00$ & 1 & 1.00E-01 & $7.87 \mathrm{E}+05$ \\
\hline
\end{tabular}




\begin{tabular}{|c|c|c|c|c|c|c|c|c|c|c|}
\hline VDS & NS & model & $\begin{array}{r}\text { simplex } \\
\text { it. }\end{array}$ & incu. Sol. & nodes & $\begin{array}{r}\text { 1st fea. } \\
\text { Time }\end{array}$ & $\begin{array}{r}\text { fea. } \\
\text { nodes }\end{array}$ & $\begin{array}{c}\text { exit } \\
\text { code }\end{array}$ & time & memory \\
\hline $\mathrm{L}$ & $\mathrm{M}$ & p0291 & $1.97 \mathrm{E}+02$ & $5.22 \mathrm{E}+03$ & $6.10 \mathrm{E}+01$ & $1.00 \mathrm{E}-02$ & $3.00 \mathrm{E}+00$ & 1 & $0.00 \mathrm{E}+00$ & $5.52 \mathrm{E}+05$ \\
\hline $\mathrm{L}$ & $\mathrm{B}$ & p0291 & $65 E+02$ & $5.22 \mathrm{E}+03$ & $1.27 \mathrm{E}+02$ & $0.00 \mathrm{E}+00$ & $3.00 \mathrm{E}+00$ & 1 & $0.00 \mathrm{E}+00$ & $5.70 \mathrm{E}+05$ \\
\hline $\mathrm{P}$ & $M$ & p0291 & $1.44 \mathrm{E}+02$ & $5.22 \mathrm{E}+03$ & $4.50 \mathrm{E}+01$ & $1.00 \mathrm{E}-02$ & $4.00 \mathrm{E}+00$ & 1 & $0.00 \mathrm{E}+00$ & $7.27 \mathrm{E}+05$ \\
\hline $\mathrm{P}$ & $\mathrm{B}$ & p0291 & $1.29 \mathrm{E}+02$ & $5.22 \mathrm{E}+03$ & $4.50 \mathrm{E}+01$ & $1.00 \mathrm{E}-02$ & $4.00 \mathrm{E}+00$ & 1 & $0.00 \mathrm{E}+00$ & $7.27 \mathrm{E}+05$ \\
\hline $\mathrm{D}$ & B & $\begin{array}{c}\text { neos- } \\
831188 \\
\end{array}$ & +06 & $2.65 \mathrm{E}+00$ & $3.94 \mathrm{E}+04$ & $4.36 \mathrm{E}+02$ & $2.00 \mathrm{E}+00$ & $\mathrm{~T}$ & $3.60 \mathrm{E}+03$ & $7.78 \mathrm{E}+07$ \\
\hline A & $\mathrm{M}$ & $\begin{array}{c}\text { neos- } \\
831188 \\
\end{array}$ & $8.18 \mathrm{E}+05$ & $2.61 \mathrm{E}+00$ & $5.31 \mathrm{E}+03$ & $7.26 \mathrm{E}+00$ & $1.00 \mathrm{E}+00$ & $\mathrm{I}$ & $1.32 \mathrm{E}+02$ & $1.49 \mathrm{E}+07$ \\
\hline D & $M$ & $\begin{array}{c}\text { neos- } \\
831188 \\
\end{array}$ & $4.86 \mathrm{E}+06$ & $2.61 \mathrm{E}+00$ & $4.14 \mathrm{E}+04$ & $9.50 \mathrm{E}+01$ & $1.00 \mathrm{E}+00$ & $\mathrm{~T}$ & $3.60 \mathrm{E}+03$ & $8.27 \mathrm{E}+07$ \\
\hline A & B & $\begin{array}{c}\text { neos- } \\
831188\end{array}$ & $8.17 \mathrm{E}+05$ & $2.61 \mathrm{E}+00$ & $5.31 \mathrm{E}+03$ & $8.08 \mathrm{E}+00$ & $1.00 \mathrm{E}+00$ & I & $1.32 \mathrm{E}+02$ & $1.96 \mathrm{E}+07$ \\
\hline L & $\mathrm{M}$ & $\begin{array}{c}\text { neos- } \\
831188\end{array}$ & $1.68 \mathrm{E}+06$ & $2.61 \mathrm{E}+00$ & $8.71 E+03$ & $7.41 \mathrm{E}+01$ & $2.00 \mathrm{E}+00$ & 1 & $2.64 \mathrm{E}+02$ & $1.87 \mathrm{E}+07$ \\
\hline $\mathrm{L}$ & $\mathrm{B}$ & $\begin{array}{c}\text { neos- } \\
831188 \\
\end{array}$ & +06 & 00 & $8.76 \mathrm{E}+03$ & $78 \mathrm{E}+02$ & $00 \mathrm{E}+00$ & 1 & $00 \mathrm{E}+02$ & $2.18 \mathrm{E}+07$ \\
\hline $\mathrm{P}$ & B & $\begin{array}{c}\text { neos- } \\
831188\end{array}$ & $7 \mathrm{E}+07$ & N & $1.10 \mathrm{E}+06$ & $0.00 \mathrm{E}+00$ & $0.00 \mathrm{E}+00$ & $T$ & $3.60 \mathrm{E}+03$ & $4.80 \mathrm{E}+08$ \\
\hline $\mathrm{P}$ & $\mathrm{M}$ & $\begin{array}{l}\text { neos- } \\
831188\end{array}$ & $1.45 \mathrm{E}+07$ & $2.63 \mathrm{E}+00$ & $6.49 \mathrm{E}+05$ & $1.37 E+03$ & $2.00 \mathrm{E}+00$ & $T$ & $3.60 \mathrm{E}+03$ & $3.55 \mathrm{E}+08$ \\
\hline D & B & $\begin{array}{l}\text { supportca } \\
\text { se26 }\end{array}$ & 06 & 3 & $0 E+06$ & 70E-01 & $E+01$ & $\mathrm{~T}$ & $E+03$ & $60 E+09$ \\
\hline $\mathrm{A}$ & $\mathrm{M}$ & $\begin{array}{l}\text { supportca } \\
\text { se26 }\end{array}$ & 1.33E+06 & $1.75 \mathrm{E}+03$ & $2.17 E+05$ & $1.12 \mathrm{E}+01$ & $1.00 \mathrm{E}+00$ & 1 & $2.09 \mathrm{E}+02$ & $1.52 \mathrm{E}+07$ \\
\hline D & $\mathrm{M}$ & $\begin{array}{l}\text { supportca } \\
\text { se26 }\end{array}$ & +06 & $\mathrm{E}+03$ & $23 \mathrm{E}+06$ & $5.69 \mathrm{E}+01$ & $00 \mathrm{E}+00$ & $\mathrm{~T}$ & $60 \mathrm{E}+03$ & $8.69 \mathrm{E}+07$ \\
\hline A & B & $\begin{array}{l}\text { supportca } \\
\text { se26 }\end{array}$ & $E+06$ & $5 E+03$ & $54 \mathrm{E}+05$ & 40E-01 & $10 \mathrm{E}+01$ & 1 & $11 E+03$ & $3.31 \mathrm{E}+08$ \\
\hline $\mathrm{L}$ & $\mathrm{M}$ & $\begin{array}{l}\text { supportca } \\
\text { se26 }\end{array}$ & $1.33 \mathrm{E}+07$ & $1.84 \mathrm{E}+03$ & $4.53 \mathrm{E}+06$ & $1.00 \mathrm{E}-02$ & $.80 \mathrm{E}+01$ & $T$ & $3.60 \mathrm{E}+03$ & $6.23 \mathrm{E}+07$ \\
\hline $\mathrm{L}$ & B & $\begin{array}{l}\text { supportca } \\
\text { se26 }\end{array}$ & +06 & 03 & 05 & DOE-02 & $=+00$ & T & $50 E+03$ & $20 \mathrm{E}+08$ \\
\hline $\mathrm{P}$ & $\mathrm{M}$ & $\begin{array}{l}\text { supportca } \\
\text { se26 }\end{array}$ & $2.07 \mathrm{E}+07$ & $1.75 \mathrm{E}+03$ & $5.87 \mathrm{E}+06$ & $41 \mathrm{E}+01$ & $50 \mathrm{E}+01$ & $\mathrm{~T}$ & $.60 E+03$ & $3.37 \mathrm{E}+07$ \\
\hline $\mathrm{P}$ & $\mathrm{B}$ & $\begin{array}{l}\text { supportca } \\
\text { se26 }\end{array}$ & $2.07 E+06$ & $1.78 \mathrm{E}+03$ & $1.33 \mathrm{E}+06$ & $3.60 \mathrm{E}-01$ & $.80 E+01$ & $\mathrm{~T}$ & $.60 E+03$ & $1.14 \mathrm{E}+09$ \\
\hline $\mathrm{D}$ & $\mathrm{B}$ & $\begin{array}{l}\text { neos- } \\
1122047\end{array}$ & $8 \mathrm{E}+04$ & $61 E+02$ & $15 \mathrm{E}+02$ & $65 \mathrm{E}+00$ & $00 \mathrm{E}+00$ & 1 & $82 \mathrm{E}+01$ & $7.25 \mathrm{E}+07$ \\
\hline $\mathrm{A}$ & $\mathrm{M}$ & $\begin{array}{l}\text { neos- } \\
1122047\end{array}$ & $9.74 \mathrm{E}+03$ & $1.61 \mathrm{E}+02$ & $3.70 \mathrm{E}+01$ & $2.90 \mathrm{E}+00$ & $.00 \mathrm{E}+00$ & 1 & $1.47 \mathrm{E}+01$ & $7.25 \mathrm{E}+07$ \\
\hline $\mathrm{D}$ & $\mathrm{M}$ & $\begin{array}{l}\text { neos- } \\
1122047 \\
\end{array}$ & $1.08 \mathrm{E}+04$ & $1.61 \mathrm{E}+02$ & $1.15 \mathrm{E}+02$ & $6.62 E+00$ & $1.00 \mathrm{E}+00$ & 1 & $1.81 \mathrm{E}+01$ & $7.25 \mathrm{E}+07$ \\
\hline $\mathrm{A}$ & $\mathrm{B}$ & $\begin{array}{l}\text { neos- } \\
1122047\end{array}$ & $9.74 \mathrm{E}+03$ & $1.61 \mathrm{E}+02$ & $3.70 \mathrm{E}+01$ & $2.93 \mathrm{E}+00$ & $2.00 \mathrm{E}+00$ & 1 & $1.48 \mathrm{E}+01$ & $7.25 \mathrm{E}+07$ \\
\hline $\mathrm{L}$ & $\mathrm{M}$ & $\begin{array}{c}\text { neos- } \\
1122047 \\
\end{array}$ & $3 E+04$ & $1.61 \mathrm{E}+02$ & $1.90 \mathrm{E}+01$ & $4.32 E+00$ & $.00 \mathrm{E}+00$ & 1 & $1.58 \mathrm{E}+01$ & $7.24 \mathrm{E}+07$ \\
\hline $\mathrm{L}$ & $\mathrm{B}$ & $\begin{array}{l}\text { neos- } \\
1122047\end{array}$ & $E+04$ & $E+02$ & $O E+01$ & $41 \mathrm{E}+00$ & $00 \mathrm{E}+00$ & 1 & $60 \mathrm{E}+01$ & $7.24 \mathrm{E}+07$ \\
\hline $\mathrm{P}$ & $\mathrm{M}$ & & $2.66 \mathrm{E}+04$ & $1.61 \mathrm{E}+02$ & $7.77 \mathrm{E}+02$ & $1.50 \mathrm{E}+01$ & $2.00 \mathrm{E}+00$ & 1 & $.80 \mathrm{E}+01$ & $1.07 \mathrm{E}+08$ \\
\hline$P$ & $B$ & $\begin{array}{c}\text { neos- } \\
1122047 \\
\end{array}$ & $2.66 \mathrm{E}+04$ & $1.61 \mathrm{E}+02$ & $7.77 \mathrm{E}+02$ & $1.50 \mathrm{E}+01$ & $2.00 \mathrm{E}+00$ & 1 & $6.79 \mathrm{E}+01$ & $1.07 \mathrm{E}+08$ \\
\hline D & B & stein45 & $3.15 \mathrm{E}+05$ & $3.00 \mathrm{E}+01$ & $4.12 \mathrm{E}+04$ & $2.00 \mathrm{E}-02$ & $3.00 \mathrm{E}+00$ & I & $2.00 \mathrm{E}+01$ & $1.80 \mathrm{E}+07$ \\
\hline
\end{tabular}




\begin{tabular}{|c|c|c|c|c|c|c|c|c|c|c|}
\hline VDS & NS & model & $\begin{array}{r}\text { simplex } \\
\text { it. }\end{array}$ & incu. Sol. & nodes & $\begin{array}{r}\text { 1st fea. } \\
\text { Time }\end{array}$ & $\begin{array}{r}\text { fea. } \\
\text { nodes }\end{array}$ & $\begin{array}{l}\text { exit } \\
\text { code }\end{array}$ & time & memory \\
\hline A & $M$ & stein45 & $2.95 \mathrm{E}+05$ & $3.00 \mathrm{E}+01$ & $4.10 \mathrm{E}+04$ & $1.00 \mathrm{E}-02$ & $3.00 \mathrm{E}+00$ & 1 & $1.30 \mathrm{E}+01$ & $1.15 \mathrm{E}+07$ \\
\hline $\mathrm{D}$ & $M$ & stein45 & $3.12 \mathrm{E}+05$ & $3.00 \mathrm{E}+01$ & $4.05 \mathrm{E}+04$ & $1.00 \mathrm{E}-02$ & $3.00 \mathrm{E}+00$ & 1 & $1.90 \mathrm{E}+01$ & $1.20 \mathrm{E}+07$ \\
\hline A & $\mathrm{D}$ & stein45 & 3.12E+05 & $3.00 \mathrm{E}+01$ & 4.72E+04 & $1.00 \mathrm{E}-02$ & $3.00 \mathrm{E}+00$ & I & $1.77 \mathrm{E}+01$ & $2.13 \mathrm{E}+07$ \\
\hline $\mathrm{L}$ & $\mathrm{M}$ & stein45 & $3.74 \mathrm{E}+05$ & $3.00 \mathrm{E}+01$ & $6.83 \mathrm{E}+04$ & $2.00 \mathrm{E}-02$ & $3.00 \mathrm{E}+00$ & 1 & $2.20 \mathrm{E}+01$ & $1.61 \mathrm{E}+07$ \\
\hline $\mathrm{L}$ & $\mathrm{B}$ & stein45 & 4.12E+05 & $3.00 \mathrm{E}+01$ & $9.33 \mathrm{E}+04$ & $2.00 \mathrm{E}-02$ & $3.00 \mathrm{E}+00$ & 1 & $4.17 \mathrm{E}+01$ & $3.47 \mathrm{E}+07$ \\
\hline $\mathrm{P}$ & $\mathrm{M}$ & stein45 & $3.26 \mathrm{E}+05$ & $3.00 \mathrm{E}+01$ & $4.81 \mathrm{E}+04$ & $6.00 \mathrm{E}-02$ & $3.00 \mathrm{E}+00$ & 1 & $1.42 \mathrm{E}+01$ & $1.39 \mathrm{E}+07$ \\
\hline $\mathrm{P}$ & $\mathrm{B}$ & stein45 & $3.26 \mathrm{E}+05$ & $3.00 \mathrm{E}+01$ & $4.93 E+04$ & $6.00 \mathrm{E}-02$ & $3.00 \mathrm{E}+00$ & 1 & $1.82 \mathrm{E}+01$ & $2.10 \mathrm{E}+07$ \\
\hline $\mathrm{D}$ & $\mathrm{B}$ & $\begin{array}{l}\text { neos- } \\
1171448 \\
\end{array}$ & $1.41 \mathrm{E}+06$ & $-3.09 E+02$ & $1.40 \mathrm{E}+04$ & $2.22 \mathrm{E}+02$ & $8.00 \mathrm{E}+00$ & 1 & $1.08 \mathrm{E}+03$ & $6.70 \mathrm{E}+07$ \\
\hline $\mathrm{A}$ & $\mathrm{M}$ & & -04 & 02 & 02 & +01 & +00 & 1 & +01 & 3.6 \\
\hline $\mathrm{D}$ & M & $\begin{array}{l}\text { neos- } \\
1171448\end{array}$ & $2.20 \mathrm{E}+06$ & $-3.09 E+02$ & $1.31 \mathrm{E}+04$ & $1.12 \mathrm{E}+03$ & $2.00 \mathrm{E}+00$ & 1 & $1.60 \mathrm{E}+03$ & $9.65 \mathrm{E}+07$ \\
\hline A & B & & $4.50 \mathrm{E}+04$ & $-3.09 E+02$ & $2.01 E+02$ & $2.71 \mathrm{E}+01$ & $1.00 \mathrm{E}+00$ & 1 & $2.90 \mathrm{E}+01$ & $3.67 \mathrm{E}+07$ \\
\hline $\mathrm{L}$ & M & & +05 & 02 & +02 & $E+01$ & $E+00$ & 1 & $E+01$ & $3.77 \mathrm{E}+07$ \\
\hline $\mathrm{L}$ & B & & 1.13E+05 & $-3.09 E+02$ & $5.47 \mathrm{E}+02$ & $7.16 \mathrm{E}+01$ & $1.00 \mathrm{E}+00$ & I & $7.35 E+01$ & $3.77 E+07$ \\
\hline $\mathrm{P}$ & $\mathrm{M}$ & & +05 & -3.0 & 3.61 & $5.20 \mathrm{E}+02$ & +00 & 1 & $5.65 \mathrm{E}+02$ & $6.85 \mathrm{E}+07$ \\
\hline $\mathrm{P}$ & $B$ & $\begin{array}{l}\text { neos- } \\
1171448\end{array}$ & $3.80 \mathrm{E}+05$ & $-3.09 E+02$ & $2.57 \mathrm{E}+03$ & $3.05 E+02$ & $2.00 \mathrm{E}+00$ & 1 & $3.55 \mathrm{E}+02$ & $6.05 \mathrm{E}+07$ \\
\hline $\mathrm{D}$ & $\mathrm{B}$ & mas76 & $2.31 \mathrm{E}+06$ & $4.00 \mathrm{E}+04$ & $6.38 \mathrm{E}+05$ & $2.00 \mathrm{E}-02$ & $1.60 \mathrm{E}+01$ & $\mathrm{~T}$ & $3.60 \mathrm{E}+03$ & $1.62 \mathrm{E}+08$ \\
\hline $\mathrm{A}$ & M & mas76 & $2.60 \mathrm{E}+07$ & $4.00 E+04$ & $6.96 \mathrm{E}+06$ & $0.00 \mathrm{E}+00$ & $1.10 \mathrm{E}+01$ & 1 & $1.15 \mathrm{E}+03$ & $9.90 \mathrm{E}+06$ \\
\hline $\mathrm{D}$ & $M$ & mas76 & $6.12 \mathrm{E}+06$ & $4.00 \mathrm{E}+04$ & $1.27 \mathrm{E}+06$ & $2.00 \mathrm{E}-02$ & $1.30 \mathrm{E}+01$ & 1 & $3.89 \mathrm{E}+02$ & $1.08 \mathrm{E}+07$ \\
\hline $\mathrm{A}$ & $\mathrm{B}$ & mas76 & 2.37E+06 & $4.00 \mathrm{E}+04$ & $7.42 \mathrm{E}+05$ & $0.00 \mathrm{E}+00$ & $1.00 \mathrm{E}+01$ & $\mathrm{~T}$ & $3.60 \mathrm{E}+03$ & $2.18 \mathrm{E}+08$ \\
\hline $\mathrm{L}$ & $\mathrm{M}$ & mas76 & $8.22 \mathrm{E}+06$ & $4.00 E+04$ & $2.23 \mathrm{E}+06$ & $1.00 \mathrm{E}-02$ & $1.50 \mathrm{E}+01$ & 1 & $5.65 E+02$ & $1.55 \mathrm{E}+07$ \\
\hline $\mathrm{L}$ & $\mathrm{B}$ & $\operatorname{mas} 76$ & $2.88 \mathrm{E}+06$ & $4.09 \mathrm{E}+04$ & $8.87 E+05$ & $1.00 \mathrm{E}-02$ & $1.70 \mathrm{E}+01$ & 1 & $3.60 \mathrm{E}+03$ & $3.72 \mathrm{E}+08$ \\
\hline $\mathrm{P}$ & $\mathrm{M}$ & mas76 & $6.49 \mathrm{E}+06$ & $4.00 \mathrm{E}+04$ & $1.91 \mathrm{E}+06$ & $3.00 \mathrm{E}-02$ & $1.50 \mathrm{E}+01$ & 1 & $3.49 \mathrm{E}+02$ & $9.91 \mathrm{E}+06$ \\
\hline $\mathrm{P}$ & B & mas76 & $3 \mathrm{E}+06$ & $4.00 \mathrm{E}+04$ & $8.68 \mathrm{E}+05$ & $.00 \mathrm{E}-02$ & $.00 E+00$ & 1 & $3.60 \mathrm{E}+03$ & $2.41 E+08$ \\
\hline D & B & & $E+06$ & $30 \mathrm{E}+01$ & $1.20 \mathrm{E}+05$ & $9.38 \mathrm{E}+01$ & $.00 \mathrm{E}+00$ & $\mathrm{~T}$ & $.60 \mathrm{E}+03$ & $1.03 \mathrm{E}+09$ \\
\hline A & $\mathrm{M}$ & & $2.54 \mathrm{E}+06$ & $9.10 \mathrm{E}+01$ & $5.90 \mathrm{E}+04$ & $0.00 E+00$ & $0.00 E+00$ & 1 & $1.09 E+03$ & $7.50 E+08$ \\
\hline D & M & $\begin{array}{l}\text { neos- } \\
1582420\end{array}$ & $1.63 \mathrm{E}+06$ & $9.10 \mathrm{E}+01$ & $4.51 E+04$ & $0.00 E+00$ & $0.00 \mathrm{E}+00$ & I & $1.74 \mathrm{E}+03$ & $6.06 \mathrm{E}+08$ \\
\hline A & B & $\begin{array}{c}\text { neos- } \\
1582420\end{array}$ & $E+06$ & $10 E+01$ & $4.24 \mathrm{E}+04$ & $2.31 \mathrm{E}+00$ & $2.00 \mathrm{E}+00$ & 1 & $6.93 \mathrm{E}+02$ & $3.52 \mathrm{E}+08$ \\
\hline $\mathrm{L}$ & $M$ & $\begin{array}{l}\text { neos- } \\
1582420\end{array}$ & $\mathrm{E}+05$ & $10 \mathrm{E}+01$ & $17 \mathrm{E}+04$ & $0.00 \mathrm{E}+00$ & $00 \mathrm{E}+00$ & 1 & $56 \mathrm{E}+02$ & $1.06 \mathrm{E}+08$ \\
\hline $\mathrm{L}$ & B & $\begin{array}{l}\text { neos- } \\
1582420\end{array}$ & $2.66 \mathrm{E}+06$ & $9.10 \mathrm{E}+01$ & $6.93 \mathrm{E}+04$ & $6.80 \mathrm{E}-01$ & $2.00 \mathrm{E}+00$ & I & $1.10 E+03$ & $1.26 \mathrm{E}+09$ \\
\hline $\mathrm{P}$ & M & $\begin{array}{l}\text { neos- } \\
1582420\end{array}$ & $6.68 \mathrm{E}+06$ & $\mathrm{~N}$ & $2.45 E+05$ & $0.00 E+00$ & $0.00 E+00$ & T & $3.60 \mathrm{E}+03$ & $4.37 E+08$ \\
\hline $\mathrm{P}$ & B & $\begin{array}{l}\text { neos- } \\
1582420\end{array}$ & $5.21 E+06$ & $9.20 \mathrm{E}+01$ & $6.31 E+05$ & $2.42 E+02$ & $3.00 \mathrm{E}+00$ & $T$ & $3.60 E+03$ & $6.19 \mathrm{E}+08$ \\
\hline D & B & $\begin{array}{l}\text { rmatr100- } \\
\text { p10 }\end{array}$ & $4.30 \mathrm{E}+05$ & $4.23 \mathrm{E}+02$ & $6.63 E+03$ & $1.75 \mathrm{E}+00$ & $7.00 \mathrm{E}+00$ & I & $2.26 \mathrm{E}+02$ & $4.91 E+08$ \\
\hline
\end{tabular}




\begin{tabular}{|c|c|c|c|c|c|c|c|c|c|c|}
\hline VDS & NS & model & $\begin{array}{r}\text { simplex } \\
\text { it. }\end{array}$ & incu. Sol. & nodes & $\begin{array}{r}\text { 1st fea. } \\
\text { Time }\end{array}$ & $\begin{array}{r}\text { fea. } \\
\text { nodes }\end{array}$ & $\begin{array}{c}\text { exit } \\
\text { code }\end{array}$ & time & memory \\
\hline A & $M$ & $\begin{array}{l}\text { rmatr100- } \\
\text { p10 }\end{array}$ & $1.97 \mathrm{E}+05$ & $4.23 E+02$ & $3.58 \mathrm{E}+03$ & $3.00 E+00$ & $1.00 \mathrm{E}+01$ & I & $9.15 E+01$ & $1.11 \mathrm{E}+08$ \\
\hline D & $M$ & $\begin{array}{l}\text { rmatr100- } \\
\text { p10 }\end{array}$ & $4.07 E+05$ & $4.23 E+02$ & $6.25 E+03$ & $9.78 \mathrm{E}+00$ & $5.00 \mathrm{E}+00$ & I & $2.16 \mathrm{E}+02$ & $3.61 E+08$ \\
\hline A & B & $\begin{array}{l}\text { rmatr100- } \\
\text { p10 }\end{array}$ & $4.09 E+05$ & $4.23 E+02$ & $9.07 E+03$ & $3.00 \mathrm{E}+00$ & $1.40 \mathrm{E}+01$ & I & $1.89 \mathrm{E}+02$ & $2.87 E+08$ \\
\hline $\mathrm{L}$ & $M$ & $\begin{array}{l}\text { rmatr100- } \\
\text { p10 }\end{array}$ & $5.18 \mathrm{E}+05$ & $4.23 E+02$ & $9.30 E+03$ & $4.70 \mathrm{E}+00$ & $6.00 \mathrm{E}+00$ & I & $2.47 \mathrm{E}+02$ & $3.36 \mathrm{E}+08$ \\
\hline $\mathrm{L}$ & B & $\begin{array}{l}\text { rmatr100- } \\
\text { p10 }\end{array}$ & $1.11 \mathrm{E}+06$ & $4.23 E+02$ & $2.57 E+04$ & $2.07 \mathrm{E}+00$ & $1.10 \mathrm{E}+01$ & I & $5.22 \mathrm{E}+02$ & $9.88 \mathrm{E}+08$ \\
\hline $\mathrm{P}$ & $M$ & $\begin{array}{l}\text { rmatr100- } \\
\text { p10 }\end{array}$ & $5.87 \mathrm{E}+05$ & $4.23 E+02$ & $1.10 \mathrm{E}+04$ & $2.07 \mathrm{E}+01$ & $3.00 E+00$ & I & $2.84 \mathrm{E}+02$ & $6.99 E+08$ \\
\hline $\mathrm{P}$ & B & $\begin{array}{l}\text { rmatr100- } \\
\text { p10 }\end{array}$ & $5.69 \mathrm{E}+05$ & $4.23 E+02$ & $1.13 \mathrm{E}+04$ & $3.47 E+00$ & $7.00 E+00$ & I & $2.82 \mathrm{E}+02$ & $8.67 E+08$ \\
\hline D & B & $\begin{array}{l}\text { neos- } \\
\text { 3610173- } \\
\text { itata }\end{array}$ & $1.40 \mathrm{E}+06$ & $1.48 \mathrm{E}+02$ & $4.96 \mathrm{E}+04$ & $6.00 \mathrm{E}-02$ & $7.00 \mathrm{E}+00$ & 1 & $8.85 E+01$ & $7.21 E+07$ \\
\hline A & $M$ & $\begin{array}{l}\text { neos- } \\
\text { 3610173- } \\
\text { itata }\end{array}$ & $3.17 E+06$ & $1.48 \mathrm{E}+02$ & $1.88 \mathrm{E}+05$ & $2.20 \mathrm{E}-01$ & $6.00 E+00$ & I & $2.17 E+02$ & $7.20 E+07$ \\
\hline D & $\mathrm{M}$ & $\begin{array}{l}\text { neos- } \\
\text { 3610173- } \\
\text { itata }\end{array}$ & $1.35 \mathrm{E}+06$ & $1.48 \mathrm{E}+02$ & $4.64 \mathrm{E}+04$ & $9.00 \mathrm{E}-02$ & $1.00 \mathrm{E}+01$ & 1 & $8.46 \mathrm{E}+01$ & $1.97 E+07$ \\
\hline A & B & $\begin{array}{l}\text { neos- } \\
\text { 3610173- } \\
\text { itata } \\
\end{array}$ & $3.45 E+06$ & $1.48 \mathrm{E}+02$ & $2.18 \mathrm{E}+05$ & $3.00 \mathrm{E}-02$ & $5.00 \mathrm{E}+00$ & $\mathrm{I}$ & $5.05 E+02$ & $2.98 \mathrm{E}+08$ \\
\hline $\mathrm{L}$ & $M$ & $\begin{array}{l}\text { neos- } \\
\text { 3610173- } \\
\text { itata }\end{array}$ & $8.02 E+05$ & $1.48 \mathrm{E}+02$ & $3.94 \mathrm{E}+04$ & $1.10 \mathrm{E}-01$ & $6.00 E+00$ & I & $4.56 \mathrm{E}+01$ & $1.42 E+07$ \\
\hline $\mathrm{L}$ & B & $\begin{array}{l}\text { neos- } \\
\text { 3610173- } \\
\text { itata }\end{array}$ & $3.51 \mathrm{E}+06$ & $1.48 \mathrm{E}+02$ & $2.70 \mathrm{E}+05$ & $2.30 \mathrm{E}-01$ & $1.90 \mathrm{E}+01$ & 1 & $3.43 E+02$ & $2.32 \mathrm{E}+08$ \\
\hline$P$ & $M$ & $\begin{array}{l}\text { neos- } \\
\text { 3610173- } \\
\text { itata }\end{array}$ & $1.56 \mathrm{E}+06$ & $1.48 \mathrm{E}+02$ & $6.44 \mathrm{E}+04$ & 4.70E-01 & $3.00 E+00$ & I & $8.55 E+01$ & $4.21 E+07$ \\
\hline $\mathrm{P}$ & B & $\begin{array}{l}\text { neos- } \\
\text { 3610173- } \\
\text { itata }\end{array}$ & $2.46 E+06$ & $1.48 \mathrm{E}+02$ & $1.55 \mathrm{E}+05$ & $1.60 \mathrm{E}-01$ & $1.00 \mathrm{E}+01$ & I & $2.23 E+02$ & $1.61 \mathrm{E}+08$ \\
\hline D & B & $\begin{array}{l}\text { neos- } \\
3610051- \\
\text { istra }\end{array}$ & $2.82 \mathrm{E}+06$ & $4.90 E+01$ & $7.51 E+04$ & $1.30 \mathrm{E}-01$ & $4.00 E+00$ & I & $1.70 E+02$ & $1.95 \mathrm{E}+07$ \\
\hline A & $\mathrm{M}$ & $\begin{array}{l}\text { neos- } \\
\text { 3610051- } \\
\text { istra }\end{array}$ & $3.30 \mathrm{E}+06$ & $4.90 \mathrm{E}+01$ & $1.34 \mathrm{E}+05$ & 4.90E-01 & $1.00 \mathrm{E}+00$ & 1 & $1.80 \mathrm{E}+02$ & $1.91 \mathrm{E}+07$ \\
\hline D & $M$ & $\begin{array}{l}\text { neos- } \\
3610051- \\
\text { istra }\end{array}$ & $2.82 \mathrm{E}+06$ & $4.90 \mathrm{E}+01$ & $7.40 \mathrm{E}+04$ & 8.20E-01 & $1.00 \mathrm{E}+00$ & 1 & $1.76 \mathrm{E}+02$ & $1.96 \mathrm{E}+07$ \\
\hline A & B & $\begin{array}{l}\text { neos- } \\
\text { 3610051- } \\
\text { istra }\end{array}$ & $3.33 \mathrm{E}+06$ & $4.90 \mathrm{E}+01$ & $1.38 \mathrm{E}+05$ & $3.00 \mathrm{E}-02$ & $5.00 \mathrm{E}+00$ & $\mathrm{I}$ & $1.89 \mathrm{E}+02$ & $2.76 \mathrm{E}+07$ \\
\hline $\mathrm{L}$ & $M$ & $\begin{array}{l}\text { neos- } \\
\text { 3610051- } \\
\text { istra }\end{array}$ & $1.03 E+06$ & $4.90 E+01$ & $4.18 \mathrm{E}+04$ & $2.10 \mathrm{E}-01$ & $4.00 E+00$ & I & $5.52 \mathrm{E}+01$ & $5.52 E+06$ \\
\hline
\end{tabular}




\begin{tabular}{|c|c|c|c|c|c|c|c|c|c|c|}
\hline VDS & NS & model & $\begin{array}{r}\text { simplex } \\
\text { it. }\end{array}$ & incu. Sol. & nodes & $\begin{array}{r}\text { 1st fea. } \\
\text { Time }\end{array}$ & $\begin{array}{r}\text { fea. } \\
\text { nodes }\end{array}$ & $\begin{array}{l}\text { exit } \\
\text { code }\end{array}$ & time & memory \\
\hline $\mathrm{L}$ & $\mathrm{B}$ & $\begin{array}{l}\text { neos- } \\
\text { 3610051- } \\
\text { istra } \\
\end{array}$ & $1.13 \mathrm{E}+06$ & $4.90 \mathrm{E}+01$ & $4.88 \mathrm{E}+04$ & $8.00 \mathrm{E}-01$ & $6.00 \mathrm{E}+00$ & $\mathrm{I}$ & $5.92 \mathrm{E}+01$ & $1.87 \mathrm{E}+07$ \\
\hline $\mathrm{P}$ & $\mathrm{M}$ & $\begin{array}{l}\text { neos- } \\
\text { 3610051- } \\
\text { istra } \\
\end{array}$ & $3.37 \mathrm{E}+06$ & $4.90 \mathrm{E}+01$ & $1.31 \mathrm{E}+05$ & $5.63 \mathrm{E}+00$ & $2.00 \mathrm{E}+00$ & 1 & $1.84 \mathrm{E}+02$ & $1.81 \mathrm{E}+07$ \\
\hline $\mathrm{P}$ & B & $\begin{array}{l}\text { neos- } \\
\text { 3610051- } \\
\text { istra }\end{array}$ & $4.19 \mathrm{E}+06$ & $4.90 \mathrm{E}+01$ & $1.57 \mathrm{E}+05$ & 3.00E-01 & $5.00 \mathrm{E}+00$ & $\mathrm{I}$ & $2.45 \mathrm{E}+02$ & $3.67 \mathrm{E}+07$ \\
\hline D & B & $\begin{array}{l}\text { neos- } \\
\text { 3611447- } \\
\text { jijia } \\
\end{array}$ & $9.43 E+05$ & $1.07 \mathrm{E}+02$ & $6.97 \mathrm{E}+04$ & 4.00E-02 & $4.00 \mathrm{E}+00$ & 1 & $5.60 \mathrm{E}+01$ & $5.03 E+07$ \\
\hline A & $\mathrm{M}$ & $\begin{array}{l}\text { neos- } \\
\text { 3611447- } \\
\text { jijia }\end{array}$ & $2.09 \mathrm{E}+06$ & $1.07 \mathrm{E}+02$ & $2.82 \mathrm{E}+05$ & $1.00 \mathrm{E}-02$ & $7.00 \mathrm{E}+00$ & 1 & $1.18 \mathrm{E}+02$ & $2.93 \mathrm{E}+07$ \\
\hline D & $\mathrm{M}$ & $\begin{array}{l}\text { neos- } \\
\text { 3611447- } \\
\text { jijia }\end{array}$ & $1.42 \mathrm{E}+06$ & $1.07 \mathrm{E}+02$ & $1.01 E+05$ & 7.00E-02 & $6.00 \mathrm{E}+00$ & 1 & $7.81 E+01$ & $2.65 \mathrm{E}+07$ \\
\hline A & $\mathrm{B}$ & $\begin{array}{l}\text { neos- } \\
\text { 3611447- } \\
\text { jijia } \\
\end{array}$ & $2.70 \mathrm{E}+06$ & $1.07 \mathrm{E}+02$ & $3.99 E+05$ & $1.00 \mathrm{E}-02$ & $8.00 E+00$ & I & $1.96 \mathrm{E}+03$ & $3.18 \mathrm{E}+08$ \\
\hline $\mathrm{L}$ & $\mathrm{M}$ & $\begin{array}{l}\text { neos- } \\
\text { 3611447- } \\
\text { jijia }\end{array}$ & $1.17 \mathrm{E}+06$ & $1.07 \mathrm{E}+02$ & $9.83 E+04$ & $5.50 \mathrm{E}-01$ & $4.00 E+00$ & I & $5.57 \mathrm{E}+01$ & $2.28 \mathrm{E}+07$ \\
\hline $\mathrm{L}$ & $\mathrm{B}$ & $\begin{array}{l}\text { neos- } \\
\text { 3611447- } \\
\text { jijia }\end{array}$ & $4.20 \mathrm{E}+06$ & $1.07 \mathrm{E}+02$ & $5.80 \mathrm{E}+05$ & 3.20E-01 & $2.10 \mathrm{E}+01$ & 1 & $1.27 \mathrm{E}+03$ & $2.86 \mathrm{E}+08$ \\
\hline$P$ & $M$ & $\begin{array}{l}\text { neos- } \\
\text { 3611447- } \\
\text { jijia }\end{array}$ & $1.49 \mathrm{E}+06$ & $1.07 \mathrm{E}+02$ & $1.35 \mathrm{E}+05$ & 7.00E-02 & $6.00 E+00$ & I & $7.22 E+01$ & $3.90 E+07$ \\
\hline $\mathrm{P}$ & B & $\begin{array}{l}\text { neos- } \\
3611447- \\
\text { jijia }\end{array}$ & $1.02 \mathrm{E}+06$ & $1.07 \mathrm{E}+02$ & $8.90 E+04$ & $9.00 \mathrm{E}-02$ & $9.00 \mathrm{E}+00$ & 1 & $6.61 E+01$ & $8.01 E+07$ \\
\hline D & $\mathrm{B}$ & $\begin{array}{l}\text { neos- } \\
\text { 3610040- } \\
\text { iskar }\end{array}$ & $4.62 \mathrm{E}+05$ & $3.70 E+01$ & $3.76 \mathrm{E}+04$ & $2.00 \mathrm{E}-02$ & $3.00 E+00$ & I & $2.53 E+01$ & $2.55 E+06$ \\
\hline A & $\mathrm{M}$ & $\begin{array}{l}\text { neos- } \\
\text { 3610040- } \\
\text { iskar }\end{array}$ & $5.83 \mathrm{E}+05$ & $3.70 \mathrm{E}+01$ & $6.93 E+04$ & $1.10 \mathrm{E}-01$ & $2.00 \mathrm{E}+00$ & 1 & $2.84 \mathrm{E}+01$ & $2.44 \mathrm{E}+06$ \\
\hline D & $M$ & $\begin{array}{l}\text { neos- } \\
\text { 3610040- } \\
\text { iskar }\end{array}$ & $4.65 E+05$ & $3.70 E+01$ & $3.79 E+04$ & 5.00E-02 & $2.00 \mathrm{E}+00$ & 1 & $2.76 \mathrm{E}+01$ & $2.46 \mathrm{E}+06$ \\
\hline A & B & $\begin{array}{l}\text { neos- } \\
\text { 3610040- } \\
\text { iskar }\end{array}$ & $5.84 \mathrm{E}+05$ & $3.70 E+01$ & $6.94 \mathrm{E}+04$ & $1.00 \mathrm{E}-02$ & $3.00 E+00$ & I & $3.05 E+01$ & $4.71 E+06$ \\
\hline $\mathrm{L}$ & $M$ & $\begin{array}{l}\text { neos- } \\
\text { 3610040- } \\
\text { iskar }\end{array}$ & $3.86 \mathrm{E}+05$ & $3.70 \mathrm{E}+01$ & $4.36 \mathrm{E}+04$ & 7.00E-02 & $3.00 E+00$ & I & $1.82 \mathrm{E}+01$ & $2.04 E+06$ \\
\hline $\mathrm{L}$ & B & $\begin{array}{l}\text { neos- } \\
3610040- \\
\text { iskar }\end{array}$ & $4.06 \mathrm{E}+05$ & $3.70 E+01$ & $5.14 \mathrm{E}+04$ & $1.30 \mathrm{E}-01$ & $8.00 \mathrm{E}+00$ & 1 & $1.97 \mathrm{E}+01$ & $7.17 E+06$ \\
\hline$P$ & $M$ & $\begin{array}{l}\text { neos- } \\
\text { 3610040- } \\
\text { iskar }\end{array}$ & $8.35 E+05$ & $3.70 \mathrm{E}+01$ & $8.95 E+04$ & 3.10E-01 & $1.00 \mathrm{E}+00$ & I & $3.78 \mathrm{E}+01$ & $3.20 E+06$ \\
\hline
\end{tabular}




\begin{tabular}{|c|c|c|c|c|c|c|c|c|c|c|}
\hline VDS & NS & model & $\begin{array}{r}\text { simplex } \\
\text { it. }\end{array}$ & incu. Sol. & nodes & $\begin{array}{r}\text { 1st fea. } \\
\text { Time }\end{array}$ & $\begin{array}{r}\text { fea. } \\
\text { nodes }\end{array}$ & $\begin{array}{l}\text { exit } \\
\text { code }\end{array}$ & time & memory \\
\hline $\mathrm{P}$ & B & $\begin{array}{l}\text { neos- } \\
\text { 3610040- } \\
\text { iskar }\end{array}$ & $8.35 \mathrm{E}+05$ & $3.70 \mathrm{E}+01$ & $9.05 E+04$ & $5.00 \mathrm{E}-02$ & $1.00 \mathrm{E}+00$ & $\mathrm{I}$ & $3.95 E+01$ & $7.08 \mathrm{E}+06$ \\
\hline D & $\mathrm{B}$ & $\begin{array}{l}\text { neos- } \\
\text { 3611689- } \\
\text { kaihu }\end{array}$ & $5.22 \mathrm{E}+06$ & $1.19 \mathrm{E}+02$ & $4.78 \mathrm{E}+05$ & $3.00 \mathrm{E}-02$ & $1.00 \mathrm{E}+01$ & 1 & $1.95 \mathrm{E}+03$ & $2.61 \mathrm{E}+08$ \\
\hline A & $\mathrm{M}$ & $\begin{array}{l}\text { neos- } \\
\text { 3611689- } \\
\text { kaihu }\end{array}$ & $1.08 \mathrm{E}+07$ & $1.19 \mathrm{E}+02$ & $1.56 \mathrm{E}+06$ & $2.00 \mathrm{E}-02$ & $4.00 \mathrm{E}+00$ & $\mathrm{I}$ & $5.37 E+02$ & $2.47 \mathrm{E}+07$ \\
\hline D & $\mathrm{M}$ & $\begin{array}{l}\text { neos- } \\
\text { 3611689- } \\
\text { kaihu }\end{array}$ & $3.56 \mathrm{E}+06$ & $1.19 \mathrm{E}+02$ & $2.42 \mathrm{E}+05$ & $3.00 \mathrm{E}-02$ & $8.00 E+00$ & 1 & $1.68 \mathrm{E}+02$ & $3.85 E+07$ \\
\hline A & B & $\begin{array}{l}\text { neos- } \\
\text { 3611689- } \\
\text { kaihu } \\
\end{array}$ & $3.68 \mathrm{E}+06$ & $1.20 \mathrm{E}+02$ & $8.46 \mathrm{E}+05$ & $1.00 \mathrm{E}-02$ & $5.00 \mathrm{E}+00$ & $\mathrm{~T}$ & $3.60 \mathrm{E}+03$ & $5.18 \mathrm{E}+08$ \\
\hline $\mathrm{L}$ & $\mathrm{M}$ & $\begin{array}{l}\text { neos- } \\
\text { 3611689- } \\
\text { kaihu }\end{array}$ & $5.03 E+06$ & $1.19 \mathrm{E}+02$ & $4.85 E+05$ & $2.40 \mathrm{E}-01$ & $2.00 \mathrm{E}+00$ & 1 & $2.06 \mathrm{E}+02$ & $3.62 E+07$ \\
\hline $\mathrm{L}$ & B & $\begin{array}{l}\text { neos- } \\
\text { 3611689- } \\
\text { kaihu }\end{array}$ & $5.61 \mathrm{E}+06$ & $1.21 E+02$ & $7.83 E+05$ & 5.10E-01 & $1.50 \mathrm{E}+01$ & $\mathrm{~T}$ & $3.60 E+03$ & $4.08 \mathrm{E}+08$ \\
\hline $\mathrm{P}$ & $\mathrm{M}$ & $\begin{array}{l}\text { neos- } \\
3611689- \\
\text { kaihu }\end{array}$ & $1.95 \mathrm{E}+06$ & $1.19 \mathrm{E}+02$ & $1.80 \mathrm{E}+05$ & $8.00 \mathrm{E}-02$ & $6.00 \mathrm{E}+00$ & I & $7.97 \mathrm{E}+01$ & $2.66 \mathrm{E}+07$ \\
\hline $\mathrm{P}$ & B & $\begin{array}{l}\text { neos- } \\
\text { 3611689- } \\
\text { kaihu }\end{array}$ & $2.35 \mathrm{E}+06$ & $1.19 \mathrm{E}+02$ & $2.38 \mathrm{E}+05$ & $7.00 \mathrm{E}-02$ & $7.00 \mathrm{E}+00$ & 1 & $5.31 \mathrm{E}+02$ & $1.35 \mathrm{E}+08$ \\
\hline $\mathrm{D}$ & B & $\operatorname{ran} 13 \times 13$ & $3.41 \mathrm{E}+06$ & $3.32 \mathrm{E}+03$ & $1.03 E+06$ & $2.00 \mathrm{E}-02$ & $1.20 \mathrm{E}+01$ & $\mathrm{~T}$ & $3.60 \mathrm{E}+03$ & $6.62 \mathrm{E}+08$ \\
\hline A & $\mathrm{M}$ & $\operatorname{ran} 13 \times 13$ & $3.47 \mathrm{E}+07$ & $3.25 E+03$ & $7.69 E+06$ & $2.00 \mathrm{E}-02$ & $1.90 \mathrm{E}+01$ & I & $1.92 \mathrm{E}+03$ & $4.33 \mathrm{E}+07$ \\
\hline D & $\mathrm{M}$ & $\operatorname{ran} 13 \times 13$ & $3.14 \mathrm{E}+06$ & $3.25 E+03$ & $5.92 \mathrm{E}+05$ & $5.00 \mathrm{E}-02$ & $1.00 \mathrm{E}+01$ & 1 & $2.32 \mathrm{E}+02$ & $3.75 E+07$ \\
\hline A & B & $\operatorname{ran} 13 \times 13$ & $4.00 \mathrm{E}+06$ & $3.33 \mathrm{E}+03$ & $8.88 \mathrm{E}+05$ & $1.00 \mathrm{E}-02$ & $2.00 \mathrm{E}+01$ & $\mathrm{~T}$ & $3.60 \mathrm{E}+03$ & $7.43 \mathrm{E}+08$ \\
\hline $\mathrm{L}$ & $\mathrm{M}$ & $\operatorname{ran} 13 \times 13$ & $2.70 \mathrm{E}+07$ & $3.25 \mathrm{E}+03$ & $5.80 \mathrm{E}+06$ & 4.20E-01 & $1.20 \mathrm{E}+01$ & I & $1.58 \mathrm{E}+03$ & $2.81 \mathrm{E}+07$ \\
\hline $\mathrm{L}$ & B & $\operatorname{ran} 13 \times 13$ & $6.49 \mathrm{E}+06$ & $4.30 \mathrm{E}+03$ & $1.93 \mathrm{E}+06$ & $1.01 \mathrm{E}+00$ & $2.00 \mathrm{E}+00$ & $\mathrm{~T}$ & $3.60 \mathrm{E}+03$ & $6.38 \mathrm{E}+08$ \\
\hline $\mathrm{P}$ & $\mathrm{M}$ & $\operatorname{ran} 13 \times 13$ & $3.90 \mathrm{E}+06$ & $3.25 E+03$ & $7.35 E+05$ & $9.00 \mathrm{E}-02$ & $1.30 \mathrm{E}+01$ & 1 & $3.47 \mathrm{E}+02$ & $2.82 \mathrm{E}+07$ \\
\hline$P$ & B & $\operatorname{ran} 13 \times 13$ & $3.35 E+06$ & $3.25 E+03$ & $1.08 \mathrm{E}+06$ & $5.90 \mathrm{E}-01$ & $9.00 \mathrm{E}+00$ & $\mathrm{~T}$ & $3.60 \mathrm{E}+03$ & $4.78 \mathrm{E}+08$ \\
\hline D & B & $\begin{array}{l}\mathrm{p} 200 \times 118 \\
8 \mathrm{c}\end{array}$ & $5.15 \mathrm{E}+06$ & $1.55 \mathrm{E}+04$ & $7.09 E+05$ & $1.98 \mathrm{E}+00$ & $1.30 \mathrm{E}+01$ & $T$ & $3.60 E+03$ & $3.68 \mathrm{E}+09$ \\
\hline A & $M$ & $\begin{array}{l}\text { p200x118 } \\
8 c\end{array}$ & $1.82 \mathrm{E}+07$ & $1.54 \mathrm{E}+04$ & $2.69 E+06$ & 4.00E-02 & $2.00 E+00$ & $\mathrm{~T}$ & $3.60 E+03$ & $7.69 E+08$ \\
\hline D & $\mathrm{M}$ & $\begin{array}{l}\mathrm{p} 200 \times 118 \\
8 \mathrm{c}\end{array}$ & $1.01 \mathrm{E}+07$ & $1.51 E+04$ & $1.26 \mathrm{E}+06$ & 1.60E-01 & $6.00 E+00$ & I & $2.46 \mathrm{E}+03$ & $6.14 \mathrm{E}+08$ \\
\hline A & B & $\begin{array}{l}\text { p200x118 } \\
8 c\end{array}$ & $4.97 \mathrm{E}+06$ & $1.54 \mathrm{E}+04$ & $5.36 \mathrm{E}+05$ & $4.00 \mathrm{E}-02$ & $2.00 \mathrm{E}+00$ & $T$ & $3.60 E+03$ & $6.02 E+09$ \\
\hline $\mathrm{L}$ & $\mathrm{M}$ & $\begin{array}{l}\mathrm{p} 200 \times 118 \\
8 \mathrm{c}\end{array}$ & $1.38 \mathrm{E}+07$ & $1.51 E+04$ & $1.99 E+06$ & 7.40E-01 & $3.00 E+00$ & $\mathrm{~T}$ & $3.60 E+03$ & $2.21 E+08$ \\
\hline $\mathrm{L}$ & $\mathrm{B}$ & $\begin{array}{l}\mathrm{p} 200 \times 118 \\
8 \mathrm{c}\end{array}$ & $7.97 E+06$ & $\mathrm{~N}$ & $1.98 \mathrm{E}+06$ & $0.00 \mathrm{E}+00$ & $0.00 E+00$ & $\mathrm{~T}$ & $3.60 E+03$ & $6.63 E+08$ \\
\hline$P$ & $\mathrm{M}$ & $\begin{array}{l}\text { p200x118 } \\
8 c\end{array}$ & $1.62 \mathrm{E}+06$ & $1.51 E+04$ & $1.94 \mathrm{E}+05$ & $1.88 \mathrm{E}+00$ & $5.00 E+00$ & I & $3.19 E+02$ & $1.97 E+08$ \\
\hline $\mathrm{P}$ & B & $\begin{array}{l}\mathrm{p} 200 \times 118 \\
8 \mathrm{c}\end{array}$ & $8.19 E+06$ & $1.61 \mathrm{E}+04$ & $2.33 \mathrm{E}+06$ & $2.98 \mathrm{E}+03$ & $1.00 \mathrm{E}+00$ & $\mathrm{~T}$ & $3.60 \mathrm{E}+03$ & $9.20 \mathrm{E}+08$ \\
\hline D & B & bienst1 & $2.41 E+06$ & $4.68 \mathrm{E}+01$ & $4.07 E+04$ & $6.00 \mathrm{E}-02$ & $7.00 E+00$ & I & $1.21 \mathrm{E}+02$ & $3.10 E+07$ \\
\hline
\end{tabular}




\begin{tabular}{|c|c|c|c|c|c|c|c|c|c|c|}
\hline VDS & NS & model & $\begin{array}{r}\text { implex } \\
\text { it. }\end{array}$ & incu. Sol. & nodes & $\begin{array}{r}\text { 1st fea. } \\
\text { Time }\end{array}$ & $\begin{array}{r}\text { fea. } \\
\text { nodes }\end{array}$ & $\begin{array}{c}\text { exit } \\
\text { code }\end{array}$ & time & memory \\
\hline A & $M$ & bienst1 & $8 \mathrm{E}+06$ & $3 E+01$ & $22 E+04$ & 4.00E-02 & $O E+00$ & I & $1.18 \mathrm{E}+02$ & $1.82 \mathrm{E}+07$ \\
\hline D & M & bienst1 & $E+06$ & $8 E+01$ & $2 E+04$ & $7.00 \mathrm{E}-02$ & $9.00 E+00$ & 1 & $18 E+02$ & $33 E+06$ \\
\hline A & D & bienst1 & $E+06$ & $4.68 \mathrm{E}+01$ & $.39 E+04$ & $4.00 \mathrm{E}-02$ & $10 E+01$ & I & $26 \mathrm{E}+02$ & $.39 \mathrm{E}+07$ \\
\hline $\mathrm{L}$ & $\mathrm{M}$ & bienst1 & $E+06$ & $8 E+01$ & $88 \mathrm{E}+04$ & $3.00 \mathrm{E}-02$ & $00 E+00$ & I & $5.18 \mathrm{E}+01$ & $.33 E+06$ \\
\hline $\mathrm{L}$ & $\mathrm{B}$ & bienst1 & $1.16 \mathrm{E}+06$ & $4.68 \mathrm{E}+01$ & $2.86 \mathrm{E}+04$ & 3.00E-02 & $1.00 \mathrm{E}+01$ & 1 & $5.60 \mathrm{E}+01$ & $3.65 \mathrm{E}+07$ \\
\hline $\mathrm{P}$ & M & bienst1 & $1.04 \mathrm{E}+06$ & $4.68 \mathrm{E}+01$ & $1.91 \mathrm{E}+04$ & $1.10 \mathrm{E}-01$ & $6.00 \mathrm{E}+00$ & I & $5.03 E+01$ & $2.70 \mathrm{E}+06$ \\
\hline $\mathrm{P}$ & $\mathrm{B}$ & bienst1 & $1.06 \mathrm{E}+06$ & $4.68 \mathrm{E}+01$ & $1.99 \mathrm{E}+04$ & $1.00 \mathrm{E}-01$ & $8.00 \mathrm{E}+00$ & I & $5.17 \mathrm{E}+01$ & 2.14E+07 \\
\hline D & $\mathrm{B}$ & bienst2 & $1.62 \mathrm{E}+07$ & $5.46 \mathrm{E}+01$ & $3.36 \mathrm{E}+05$ & $6.00 \mathrm{E}-02$ & $1.40 \mathrm{E}+01$ & I & $1.23 \mathrm{E}+03$ & $3.66 \mathrm{E}+08$ \\
\hline A & $M$ & bienst2 & $1.91 \mathrm{E}+07$ & $5.46 \mathrm{E}+01$ & $4.81 \mathrm{E}+05$ & 4.00E-02 & $1.50 \mathrm{E}+01$ & I & $9.71 \mathrm{E}+02$ & $1.24 \mathrm{E}+08$ \\
\hline D & M & bienst2 & $1.63 \mathrm{E}+07$ & $5.46 \mathrm{E}+01$ & $3.35 \mathrm{E}+05$ & $1.20 \mathrm{E}-01$ & $1.10 \mathrm{E}+01$ & 1 & $7.84 E+02$ & $1.03 E+07$ \\
\hline A & $\mathrm{B}$ & bienst2 & $1.93 \mathrm{E}+07$ & $5.46 \mathrm{E}+01$ & $4.87 \mathrm{E}+05$ & 4.00E-02 & $1.40 \mathrm{E}+01$ & 1 & $2.36 \mathrm{E}+03$ & 4.50E+08 \\
\hline $\mathrm{L}$ & $\mathrm{M}$ & bienst2 & $6.34 \mathrm{E}+06$ & $5.46 \mathrm{E}+01$ & $1.98 \mathrm{E}+05$ & 4.00E-02 & $1.00 \mathrm{E}+01$ & 1 & $2.96 \mathrm{E}+02$ & $3.06 \mathrm{E}+07$ \\
\hline L & $\mathrm{B}$ & bienst2 & $6.85 \mathrm{E}+06$ & $5.46 \mathrm{E}+01$ & $2.20 \mathrm{E}+05$ & 4.00E-02 & $1.50 \mathrm{E}+01$ & 1 & $4.21 \mathrm{E}+02$ & $2.48 \mathrm{E}+08$ \\
\hline $\mathrm{P}$ & $\mathrm{M}$ & bienst2 & $1.31 \mathrm{E}+07$ & $5.46 \mathrm{E}+01$ & $3.54 \mathrm{E}+05$ & $1.30 \mathrm{E}-01$ & $1.00 \mathrm{E}+01$ & 1 & $.02 E+02$ & $1.23 \mathrm{E}+07$ \\
\hline $\mathrm{P}$ & $\mathrm{B}$ & bienst2 & $E+07$ & $5.46 \mathrm{E}+01$ & $.99 \mathrm{E}+05$ & $1.30 \mathrm{E}-01$ & $1.60 \mathrm{E}+01$ & 1 & $1.63 \mathrm{E}+03$ & $3.69 \mathrm{E}+08$ \\
\hline D & $B$ & blend2 & $1.36 \mathrm{E}+04$ & $7.60 \mathrm{E}+00$ & $3.96 \mathrm{E}+03$ & $\mathrm{E}-02$ & $6.00 \mathrm{E}+00$ & 1 & $1.10 \mathrm{E}+00$ & $2.43 \mathrm{E}+06$ \\
\hline A & $\mathrm{M}$ & blend2 & $2.02 \mathrm{E}+04$ & $7.60 \mathrm{E}+00$ & $6.68 \mathrm{E}+03$ & $1.00 \mathrm{E}-02$ & $4.00 \mathrm{E}+00$ & I & $2.10 \mathrm{E}+00$ & $1.46 \mathrm{E}+06$ \\
\hline D & $\mathrm{M}$ & blend2 & $6.42 \mathrm{E}+03$ & $7.60 E+00$ & $1.46 \mathrm{E}+03$ & $5.00 \mathrm{E}-02$ & $7.00 \mathrm{E}+00$ & I & $5.00 \mathrm{E}-01$ & $8.84 \mathrm{E}+05$ \\
\hline A & $\mathrm{B}$ & blend2 & $5.88 \mathrm{E}+04$ & $7.60 \mathrm{E}+00$ & $1.75 \mathrm{E}+04$ & $1.20 \mathrm{E}-01$ & $7.00 \mathrm{E}+00$ & I & $5.30 \mathrm{E}+00$ & $6.49 \mathrm{E}+06$ \\
\hline L & $M$ & blend2 & $1.02 \mathrm{E}+05$ & $7.60 E+00$ & $2.92 E+04$ & 1.10E-01 & $1.00 \mathrm{E}+01$ & I & $5.90 \mathrm{E}+00$ & $5.19 \mathrm{E}+06$ \\
\hline L & $\mathrm{B}$ & blend2 & $1.04 \mathrm{E}+05$ & $7.60 \mathrm{E}+00$ & $5.72 \mathrm{E}+04$ & $7.29 \mathrm{E}+00$ & $2.00 \mathrm{E}+00$ & 1 & $8.10 \mathrm{E}+00$ & $1.64 \mathrm{E}+07$ \\
\hline$P$ & $\mathrm{M}$ & blend2 & $6.32 \mathrm{E}+03$ & $7.60 \mathrm{E}+00$ & $2.32 \mathrm{E}+03$ & 1.10E-01 & $7.00 \mathrm{E}+00$ & 1 & OOE-01 & $1.26 \mathrm{E}+06$ \\
\hline$P$ & $B$ & blend & $1.01 \mathrm{E}+04$ & $7.60 \mathrm{E}+00$ & $4.74 \mathrm{E}+03$ & $.40 \mathrm{E}-01$ & $.00 \mathrm{E}+00$ & 1 & $E-01$ & $1.82 \mathrm{E}+06$ \\
\hline D & B & $\mathrm{ph}$ & $33 \mathrm{E}+06$ & $1.10 \mathrm{E}+01$ & $4.71 \mathrm{E}+05$ & OOE-02 & $1.60 \mathrm{E}+01$ & 1 & 0 & $1.38 \mathrm{E}+08$ \\
\hline A & $N$ & pk1 & +06 & DE+01 & 06 & $50 \mathrm{E}-01$ & $00 \mathrm{E}+00$ & 1 & 02 & +07 \\
\hline D & $M$ & pk1 & $3.10 \mathrm{E}+06$ & $1.10 \mathrm{E}+01$ & $3.77 \mathrm{E}+05$ & $1.00 \mathrm{E}-01$ & $6.00 \mathrm{E}+00$ & 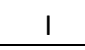 & $1.04 \mathrm{E}+02$ & $1.46 \mathrm{E}+07$ \\
\hline A & $\mathrm{B}$ & $\mathrm{pk} 1$ & $5.21 \mathrm{E}+06$ & $1.50 \mathrm{E}+01$ & $1.15 \mathrm{E}+06$ & $0.00 \mathrm{E}+00$ & $1.50 \mathrm{E}+01$ & 1 & $3.60 \mathrm{E}+03$ & $3.54 \mathrm{E}+08$ \\
\hline $\mathrm{L}$ & $\mathrm{M}$ & pk1 & $3.95 \mathrm{E}+06$ & $1.10 \mathrm{E}+01$ & $6.19 E+05$ & 2.00E-02 & 1.10E+01 & 1 & $1.86 \mathrm{E}+02$ & $1.81 \mathrm{E}+07$ \\
\hline $\mathrm{L}$ & $B$ & pk1 & $4.86 \mathrm{E}+06$ & $2.00 \mathrm{E}+01$ & $8.97 \mathrm{E}+05$ & $1.00 \mathrm{E}-02$ & $4.00 \mathrm{E}+00$ & $\mathrm{~T}$ & $3.60 \mathrm{E}+03$ & $3.46 \mathrm{E}+08$ \\
\hline $\mathrm{P}$ & $M$ & pk1 & $3.49 \mathrm{E}+06$ & $1.10 \mathrm{E}+01$ & $6.25 \mathrm{E}+05$ & 4.00E-02 & $5.00 \mathrm{E}+00$ & 1 & $1.10 \mathrm{E}+02$ & $1.09 \mathrm{E}+07$ \\
\hline $\mathrm{P}$ & $\mathrm{B}$ & pk1 & $2.68 \mathrm{E}+06$ & $1.10 \mathrm{E}+01$ & $6.44 \mathrm{E}+05$ & $2.00 \mathrm{E}-02$ & $1.40 \mathrm{E}+01$ & $\mathrm{~T}$ & $3.60 \mathrm{E}+03$ & $1.88 \mathrm{E}+08$ \\
\hline D & B & dano3_3 & $1.71 \mathrm{E}+04$ & $5.76 \mathrm{E}+02$ & $7.10 \mathrm{E}+01$ & $2.02 \mathrm{E}+00$ & $2.00 \mathrm{E}+00$ & 1 & $1.27 \mathrm{E}+01$ & $2.36 \mathrm{E}+07$ \\
\hline A & $\mathrm{M}$ & dano3_3 & $2.15 \mathrm{E}+04$ & $5.76 \mathrm{E}+02$ & $5.90 \mathrm{E}+01$ & $1.63 \mathrm{E}+00$ & $2.00 \mathrm{E}+00$ & 1 & $1.50 \mathrm{E}+01$ & $2.36 \mathrm{E}+07$ \\
\hline D & $\mathrm{M}$ & dano3_3 & $1.75 \mathrm{E}+04$ & $5.76 \mathrm{E}+02$ & $6.70 \mathrm{E}+01$ & $2.00 \mathrm{E}+00$ & $3.00 \mathrm{E}+00$ & $\mathrm{I}$ & $1.30 \mathrm{E}+01$ & $2.35 \mathrm{E}+07$ \\
\hline $\mathrm{A}$ & $\mathrm{D}$ & dano3_3 & $3.72 \mathrm{E}+04$ & $5.76 \mathrm{E}+02$ & $8.90 \mathrm{E}+01$ & $1.62 \mathrm{E}+00$ & $3.00 \mathrm{E}+00$ & 1 & $2.42 \mathrm{E}+01$ & $2.39 \mathrm{E}+07$ \\
\hline L & $\mathrm{M}$ & dano3_3 & $2.22 \mathrm{E}+04$ & $5.76 \mathrm{E}+02$ & $5.10 \mathrm{E}+01$ & $1.49 \mathrm{E}+00$ & $4.00 \mathrm{E}+00$ & 1 & $1.54 \mathrm{E}+01$ & 2.37E+07 \\
\hline L & B & 33 & $2.30 \mathrm{E}+04$ & $5.76 \mathrm{E}+02$ & $4.70 \mathrm{E}+01$ & $1.50 \mathrm{E}+00$ & $3.00 \mathrm{E}+00$ & 1 & $1.58 \mathrm{E}+01$ & $2.37 E+07$ \\
\hline $\mathrm{P}$ & $M$ & $3 \_3$ & E+04 & $5.76 \mathrm{E}+02$ & $4.90 \mathrm{E}+01$ & $2.70 \mathrm{E}+00$ & $00 \mathrm{E}+00$ & I & $1.26 \mathrm{E}+01$ & $.20 \mathrm{E}+07$ \\
\hline $\mathrm{P}$ & $B$ & 03_3 & $1.44 \mathrm{E}+04$ & $5.76 \mathrm{E}+02$ & $4.90 \mathrm{E}+01$ & $2.71 \mathrm{E}+00$ & $1.00 \mathrm{E}+00$ & 1 & $1.26 \mathrm{E}+01$ & $3.16 \mathrm{E}+07$ \\
\hline D & B & no3_4 & $4.05 E+04$ & $5.76 \mathrm{E}+02$ & $2.79 E+02$ & $5.33 E+00$ & $4.00 E+00$ & 1 & $2.90 \mathrm{E}+01$ & $2.57 \mathrm{E}+07$ \\
\hline
\end{tabular}




\begin{tabular}{|c|c|c|c|c|c|c|c|c|c|c|}
\hline VDS & NS & model & $\begin{array}{r}\text { simplex } \\
\text { it. }\end{array}$ & incu. Sol. & nodes & $\begin{array}{r}\text { 1st fea. } \\
\text { Time }\end{array}$ & $\begin{array}{r}\text { fea. } \\
\text { nodes }\end{array}$ & $\begin{array}{l}\text { exit } \\
\text { code }\end{array}$ & time & memory \\
\hline $\mathrm{A}$ & $M$ & dano3_4 & $4.03 E+04$ & $5.76 \mathrm{E}+02$ & $1.23 E+02$ & $2.55 \mathrm{E}+00$ & $3.00 \mathrm{E}+00$ & 1 & $2.62 \mathrm{E}+01$ & $2.42 \mathrm{E}+07$ \\
\hline D & $\mathrm{M}$ & dano3_4 & $4.65 E+04$ & $5.76 \mathrm{E}+02$ & $3.61 \mathrm{E}+02$ & $1.09 \mathrm{E}+01$ & $4.00 E+00$ & 1 & $3.29 E+01$ & $2.55 \mathrm{E}+07$ \\
\hline A & $\mathrm{D}$ & dano3_4 & $8.69 \mathrm{E}+04$ & $5.76 \mathrm{E}+02$ & $1.95 \mathrm{E}+02$ & $2.55 \mathrm{E}+00$ & $5.00 \mathrm{E}+00$ & I & $5.40 \mathrm{E}+01$ & $2.48 \mathrm{E}+07$ \\
\hline $\mathrm{L}$ & $M$ & dano3_4 & $4.91 \mathrm{E}+04$ & $5.76 \mathrm{E}+02$ & $2.03 E+02$ & $3.63 E+00$ & $6.00 E+00$ & $\mathrm{I}$ & $3.21 \mathrm{E}+01$ & $2.42 E+07$ \\
\hline $\mathrm{L}$ & $\mathrm{B}$ & dano3_4 & $7.01 \mathrm{E}+04$ & $5.76 \mathrm{E}+02$ & $1.91 \mathrm{E}+02$ & $2.52 \mathrm{E}+00$ & $5.00 \mathrm{E}+00$ & I & $4.45 E+01$ & $2.56 \mathrm{E}+07$ \\
\hline$P$ & $M$ & dano3_4 & $4.22 \mathrm{E}+04$ & $5.76 \mathrm{E}+02$ & $1.33 \mathrm{E}+02$ & $2.10 \mathrm{E}+01$ & $1.00 \mathrm{E}+00$ & I & $3.01 \mathrm{E}+01$ & $3.17 \mathrm{E}+07$ \\
\hline $\mathrm{P}$ & B & dano3_4 & $1.93 \mathrm{E}+04$ & $5.76 \mathrm{E}+02$ & $1.05 \mathrm{E}+02$ & $5.38 \mathrm{E}+00$ & $1.00 E+00$ & 1 & $1.75 \mathrm{E}+01$ & $3.16 \mathrm{E}+07$ \\
\hline D & B & dano3_5 & $2.99 \mathrm{E}+05$ & $5.77 \mathrm{E}+02$ & $2.00 \mathrm{E}+03$ & $7.12 \mathrm{E}+00$ & $5.00 \mathrm{E}+00$ & 1 & $2.12 \mathrm{E}+02$ & $4.47 \mathrm{E}+07$ \\
\hline A & $M$ & dano3_5 & $1.18 \mathrm{E}+06$ & $5.77 \mathrm{E}+02$ & $5.35 E+03$ & $3.96 \mathrm{E}+00$ & $1.10 \mathrm{E}+01$ & 1 & $7.35 E+02$ & $3.33 E+07$ \\
\hline D & $M$ & dano3_5 & $3.15 E+05$ & $5.77 \mathrm{E}+02$ & $1.98 \mathrm{E}+03$ & $1.02 \mathrm{E}+01$ & $5.00 \mathrm{E}+00$ & 1 & $2.20 \mathrm{E}+02$ & $3.50 \mathrm{E}+07$ \\
\hline $\mathrm{A}$ & $\mathrm{D}$ & dano3_5 & $2.26 \mathrm{E}+06$ & $5.77 \mathrm{E}+02$ & $7.36 \mathrm{E}+03$ & $3.94 \mathrm{E}+00$ & $1.80 \mathrm{E}+01$ & I & $1.37 \mathrm{E}+03$ & $1.02 \mathrm{E}+08$ \\
\hline $\mathrm{L}$ & $\mathrm{M}$ & dano3_5 & $2.96 \mathrm{E}+05$ & $5.77 \mathrm{E}+02$ & $1.25 \mathrm{E}+03$ & $4.05 E+00$ & $7.00 \mathrm{E}+00$ & 1 & $1.87 \mathrm{E}+02$ & $2.76 \mathrm{E}+07$ \\
\hline $\mathrm{L}$ & B & dano3_5 & $8.00 \mathrm{E}+05$ & $5.77 \mathrm{E}+02$ & $2.46 \mathrm{E}+03$ & $3.07 \mathrm{E}+00$ & $9.00 \mathrm{E}+00$ & 1 & $4.90 \mathrm{E}+02$ & $7.24 \mathrm{E}+07$ \\
\hline $\mathrm{P}$ & $M$ & dano3_5 & $3.00 E+05$ & $5.77 \mathrm{E}+02$ & $1.80 \mathrm{E}+03$ & $2.15 \mathrm{E}+01$ & $4.00 E+00$ & 1 & $2.02 E+02$ & $4.39 E+07$ \\
\hline $\mathrm{P}$ & B & dano3_5 & $2.64 \mathrm{E}+05$ & $5.77 \mathrm{E}+02$ & $1.72 \mathrm{E}+03$ & $7.62 \mathrm{E}+00$ & $4.00 \mathrm{E}+00$ & I & $1.81 \mathrm{E}+02$ & $4.52 \mathrm{E}+07$ \\
\hline D & B & swath1 & $1.31 \mathrm{E}+04$ & $3.79 \mathrm{E}+02$ & $1.65 \mathrm{E}+03$ & $2.90 \mathrm{E}-01$ & $4.00 \mathrm{E}+00$ & 1 & $8.40 \mathrm{E}+00$ & $1.40 \mathrm{E}+07$ \\
\hline A & $\mathrm{M}$ & swath1 & $8.46 \mathrm{E}+05$ & $3.79 E+02$ & $1.18 \mathrm{E}+05$ & $1.30 \mathrm{E}-01$ & $1.10 \mathrm{E}+01$ & $\mathrm{I}$ & $4.26 \mathrm{E}+02$ & $5.13 E+07$ \\
\hline D & $\mathrm{M}$ & swath1 & $8.72 \mathrm{E}+03$ & $3.79 \mathrm{E}+02$ & $1.06 \mathrm{E}+03$ & $1.60 \mathrm{E}-01$ & $4.00 \mathrm{E}+00$ & I & $6.00 \mathrm{E}+00$ & $1.04 \mathrm{E}+07$ \\
\hline A & B & swath1 & $9.16 \mathrm{E}+05$ & $3.79 \mathrm{E}+02$ & $1.28 \mathrm{E}+05$ & $1.27 \mathrm{E}+00$ & $4.00 E+00$ & 1 & $4.72 E+02$ & $3.41 E+08$ \\
\hline $\mathrm{L}$ & $M$ & swath1 & $1.84 \mathrm{E}+05$ & $3.79 E+02$ & $2.12 E+04$ & $3.40 \mathrm{E}-01$ & $1.40 \mathrm{E}+01$ & 1 & $8.56 \mathrm{E}+01$ & $2.43 \mathrm{E}+07$ \\
\hline $\mathrm{L}$ & B & swath1 & $3.39 \mathrm{E}+05$ & $3.79 \mathrm{E}+02$ & $4.96 \mathrm{E}+04$ & $5.25 \mathrm{E}+00$ & $4.00 \mathrm{E}+00$ & I & $1.87 \mathrm{E}+02$ & $1.31 \mathrm{E}+08$ \\
\hline $\mathrm{P}$ & $\mathrm{M}$ & swath1 & $2.76 \mathrm{E}+05$ & $3.79 E+02$ & $3.94 \mathrm{E}+04$ & $1.85 \mathrm{E}+01$ & $6.00 \mathrm{E}+00$ & 1 & $1.61 \mathrm{E}+02$ & $4.35 \mathrm{E}+07$ \\
\hline $\mathrm{P}$ & $B$ & swath1 & $1.21 \mathrm{E}+06$ & $3.79 \mathrm{E}+02$ & $1.36 \mathrm{E}+05$ & $2.69 \mathrm{E}+01$ & $1.30 \mathrm{E}+01$ & 1 & $7.49 \mathrm{E}+02$ & $1.98 \mathrm{E}+08$ \\
\hline $\mathrm{D}$ & B & $\begin{array}{l}\text { neos- } \\
\text { 3083819- } \\
\text { nubu }\end{array}$ & $8.95 \mathrm{E}+04$ & $6.31 \mathrm{E}+06$ & $9.14 \mathrm{E}+03$ & $0.00 \mathrm{E}+00$ & $0.00 \mathrm{E}+00$ & 1 & $1.74 \mathrm{E}+02$ & $8.90 \mathrm{E}+07$ \\
\hline A & $\mathrm{M}$ & $\begin{array}{l}\text { neos- } \\
\text { 3083819- } \\
\text { nubu }\end{array}$ & $8.02 \mathrm{E}+05$ & $6.31 \mathrm{E}+06$ & $1.13 \mathrm{E}+05$ & $1.25 \mathrm{E}+00$ & $2.00 \mathrm{E}+00$ & I & $8.05 E+02$ & $2.67 E+08$ \\
\hline D & $M$ & $\begin{array}{l}\text { neos- } \\
\text { 3083819- } \\
\text { nubu }\end{array}$ & $7.07 E+04$ & $6.31 \mathrm{E}+06$ & $7.16 E+03$ & $9.98 \mathrm{E}+00$ & $3.00 E+00$ & I & $1.31 \mathrm{E}+02$ & $2.56 \mathrm{E}+07$ \\
\hline A & B & $\begin{array}{l}\text { neos- } \\
\text { 3083819- } \\
\text { nubu }\end{array}$ & $8.93 E+05$ & $6.31 \mathrm{E}+06$ & $1.14 \mathrm{E}+05$ & $6.40 \mathrm{E}-01$ & $1.00 E+00$ & I & $8.57 E+02$ & $1.01 E+09$ \\
\hline $\mathrm{L}$ & $\mathrm{M}$ & $\begin{array}{l}\text { neos- } \\
\text { 3083819- } \\
\text { nubu }\end{array}$ & $2.32 \mathrm{E}+06$ & $6.31 E+06$ & $3.91 \mathrm{E}+05$ & $0.00 E+00$ & $0.00 E+00$ & $T$ & $3.60 E+03$ & $1.34 \mathrm{E}+09$ \\
\hline $\mathrm{L}$ & B & $\begin{array}{l}\text { neos- } \\
\text { 3083819- } \\
\text { nubu }\end{array}$ & $5.41 \mathrm{E}+06$ & $6.34 \mathrm{E}+06$ & $3.39 E+05$ & $0.00 \mathrm{E}+00$ & $0.00 \mathrm{E}+00$ & $\mathrm{~T}$ & $3.60 \mathrm{E}+03$ & $6.40 \mathrm{E}+09$ \\
\hline $\mathrm{P}$ & $\mathrm{M}$ & $\begin{array}{l}\text { neos- } \\
\text { 3083819- } \\
\text { nubu }\end{array}$ & $3.40 \mathrm{E}+05$ & $6.31 E+06$ & $4.93 E+04$ & $0.00 \mathrm{E}+00$ & $0.00 E+00$ & I & $3.28 \mathrm{E}+02$ & $1.08 \mathrm{E}+08$ \\
\hline$P$ & B & $\begin{array}{l}\text { neos- } \\
\text { 3083819- } \\
\text { nubu }\end{array}$ & $4.92 \mathrm{E}+05$ & $6.31 \mathrm{E}+06$ & $8.35 E+04$ & $0.00 \mathrm{E}+00$ & $0.00 E+00$ & I & $5.44 \mathrm{E}+02$ & $3.78 \mathrm{E}+08$ \\
\hline
\end{tabular}




\begin{tabular}{|c|c|c|c|c|c|c|c|c|c|c|}
\hline VDS & NS & model & $\begin{array}{r}\text { simplex } \\
\text { it. }\end{array}$ & incu. Sol. & nodes & $\begin{array}{r}\text { 1st fea. } \\
\text { Time }\end{array}$ & $\begin{array}{r}\text { fea. } \\
\text { nodes }\end{array}$ & $\begin{array}{l}\text { exit } \\
\text { code }\end{array}$ & time & memory \\
\hline $\mathrm{D}$ & $\mathrm{B}$ & $\begin{array}{l}\text { ns195266 } \\
7\end{array}$ & $3.33 E+04$ & $0.00 \mathrm{E}+00$ & $9.21 \mathrm{E}+02$ & $1.45 \mathrm{E}+02$ & $1.00 \mathrm{E}+00$ & 1 & $1.46 \mathrm{E}+02$ & $6.83 \mathrm{E}+07$ \\
\hline A & $\mathrm{M}$ & $\begin{array}{l}\text { ns195266 } \\
7\end{array}$ & $9 \mathrm{E}+06$ & $\mathrm{~N}$ & $4.62 \mathrm{E}+04$ & $0.00 \mathrm{E}+00$ & $0.00 \mathrm{E}+00$ & T & $3.60 E+03$ & $1.00 \mathrm{E}+08$ \\
\hline D & $\mathrm{M}$ & $\begin{array}{l}\text { ns195266 } \\
7 \\
\end{array}$ & $3.33 E+04$ & $0.00 \mathrm{E}+00$ & $9.21 \mathrm{E}+02$ & $1.43 \mathrm{E}+02$ & $1.00 \mathrm{E}+00$ & 1 & $1.44 \mathrm{E}+02$ & $6.83 \mathrm{E}+07$ \\
\hline $\mathrm{A}$ & $\mathrm{B}$ & $\begin{array}{l}\text { ns195266 } \\
7 \\
\end{array}$ & $1.49 \mathrm{E}+06$ & $\mathrm{~N}$ & $4.62 E+04$ & $0.00 E+00$ & $0.00 \mathrm{E}+00$ & $\mathrm{~T}$ & $3.60 \mathrm{E}+03$ & $1.00 \mathrm{E}+08$ \\
\hline $\mathrm{L}$ & $\mathrm{M}$ & $\begin{array}{l}\text { ns195266 } \\
7\end{array}$ & +05 & $\mathrm{~N}$ & -04 & $0.00 \mathrm{E}+00$ & $00 \mathrm{E}+00$ & $\mathrm{~T}$ & $3.60 \mathrm{E}+03$ & $1.07 \mathrm{E}+08$ \\
\hline $\mathrm{L}$ & $\mathrm{B}$ & $\begin{array}{l}\text { ns195266 } \\
7\end{array}$ & $5.32 \mathrm{E}+05$ & $\mathrm{~N}$ & $2.05 \mathrm{E}+04$ & $0.00 \mathrm{E}+00$ & $0.00 \mathrm{E}+00$ & $\mathrm{~T}$ & $3.60 \mathrm{E}+03$ & $1.07 \mathrm{E}+08$ \\
\hline $\mathrm{P}$ & $\mathrm{M}$ & $\begin{array}{l}\text { ns195266 } \\
7 \\
\end{array}$ & +06 & $\mathrm{~N}$ & $E+04$ & $0.00 \mathrm{E}+00$ & $.00 \mathrm{E}+00$ & $\mathrm{~T}$ & $3.60 \mathrm{E}+03$ & $2.09 \mathrm{E}+08$ \\
\hline $\mathrm{P}$ & $\mathrm{B}$ & $\begin{array}{l}\text { ns195266 } \\
7\end{array}$ & $5 \mathrm{E}+06$ & $\mathrm{~N}$ & $30 \mathrm{E}+04$ & $00 \mathrm{E}+00$ & $.00 \mathrm{E}+00$ & $T$ & $3.60 E+03$ & $2.09 \mathrm{E}+08$ \\
\hline $\mathrm{D}$ & B & $\begin{array}{l}\text { markshar } \\
\text { e_4_0 }\end{array}$ & $4.24 \mathrm{E}+06$ & $1.00 \mathrm{E}+00$ & $1.33 \mathrm{E}+06$ & $0.00 \mathrm{E}+00$ & $4.00 \mathrm{E}+00$ & 1 & $8.19 E+02$ & $3.09 \mathrm{E}+07$ \\
\hline A & $\mathrm{M}$ & $\begin{array}{l}\text { markshar } \\
\text { e_4_0 }\end{array}$ & & +00 & 06 & OE-02 & $E+00$ & 1 & $66 \mathrm{E}+01$ & $1.03 \mathrm{E}+06$ \\
\hline D & $\mathrm{M}$ & $\begin{array}{l}\text { markshar } \\
\text { e_4_0 }\end{array}$ & $E+06$ & $00 E+00$ & $33 E+06$ & $00 \mathrm{E}+00$ & $00 \mathrm{E}+00$ & 1 & $.39 \mathrm{E}+01$ & $8.49 \mathrm{E}+05$ \\
\hline A & B & $\begin{array}{l}\text { markshar } \\
\text { e_4_0 }\end{array}$ & +06 & $00 \mathrm{E}+00$ & $1.41 \mathrm{E}+06$ & OOE-02 & $2.00 \mathrm{E}+00$ & $\mathrm{~T}$ & $3.60 \mathrm{E}+03$ & $5.51 \mathrm{E}+07$ \\
\hline $\mathrm{L}$ & M & $\begin{array}{l}\text { markshar } \\
\text { e_4_0 }\end{array}$ & 06 & 0 & 06 & -00 & 00 & 1 & $E+01$ & $E+06$ \\
\hline $\mathrm{L}$ & B & $\begin{array}{l}\text { markshar } \\
\text { e_4_0 }\end{array}$ & $7 E+06$ & $00 \mathrm{E}+00$ & $1.50 \mathrm{E}+06$ & $0.00 \mathrm{E}+00$ & $0.00 \mathrm{E}+00$ & 1 & $1.35 \mathrm{E}+03$ & $4.81 \mathrm{E}+07$ \\
\hline $\mathrm{P}$ & $\mathrm{M}$ & $\begin{array}{l}\text { markshar } \\
\text { e_4_0 }\end{array}$ & -06 & $E+00$ & $E+06$ & 00E-02 & $00 \mathrm{E}+00$ & 1 & $93 \mathrm{E}+01$ & $1.19 \mathrm{E}+06$ \\
\hline $\mathrm{P}$ & $B$ & $\begin{array}{l}\text { markshar } \\
\text { e_4_0 }\end{array}$ & $4.41 E+06$ & $1.00 \mathrm{E}+00$ & $2.12 \mathrm{E}+06$ & $1.00 \mathrm{E}-02$ & $1.00 \mathrm{E}+00$ & 1 & $1.96 \mathrm{E}+03$ & $3.60 \mathrm{E}+07$ \\
\hline $\mathrm{D}$ & $\mathrm{B}$ & neos8 & $1.18 \mathrm{E}+03$ & $-3.72 E+03$ & $2.10 \mathrm{E}+01$ & $4.54 \mathrm{E}+00$ & $1.00 \mathrm{E}+00$ & 1 & $1.80 \mathrm{E}+01$ & $9.34 \mathrm{E}+07$ \\
\hline $\mathrm{A}$ & $M$ & neos8 & $9.81 E+02$ & $-3.72 E+03$ & $2.70 \mathrm{E}+01$ & $1.43 \mathrm{E}+00$ & $1.00 \mathrm{E}+00$ & 1 & $2.60 \mathrm{E}+00$ & $9.27 \mathrm{E}+07$ \\
\hline $\mathrm{D}$ & $M$ & neos8 & $1.21 E+03$ & $-3.72 E+03$ & $2.10 \mathrm{E}+01$ & $4.85 \mathrm{E}+00$ & $1.00 \mathrm{E}+00$ & 1 & $2.04 \mathrm{E}+01$ & $9.34 \mathrm{E}+07$ \\
\hline $\mathrm{A}$ & $\mathrm{B}$ & neos8 & $1.22 \mathrm{E}+03$ & $-3.72 E+03$ & $2.70 \mathrm{E}+01$ & $1.42 \mathrm{E}+00$ & $2.00 \mathrm{E}+00$ & 1 & $3.00 \mathrm{E}+00$ & $9.27 \mathrm{E}+07$ \\
\hline $\mathrm{L}$ & $M$ & neos 8 & $9.99 \mathrm{E}+02$ & $-3.72 E+03$ & $1.50 \mathrm{E}+01$ & $1.21 \mathrm{E}+00$ & $1.00 \mathrm{E}+00$ & 1 & $2.20 \mathrm{E}+00$ & $9.26 \mathrm{E}+07$ \\
\hline L & $\mathrm{B}$ & neos8 & $1.15 \mathrm{E}+03$ & $-3.72 \mathrm{E}+03$ & $1.70 \mathrm{E}+01$ & $1.55 \mathrm{E}+00$ & $1.00 \mathrm{E}+00$ & 1 & $2.60 \mathrm{E}+00$ & $9.26 \mathrm{E}+07$ \\
\hline $\mathrm{P}$ & $M$ & neos8 & & & & & & $\mathrm{E}$ & & \\
\hline$P$ & $\mathrm{~B}$ & neos8 & $1.29 \mathrm{E}+03$ & $-3.72 E+03$ & $1.63 \mathrm{E}+02$ & $4.65 \mathrm{E}+01$ & $1.00 \mathrm{E}+00$ & 1 & $5.04 \mathrm{E}+01$ & $1.31 \mathrm{E}+08$ \\
\hline D & $\mathrm{B}$ & $\begin{array}{l}\text { piperout- } \\
27\end{array}$ & $E+04$ & $\mathrm{~N}$ & $31 \mathrm{E}+03$ & $0.00 \mathrm{E}+00$ & $00 \mathrm{E}+00$ & $\mathrm{~T}$ & $.61 \mathrm{E}+03$ & $2.64 \mathrm{E}+07$ \\
\hline A & $\mathrm{M}$ & $\begin{array}{l}\text { piperout- } \\
27\end{array}$ & +04 & $2 \mathrm{E}+03$ & +03 & $53 \mathrm{E}+01$ & $00 \mathrm{E}+00$ & 1 & $.09 \mathrm{E}+01$ & $3.17 \mathrm{E}+07$ \\
\hline D & $\mathrm{M}$ & $\begin{array}{l}\text { piperout- } \\
27\end{array}$ & $5.11 E+04$ & 10 & $1.07 \mathrm{E}+04$ & $0.00 \mathrm{E}+00$ & $0.00 \mathrm{E}+00$ & $T$ & $3.61 \mathrm{E}+03$ & $2.99 \mathrm{E}+07$ \\
\hline A & B & $\begin{array}{l}\text { piperout- } \\
27\end{array}$ & $8 E+05$ & $12 \mathrm{E}+03$ & $1.58 \mathrm{E}+04$ & $2.52 E+02$ & $1.00 E+00$ & 1 & $2.58 \mathrm{E}+02$ & $1.74 \mathrm{E}+08$ \\
\hline $\mathrm{L}$ & $\mathrm{M}$ & $\begin{array}{l}\text { piperout- } \\
27\end{array}$ & $1.93 \mathrm{E}+05$ & $8.12 \mathrm{E}+03$ & $1.51 \mathrm{E}+04$ & $1.05 \mathrm{E}+01$ & $1.00 \mathrm{E}+00$ & 1 & $1.99 \mathrm{E}+02$ & $3.40 \mathrm{E}+07$ \\
\hline L & B & $\begin{array}{l}\text { piperout- } \\
27\end{array}$ & $3.78 \mathrm{E}+06$ & $8.12 \mathrm{E}+03$ & $7.61 E+04$ & $1.78 \mathrm{E}+03$ & $1.00 \mathrm{E}+00$ & 1 & $1.79 \mathrm{E}+03$ & $5.86 \mathrm{E}+08$ \\
\hline
\end{tabular}




\begin{tabular}{|c|c|c|c|c|c|c|c|c|c|c|}
\hline VDS & IS & model & $\begin{array}{r}\text { simplex } \\
\text { it. }\end{array}$ & ol. & nodes & $\begin{array}{r}\text { 1st fea. } \\
\text { Time }\end{array}$ & $\begin{array}{r}\text { fea. } \\
\text { nodes }\end{array}$ & $\begin{array}{l}\text { exit } \\
\text { code }\end{array}$ & time & memory \\
\hline $\mathrm{P}$ & M & $\begin{array}{l}\text { piperout- } \\
27\end{array}$ & $54 \mathrm{E}+05$ & $8.12 \mathrm{E}+03$ & $40 \mathrm{E}+03$ & $3.96 \mathrm{E}+02$ & $1.00 \mathrm{E}+00$ & 1 & $4.02 \mathrm{E}+02$ & $6.46 \mathrm{E}+07$ \\
\hline $\mathrm{P}$ & B & $\begin{array}{l}\text { piperout- } \\
27\end{array}$ & +05 & & 04 & $6 \mathrm{E}+02$ & $0 \mathrm{EE}+00$ & I & $00 E+03$ & $33 E+08$ \\
\hline $\mathrm{D}$ & B & $\begin{array}{l}\text { piperout- } \\
08\end{array}$ & $44 E+05$ & $\mathrm{~N}$ & $27 E+04$ & $0.00 \mathrm{E}+00$ & $.00 E+00$ & $\mathrm{~T}$ & $3.60 \mathrm{E}+03$ & $4.04 \mathrm{E}+07$ \\
\hline A & $\mathrm{M}$ & $\begin{array}{l}\text { piperout- } \\
08\end{array}$ & $10 \mathrm{E}+05$ & $.25 \mathrm{E}+05$ & $1.49 \mathrm{E}+04$ & $1.07 \mathrm{E}+02$ & $2.00 \mathrm{E}+00$ & 1 & $1.83 \mathrm{E}+02$ & $7.72 \mathrm{E}+07$ \\
\hline D & $\mathrm{M}$ & $\begin{array}{l}\text { piperout- } \\
08\end{array}$ & +05 & $\mathrm{~N}$ & 03 & $0.00 E+00$ & $0 \mathrm{E}+00$ & $\mathrm{~T}$ & $60 E+03$ & $3.57 \mathrm{E}+07$ \\
\hline A & B & $\begin{array}{l}\text { piperout- } \\
08\end{array}$ & $7.39 \mathrm{E}+05$ & $1.25 \mathrm{E}+05$ & $3.09 \mathrm{E}+04$ & $2.80 \mathrm{E}+02$ & $1.00 \mathrm{E}+00$ & 1 & $2.83 \mathrm{E}+02$ & $1.96 \mathrm{E}+08$ \\
\hline $\mathrm{L}$ & $\mathrm{M}$ & $\begin{array}{l}\text { piperout- } \\
08\end{array}$ & +06 & & 55 & +02 & +00 & $\mathrm{~T}$ & 03 & $E+08$ \\
\hline $\mathrm{P}$ & $\mathrm{M}$ & $\begin{array}{l}\text { piperout- } \\
08\end{array}$ & $2 \mathrm{E}+05$ & -05 & $7 \mathrm{E}+04$ & $67 \mathrm{E}+02$ & $00 \mathrm{E}+00$ & 1 & $91 E+02$ & $.74 E+07$ \\
\hline $\mathrm{L}$ & B & $\begin{array}{l}\text { piperout- } \\
08\end{array}$ & $1.10 \mathrm{E}+07$ & $\mathrm{~N}$ & $1.69 \mathrm{E}+05$ & $0.00 E+00$ & $0.00 E+00$ & $\mathrm{~T}$ & $3.60 E+03$ & $1.45 \mathrm{E}+09$ \\
\hline $\mathrm{P}$ & B & $\begin{array}{l}\text { piperout- } \\
08\end{array}$ & $E+06$ & +05 & $4.03 E+05$ & $2.59 E+03$ & $.00 E+00$ & 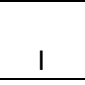 & $59 E+03$ & $2.92 \mathrm{E}+08$ \\
\hline $\mathrm{D}$ & $\mathrm{B}$ & misc07 & $2.12 \mathrm{E}+05$ & $2.81 \mathrm{E}+03$ & $2.41 E+04$ & $1.00 \mathrm{E}-02$ & $4.00 \mathrm{E}+00$ & 1 & $2.79 \mathrm{E}+01$ & $1.46 \mathrm{E}+07$ \\
\hline A & $\mathrm{M}$ & $\operatorname{misc07}$ & $2.01 E+05$ & $2.81 E+03$ & $2.19 \mathrm{E}+04$ & $1.00 \mathrm{E}-02$ & $6.00 \mathrm{E}+00$ & I & $1.28 \mathrm{E}+01$ & $4.63 \mathrm{E}+06$ \\
\hline D & $M$ & $\operatorname{misc} 07$ & $2.11 E+05$ & $2.81 \mathrm{E}+03$ & $2.38 \mathrm{E}+04$ & $1.00 \mathrm{E}-02$ & $3.00 \mathrm{E}+00$ & 1 & $2.61 \mathrm{E}+01$ & $4.67 \mathrm{E}+06$ \\
\hline A & $\mathrm{D}$ & $\operatorname{misc} 07$ & $1.99 \mathrm{E}+05$ & $2.81 \mathrm{E}+03$ & $2.17 \mathrm{E}+04$ & $1.00 \mathrm{E}-02$ & $6.00 \mathrm{E}+00$ & 1 & $1.35 \mathrm{E}+01$ & $1.61 \mathrm{E}+07$ \\
\hline $\mathrm{L}$ & $\mathrm{M}$ & misc07 & $3.55 E+05$ & $2.81 \mathrm{E}+03$ & $4.61 E+04$ & $1.00 \mathrm{E}-02$ & $4.00 \mathrm{E}+00$ & I & $3.40 \mathrm{E}+01$ & $8.84 \mathrm{E}+06$ \\
\hline $\mathrm{L}$ & B & $\operatorname{misc07}$ & $3.62 \mathrm{E}+05$ & $2.81 E+03$ & $4.72 \mathrm{E}+04$ & $1.00 \mathrm{E}-02$ & $5.00 \mathrm{E}+00$ & 1 & $3.78 \mathrm{E}+01$ & $3.15 \mathrm{E}+07$ \\
\hline$P$ & $\mathrm{~N}$ & $\operatorname{misc} 07$ & $5.60 \mathrm{E}+05$ & $2.81 \mathrm{E}+03$ & $7.10 \mathrm{E}+04$ & $4.90 \mathrm{E}-01$ & $3.00 \mathrm{E}+00$ & 1 & $5.04 \mathrm{E}+01$ & $1.79 \mathrm{E}+07$ \\
\hline$P$ & $\mathrm{~B}$ & misc07 & $6.15 \mathrm{E}+05$ & $2.81 \mathrm{E}+03$ & $8.09 \mathrm{E}+04$ & $5.80 \mathrm{E}-01$ & $6.00 \mathrm{E}+00$ & 1 & $8.41 \mathrm{E}+01$ & $4.39 \mathrm{E}+07$ \\
\hline D & B & vpm1 & $1.49 \mathrm{E}+06$ & $2.00 \mathrm{E}+01$ & $3.52 E+05$ & $1.00 \mathrm{E}-02$ & $3.00 \mathrm{E}+00$ & 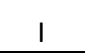 & $3.55 E+02$ & $2.66 \mathrm{E}+07$ \\
\hline A & $\mathrm{N}$ & vpm1 & $2.00 \mathrm{E}+07$ & $2.00 \mathrm{E}+01$ & $3.83 \mathrm{E}+06$ & $2.30 \mathrm{E}-01$ & $1.00 \mathrm{E}+00$ & 1 & $7.90 \mathrm{E}+02$ & $6.65 \mathrm{E}+06$ \\
\hline D & $M$ & vpm1 & $1.49 \mathrm{E}+06$ & $2.00 \mathrm{E}+01$ & $3.49 \mathrm{E}+05$ & $.00 \mathrm{E}-02$ & $1.00 \mathrm{E}+00$ & - & $9.23 \mathrm{E}+01$ & $4.98 \mathrm{E}+06$ \\
\hline A & $\mathrm{D}$ & vpm1 & $2.47 \mathrm{E}+06$ & $2.00 \mathrm{E}+01$ & $8.45 \mathrm{E}+05$ & $0.00 E+00$ & $3.00 \mathrm{E}+00$ & $\mathrm{~T}$ & $3.60 \mathrm{E}+03$ & $2.42 \mathrm{E}+08$ \\
\hline $\mathrm{L}$ & $\mathrm{M}$ & vpm1 & $1.92 \mathrm{E}+07$ & $2.00 \mathrm{E}+01$ & $3.73 \mathrm{E}+06$ & $3.27 E+00$ & $5.00 \mathrm{E}+00$ & 1 & $7.45 E+02$ & $9.87 E+06$ \\
\hline $\mathrm{L}$ & B & vpm1 & $3.21 \mathrm{E}+06$ & $\mathrm{~N}$ & $1.29 \mathrm{E}+06$ & $0.00 \mathrm{E}+00$ & $0.00 \mathrm{E}+00$ & $\mathrm{~T}$ & $3.60 \mathrm{E}+03$ & $4.38 \mathrm{E}+08$ \\
\hline $\mathrm{P}$ & $M$ & vpm1 & $3.21 \mathrm{E}+06$ & $2.00 \mathrm{E}+01$ & $7.16 \mathrm{E}+05$ & $1.00 \mathrm{E}-01$ & $1.00 \mathrm{E}+00$ & 1 & $1.44 \mathrm{E}+02$ & $6.11 \mathrm{E}+06$ \\
\hline$P$ & $B$ & vpm1 & $2.03 E+06$ & $2.00 \mathrm{E}+01$ & 4.07E+05 & $4.00 E-02$ & $.00 E+00$ & 1 & $7.97 \mathrm{E}+02$ & $3.76 \mathrm{E}+07$ \\
\hline D & D & $\begin{array}{l}\text { neos- } \\
806323\end{array}$ & $27 \mathrm{E}+05$ & $2.15 \mathrm{E}+02$ & $9.90 \mathrm{E}+04$ & $1.57 \mathrm{E}+00$ & $6.00 \mathrm{E}+00$ & 1 & $1.48 \mathrm{E}+02$ & $2.16 \mathrm{E}+08$ \\
\hline A & M & $\begin{array}{c}\text { neos- } \\
806323\end{array}$ & & & +04 & +00 & $E+00$ & I & $\mathrm{E}+01$ & $1.94 \mathrm{E}+07$ \\
\hline D & $\mathrm{M}$ & & +05 & $\mathrm{E}+02$ & $82 \mathrm{E}+04$ & $.95 \mathrm{E}+00$ & $.00 \mathrm{E}+00$ & 1 & $4.64 \mathrm{E}+01$ & $2.97 E+07$ \\
\hline A & $\mathrm{D}$ & $\begin{array}{l}\text { neos- } \\
806323 \\
\end{array}$ & +05 & 22 & $2 \mathrm{E}+04$ & $10 \mathrm{E}+01$ & $E+00$ & 1 & $E+01$ & $.45 \mathrm{E}+07$ \\
\hline L & M & $\begin{array}{c}\text { neos- } \\
806323\end{array}$ & $6.37 E+05$ & $2.15 E+02$ & $9.66 \mathrm{E}+04$ & $9.05 \mathrm{E}+00$ & $3.00 \mathrm{E}+00$ & I & $1.79 E+02$ & $1.32 \mathrm{E}+08$ \\
\hline $\mathrm{L}$ & B & $\begin{array}{c}\text { neos- } \\
806323 \\
\end{array}$ & $1.09 \mathrm{E}+06$ & $2.15 E+02$ & $1.50 \mathrm{E}+05$ & $6.23 \mathrm{E}+01$ & $3.00 \mathrm{E}+00$ & 1 & $2.78 \mathrm{E}+02$ & $4.33 \mathrm{E}+08$ \\
\hline
\end{tabular}




\begin{tabular}{|c|c|c|c|c|c|c|c|c|c|c|}
\hline VDS & NS & model & $\begin{array}{r}\text { simplex } \\
\text { it. }\end{array}$ & cu. Sol. & nodes & $\begin{array}{r}\text { 1st fea. } \\
\text { Time }\end{array}$ & $\begin{array}{r}\text { fea. } \\
\text { nodes }\end{array}$ & $\begin{array}{l}\text { exit } \\
\text { code }\end{array}$ & time & memory \\
\hline $\mathrm{P}$ & $\mathrm{M}$ & $\begin{array}{c}\text { neos- } \\
806323\end{array}$ & $19 E+05$ & $15 E+02$ & $2.47 \mathrm{E}+04$ & $2.56 \mathrm{E}+00$ & $1.00 \mathrm{E}+00$ & 1 & $4.27 \mathrm{E}+01$ & $5.26 \mathrm{E}+07$ \\
\hline $\mathrm{P}$ & B & $\begin{array}{c}\text { neos- } \\
806323\end{array}$ & +05 & $E+02$ & $0 \mathrm{E}+05$ & $3.05 \mathrm{E}+00$ & $00 \mathrm{E}+01$ & 1 & $1.24 \mathrm{E}+02$ & $2.55 \mathrm{E}+08$ \\
\hline D & B & $\begin{array}{l}\text { neos- } \\
807639 \\
\end{array}$ & $7.70 \mathrm{E}+05$ & $4.54 E+02$ & $1.28 \mathrm{E}+05$ & $5.40 \mathrm{E}-01$ & $3.00 \mathrm{E}+00$ & 1 & $2.85 \mathrm{E}+02$ & $3.38 \mathrm{E}+08$ \\
\hline $\mathrm{A}$ & $\mathrm{M}$ & $\begin{array}{c}\text { neos- } \\
807639 \\
\end{array}$ & $2.25 \mathrm{E}+05$ & $54 E+02$ & $3.30 \mathrm{E}+04$ & $2.05 E+00$ & $5.00 \mathrm{E}+00$ & 1 & $5.75 \mathrm{E}+01$ & $4.10 \mathrm{E}+07$ \\
\hline D & $\mathrm{M}$ & $\begin{array}{c}\text { neos- } \\
807639\end{array}$ & $E+05$ & 02 & $1.30 \mathrm{E}+05$ & $36 \mathrm{E}+00$ & $0 \mathrm{E}+00$ & 1 & $2.35 \mathrm{E}+02$ & $5.49 \mathrm{E}+07$ \\
\hline A & D & $\begin{array}{l}\text { neos- } \\
807639\end{array}$ & $2.27 \mathrm{E}+05$ & $4.54 \mathrm{E}+02$ & $3.45 \mathrm{E}+04$ & $8.00 \mathrm{E}-02$ & $4.00 \mathrm{E}+00$ & 1 & $5.93 \mathrm{E}+01$ & $7.64 \mathrm{E}+07$ \\
\hline L & M & & & 02 & 04 & $E+00$ & +00 & I & $E+02$ & +08 \\
\hline $\mathrm{L}$ & B & $\begin{array}{c}\text { neos- } \\
807639 \\
\end{array}$ & $E+05$ & $4 \mathrm{E}+02$ & $8.75 \mathrm{E}+04$ & $1.30 \mathrm{E}-01$ & $.00 E+00$ & 1 & $1.56 \mathrm{E}+02$ & $1.56 \mathrm{E}+08$ \\
\hline $\mathrm{P}$ & $\mathrm{M}$ & $\begin{array}{c}\text { neos- } \\
807639\end{array}$ & 4. $42 \mathrm{E}+05$ & $4.54 \mathrm{E}+02$ & $6.24 \mathrm{E}+04$ & $5.65 \mathrm{E}+00$ & $1.00 \mathrm{E}+00$ & 1 & $1.16 \mathrm{E}+02$ & $3.93 \mathrm{E}+07$ \\
\hline $\mathrm{P}$ & B & & & & 05 & $E+00$ & +00 & 1 & $69 \mathrm{E}+02$ & $3.09 \mathrm{E}+08$ \\
\hline $\mathrm{D}$ & B & $\begin{array}{c}\text { neos- } \\
827175\end{array}$ & $E+05$ & $\mathrm{E}+02$ & $4.81 \mathrm{E}+02$ & $34 \mathrm{E}+02$ & $.00 \mathrm{E}+00$ & 1 & $2.75 \mathrm{E}+02$ & $4.40 \mathrm{E}+07$ \\
\hline A & $\mathrm{M}$ & & $E+05$ & 02 & $3.27 \mathrm{E}+02$ & $6.15 \mathrm{E}+01$ & $1.00 \mathrm{E}+00$ & 1 & $1.03 E+02$ & $4.33 \mathrm{E}+07$ \\
\hline D & M & $\begin{array}{c}\text { neos- } \\
827175\end{array}$ & +05 & -02 & $31 \mathrm{E}+02$ & $7 \mathrm{E}+02$ & $\mathrm{DOE}+00$ & I & $68 \mathrm{E}+02$ & $.40 \mathrm{E}+07$ \\
\hline A & B & & $3 \mathrm{E}+05$ & $.12 \mathrm{E}+02$ & $3.27 \mathrm{E}+02$ & $6.19 E+01$ & $1.00 \mathrm{E}+00$ & 1 & $1.03 \mathrm{E}+02$ & $4.33 E+07$ \\
\hline $\mathrm{L}$ & $\mathrm{M}$ & & +04 & & $2.05 \mathrm{E}+02$ & $3.23 \mathrm{E}+01$ & $00 E+00$ & 1 & $41 E+01$ & $.26 \mathrm{E}+07$ \\
\hline $\mathrm{L}$ & B & $\begin{array}{c}\text { neos- } \\
827175 \\
\end{array}$ & $E+04$ & +02 & $5 \mathrm{E}+02$ & $22 \mathrm{E}+01$ & $0 \mathrm{OE}+00$ & 1 & $32 \mathrm{E}+01$ & $4.26 \mathrm{E}+07$ \\
\hline $\mathrm{P}$ & $\mathrm{M}$ & & $E+05$ & $2 \mathrm{E}+02$ & $4.81 \mathrm{E}+02$ & $5.46 \mathrm{E}+02$ & $1.00 \mathrm{E}+00$ & 1 & $5.87 E+02$ & $6.08 \mathrm{E}+07$ \\
\hline$P$ & B & $\begin{array}{c}\text { neos- } \\
827175\end{array}$ & $1.33 \mathrm{E}+05$ & $1.12 \mathrm{E}+02$ & $4.81 \mathrm{E}+02$ & $5.50 \mathrm{E}+02$ & $1.00 \mathrm{E}+00$ & 1 & $5.91 \mathrm{E}+02$ & $6.08 \mathrm{E}+07$ \\
\hline D & B & qap10 & $8.81 E+04$ & $3.40 E+02$ & $8.30 \mathrm{E}+01$ & $6.80 \mathrm{E}-01$ & $5.00 \mathrm{E}+00$ & 1 & $3.72 \mathrm{E}+01$ & $9.37 \mathrm{E}+06$ \\
\hline $\mathrm{A}$ & $M$ & qap10 & 4. $43 \mathrm{E}+04$ & $3.40 \mathrm{E}+02$ & $1.90 \mathrm{E}+01$ & 1. $23 \mathrm{E}+00$ & $3.00 \mathrm{E}+00$ & 1 & $1.37 \mathrm{E}+01$ & $9.45 \mathrm{E}+06$ \\
\hline $\mathrm{D}$ & $\mathrm{M}$ & qap10 & $6.43 \mathrm{E}+04$ & $3.40 \mathrm{E}+02$ & $6.10 \mathrm{E}+01$ & $6.20 \mathrm{E}+00$ & $3.00 \mathrm{E}+00$ & 1 & $2.67 \mathrm{E}+01$ & $9.51 \mathrm{E}+06$ \\
\hline $\mathrm{A}$ & $\mathrm{D}$ & qap10 & $3.93 E+04$ & $3.40 \mathrm{E}+02$ & $1.70 \mathrm{E}+01$ & $1.04 \mathrm{E}+00$ & $3.00 \mathrm{E}+00$ & 1 & $1.29 \mathrm{E}+01$ & $9.39 \mathrm{E}+06$ \\
\hline $\mathrm{L}$ & $\mathrm{M}$ & qap10 & 4.32E+04 & $3.40 E+02$ & $2.10 \mathrm{E}+01$ & $1.57 \mathrm{E}+00$ & $5.00 \mathrm{E}+00$ & 1 & $1.35 \mathrm{E}+01$ & $9.50 \mathrm{E}+06$ \\
\hline $\mathrm{L}$ & $\mathrm{B}$ & qap10 & 4. $32 \mathrm{E}+04$ & $3.40 \mathrm{E}+02$ & $2.10 \mathrm{E}+01$ & $1.57 \mathrm{E}+00$ & $5.00 \mathrm{E}+00$ & 1 & $1.35 \mathrm{E}+01$ & $9.49 \mathrm{E}+06$ \\
\hline $\mathrm{P}$ & $M$ & qap10 & $9.69 \mathrm{E}+04$ & $3.40 \mathrm{E}+02$ & $6.95 \mathrm{E}+02$ & $5.66 \mathrm{E}+01$ & $6.00 \mathrm{E}+00$ & 1 & $8.73 \mathrm{E}+01$ & $1.33 \mathrm{E}+07$ \\
\hline $\mathrm{P}$ & $\mathrm{B}$ & qap10 & $1.16 \mathrm{E}+05$ & $3.40 \mathrm{E}+02$ & $2.09 \mathrm{E}+03$ & $9.27 \mathrm{E}+01$ & $4.00 \mathrm{E}+00$ & 1 & $1.09 \mathrm{E}+02$ & $1.33 \mathrm{E}+07$ \\
\hline $\mathrm{D}$ & $\mathrm{B}$ & air05 & $1.38 \mathrm{E}+06$ & $2.64 E+04$ & $3.93 E+04$ & $7.16 \mathrm{E}+00$ & $9.00 \mathrm{E}+00$ & 1 & $1.88 \mathrm{E}+03$ & $2.41 \mathrm{E}+08$ \\
\hline $\mathrm{A}$ & $M$ & air05 & $1.48 \mathrm{E}+06$ & $2.64 \mathrm{E}+04$ & $5.22 \mathrm{E}+04$ & 4.20E-01 & $1.00 \mathrm{E}+01$ & 1 & $3.58 \mathrm{E}+02$ & $1.29 \mathrm{E}+08$ \\
\hline $\mathrm{D}$ & $\mathrm{M}$ & air05 & $8.12 E+05$ & $2.64 \mathrm{E}+04$ & $2.25 E+04$ & $7.11 \mathrm{E}+00$ & $1.20 \mathrm{E}+01$ & 1 & $1.08 \mathrm{E}+03$ & $9.99 \mathrm{E}+07$ \\
\hline A & $\mathrm{D}$ & air05 & $2.11 E+06$ & $2.64 E+04$ & $6.31 E+04$ & 4.30E-01 & $1.30 \mathrm{E}+01$ & 1 & $4.93 \mathrm{E}+02$ & $3.43 E+08$ \\
\hline $\mathrm{L}$ & $M$ & air05 & $3.69 \mathrm{E}+06$ & $2.64 \mathrm{E}+04$ & $1.38 \mathrm{E}+05$ & $3.30 \mathrm{E}-01$ & $1.00 \mathrm{E}+01$ & 1 & $1.03 \mathrm{E}+03$ & $3.36 \mathrm{E}+08$ \\
\hline L & B & air05 & $2.59 \mathrm{E}+06$ & $2.64 \mathrm{E}+04$ & $7.60 \mathrm{E}+04$ & $3.30 \mathrm{E}-01$ & $9.00 \mathrm{E}+00$ & 1 & $6.70 E+02$ & $3.57 \mathrm{E}+08$ \\
\hline
\end{tabular}




\begin{tabular}{|c|c|c|c|c|c|c|c|c|c|c|}
\hline VDS & NS & model & $\begin{array}{r}\text { simplex } \\
\text { it. }\end{array}$ & incu. Sol. & nodes & $\begin{array}{r}\text { 1st fea. } \\
\text { Time }\end{array}$ & $\begin{array}{r}\text { fea. } \\
\text { nodes }\end{array}$ & $\begin{array}{l}\text { exit } \\
\text { code }\end{array}$ & time & memory \\
\hline $\mathrm{P}$ & $M$ & $\mathrm{ir05}$ & $1.02 \mathrm{E}+05$ & $2.64 \mathrm{E}+04$ & $2.77 \mathrm{E}+03$ & $2.87 \mathrm{E}+01$ & $3.00 \mathrm{E}+00$ & 1 & $5.00 \mathrm{E}+01$ & $3.48 \mathrm{E}+07$ \\
\hline$P$ & B & air05 & $72 \mathrm{E}+05$ & $2.64 \mathrm{E}+04$ & $6.59 \mathrm{E}+03$ & $1.03 E+01$ & $7.00 \mathrm{E}+00$ & 1 & $6.16 \mathrm{E}+01$ & $4.83 \mathrm{E}+07$ \\
\hline $\mathrm{D}$ & B & air04 & $.56 \mathrm{E}+06$ & $5.61 \mathrm{E}+04$ & $4.80 E+04$ & $7.98 \mathrm{E}+01$ & $8.00 E+00$ & $\mathrm{~T}$ & $3.60 \mathrm{E}+03$ & $3.51 \mathrm{E}+08$ \\
\hline $\mathrm{A}$ & $M$ & air04 & $6.81 \mathrm{E}+06$ & $5.61 E+04$ & $1.82 \mathrm{E}+05$ & $7.70 \mathrm{E}-01$ & $3.00 \mathrm{E}+00$ & 1 & $2.09 \mathrm{E}+03$ & $3.29 \mathrm{E}+08$ \\
\hline $\mathrm{D}$ & $\mathrm{M}$ & air04 & $2.73 E+06$ & $5.61 \mathrm{E}+04$ & $5.54 \mathrm{E}+04$ & $1.75 \mathrm{E}+01$ & $1.20 \mathrm{E}+01$ & $\mathrm{~T}$ & $3.60 \mathrm{E}+03$ & $2.54 \mathrm{E}+08$ \\
\hline $\mathrm{A}$ & $\mathrm{D}$ & air04 & $6.78 \mathrm{E}+06$ & $5.61 E+04$ & $1.81 \mathrm{E}+05$ & 7.70E-01 & $2.00 \mathrm{E}+00$ & 1 & $2.12 \mathrm{E}+03$ & $5.43 E+08$ \\
\hline L & $M$ & air04 & $6.87 \mathrm{E}+06$ & $5.61 \mathrm{E}+04$ & $1.44 \mathrm{E}+05$ & $1.98 \mathrm{E}+01$ & $2.00 \mathrm{E}+01$ & 1 & $2.01 \mathrm{E}+03$ & $3.17 \mathrm{E}+08$ \\
\hline $\mathrm{L}$ & B & air04 & $6.27 \mathrm{E}+06$ & $5.61 \mathrm{E}+04$ & $1.38 \mathrm{E}+05$ & $7.73 \mathrm{E}+00$ & $9.00 \mathrm{E}+00$ & 1 & $1.91 \mathrm{E}+03$ & $4.50 \mathrm{E}+08$ \\
\hline $\mathrm{P}$ & $M$ & air04 & $7.99 \mathrm{E}+04$ & $5.61 \mathrm{E}+04$ & $1.25 \mathrm{E}+03$ & $4.34 \mathrm{E}+01$ & $5.00 \mathrm{E}+00$ & 1 & $6.13 \mathrm{E}+01$ & $2.65 \mathrm{E}+07$ \\
\hline $\mathrm{P}$ & B & air04 & $8.26 \mathrm{E}+04$ & $5.61 E+04$ & $1.46 \mathrm{E}+03$ & $1.86 \mathrm{E}+01$ & $4.00 \mathrm{E}+00$ & 1 & $4.93 \mathrm{E}+01$ & $3.09 \mathrm{E}+07$ \\
\hline $\mathrm{D}$ & B & irp & $1.80 \mathrm{E}+04$ & $1.22 \mathrm{E}+04$ & $5.02 \mathrm{E}+03$ & $1.29 \mathrm{E}+00$ & $9.00 \mathrm{E}+00$ & 1 & $1.00 \mathrm{E}+02$ & $4.60 \mathrm{E}+07$ \\
\hline $\mathrm{A}$ & $\mathrm{M}$ & irp & $1.82 \mathrm{E}+03$ & $1.22 \mathrm{E}+04$ & $7.75 E+02$ & $1.00 \mathrm{E}-01$ & $1.00 \mathrm{E}+01$ & 1 & $9.30 \mathrm{E}+00$ & $2.65 \mathrm{E}+07$ \\
\hline $\mathrm{D}$ & $M$ & irp & $1.16 \mathrm{E}+04$ & $1.22 \mathrm{E}+04$ & $2.92 \mathrm{E}+03$ & $1.30 \mathrm{E}+00$ & $6.00 \mathrm{E}+00$ & 1 & $6.43 \mathrm{E}+01$ & 2.97E+07 \\
\hline $\mathrm{A}$ & $\mathrm{D}$ & irp & $7.46 \mathrm{E}+03$ & $1.22 \mathrm{E}+04$ & $2.69 \mathrm{E}+03$ & $9.00 \mathrm{E}-02$ & $9.00 \mathrm{E}+00$ & 1 & $2.82 \mathrm{E}+01$ & $1.95 \mathrm{E}+08$ \\
\hline L & $M$ & irp & $7.10 \mathrm{E}+05$ & $1.22 \mathrm{E}+04$ & $3.25 \mathrm{E}+05$ & $9.00 \mathrm{E}-02$ & $1.00 \mathrm{E}+01$ & $\mathrm{~T}$ & $3.60 \mathrm{E}+03$ & $6.94 \mathrm{E}+08$ \\
\hline $\mathrm{L}$ & B & irp & 4.62E+05 & $1.22 \mathrm{E}+04$ & $3.26 \mathrm{E}+05$ & $9.00 \mathrm{E}-02$ & $8.00 \mathrm{E}+00$ & $\mathrm{~T}$ & $3.60 \mathrm{E}+03$ & $1.19 \mathrm{E}+09$ \\
\hline $\mathrm{P}$ & $\mathrm{M}$ & irp & $2.52 \mathrm{E}+03$ & $1.22 \mathrm{E}+04$ & $1.14 \mathrm{E}+03$ & $1.55 \mathrm{E}+01$ & $1.00 \mathrm{E}+00$ & 1 & $2.50 \mathrm{E}+01$ & $3.39 \mathrm{E}+07$ \\
\hline $\mathrm{P}$ & B & irp & $1 \mathrm{E}+03$ & $1.22 \mathrm{E}+04$ & $1.14 \mathrm{E}+03$ & $1.54 \mathrm{E}+01$ & $1.00 \mathrm{E}+00$ & 1 & $49 E+01$ & $3.66 \mathrm{E}+07$ \\
\hline D & B & & +05 & +01 & +03 & $E+01$ & $E+00$ & 1 & $E+02$ & $E+08$ \\
\hline A & $\mathrm{M}$ & & 6 & & 04 & 01 & -00 & $\mathrm{~T}$ & +03 & +09 \\
\hline $\mathrm{D}$ & $\mathrm{M}$ & & +05 & $42 \mathrm{E}+01$ & $5.75 \mathrm{E}+02$ & $1.96 \mathrm{E}+02$ & $3.00 \mathrm{E}+00$ & 1 & $5.23 \mathrm{E}+02$ & $1.03 \mathrm{E}+08$ \\
\hline A & B & & $E+06$ & +01 & +04 & $E+01$ & $E+00$ & $\mathrm{~T}$ & $\mathrm{E}+03$ & $.22 \mathrm{E}+09$ \\
\hline $\mathrm{L}$ & M & $\begin{array}{l}\text { tbfp- } \\
\text { network }\end{array}$ & +06 & 01 & -04 & +01 & $E+00$ & $\mathrm{~T}$ & +03 & $4.53 \mathrm{E}+08$ \\
\hline L & B & tbfp-r & & & & & & E & & \\
\hline $\mathrm{P}$ & $\mathrm{M}$ & & +06 & 01 & $2.85 \mathrm{E}+03$ & $1.53 \mathrm{E}+01$ & $4.00 \mathrm{E}+00$ & $\mathrm{~T}$ & $3.61 \mathrm{E}+03$ & $4.62 \mathrm{E}+08$ \\
\hline $\mathrm{P}$ & B & $\begin{array}{l}\text { tbfp- } \\
\text { network }\end{array}$ & $5.68 \mathrm{E}+05$ & $3.43 \mathrm{E}+01$ & $2.73 E+04$ & $1.71 \mathrm{E}+03$ & $3.00 \mathrm{E}+00$ & $T$ & $3.61 \mathrm{E}+03$ & $1.44 \mathrm{E}+08$ \\
\hline $\mathrm{D}$ & $\mathrm{B}$ & nw04 & $3.16 \mathrm{E}+03$ & $1.69 \mathrm{E}+04$ & $6.25 \mathrm{E}+02$ & $1.03 E+01$ & $7.00 \mathrm{E}+00$ & 1 & $1.32 \mathrm{E}+02$ & $1.64 \mathrm{E}+08$ \\
\hline A & $M$ & nw04 & $9.44 \mathrm{E}+03$ & $1.69 E+04$ & $4.05 E+03$ & 8.60E-01 & $3.00 \mathrm{E}+00$ & 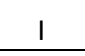 & $5.69 \mathrm{E}+02$ & $1.45 \mathrm{E}+08$ \\
\hline $\mathrm{D}$ & $M$ & nw04 & $2.84 \mathrm{E}+03$ & $1.69 \mathrm{E}+04$ & $6.23 E+02$ & $1.02 \mathrm{E}+01$ & $9.00 \mathrm{E}+00$ & 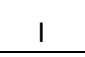 & $1.32 \mathrm{E}+02$ & $1.65 E+08$ \\
\hline $\mathrm{A}$ & B & nw04 & $9.44 \mathrm{E}+03$ & $1.69 \mathrm{E}+04$ & $4.04 \mathrm{E}+03$ & 8.70E-01 & $3.00 \mathrm{E}+00$ & 1 & $5.69 \mathrm{E}+02$ & $1.40 \mathrm{E}+08$ \\
\hline $\mathrm{L}$ & $\mathrm{M}$ & nw04 & $8.45 \mathrm{E}+03$ & $1.69 \mathrm{E}+04$ & $2.21 \mathrm{E}+03$ & $9.60 \mathrm{E}-01$ & $2.00 \mathrm{E}+00$ & I & $4.76 \mathrm{E}+02$ & $1.45 \mathrm{E}+08$ \\
\hline $\mathrm{L}$ & $\mathrm{B}$ & nw04 & $8.46 \mathrm{E}+03$ & $1.69 E+04$ & $2.23 \mathrm{E}+03$ & $9.70 \mathrm{E}-01$ & $2.00 \mathrm{E}+00$ & 1 & $4.75 \mathrm{E}+02$ & 1.45E+08 \\
\hline $\mathrm{P}$ & $\mathrm{M}$ & nw04 & $7.16 \mathrm{E}+03$ & $1.69 \mathrm{E}+04$ & $3.53 E+03$ & $4.12 \mathrm{E}+02$ & $5.00 \mathrm{E}+00$ & $\mathrm{I}$ & $6.56 \mathrm{E}+02$ & $2.40 \mathrm{E}+08$ \\
\hline $\mathrm{P}$ & $\mathrm{B}$ & nw04 & $7.32 \mathrm{E}+03$ & $1.69 E+04$ & $3.56 \mathrm{E}+03$ & $4.13 E+02$ & $4.00 \mathrm{E}+00$ & 1 & $6.49 \mathrm{E}+02$ & $2.73 E+08$ \\
\hline $\mathrm{D}$ & $\mathrm{B}$ & eil33-2 & $6.78 \mathrm{E}+04$ & $9.34 \mathrm{E}+02$ & $1.29 \mathrm{E}+04$ & 1.70E-01 & $9.00 \mathrm{E}+00$ & 1 & $1.02 \mathrm{E}+02$ & $4.38 \mathrm{E}+07$ \\
\hline $\mathrm{A}$ & $\mathrm{M}$ & eil33-2 & $3.56 \mathrm{E}+04$ & $9.34 \mathrm{E}+02$ & $9.55 \mathrm{E}+03$ & 2.00E-02 & $1.10 \mathrm{E}+01$ & I & $4.56 \mathrm{E}+01$ & $2.21 \mathrm{E}+07$ \\
\hline D & M & eil33-2 & $6.09 \mathrm{E}+04$ & $9.34 \mathrm{E}+02$ & $1.19 \mathrm{E}+04$ & $1.70 \mathrm{E}-01$ & 1.10E+01 & I & $9.31 \mathrm{E}+01$ & $2.45 \mathrm{E}+07$ \\
\hline
\end{tabular}




\begin{tabular}{|c|c|c|c|c|c|c|c|c|c|c|}
\hline VDS & NS & model & $\begin{array}{r}\text { simplex } \\
\text { it. }\end{array}$ & incu. Sol. & nodes & $\begin{array}{r}\text { 1st fea. } \\
\text { Time }\end{array}$ & $\begin{array}{r}\text { fea. } \\
\text { nodes }\end{array}$ & $\begin{array}{l}\text { exit } \\
\text { code }\end{array}$ & time & memory \\
\hline A & B & eil33-2 & $3.25 E+04$ & $9.34 \mathrm{E}+02$ & $8.17 E+03$ & $2.00 \mathrm{E}-02$ & $6.00 \mathrm{E}+00$ & I & $4.20 E+01$ & $3.50 E+07$ \\
\hline $\mathrm{L}$ & $\mathrm{M}$ & eil33-2 & $6.12 \mathrm{E}+04$ & $9.34 \mathrm{E}+02$ & $2.02 E+04$ & $3.00 \mathrm{E}-02$ & $9.00 E+00$ & 1 & $1.19 \mathrm{E}+02$ & $3.03 E+07$ \\
\hline $\mathrm{L}$ & B & eil33-2 & $6.97 \mathrm{E}+04$ & $9.34 \mathrm{E}+02$ & $2.04 E+04$ & $3.00 \mathrm{E}-02$ & $9.00 \mathrm{E}+00$ & 1 & $1.22 \mathrm{E}+02$ & $6.08 \mathrm{E}+07$ \\
\hline $\mathrm{P}$ & $\mathrm{M}$ & eil33-2 & $9.42 \mathrm{E}+04$ & $9.34 \mathrm{E}+02$ & $4.57 \mathrm{E}+04$ & $1.58 \mathrm{E}+00$ & $8.00 \mathrm{E}+00$ & I & $2.04 \mathrm{E}+02$ & $5.29 \mathrm{E}+07$ \\
\hline$P$ & B & eil33-2 & $1.01 \mathrm{E}+05$ & $9.34 \mathrm{E}+02$ & $3.76 E+04$ & $2.63 E+01$ & $1.00 \mathrm{E}+01$ & I & $1.71 \mathrm{E}+02$ & $6.97 E+07$ \\
\hline D & $\mathrm{B}$ & $\begin{array}{l}\text { supportca } \\
\text { se6 }\end{array}$ & $8.02 E+03$ & $5.19 \mathrm{E}+04$ & $1.23 \mathrm{E}+02$ & $1.87 \mathrm{E}+01$ & $4.00 \mathrm{E}+00$ & I & $9.27 \mathrm{E}+01$ & $1.63 \mathrm{E}+08$ \\
\hline $\mathrm{A}$ & $\mathrm{M}$ & $\begin{array}{l}\text { supportca } \\
\text { se6 }\end{array}$ & $2.08 \mathrm{E}+05$ & $5.20 \mathrm{E}+04$ & $1.82 \mathrm{E}+04$ & $2.84 \mathrm{E}+00$ & $6.00 \mathrm{E}+00$ & $\mathrm{~T}$ & $3.61 E+03$ & $1.97 E+08$ \\
\hline D & $\mathrm{M}$ & $\begin{array}{l}\text { supportca } \\
\text { se6 }\end{array}$ & $9.16 \mathrm{E}+03$ & $5.19 E+04$ & $1.85 \mathrm{E}+02$ & $1.86 \mathrm{E}+01$ & $4.00 \mathrm{E}+00$ & 1 & $1.32 \mathrm{E}+02$ & $1.69 \mathrm{E}+08$ \\
\hline $\mathrm{A}$ & $\mathrm{B}$ & $\begin{array}{l}\text { supportca } \\
\text { se6 }\end{array}$ & $1.52 \mathrm{E}+06$ & $5.19 E+04$ & $1.16 \mathrm{E}+04$ & $2.79 E+00$ & $4.00 \mathrm{E}+00$ & $\mathrm{~T}$ & $3.61 E+03$ & $2.90 E+09$ \\
\hline $\mathrm{L}$ & $\mathrm{M}$ & $\begin{array}{l}\text { supportca } \\
\text { se6 }\end{array}$ & $4.38 \mathrm{E}+05$ & $5.20 \mathrm{E}+04$ & $1.79 \mathrm{E}+04$ & $1.06 \mathrm{E}+01$ & $5.00 \mathrm{E}+00$ & $\mathrm{~T}$ & $3.61 E+03$ & $3.75 E+08$ \\
\hline $\mathrm{L}$ & B & $\begin{array}{l}\text { supportca } \\
\text { se6 }\end{array}$ & $1.14 \mathrm{E}+06$ & $5.19 E+04$ & $9.80 \mathrm{E}+03$ & $3.73 E+00$ & $2.00 \mathrm{E}+00$ & $T$ & $3.61 E+03$ & $1.79 E+09$ \\
\hline $\mathrm{P}$ & $\mathrm{M}$ & $\begin{array}{l}\text { supportca } \\
\text { se6 }\end{array}$ & $2.36 \mathrm{E}+04$ & $5.19 \mathrm{E}+04$ & $2.35 \mathrm{E}+03$ & $1.27 \mathrm{E}+02$ & $7.00 \mathrm{E}+00$ & I & $4.31 E+02$ & $2.23 E+08$ \\
\hline$P$ & $\mathrm{~B}$ & $\begin{array}{l}\text { supportca } \\
\text { se6 }\end{array}$ & $2.39 \mathrm{E}+04$ & $5.19 \mathrm{E}+04$ & $1.13 \mathrm{E}+03$ & $1.28 \mathrm{E}+02$ & $4.00 \mathrm{E}+00$ & 1 & $3.25 \mathrm{E}+02$ & $2.73 \mathrm{E}+08$ \\
\hline D & $\mathrm{B}$ & dcmulti & $5.70 \mathrm{E}+03$ & $1.88 \mathrm{E}+05$ & $1.35 \mathrm{E}+03$ & $3.00 \mathrm{E}-02$ & $1.10 \mathrm{E}+01$ & 1 & $6.00 \mathrm{E}-01$ & $1.26 \mathrm{E}+06$ \\
\hline $\mathrm{A}$ & $M$ & dcmulti & $6.50 \mathrm{E}+04$ & $1.88 \mathrm{E}+05$ & $1.70 \mathrm{E}+04$ & $3.00 \mathrm{E}-02$ & $1.80 \mathrm{E}+01$ & 1 & $5.80 \mathrm{E}+00$ & $1.03 E+06$ \\
\hline D & $\mathrm{M}$ & dcmulti & $9.46 \mathrm{E}+03$ & $1.88 \mathrm{E}+05$ & $2.72 \mathrm{E}+03$ & $3.00 \mathrm{E}-02$ & $1.30 \mathrm{E}+01$ & 1 & $1.20 \mathrm{E}+00$ & $9.82 \mathrm{E}+05$ \\
\hline A & $\mathrm{B}$ & demulti & $7.69 \mathrm{E}+04$ & $1.88 \mathrm{E}+05$ & $2.12 \mathrm{E}+04$ & $1.00 \mathrm{E}-02$ & $1.50 \mathrm{E}+01$ & 1 & $7.30 \mathrm{E}+00$ & $7.11 \mathrm{E}+06$ \\
\hline $\mathrm{L}$ & $\mathrm{M}$ & dcmulti & $2.37 E+04$ & $1.88 \mathrm{E}+05$ & $4.86 \mathrm{E}+03$ & $4.00 \mathrm{E}-02$ & $3.10 \mathrm{E}+01$ & I & $1.90 \mathrm{E}+00$ & $1.77 \mathrm{E}+06$ \\
\hline $\mathrm{L}$ & $\mathrm{B}$ & dcmulti & $2.74 \mathrm{E}+04$ & $1.88 \mathrm{E}+05$ & $5.58 \mathrm{E}+03$ & $2.90 \mathrm{E}-01$ & $8.00 \mathrm{E}+00$ & 1 & $2.10 \mathrm{E}+00$ & $3.15 E+06$ \\
\hline $\mathrm{P}$ & $\mathrm{M}$ & dcmulti & $7.49 \mathrm{E}+03$ & $1.88 \mathrm{E}+05$ & $3.26 \mathrm{E}+03$ & $7.00 \mathrm{E}-02$ & $1.40 \mathrm{E}+01$ & 1 & $1.10 \mathrm{E}+00$ & $1.11 \mathrm{E}+06$ \\
\hline $\mathrm{P}$ & $\mathrm{B}$ & dcmulti & $2.76 \mathrm{E}+03$ & $1.88 \mathrm{E}+05$ & $8.05 E+02$ & $7.00 \mathrm{E}-02$ & $5.00 \mathrm{E}+00$ & I & $3.00 \mathrm{E}-01$ & $1.14 \mathrm{E}+06$ \\
\hline D & B & aflow30a & $5.57 \mathrm{E}+06$ & $1.16 \mathrm{E}+03$ & $6.72 E+05$ & $2.10 \mathrm{E}-01$ & $1.00 \mathrm{E}+01$ & $\mathrm{~T}$ & $3.60 \mathrm{E}+03$ & $6.72 \mathrm{E}+08$ \\
\hline $\mathrm{A}$ & $M$ & aflow30a & $2.22 \mathrm{E}+07$ & $1.16 \mathrm{E}+03$ & $3.39 \mathrm{E}+06$ & $9.00 \mathrm{E}-02$ & $1.50 \mathrm{E}+01$ & 1 & $2.10 E+03$ & $9.23 E+07$ \\
\hline $\mathrm{D}$ & $M$ & aflow30a & $4.38 \mathrm{E}+06$ & $1.16 \mathrm{E}+03$ & $4.48 \mathrm{E}+05$ & $3.87 \mathrm{E}+00$ & $4.00 \mathrm{E}+00$ & 1 & $5.80 \mathrm{E}+02$ & $8.93 \mathrm{E}+07$ \\
\hline $\mathrm{A}$ & B & aflow30a & $5.67 \mathrm{E}+06$ & $1.18 \mathrm{E}+03$ & $6.55 \mathrm{E}+05$ & $1.80 \mathrm{E}-01$ & $6.00 \mathrm{E}+00$ & $\mathrm{~T}$ & $3.60 \mathrm{E}+03$ & $8.22 \mathrm{E}+08$ \\
\hline $\mathrm{L}$ & $\mathrm{M}$ & aflow30a & $3.29 \mathrm{E}+07$ & $1.17 \mathrm{E}+03$ & $5.03 E+06$ & $1.50 \mathrm{E}-01$ & $1.20 \mathrm{E}+01$ & $\mathrm{~T}$ & $3.60 \mathrm{E}+03$ & $1.03 E+08$ \\
\hline $\mathrm{L}$ & B & aflow30a & $2.14 \mathrm{E}+07$ & $1.85 \mathrm{E}+03$ & $1.30 \mathrm{E}+06$ & $3.38 \mathrm{E}+03$ & $1.00 \mathrm{E}+00$ & $\mathrm{~T}$ & $3.60 \mathrm{E}+03$ & $1.72 \mathrm{E}+09$ \\
\hline $\mathrm{P}$ & $\mathrm{M}$ & aflow30a & $9.52 \mathrm{E}+05$ & $1.16 \mathrm{E}+03$ & $1.07 \mathrm{E}+05$ & $3.17 \mathrm{E}+00$ & $7.00 \mathrm{E}+00$ & 1 & $8.14 \mathrm{E}+01$ & $5.53 E+07$ \\
\hline$P$ & B & aflow30a & $7.31 \mathrm{E}+06$ & $1.18 \mathrm{E}+03$ & $1.50 \mathrm{E}+06$ & $2.22 \mathrm{E}+01$ & $1.20 \mathrm{E}+01$ & $\mathrm{~T}$ & $3.60 E+03$ & $7.14 \mathrm{E}+08$ \\
\hline
\end{tabular}


Table B.2: Results for models not solved to optimality by any VDS / NS in the time limit, but an incumbent solution was found by at least one VDS / NS configuration.

\begin{tabular}{|c|c|c|c|c|c|c|c|c|c|c|}
\hline VDS & NS & model & $\begin{array}{r}\text { simplex } \\
\text { it. }\end{array}$ & incu. Sol. & nodes & $\begin{array}{r}\text { 1st fea. } \\
\text { Time }\end{array}$ & $\begin{array}{r}\text { fea. } \\
\text { nodes }\end{array}$ & $\begin{array}{c}\text { exit } \\
\text { code }\end{array}$ & time & memory \\
\hline D & B & $\begin{array}{l}\text { graphdraw- } \\
\text { domain }\end{array}$ & $5.13 E+06$ & $2.29 \mathrm{E}+04$ & $1.43 E+06$ & 0.54 & 7 & $\mathrm{~T}$ & 3600.1 & $9.25 E+08$ \\
\hline A & $\mathrm{M}$ & $\begin{array}{l}\text { graphdraw- } \\
\text { domain }\end{array}$ & $3.38 E+06$ & $2.43 E+04$ & $7.67 \mathrm{E}+05$ & 3.39 & 11 & $\mathrm{~T}$ & 3600 & $5.31 E+08$ \\
\hline D & $\mathrm{M}$ & $\begin{array}{l}\text { graphdraw- } \\
\text { domain }\end{array}$ & $3.56 \mathrm{E}+06$ & $2.16 \mathrm{E}+04$ & $7.40 \mathrm{E}+05$ & 2.66 & 12 & $\mathrm{~T}$ & 3600 & $4.43 E+08$ \\
\hline$A$ & B & $\begin{array}{l}\text { graphdraw- } \\
\text { domain }\end{array}$ & $8.35 E+06$ & $2.45 E+04$ & $1.57 \mathrm{E}+06$ & 0.11 & 10 & $\mathrm{~T}$ & 3600.2 & $1.53 E+09$ \\
\hline $\mathrm{L}$ & $\mathrm{M}$ & $\begin{array}{l}\text { graphdraw- } \\
\text { domain }\end{array}$ & $4.20 E+06$ & $2.63 E+04$ & $6.71 E+05$ & 4.57 & 10 & $\mathrm{~T}$ & 3600 & $4.91 E+08$ \\
\hline D & B & $\begin{array}{l}\text { nexp-50-20- } \\
4-2\end{array}$ & $5.31 E+06$ & $7.60 \mathrm{E}+01$ & $2.32 \mathrm{E}+06$ & 0.19 & 16 & $\mathrm{~T}$ & 3600.2 & $1.22 \mathrm{E}+09$ \\
\hline A & $\mathrm{M}$ & $\begin{array}{l}\text { nexp-50-20- } \\
4-2\end{array}$ & $2.98 \mathrm{E}+06$ & $8.00 \mathrm{E}+01$ & $9.81 \mathrm{E}+05$ & 72.83 & 4 & $\mathrm{~T}$ & 3600.1 & $1.18 \mathrm{E}+09$ \\
\hline D & $\mathrm{M}$ & $\begin{array}{l}\text { nexp-50-20- } \\
4-2\end{array}$ & $4.02 E+06$ & $7.60 \mathrm{E}+01$ & $1.61 \mathrm{E}+06$ & 3.09 & 5 & $\mathrm{~T}$ & 3600.1 & $1.30 \mathrm{E}+09$ \\
\hline A & B & $\begin{array}{l}\text { nexp-50-20- } \\
4-2\end{array}$ & $6.40 E+06$ & $9.70 \mathrm{E}+01$ & $1.72 \mathrm{E}+06$ & 0.02 & 12 & $\mathrm{~T}$ & 3600.1 & $1.40 \mathrm{E}+09$ \\
\hline $\mathrm{L}$ & $\mathrm{M}$ & $\begin{array}{l}\text { nexp-50-20- } \\
4-2\end{array}$ & $3.54 E+06$ & $8.30 \mathrm{E}+01$ & $1.02 \mathrm{E}+06$ & 2.59 & 5 & $\mathrm{~T}$ & 3600.1 & $1.08 \mathrm{E}+09$ \\
\hline D & B & neos-631517 & $9.83 E+06$ & 1.17E+07 & $1.93 \mathrm{E}+06$ & 0.74 & 12 & $\mathrm{~T}$ & 3600.1 & $2.67 E+09$ \\
\hline A & $\mathrm{M}$ & neos-631517 & $9.18 \mathrm{E}+06$ & $\mathrm{~N}$ & $1.58 \mathrm{E}+06$ & 0 & 0 & $\mathrm{~T}$ & 3600.1 & $7.05 E+08$ \\
\hline D & $\mathrm{M}$ & neos-631517 & $7.88 \mathrm{E}+06$ & $\mathrm{~N}$ & $1.50 \mathrm{E}+06$ & 0 & 0 & $\mathrm{~T}$ & 3600.1 & $5.52 E+08$ \\
\hline A & B & neos-631517 & $1.57 E+07$ & $1.20 \mathrm{E}+07$ & $2.97 \mathrm{E}+06$ & 0.08 & 7 & $\mathrm{~T}$ & 3600.4 & $8.39 E+09$ \\
\hline $\mathrm{L}$ & $\mathrm{M}$ & neos-631517 & $4.40 E+06$ & $1.24 \mathrm{E}+07$ & $1.46 \mathrm{E}+06$ & 1.55 & 1 & $\mathrm{~T}$ & 3600.2 & $3.85 E+09$ \\
\hline D & B & g200x740 & $2.71 E+06$ & $5.32 E+04$ & $1.52 E+06$ & 1.14 & 12 & $\mathrm{~T}$ & 3600.1 & $4.23 E+08$ \\
\hline A & $\mathrm{M}$ & g200x740 & $3.99 E+06$ & $4.46 \mathrm{E}+04$ & $4.83 E+06$ & 0.22 & 8 & $\mathrm{~T}$ & 3600.1 & $1.27 \mathrm{E}+09$ \\
\hline $\mathrm{D}$ & $\mathrm{M}$ & g200x740 & $3.24 E+06$ & $4.45 \mathrm{E}+04$ & $1.11 \mathrm{E}+06$ & 12.53 & 6 & $\mathrm{~T}$ & 3600.1 & $5.56 \mathrm{E}+08$ \\
\hline$A$ & $\mathrm{~B}$ & g200x740 & $3.94 E+06$ & $4.53 E+04$ & $4.98 \mathrm{E}+06$ & 0.11 & 4 & $\mathrm{~T}$ & 3600.2 & 1.17E+09 \\
\hline $\mathrm{L}$ & $\mathrm{M}$ & g200x740 & $4.94 \mathrm{E}+06$ & $4.45 E+04$ & $1.19 \mathrm{E}+06$ & 90.91 & 5 & $\mathrm{~T}$ & 3600.1 & $4.55 E+08$ \\
\hline D & B & app2-2 & $8.15 E+05$ & $2.12 \mathrm{E}+05$ & $1.30 \mathrm{E}+06$ & 0.01 & 2 & $\mathrm{~T}$ & 3600.1 & $3.15 E+08$ \\
\hline A & $\mathrm{M}$ & app2-2 & $6.45 \mathrm{E}+05$ & $2.12 \mathrm{E}+05$ & 7.17E+05 & 0.01 & 5 & $\mathrm{~T}$ & 3600 & $1.51 E+08$ \\
\hline $\mathrm{D}$ & $\mathrm{M}$ & app2-2 & $6.41 E+05$ & $2.12 \mathrm{E}+05$ & 7.37E+05 & 0.04 & 13 & $\mathrm{~T}$ & 3600 & $1.75 \mathrm{E}+08$ \\
\hline A & B & app2-2 & $6.03 E+05$ & $2.12 \mathrm{E}+05$ & $7.61 \mathrm{E}+05$ & 0.01 & 4 & $\mathrm{~T}$ & 3600 & $3.11 E+08$ \\
\hline $\mathrm{L}$ & $M$ & app2-2 & $6.47 E+05$ & $2.12 E+05$ & $7.19 \mathrm{E}+05$ & 0.1 & 2 & $\mathrm{~T}$ & 3600 & $1.48 \mathrm{E}+08$ \\
\hline D & B & $\begin{array}{l}\text { ic97_potentia } \\
\text { । }\end{array}$ & $6.42 E+06$ & $4.09 E+03$ & $1.12 \mathrm{E}+06$ & 1.45 & 4 & $\mathrm{~T}$ & 3600.1 & $8.18 \mathrm{E}+08$ \\
\hline A & $M$ & $\begin{array}{l}\text { ic97_potentia } \\
\text { । }\end{array}$ & $5.45 E+06$ & $\mathrm{~N}$ & $1.06 \mathrm{E}+06$ & 0 & 0 & $\mathrm{~T}$ & 3600.1 & $4.73 E+08$ \\
\hline
\end{tabular}




\begin{tabular}{|c|c|c|c|c|c|c|c|c|c|c|}
\hline VDS & NS & model & $\begin{array}{r}\text { simplex } \\
\text { it. }\end{array}$ & incu. Sol. & nodes & $\begin{array}{r}\text { 1st fea. } \\
\text { Time }\end{array}$ & $\begin{array}{r}\text { fea. } \\
\text { nodes }\end{array}$ & $\begin{array}{l}\text { exit } \\
\text { code }\end{array}$ & time & memory \\
\hline D & $\mathrm{M}$ & $\begin{array}{l}\text { ic97_potentia } \\
\text { । }\end{array}$ & $4.95 E+06$ & $\mathrm{~N}$ & $8.63 \mathrm{E}+05$ & 0 & 0 & $\mathrm{~T}$ & 3600.1 & $7.64 \mathrm{E}+08$ \\
\hline A & B & $\begin{array}{l}\text { ic97_potentia } \\
\text { । }\end{array}$ & $9.34 \mathrm{E}+06$ & 4.17E+03 & $1.11 \mathrm{E}+06$ & 2.07 & 7 & $\mathrm{~T}$ & 3600.1 & $1.22 \mathrm{E}+09$ \\
\hline $\mathrm{L}$ & $\mathrm{M}$ & $\begin{array}{l}\text { ic97_potentia } \\
\text { I }\end{array}$ & $5.89 \mathrm{E}+06$ & $\mathrm{~N}$ & $7.38 \mathrm{E}+05$ & 0 & 0 & $\mathrm{~T}$ & 3600.1 & $9.06 \mathrm{E}+08$ \\
\hline D & B & neos-911970 & $4.35 \mathrm{E}+06$ & $6.20 \mathrm{E}+01$ & $9.70 \mathrm{E}+05$ & 0.18 & 20 & $\mathrm{~T}$ & 3600.1 & $4.47 \mathrm{E}+08$ \\
\hline A & $\mathrm{M}$ & neos-911970 & $3.34 \mathrm{E}+06$ & $6.45 \mathrm{E}+01$ & $6.85 \mathrm{E}+05$ & 0.03 & 11 & $\mathrm{~T}$ & 3600 & $6.80 \mathrm{E}+08$ \\
\hline D & $\mathrm{M}$ & neos-911970 & $3.42 \mathrm{E}+06$ & $7.22 \mathrm{E}+01$ & $7.32 \mathrm{E}+05$ & 0.28 & 9 & $\mathrm{~T}$ & 3600 & $3.70 \mathrm{E}+08$ \\
\hline A & $\mathrm{B}$ & neos-911970 & $4.46 \mathrm{E}+06$ & $1.01 \mathrm{E}+02$ & $9.44 \mathrm{E}+05$ & 0.01 & 35 & $\mathrm{~T}$ & 3600.1 & $1.18 \mathrm{E}+09$ \\
\hline $\mathrm{L}$ & $\mathrm{M}$ & neos-911970 & $2.11 \mathrm{E}+06$ & $7.47 \mathrm{E}+01$ & $7.04 \mathrm{E}+05$ & 0.01 & 34 & $\mathrm{~T}$ & 3600 & $3.32 \mathrm{E}+08$ \\
\hline $\mathrm{D}$ & B & haprp & $2.54 \mathrm{E}+05$ & $3.68 \mathrm{E}+06$ & $6.63 \mathrm{E}+05$ & 0 & 0 & $\mathrm{~T}$ & 3600.1 & $5.19 E+08$ \\
\hline A & $\mathrm{M}$ & haprp & $1.24 \mathrm{E}+06$ & $3.69 \mathrm{E}+06$ & $1.30 \mathrm{E}+06$ & 0 & 0 & $\mathrm{~T}$ & 3600 & $2.40 E+08$ \\
\hline D & $\mathrm{M}$ & haprp & $1.25 \mathrm{E}+06$ & $\mathrm{~N}$ & $1.05 \mathrm{E}+06$ & 0 & 0 & $\mathrm{~T}$ & 3600.1 & $6.09 \mathrm{E}+08$ \\
\hline A & B & haprp & $9.81 \mathrm{E}+05$ & $3.69 \mathrm{E}+06$ & $4.12 \mathrm{E}+06$ & 0 & 0 & $\mathrm{~T}$ & 3600.1 & $3.18 \mathrm{E}+09$ \\
\hline $\mathrm{L}$ & $\mathrm{M}$ & haprp & $2.06 \mathrm{E}+06$ & $3.68 \mathrm{E}+06$ & $1.07 E+06$ & 0 & 0 & $\mathrm{~T}$ & 3600 & $9.15 \mathrm{E}+08$ \\
\hline D & B & $\begin{array}{l}\text { neos- } \\
3421095- \\
\text { cinca }\end{array}$ & $8.51 E+06$ & $4.48 \mathrm{E}+07$ & $9.90 E+05$ & 0.13 & 13 & $\mathrm{~T}$ & 3600.2 & $9.40 \mathrm{E}+08$ \\
\hline A & $\mathrm{M}$ & $\begin{array}{l}\text { neos- } \\
3421095- \\
\text { cinca }\end{array}$ & $5.43 \mathrm{E}+06$ & $\mathrm{~N}$ & $7.08 \mathrm{E}+05$ & 0 & 0 & $\mathrm{~T}$ & 3600.1 & $7.24 \mathrm{E}+08$ \\
\hline D & $\mathrm{M}$ & $\begin{array}{l}\text { neos- } \\
\text { 3421095- } \\
\text { cinca }\end{array}$ & $4.40 \mathrm{E}+06$ & $4.51 \mathrm{E}+07$ & $5.26 \mathrm{E}+05$ & 0.22 & 13 & $\mathrm{~T}$ & 3600.1 & $5.20 E+08$ \\
\hline A & B & $\begin{array}{l}\text { neos- } \\
3421095- \\
\text { cinca }\end{array}$ & $9.72 \mathrm{E}+06$ & $4.43 \mathrm{E}+07$ & $1.08 \mathrm{E}+06$ & 0.03 & 7 & $\mathrm{~T}$ & 3600.2 & $1.29 \mathrm{E}+09$ \\
\hline $\mathrm{L}$ & $\mathrm{M}$ & $\begin{array}{l}\text { neos- } \\
\text { 3421095- } \\
\text { cinca }\end{array}$ & $5.04 \mathrm{E}+06$ & $4.46 \mathrm{E}+07$ & $6.93 \mathrm{E}+05$ & 0.18 & 5 & $\mathrm{~T}$ & 3600.1 & $4.69 \mathrm{E}+08$ \\
\hline D & B & assign1-5-8 & $9.86 \mathrm{E}+06$ & $2.12 \mathrm{E}+02$ & $1.87 \mathrm{E}+06$ & 0.1 & 6 & $\mathrm{~T}$ & 3600.2 & $6.60 E+08$ \\
\hline A & $\mathrm{M}$ & assign1-5-8 & $7.16 \mathrm{E}+06$ & $2.12 \mathrm{E}+02$ & $7.78 \mathrm{E}+05$ & 541.75 & 3 & $\mathrm{~T}$ & 3600 & $4.31 E+08$ \\
\hline $\mathrm{D}$ & $\mathrm{M}$ & assign1-5-8 & $6.56 \mathrm{E}+06$ & $2.12 \mathrm{E}+02$ & 1.19E+06 & 0.13 & 3 & $\mathrm{~T}$ & 3600 & $4.69 E+08$ \\
\hline A & B & assign1-5-8 & $1.37 \mathrm{E}+07$ & $2.14 \mathrm{E}+02$ & $1.23 \mathrm{E}+06$ & 0.02 & 4 & $\mathrm{~T}$ & 3600.1 & $7.65 E+08$ \\
\hline $\mathrm{L}$ & $\mathrm{M}$ & assign1-5-8 & $3.41 \mathrm{E}+06$ & $2.12 \mathrm{E}+02$ & $7.70 \mathrm{E}+05$ & 0.26 & 4 & $\mathrm{~T}$ & 3600 & $2.75 \mathrm{E}+08$ \\
\hline D & B & gsvm $2 \mathrm{rl3}$ & $5.56 \mathrm{E}+06$ & $3.88 \mathrm{E}-01$ & $2.04 \mathrm{E}+06$ & 0.03 & 3 & $\mathrm{~T}$ & 3600.1 & $6.97 \mathrm{E}+08$ \\
\hline A & $\mathrm{M}$ & gsvm $2 \mathrm{rl3}$ & $1.25 \mathrm{E}+06$ & 5.94E-01 & $1.17 \mathrm{E}+06$ & 0.01 & 3 & $\mathrm{~T}$ & 3600.2 & $2.49 E+09$ \\
\hline D & $\mathrm{M}$ & gsvm $2 \mathrm{rl3}$ & $4.04 \mathrm{E}+06$ & 3.37E-01 & $8.95 \mathrm{E}+05$ & 0.37 & 1 & $\mathrm{~T}$ & 3600 & $1.39 \mathrm{E}+08$ \\
\hline A & B & gsvm $2 \mathrm{rl3}$ & $1.34 \mathrm{E}+06$ & 4.74E-01 & $1.63 \mathrm{E}+06$ & 0.01 & 11 & $\mathrm{~T}$ & 3600.3 & $3.22 \mathrm{E}+09$ \\
\hline $\mathrm{L}$ & $\mathrm{M}$ & gsvm2rl3 & $3.09 \mathrm{E}+06$ & 3.37E-01 & $6.86 \mathrm{E}+05$ & 0.09 & 1 & $\mathrm{~T}$ & 3600 & $2.27 E+08$ \\
\hline $\mathrm{D}$ & B & nsa & $1.32 \mathrm{E}+07$ & $1.23 \mathrm{E}+02$ & $9.83 E+05$ & 0.07 & 9 & $\mathrm{~T}$ & 3600.1 & $1.01 \mathrm{E}+09$ \\
\hline A & $M$ & nsa & $1.16 \mathrm{E}+07$ & $1.26 \mathrm{E}+02$ & $6.99 \mathrm{E}+05$ & 42.18 & 2 & $\mathrm{~T}$ & 3600.1 & $9.63 \mathrm{E}+08$ \\
\hline D & $\mathrm{M}$ & nsa & $1.09 \mathrm{E}+07$ & $1.20 \mathrm{E}+02$ & $6.35 \mathrm{E}+05$ & 0.29 & 7 & $\mathrm{~T}$ & 3600.1 & $6.82 \mathrm{E}+08$ \\
\hline A & $\mathrm{B}$ & nsa & $2.05 E+07$ & $1.31 \mathrm{E}+02$ & $1.21 \mathrm{E}+06$ & 0.07 & 24 & $\mathrm{~T}$ & 3600.1 & $1.09 \mathrm{E}+09$ \\
\hline
\end{tabular}




\begin{tabular}{|c|c|c|c|c|c|c|c|c|c|c|}
\hline VDS & NS & model & $\begin{array}{r}\text { simplex } \\
\text { it. }\end{array}$ & incu. Sol. & nodes & $\begin{array}{r}\text { 1st fea. } \\
\text { Time }\end{array}$ & $\begin{array}{r}\text { fea. } \\
\text { nodes }\end{array}$ & $\begin{array}{l}\text { exit } \\
\text { code }\end{array}$ & time & memory \\
\hline $\mathrm{L}$ & $M$ & nsa & $1.02 \mathrm{E}+07$ & $1.36 \mathrm{E}+02$ & $6.79 E+05$ & 1.89 & 7 & $\mathrm{~T}$ & 3600.1 & $1.11 E+09$ \\
\hline D & B & $\begin{array}{l}\text { neos- } \\
\text { 3530903- } \\
\text { gauja }\end{array}$ & $2.39 \mathrm{E}+06$ & $1.80 \mathrm{E}+02$ & $1.11 \mathrm{E}+06$ & 0 & 0 & $\mathrm{~T}$ & 3600 & $3.96 \mathrm{E}+08$ \\
\hline A & $\mathrm{M}$ & $\begin{array}{l}\text { neos- } \\
\text { 3530903- } \\
\text { gauja }\end{array}$ & $7.52 E+06$ & $\mathrm{~N}$ & $4.25 E+06$ & 0 & 0 & $\mathrm{~T}$ & 3600.1 & $1.75 \mathrm{E}+09$ \\
\hline D & $\mathrm{M}$ & $\begin{array}{l}\text { neos- } \\
\text { 3530903- } \\
\text { gauja }\end{array}$ & $1.69 E+06$ & $\mathrm{~N}$ & $1.49 \mathrm{E}+06$ & 0 & 0 & $\mathrm{~T}$ & 3600.1 & $5.84 \mathrm{E}+08$ \\
\hline A & B & $\begin{array}{l}\text { neos- } \\
\text { 3530903- } \\
\text { gauja }\end{array}$ & $8.81 E+06$ & $1.87 \mathrm{E}+02$ & $4.76 \mathrm{E}+06$ & 0 & 0 & T & 3600.4 & $1.87 \mathrm{E}+09$ \\
\hline L & $\mathrm{M}$ & $\begin{array}{l}\text { neos- } \\
\text { 3530903- } \\
\text { gauja }\end{array}$ & $3.51 E+06$ & $\mathrm{~N}$ & $1.19 \mathrm{E}+06$ & 0 & 0 & $\mathrm{~T}$ & 3600 & $3.15 E+08$ \\
\hline D & B & $\begin{array}{l}\text { neos- } \\
\text { 3118745-obra }\end{array}$ & $3.53 E+06$ & $2.59 \mathrm{E}+02$ & $1.25 \mathrm{E}+06$ & 19.55 & 1 & $\mathrm{~T}$ & 3600.1 & $4.55 E+08$ \\
\hline A & $\mathrm{M}$ & $\begin{array}{l}\text { neos- } \\
3118745 \text {-obra }\end{array}$ & $2.59 \mathrm{E}+06$ & $2.56 \mathrm{E}+02$ & $1.10 \mathrm{E}+06$ & 0 & 0 & $\mathrm{~T}$ & 3600 & $5.79 \mathrm{E}+08$ \\
\hline D & $\mathrm{M}$ & $\begin{array}{l}\text { neos- } \\
\text { 3118745-obra }\end{array}$ & $3.59 E+06$ & $2.56 \mathrm{E}+02$ & $6.58 \mathrm{E}+05$ & 375.96 & 1 & $\mathrm{~T}$ & 3600 & $1.21 \mathrm{E}+08$ \\
\hline A & B & $\begin{array}{l}\text { neos- } \\
\text { 3118745-obra }\end{array}$ & $2.02 \mathrm{E}+06$ & $2.56 \mathrm{E}+02$ & $7.39 \mathrm{E}+05$ & 0 & 0 & $\mathrm{~T}$ & 3600 & $1.86 \mathrm{E}+08$ \\
\hline $\mathrm{L}$ & $\mathrm{M}$ & $\begin{array}{l}\text { neos- } \\
\text { 3118745-obra }\end{array}$ & $2.37 E+06$ & $2.56 \mathrm{E}+02$ & $1.16 \mathrm{E}+06$ & 0 & 0 & $\mathrm{~T}$ & 3600.1 & $5.71 \mathrm{E}+08$ \\
\hline $\mathrm{D}$ & $\mathrm{B}$ & gmu-35-40 & $2.21 E+08$ & $-2.39 E+06$ & $2.16 \mathrm{E}+05$ & 5.85 & 8 & $\mathrm{~T}$ & 3600 & $8.36 \mathrm{E}+07$ \\
\hline A & $\mathrm{M}$ & gmu-35-40 & $1.39 \mathrm{E}+06$ & $-2.40 E+06$ & $7.35 \mathrm{E}+05$ & 0.84 & 3 & $\mathrm{~T}$ & & \\
\hline D & $\mathrm{M}$ & gmu-35-40 & $2.42 E+08$ & $-2.38 \mathrm{E}+06$ & $7.21 \mathrm{E}+03$ & 2.08 & 2 & $\mathrm{~T}$ & & \\
\hline $\mathrm{A}$ & $\mathrm{B}$ & gmu-35-40 & $1.12 \mathrm{E}+08$ & $\mathrm{~N}$ & $9.19 \mathrm{E}+05$ & 0 & 0 & $\mathrm{~T}$ & 3600.1 & $6.15 \mathrm{E}+08$ \\
\hline L & $\mathrm{M}$ & gmu-35-40 & $1.64 \mathrm{E}+06$ & $-2.41 E+06$ & $6.29 \mathrm{E}+05$ & 1.63 & 9 & $\mathrm{~T}$ & & \\
\hline D & $\mathrm{B}$ & mtest4ma & $1.89 \mathrm{E}+06$ & $6.07 \mathrm{E}+04$ & $1.69 \mathrm{E}+06$ & 0.77 & 33 & $\mathrm{~T}$ & 3600.3 & $1.69 \mathrm{E}+09$ \\
\hline A & $\mathrm{M}$ & mtest4ma & $1.58 \mathrm{E}+06$ & $5.62 \mathrm{E}+04$ & $2.38 \mathrm{E}+06$ & 9.62 & 3 & $\mathrm{~T}$ & 3600.4 & $5.38 \mathrm{E}+09$ \\
\hline $\mathrm{D}$ & $\mathrm{M}$ & mtest4ma & $8.39 E+05$ & $5.34 \mathrm{E}+04$ & $6.09 \mathrm{E}+05$ & 2.69 & 29 & $\mathrm{~T}$ & 3600.1 & $2.85 E+08$ \\
\hline A & $\mathrm{B}$ & mtest4ma & $1.99 \mathrm{E}+06$ & $5.99 \mathrm{E}+04$ & $2.90 \mathrm{E}+06$ & 0.07 & 3 & $\mathrm{~T}$ & 3600.3 & $5.05 E+09$ \\
\hline $\mathrm{L}$ & $\mathrm{M}$ & mtest4ma & $8.99 E+05$ & $5.45 \mathrm{E}+04$ & 1.27E+06 & 34.42 & 9 & $\mathrm{~T}$ & 3600.1 & $1.41 \mathrm{E}+09$ \\
\hline $\mathrm{D}$ & $\mathrm{B}$ & neos17 & $9.97 \mathrm{E}+06$ & $1.71 \mathrm{E}-01$ & $7.11 \mathrm{E}+05$ & 16.11 & 8 & $\mathrm{~T}$ & 3600 & $2.90 \mathrm{E}+08$ \\
\hline A & $\mathrm{M}$ & neos17 & $1.30 \mathrm{E}+07$ & $\mathrm{~N}$ & $9.10 \mathrm{E}+05$ & 0 & 0 & $\mathrm{~T}$ & 3600 & $4.42 \mathrm{E}+08$ \\
\hline D & $\mathrm{M}$ & neos17 & $9.37 \mathrm{E}+07$ & $5.30 \mathrm{E}-01$ & $1.38 \mathrm{E}+06$ & 0.8 & 4 & $\mathrm{~T}$ & 3600 & $2.65 \mathrm{E}+06$ \\
\hline A & $B$ & neos17 & $1.03 \mathrm{E}+07$ & $2.20 \mathrm{E}-01$ & $1.45 \mathrm{E}+06$ & 0.08 & 2 & $\mathrm{~T}$ & 3600.1 & $4.74 \mathrm{E}+08$ \\
\hline $\mathrm{L}$ & $\mathrm{M}$ & neos17 & $1.13 \mathrm{E}+07$ & $\mathrm{~N}$ & $7.36 \mathrm{E}+05$ & 0 & 0 & $\mathrm{~T}$ & 3600.1 & $2.71 E+08$ \\
\hline D & $\mathrm{B}$ & $\begin{array}{l}\text { neos- } \\
3627168- \\
\text { kasai }\end{array}$ & $2.52 E+06$ & $\mathrm{~N}$ & $1.68 \mathrm{E}+06$ & 0 & 0 & $\mathrm{~T}$ & 3600.2 & $5.45 \mathrm{E}+08$ \\
\hline A & $\mathrm{M}$ & $\begin{array}{l}\text { neos- } \\
\text { 3627168- } \\
\text { kasai }\end{array}$ & $1.10 \mathrm{E}+07$ & $9.90 \mathrm{E}+05$ & $2.98 \mathrm{E}+06$ & 0.39 & 1 & $\mathrm{~T}$ & 3600.1 & $3.06 \mathrm{E}+06$ \\
\hline
\end{tabular}




\begin{tabular}{|c|c|c|c|c|c|c|c|c|c|c|}
\hline VDS & NS & model & $\begin{array}{r}\text { simplex } \\
\text { it. }\end{array}$ & incu. Sol. & nodes & $\begin{array}{r}\text { 1st fea. } \\
\text { Time }\end{array}$ & $\begin{array}{r}\text { fea. } \\
\text { nodes }\end{array}$ & $\begin{array}{l}\text { exit } \\
\text { code }\end{array}$ & time & memory \\
\hline D & M & $\begin{array}{l}\text { neos- } \\
3627168- \\
\text { kasai }\end{array}$ & $4.94 \mathrm{E}+06$ & $9.95 \mathrm{E}+05$ & $1.63 \mathrm{E}+06$ & 1.78 & 2 & $\mathrm{~T}$ & 3600.1 & $3.27 E+06$ \\
\hline A & B & $\begin{array}{l}\text { neos- } \\
\text { 3627168- } \\
\text { kasai }\end{array}$ & $4.02 \mathrm{E}+06$ & $9.90 \mathrm{E}+05$ & $2.79 E+06$ & 0.15 & 2 & $\mathrm{~T}$ & 3600.1 & $7.29 E+08$ \\
\hline $\mathrm{L}$ & M & $\begin{array}{l}\text { neos- } \\
3627168- \\
\text { kasai }\end{array}$ & $7.86 \mathrm{E}+06$ & $1.00 \mathrm{E}+06$ & $5.83 E+05$ & 0.34 & 1 & $\mathrm{~T}$ & 3600.1 & $9.22 \mathrm{E}+07$ \\
\hline $\mathrm{D}$ & B & $\mathrm{pg}$ & $1.25 \mathrm{E}+07$ & $-8.41 E+03$ & $1.60 \mathrm{E}+06$ & 0.31 & 5 & $\mathrm{~T}$ & 3600.1 & $1.06 \mathrm{E}+09$ \\
\hline A & $M$ & $\mathrm{pg}$ & $1.47 \mathrm{E}+07$ & $-8.65 E+03$ & $1.31 \mathrm{E}+06$ & 6.49 & 17 & $T$ & 3600.2 & $1.24 \mathrm{E}+09$ \\
\hline $\mathrm{D}$ & $\mathrm{M}$ & $\mathrm{pg}$ & $1.25 \mathrm{E}+07$ & $-8.62 E+03$ & $1.24 \mathrm{E}+06$ & 2.09 & 16 & $\mathrm{~T}$ & 3600.1 & $8.16 \mathrm{E}+08$ \\
\hline $\mathrm{A}$ & B & $\mathrm{pg}$ & $1.80 \mathrm{E}+07$ & $-8.02 E+03$ & $1.79 \mathrm{E}+06$ & 0.07 & 21 & $\mathrm{~T}$ & 3600.2 & $1.84 \mathrm{E}+09$ \\
\hline $\mathrm{L}$ & $\mathrm{M}$ & $\mathrm{pg}$ & $1.70 \mathrm{E}+07$ & $\mathrm{~N}$ & $1.11 \mathrm{E}+06$ & 0 & 0 & $\mathrm{~T}$ & 3600.1 & 1.17E+09 \\
\hline D & B & $\begin{array}{l}\text { supportcase1 } \\
7\end{array}$ & $2.31 \mathrm{E}+06$ & $\mathrm{~N}$ & $5.17 E+05$ & 0 & 0 & $T$ & 3600.1 & $1.62 \mathrm{E}+08$ \\
\hline A & $\mathrm{M}$ & $\begin{array}{l}\text { supportcase1 } \\
7\end{array}$ & $2.06 \mathrm{E}+07$ & $\mathrm{~N}$ & $9.85 \mathrm{E}+05$ & 0 & 0 & $T$ & 3600.1 & $7.33 E+08$ \\
\hline D & $\mathrm{M}$ & $\begin{array}{l}\text { supportcase1 } \\
77\end{array}$ & $4.84 \mathrm{E}+05$ & $\mathrm{~N}$ & $9.61 E+05$ & 0 & 0 & $\mathrm{~T}$ & 3600 & $3.98 \mathrm{E}+06$ \\
\hline A & B & $\begin{array}{l}\text { supportcase1 } \\
7\end{array}$ & $1.82 \mathrm{E}+07$ & $\mathrm{~N}$ & $7.81 E+05$ & 0 & 0 & $\mathrm{~T}$ & 3600.1 & $8.36 \mathrm{E}+08$ \\
\hline $\mathrm{L}$ & $\mathrm{M}$ & $\begin{array}{l}\text { supportcase1 } \\
7\end{array}$ & $4.08 \mathrm{E}+06$ & $1.93 \mathrm{E}+03$ & $5.85 \mathrm{E}+05$ & 0.14 & 14 & $\mathrm{~T}$ & 3600.1 & 4.47E+08 \\
\hline $\mathrm{D}$ & B & ta1-UUM & $1.18 \mathrm{E}+07$ & $1.08 \mathrm{E}+07$ & $2.13 E+06$ & 0.65 & 12 & $\mathrm{~T}$ & 3600.5 & $6.68 \mathrm{E}+09$ \\
\hline A & $\mathrm{M}$ & ta1-UUM & $4.40 \mathrm{E}+06$ & $8.03 \mathrm{E}+06$ & $5.55 \mathrm{E}+05$ & 18.24 & 8 & $\mathrm{~T}$ & 3600.4 & $7.35 \mathrm{E}+09$ \\
\hline $\mathrm{D}$ & $\mathrm{M}$ & ta1-UUM & $4.96 \mathrm{E}+06$ & $\mathrm{~N}$ & $9.83 E+05$ & 0 & 0 & $\mathrm{~T}$ & 3600.1 & $3.28 \mathrm{E}+08$ \\
\hline A & $\mathrm{B}$ & ta1-UUM & $2.17 \mathrm{E}+07$ & $1.02 \mathrm{E}+07$ & $8.55 E+05$ & 0.04 & 27 & $\mathrm{~T}$ & 3871.5 & $2.14 \mathrm{E}+10$ \\
\hline $\mathrm{L}$ & $\mathrm{M}$ & ta1-UUM & $6.25 \mathrm{E}+06$ & $9.24 \mathrm{E}+06$ & $1.51 E+06$ & 383.84 & 2 & $\mathrm{~T}$ & 3600.2 & $3.13 E+09$ \\
\hline$D$ & $\mathrm{~B}$ & $\begin{array}{l}\text { nh97_potenti } \\
\text { al }\end{array}$ & $6.85 \mathrm{E}+06$ & $1.45 \mathrm{E}+03$ & $6.46 \mathrm{E}+05$ & 588.78 & 4 & $\mathrm{~T}$ & 3600.1 & $8.12 \mathrm{E}+08$ \\
\hline $\mathrm{A}$ & $\mathrm{M}$ & $\begin{array}{l}\text { nh97_potenti } \\
\text { al }\end{array}$ & $8.28 \mathrm{E}+06$ & $\mathrm{~N}$ & $24 \mathrm{E}+06$ & 0 & 0 & $\mathrm{~T}$ & 3600.1 & $82 \mathrm{E}+08$ \\
\hline $\mathrm{D}$ & $\mathrm{M}$ & $\begin{array}{l}\text { nh97_potenti } \\
\text { al }\end{array}$ & $7.14 \mathrm{E}+06$ & $\mathrm{~N}$ & $4.35 E+05$ & 0 & 0 & $\mathrm{~T}$ & 3600.1 & $8.55 \mathrm{E}+08$ \\
\hline A & B & $\begin{array}{l}\text { nh97_potenti } \\
\text { al }\end{array}$ & $3 E+06$ & $\mathrm{~N}$ & $8.86 \mathrm{E}+05$ & 0 & 0 & $\mathrm{~T}$ & 3600.1 & $5.03 E+08$ \\
\hline $\mathrm{L}$ & $M$ & $\begin{array}{l}\text { nh97_potenti } \\
\text { al }\end{array}$ & $1.34 \mathrm{E}+07$ & $\mathrm{~N}$ & $5.94 \mathrm{E}+05$ & 0 & 0 & $\mathrm{~T}$ & 3600.2 & $1.62 \mathrm{E}+09$ \\
\hline $\mathrm{D}$ & $\mathrm{B}$ & mc11 & $1.48 \mathrm{E}+06$ & $2.36 \mathrm{E}+04$ & $4.12 E+05$ & 11.73 & 7 & $\mathrm{~T}$ & 3600.3 & $1.31 \mathrm{E}+08$ \\
\hline $\mathrm{A}$ & $\mathrm{M}$ & mc11 & $2.23 \mathrm{E}+07$ & $1.30 \mathrm{E}+04$ & $2.58 \mathrm{E}+06$ & 146.2 & 1 & $\mathrm{~T}$ & 3600.3 & $1.10 \mathrm{E}+09$ \\
\hline D & $\mathrm{M}$ & mc11 & $7.01 \mathrm{E}+05$ & $1.71 \mathrm{E}+04$ & $2.84 \mathrm{E}+05$ & 236.93 & 13 & $T$ & 3600.2 & $8.40 E+07$ \\
\hline A & $\mathrm{B}$ & mc11 & $2.15 E+07$ & $1.29 \mathrm{E}+04$ & $2.53 \mathrm{E}+06$ & 0.93 & 3 & $\mathrm{~T}$ & 3600.3 & $1.11 \mathrm{E}+09$ \\
\hline $\mathrm{L}$ & $M$ & mc11 & $2.35 \mathrm{E}+06$ & $\mathrm{~N}$ & $8.30 E+05$ & 0 & 0 & $T$ & 3600.3 & $2.57 \mathrm{E}+08$ \\
\hline $\mathrm{D}$ & $\mathrm{B}$ & csched010 & $1.27 \mathrm{E}+07$ & $5.87 \mathrm{E}+02$ & $1.06 \mathrm{E}+06$ & 476.06 & 1 & $\mathrm{~T}$ & 3600.1 & $6.83 \mathrm{E}+08$ \\
\hline A & $M$ & csched010 & $1.20 \mathrm{E}+07$ & $4.08 \mathrm{E}+02$ & $6.68 \mathrm{E}+05$ & 77.2 & 3 & $\mathrm{~T}$ & 3600.1 & $8.34 \mathrm{E}+08$ \\
\hline D & M & csched 010 & $1.15 \mathrm{E}+07$ & $\mathrm{~N}$ & $7.69 \mathrm{E}+05$ & 0 & 0 & $\mathrm{~T}$ & 3600.1 & $5.35 \mathrm{E}+08$ \\
\hline
\end{tabular}




\begin{tabular}{|c|c|c|c|c|c|c|c|c|c|c|}
\hline VDS & NS & model & $\begin{array}{r}\text { simplex } \\
\text { it. }\end{array}$ & incu. Sol. & nodes & $\begin{array}{r}\text { 1st fea. } \\
\text { Time }\end{array}$ & $\begin{array}{r}\text { fea. } \\
\text { nodes }\end{array}$ & $\begin{array}{l}\text { exit } \\
\text { code }\end{array}$ & time & memory \\
\hline$A$ & B & csched010 & $2.81 \mathrm{E}+07$ & $\mathrm{~N}$ & $7.31 \mathrm{E}+05$ & 0 & 0 & $\mathrm{~T}$ & 3600.1 & $8.47 \mathrm{E}+08$ \\
\hline $\mathrm{L}$ & $M$ & csched010 & $2.41 \mathrm{E}+07$ & $\mathrm{~N}$ & $6.94 \mathrm{E}+05$ & 0 & 0 & $\mathrm{~T}$ & 3600.1 & $1.02 E+09$ \\
\hline D & B & $\begin{array}{l}\text { neos- } \\
4650160- \\
\text { yukon }\end{array}$ & $1.16 \mathrm{E}+06$ & $7.36 \mathrm{E}+01$ & $6.67 \mathrm{E}+05$ & 1.65 & 6 & $\mathrm{~T}$ & 3600.1 & $3.97 E+08$ \\
\hline A & $\mathrm{M}$ & $\begin{array}{l}\text { neos- } \\
4650160- \\
\text { yukon }\end{array}$ & $1.58 \mathrm{E}+06$ & $\mathrm{~N}$ & $1.50 \mathrm{E}+06$ & 0 & 0 & $\mathrm{~T}$ & 3600.2 & $9.13 E+08$ \\
\hline D & $\mathrm{M}$ & $\begin{array}{l}\text { neos- } \\
4650160- \\
\text { yukon }\end{array}$ & $7.09 \mathrm{E}+06$ & $7.40 \mathrm{E}+01$ & $1.86 \mathrm{E}+06$ & 1.63 & 5 & $\mathrm{~T}$ & 3600.1 & $2.01 E+07$ \\
\hline A & B & $\begin{array}{l}\text { neos- } \\
4650160- \\
\text { yukon }\end{array}$ & $5.14 \mathrm{E}+06$ & $\mathrm{~N}$ & $2.93 E+06$ & 0 & 0 & $\mathrm{~T}$ & 3600.4 & $3.07 E+09$ \\
\hline $\mathrm{L}$ & $\mathrm{M}$ & $\begin{array}{l}\text { neos- } \\
4650160- \\
\text { yukon }\end{array}$ & $3.88 \mathrm{E}+06$ & $\mathrm{~N}$ & $1.54 \mathrm{E}+06$ & 0 & 0 & $\mathrm{~T}$ & 3600.2 & $1.28 \mathrm{E}+09$ \\
\hline D & B & $\begin{array}{l}\text { neos- } \\
1112787\end{array}$ & $3.25 \mathrm{E}+06$ & $5.96 \mathrm{E}+11$ & $1.96 \mathrm{E}+06$ & 1.76 & 13 & $\mathrm{~T}$ & 3600.1 & $1.58 \mathrm{E}+09$ \\
\hline A & $\mathrm{M}$ & $\begin{array}{l}\text { neos- } \\
1112787\end{array}$ & $2.72 \mathrm{E}+06$ & $5.73 \mathrm{E}+11$ & $1.50 \mathrm{E}+06$ & 0.07 & 91 & $\mathrm{~T}$ & 3600.1 & $1.87 \mathrm{E}+09$ \\
\hline D & $\mathrm{M}$ & $\begin{array}{l}\text { neos- } \\
1112787\end{array}$ & $8.85 E+06$ & $6.07 E+11$ & $6.64 \mathrm{E}+05$ & 1.87 & 1 & $\mathrm{~T}$ & 3600 & $6.31 E+08$ \\
\hline A & B & $\begin{array}{l}\text { neos- } \\
1112787\end{array}$ & $2.53 \mathrm{E}+06$ & $5.72 \mathrm{E}+11$ & $1.96 \mathrm{E}+06$ & 0.07 & 18 & $\mathrm{~T}$ & 3600.6 & $1.07 \mathrm{E}+10$ \\
\hline $\mathrm{L}$ & $\mathrm{M}$ & $\begin{array}{l}\text { neos- } \\
1112787\end{array}$ & $5.56 \mathrm{E}+06$ & $5.97 \mathrm{E}+11$ & $3.04 \mathrm{E}+06$ & 2.86 & 1 & $\mathrm{~T}$ & 3600.1 & $9.92 \mathrm{E}+08$ \\
\hline D & B & cvs08r139-94 & 1.70E+06 & $-1.13 E+02$ & $6.35 E+04$ & 0 & 0 & $\mathrm{~T}$ & 3600.4 & $5.99 \mathrm{E}+07$ \\
\hline A & $\mathrm{M}$ & cvs08r139-94 & $1.74 \mathrm{E}+07$ & $-1.16 \mathrm{E}+02$ & $1.79 \mathrm{E}+05$ & 12.99 & 4 & $\mathrm{~T}$ & 3600.4 & $4.43 E+08$ \\
\hline $\mathrm{D}$ & $\mathrm{M}$ & cvs08r139-94 & $2.00 \mathrm{E}+06$ & $-1.14 \mathrm{E}+02$ & $8.20 \mathrm{E}+04$ & 401.79 & 2 & $\mathrm{~T}$ & 3600.4 & $7.54 \mathrm{E}+07$ \\
\hline $\mathrm{A}$ & B & cvs08r139-94 & $1.80 \mathrm{E}+07$ & $-1.14 \mathrm{E}+02$ & $1.79 \mathrm{E}+05$ & 0.47 & 3 & $\mathrm{~T}$ & 3600.4 & $6.11 \mathrm{E}+08$ \\
\hline $\mathrm{L}$ & $\mathrm{M}$ & cvs08r139-94 & $1.85 \mathrm{E}+07$ & $-1.13 E+02$ & $2.95 \mathrm{E}+05$ & 3.7 & 3 & $\mathrm{~T}$ & 3600.4 & $3.67 E+08$ \\
\hline D & B & pg5_34 & $1.25 \mathrm{E}+07$ & $-1.42 \mathrm{E}+04$ & $1.58 \mathrm{E}+06$ & 0.31 & 2 & $\mathrm{~T}$ & 3600.1 & $1.16 \mathrm{E}+09$ \\
\hline $\mathrm{A}$ & $\mathrm{M}$ & pg5_34 & $2.30 \mathrm{E}+07$ & $-1.41 E+04$ & $1.18 \mathrm{E}+06$ & 11.95 & 3 & $\mathrm{~T}$ & 3600.1 & $7.21 \mathrm{E}+08$ \\
\hline D & $M$ & pg5_34 & $1.25 \mathrm{E}+07$ & $-1.43 E+04$ & $8.95 E+05$ & 2.15 & 15 & $\mathrm{~T}$ & 3600.1 & $6.13 E+08$ \\
\hline $\mathrm{A}$ & B & pg5_34 & $4.01 \mathrm{E}+07$ & $-1.21 E+04$ & $1.85 \mathrm{E}+06$ & 2289.89 & 2 & $\mathrm{~T}$ & 3600.2 & $1.14 \mathrm{E}+09$ \\
\hline $\mathrm{L}$ & $\mathrm{M}$ & pg5_34 & $1.83 \mathrm{E}+07$ & $-1.43 E+04$ & 1.49E+06 & 283.39 & 5 & $\mathrm{~T}$ & 3600.2 & $1.56 \mathrm{E}+09$ \\
\hline D & B & $\begin{array}{l}\text { neos- } \\
1112782\end{array}$ & $2.54 \mathrm{E}+06$ & $6.20 \mathrm{E}+11$ & $1.62 \mathrm{E}+06$ & 1.86 & 5 & $\mathrm{~T}$ & 3600.1 & $1.49 \mathrm{E}+09$ \\
\hline $\mathrm{A}$ & $\mathrm{M}$ & $\begin{array}{l}\text { neos- } \\
1112782 \\
\end{array}$ & $2.81 \mathrm{E}+06$ & $5.84 \mathrm{E}+11$ & $1.43 E+06$ & 0.1 & 141 & $\mathrm{~T}$ & 3600 & $2.81 E+08$ \\
\hline D & $\mathrm{M}$ & $\begin{array}{l}\text { neos- } \\
1112782\end{array}$ & $1.55 \mathrm{E}+07$ & $6.00 \mathrm{E}+11$ & $4.95 \mathrm{E}+05$ & 2.66 & 112 & $\mathrm{~T}$ & 3600.1 & $8.18 \mathrm{E}+08$ \\
\hline $\mathrm{A}$ & B & \multicolumn{2}{|c|}{ neos-1112782 } & & & & & $\mathrm{F}$ & & \\
\hline $\mathrm{L}$ & $\mathrm{M}$ & $\begin{array}{c}\text { neos- } \\
1112782 \\
\end{array}$ & $5.29 E+06$ & $6.11 \mathrm{E}+11$ & $2.80 \mathrm{E}+06$ & 6.49 & 6 & $\mathrm{~T}$ & 3600.1 & $9.43 E+08$ \\
\hline D & B & $\begin{array}{l}\text { chromaticind } \\
\text { ex32-8 }\end{array}$ & $1.70 \mathrm{E}+07$ & $4.00 \mathrm{E}+00$ & 1.17E+05 & 3.17 & 1 & $\mathrm{~T}$ & 3600.3 & $6.42 E+06$ \\
\hline
\end{tabular}




\begin{tabular}{|c|c|c|c|c|c|c|c|c|c|c|}
\hline VDS & NS & model & $\begin{array}{r}\text { simplex } \\
\text { it. }\end{array}$ & incu. Sol. & nodes & $\begin{array}{r}\text { 1st fea. } \\
\text { Time }\end{array}$ & $\begin{array}{r}\text { fea. } \\
\text { nodes }\end{array}$ & $\begin{array}{l}\text { exit } \\
\text { code }\end{array}$ & time & memory \\
\hline A & M & $\begin{array}{l}\text { chromaticind } \\
\text { ex32-8 }\end{array}$ & $2.87 \mathrm{E}+07$ & $\mathrm{~N}$ & $2.25 \mathrm{E}+05$ & 0 & 0 & $T$ & 3600.3 & $9.07 E+08$ \\
\hline D & M & $\begin{array}{l}\text { chromaticind } \\
\text { ex32-8 }\end{array}$ & $1.99 \mathrm{E}+07$ & $4.00 \mathrm{E}+00$ & $1.39 \mathrm{E}+05$ & 4.72 & 1 & $\mathrm{~T}$ & 3600.3 & $1.05 E+07$ \\
\hline A & $\mathrm{B}$ & $\begin{array}{l}\text { chromaticind } \\
\text { ex32-8 }\end{array}$ & $2.90 \mathrm{E}+07$ & $\mathrm{~N}$ & $2.26 \mathrm{E}+05$ & 0 & 0 & $\mathrm{~T}$ & 3600.3 & $9.30 \mathrm{E}+08$ \\
\hline $\mathrm{L}$ & M & $\begin{array}{l}\text { chromaticind } \\
\text { ex32-8 }\end{array}$ & $2.56 \mathrm{E}+07$ & $\mathrm{~N}$ & $3.27 E+05$ & 0 & 0 & $\mathrm{~T}$ & 3600.3 & $8.38 \mathrm{E}+08$ \\
\hline D & B & lotsize & $3.39 E+05$ & $\mathrm{~N}$ & $2.33 E+05$ & 0 & 0 & $\mathrm{~T}$ & 3600.1 & $8.86 \mathrm{E}+07$ \\
\hline $\mathrm{A}$ & $M$ & lotsize & $5.95 \mathrm{E}+06$ & $1.84 \mathrm{E}+06$ & $2.38 \mathrm{E}+06$ & 286.35 & 11 & $\mathrm{~T}$ & 3601.2 & $1.58 \mathrm{E}+10$ \\
\hline D & $M$ & lotsize & $3.30 E+05$ & $\mathrm{~N}$ & $2.32 \mathrm{E}+05$ & 0 & 0 & $\mathrm{~T}$ & 3600.1 & $8.36 \mathrm{E}+07$ \\
\hline A & B & lotsize & $7.99 \mathrm{E}+06$ & $\mathrm{~N}$ & $3.13 E+06$ & 0 & 0 & $\mathrm{~T}$ & 3600.2 & $2.45 \mathrm{E}+09$ \\
\hline $\mathrm{L}$ & $\mathrm{M}$ & lotsize & $3.33 E+06$ & $\mathrm{~N}$ & $7.37 \mathrm{E}+05$ & 0 & 0 & $\mathrm{~T}$ & 3600.2 & $2.00 \mathrm{E}+09$ \\
\hline $\mathrm{D}$ & B & cvs16r70-62 & $1.73 \mathrm{E}+06$ & $-4.10 \mathrm{E}+01$ & $4.77 \mathrm{E}+04$ & 51.05 & 1 & $\mathrm{~T}$ & 3600.9 & $5.75 \mathrm{E}+07$ \\
\hline A & $\mathrm{M}$ & cvs16r70-62 & $1.71 \mathrm{E}+07$ & $-4.00 \mathrm{E}+01$ & $7.06 \mathrm{E}+05$ & 0.79 & 4 & $\mathrm{~T}$ & 3600.8 & $2.13 E+07$ \\
\hline $\mathrm{D}$ & $\mathrm{M}$ & cvs16r70-62 & $2.78 \mathrm{E}+06$ & $-4.10 \mathrm{E}+01$ & $1.06 \mathrm{E}+05$ & 156.19 & 2 & $\mathrm{~T}$ & 3600.9 & 1.03E+08 \\
\hline A & $\mathrm{B}$ & cvs16r70-62 & $1.60 \mathrm{E}+07$ & $-4.00 E+01$ & $1.15 \mathrm{E}+05$ & 0.64 & 4 & $\mathrm{~T}$ & 3600.9 & $7.29 \mathrm{E}+08$ \\
\hline L & $M$ & cvs16r70-62 & $9.08 \mathrm{E}+06$ & $-3.70 \mathrm{E}+01$ & $4.96 \mathrm{E}+05$ & 0 & 0 & $\mathrm{~T}$ & 3600.9 & $79 \mathrm{E}+08$ \\
\hline D & B & markshare1 & $2.38 \mathrm{E}+06$ & $1.60 \mathrm{E}+01$ & $8.61 \mathrm{E}+05$ & 0 & 0 & $\mathrm{~T}$ & 600 & $1.59 \mathrm{E}+08$ \\
\hline A & $\mathrm{M}$ & markshare1 & $1.77 \mathrm{E}+08$ & $2.00 \mathrm{E}+00$ & $6.70 \mathrm{E}+07$ & 0.01 & 3 & $\mathrm{~T}$ & 3600 & $2.47 \mathrm{E}+06$ \\
\hline D & $\mathrm{M}$ & markshare1 & $1.64 \mathrm{E}+08$ & $7.00 E+00$ & $4.01 \mathrm{E}+07$ & 0 & 0 & $\mathrm{~T}$ & 3600 & $2.32 \mathrm{E}+06$ \\
\hline A & B & markshare1 & $1.60 \mathrm{E}+06$ & $1.90 \mathrm{E}+01$ & $7.90 \mathrm{E}+05$ & 0.11 & 4 & $\mathrm{~T}$ & 3600 & 1.73E+08 \\
\hline $\mathrm{L}$ & $\mathrm{M}$ & markshare1 & $1.58 \mathrm{E}+08$ & $3.00 \mathrm{E}+00$ & $5.23 \mathrm{E}+07$ & 0 & 0 & $\mathrm{~T}$ & 3600 & $3.22 \mathrm{E}+06$ \\
\hline D & $\mathrm{B}$ & $\mathrm{pp08a}$ & $3.90 \mathrm{E}+06$ & $7.83 E+03$ & $1.96 \mathrm{E}+06$ & 0.02 & 10 & $\mathrm{~T}$ & 3600.1 & $2.18 \mathrm{E}+09$ \\
\hline $\mathrm{A}$ & $M$ & pp08a & $3.53 \mathrm{E}+07$ & $7.53 E+03$ & $8.33 E+06$ & 0.02 & 27 & $\mathrm{~T}$ & 3600 & $1.04 \mathrm{E}+08$ \\
\hline D & $\mathrm{M}$ & pp08a & $2.21 \mathrm{E}+07$ & $7.47 \mathrm{E}+03$ & $4.79 \mathrm{E}+06$ & 0.3 & 7 & $\mathrm{~T}$ & 3600 & $7.60 \mathrm{E}+07$ \\
\hline A & $\mathrm{B}$ & pp08a & $2.75 E+06$ & $9.66 \mathrm{E}+03$ & $1.95 \mathrm{E}+06$ & 0.01 & 19 & $\mathrm{~T}$ & 3600.3 & $3.87 \mathrm{E}+09$ \\
\hline $\mathrm{L}$ & $M$ & pp08a & $5.98 \mathrm{E}+07$ & $7.66 \mathrm{E}+03$ & $1.42 \mathrm{E}+07$ & 2.2 & 8 & $\mathrm{~T}$ & 3600 & $1.92 \mathrm{E}+07$ \\
\hline D & $\mathrm{B}$ & noswot & $4.72 \mathrm{E}+06$ & $-4.10 E+01$ & $1.06 \mathrm{E}+06$ & 0.01 & 6 & $\mathrm{~T}$ & 3600 & $2.48 \mathrm{E}+08$ \\
\hline A & $\mathrm{M}$ & noswot & $9.08 \mathrm{E}+07$ & $-4.10 E+01$ & $2.90 \mathrm{E}+07$ & 1.11 & 6 & $\mathrm{~T}$ & 3600 & $7.73 E+06$ \\
\hline D & $\mathrm{M}$ & noswot & $6.64 \mathrm{E}+07$ & $-4.10 E+01$ & $1.96 \mathrm{E}+07$ & 0.06 & 3 & $\mathrm{~T}$ & 3600 & $8.98 \mathrm{E}+06$ \\
\hline A & $\mathrm{B}$ & noswot & $2.26 \mathrm{E}+06$ & $-4.10 E+01$ & $7.74 \mathrm{E}+05$ & 0.01 & 8 & $\mathrm{~T}$ & 3600 & $2.86 \mathrm{E}+08$ \\
\hline $\mathrm{L}$ & $\mathrm{M}$ & noswot & $6.43 E+07$ & $-4.00 E+01$ & $3.86 \mathrm{E}+07$ & 0.09 & 4 & $\mathrm{~T}$ & 3600 & $6.92 \mathrm{E}+06$ \\
\hline D & B & timtab1 & $4.33 \mathrm{E}+06$ & $9.12 \mathrm{E}+05$ & $1.43 \mathrm{E}+06$ & 10.74 & 3 & $\mathrm{~T}$ & 3600.1 & $5.38 \mathrm{E}+08$ \\
\hline A & $\mathrm{M}$ & timtab1 & $8.94 \mathrm{E}+07$ & $\mathrm{~N}$ & $1.91 \mathrm{E}+07$ & 0 & 0 & $\mathrm{~T}$ & 3600 & $1.35 \mathrm{E}+07$ \\
\hline D & $M$ & timtab1 & $1.96 \mathrm{E}+07$ & $9.01 \mathrm{E}+05$ & $4.37 \mathrm{E}+06$ & 21.22 & 61 & $\mathrm{~T}$ & 3600 & $2.23 \mathrm{E}+07$ \\
\hline A & $\mathrm{B}$ & timtab1 & $4.23 E+06$ & $1.07 \mathrm{E}+06$ & $1.95 \mathrm{E}+06$ & 1.9 & 4 & $\mathrm{~T}$ & 3600 & $7.11 \mathrm{E}+08$ \\
\hline $\mathrm{L}$ & $\mathrm{M}$ & timtab1 & $5.26 \mathrm{E}+07$ & $8.10 E+05$ & $1.19 \mathrm{E}+07$ & 4.4 & 4 & $\mathrm{~T}$ & 3600 & $2.26 \mathrm{E}+07$ \\
\hline D & B & modglob & $3.32 E+06$ & $2.09 \mathrm{E}+07$ & $1.96 \mathrm{E}+06$ & 0.04 & 18 & $\mathrm{~T}$ & 3600.1 & $5.74 \mathrm{E}+08$ \\
\hline A & $M$ & modglob & $1.85 \mathrm{E}+07$ & $2.07 E+07$ & $6.69 \mathrm{E}+06$ & 0.39 & 4 & $T$ & 3600 & $1.48 \mathrm{E}+07$ \\
\hline
\end{tabular}




\begin{tabular}{|c|c|c|c|c|c|c|c|c|c|c|}
\hline VDS & NS & model & $\begin{array}{r}\text { simplex } \\
\text { it. }\end{array}$ & incu. Sol. & nodes & $\begin{array}{r}\text { 1st fea. } \\
\text { Time }\end{array}$ & $\begin{array}{r}\text { fea. } \\
\text { nodes }\end{array}$ & $\begin{array}{l}\text { exit } \\
\text { code }\end{array}$ & time & memory \\
\hline D & $\mathrm{M}$ & modglob & $2.03 E+07$ & $2.07 E+07$ & $5.24 \mathrm{E}+06$ & 0.04 & 10 & $\mathrm{~T}$ & 3600 & $1.58 \mathrm{E}+07$ \\
\hline A & B & modglob & $1.64 E+06$ & $2.07 E+07$ & $1.90 \mathrm{E}+06$ & 0.01 & 2 & $\mathrm{~T}$ & 3600.1 & $5.72 \mathrm{E}+08$ \\
\hline $\mathrm{L}$ & $\mathrm{M}$ & modglob & $1.85 \mathrm{E}+07$ & $2.07 \mathrm{E}+07$ & $7.18 \mathrm{E}+06$ & 0.01 & 7 & $\mathrm{~T}$ & 3600 & $1.43 \mathrm{E}+07$ \\
\hline D & B & set1ch & $2.70 E+06$ & $6.50 \mathrm{E}+04$ & $2.85 E+06$ & 0.15 & 18 & $\mathrm{~T}$ & 3600.1 & $1.28 \mathrm{E}+09$ \\
\hline A & $\mathrm{M}$ & set1ch & $1.57 E+07$ & $5.64 \mathrm{E}+04$ & $5.13 E+06$ & 0.11 & 115 & $\mathrm{~T}$ & 3600 & $2.46 \mathrm{E}+07$ \\
\hline D & $\mathrm{M}$ & set1ch & $1.08 \mathrm{E}+07$ & $5.74 \mathrm{E}+04$ & $3.40 \mathrm{E}+06$ & 0.21 & 78 & $\mathrm{~T}$ & 3600 & $5.69 \mathrm{E}+07$ \\
\hline A & B & set1ch & $5.74 \mathrm{E}+06$ & $7.00 \mathrm{E}+04$ & $2.95 \mathrm{E}+06$ & 0.03 & 10 & $\mathrm{~T}$ & 3600.3 & $1.37 \mathrm{E}+09$ \\
\hline $\mathrm{L}$ & $\mathrm{M}$ & set1ch & $1.28 \mathrm{E}+07$ & $5.94 \mathrm{E}+04$ & $4.13 E+06$ & 10.24 & 165 & $\mathrm{~T}$ & 3600 & $1.34 \mathrm{E}+07$ \\
\hline D & B & germanrr & $3.78 \mathrm{E}+05$ & $\mathrm{~N}$ & $1.45 \mathrm{E}+04$ & 0 & 0 & $\mathrm{~T}$ & 3603.4 & $6.08 \mathrm{E}+07$ \\
\hline A & $\mathrm{M}$ & germanrr & $4.20 E+06$ & $4.84 \mathrm{E}+07$ & $1.61 \mathrm{E}+05$ & 45.33 & 2 & $\mathrm{~T}$ & 3603.1 & $9.17 E+08$ \\
\hline D & $\mathrm{M}$ & germanrr & $3.86 \mathrm{E}+05$ & $\mathrm{~N}$ & $1.59 \mathrm{E}+04$ & 0 & 0 & $\mathrm{~T}$ & 3603.1 & $6.25 E+07$ \\
\hline A & B & germanrr & $4.80 E+06$ & $4.82 \mathrm{E}+07$ & 1.17E+05 & 43.72 & 6 & $\mathrm{~T}$ & 3603.1 & $7.53 E+08$ \\
\hline $\mathrm{L}$ & $\mathrm{M}$ & germanrr & $3.00 E+06$ & $\mathrm{~N}$ & $1.40 \mathrm{E}+05$ & 0 & 0 & $\mathrm{~T}$ & 3603 & $4.58 \mathrm{E}+08$ \\
\hline D & B & mzzv11 & $5.07 E+05$ & $-1.90 E+04$ & $8.50 \mathrm{E}+03$ & 1822.63 & 3 & $\mathrm{~T}$ & 3602 & $5.31 E+07$ \\
\hline A & $\mathrm{M}$ & mzzv11 & $3.07 E+06$ & $-1.94 \mathrm{E}+04$ & $1.82 \mathrm{E}+05$ & 3.27 & 6 & $\mathrm{~T}$ & 3601.9 & $5.99 E+08$ \\
\hline D & $\mathrm{M}$ & mzzv11 & & & & & & $\mathrm{F}$ & & \\
\hline$A$ & B & mzzv11 & $6.19 E+06$ & $-1.93 E+04$ & $7.61 \mathrm{E}+04$ & 529.68 & 4 & $\mathrm{~T}$ & 3601.9 & $5.02 E+08$ \\
\hline $\mathrm{L}$ & $\mathrm{M}$ & mzzv11 & & & & & & $\mathrm{F}$ & & \\
\hline D & B & neos-480878 & $2.23 \mathrm{E}+06$ & $4.93 \mathrm{E}+02$ & $3.33 \mathrm{E}+05$ & 0.3 & 8 & $\mathrm{~T}$ & 3600.1 & $8.08 \mathrm{E}+08$ \\
\hline $\mathrm{A}$ & $\mathrm{M}$ & neos-480878 & $2.86 \mathrm{E}+06$ & $4.93 \mathrm{E}+02$ & $5.24 \mathrm{E}+05$ & 291.64 & 11 & $\mathrm{~T}$ & 3600.1 & $3.48 E+08$ \\
\hline $\mathrm{D}$ & $\mathrm{M}$ & neos-480878 & $2.44 \mathrm{E}+06$ & $4.93 \mathrm{E}+02$ & $3.87 E+05$ & 329.84 & 5 & $\mathrm{~T}$ & 3600.1 & $3.44 \mathrm{E}+08$ \\
\hline $\mathrm{A}$ & $\mathrm{B}$ & neos-480878 & $5.40 \mathrm{E}+06$ & $4.94 \mathrm{E}+02$ & $6.82 \mathrm{E}+05$ & 0.09 & 13 & $\mathrm{~T}$ & 3600.2 & $1.78 \mathrm{E}+09$ \\
\hline $\mathrm{L}$ & $\mathrm{M}$ & neos-480878 & $3.28 \mathrm{E}+06$ & $4.93 E+02$ & $4.92 \mathrm{E}+05$ & 382.39 & 7 & $\mathrm{~T}$ & 3600.1 & $5.36 \mathrm{E}+08$ \\
\hline D & $\mathrm{B}$ & p2756 & $1.04 \mathrm{E}+06$ & $3.14 \mathrm{E}+03$ & $1.04 \mathrm{E}+06$ & 37.13 & 7 & $\mathrm{~T}$ & 3600.1 & $6.88 \mathrm{E}+08$ \\
\hline $\mathrm{A}$ & $\mathrm{M}$ & p2756 & $6.17 \mathrm{E}+06$ & $3.58 \mathrm{E}+03$ & $1.80 \mathrm{E}+06$ & 84.39 & 20 & $\mathrm{~T}$ & 3600 & $3.10 E+07$ \\
\hline D & $\mathrm{M}$ & p2756 & $3.82 \mathrm{E}+06$ & $3.24 \mathrm{E}+03$ & $1.45 \mathrm{E}+06$ & 1.48 & 50 & $\mathrm{~T}$ & 3600 & $2.96 \mathrm{E}+07$ \\
\hline A & $\mathrm{B}$ & p2756 & $3.57 E+06$ & $\mathrm{~N}$ & $1.51 \mathrm{E}+06$ & 0 & 0 & $\mathrm{~T}$ & 3600 & 4.17E+08 \\
\hline $\mathrm{L}$ & $M$ & p2756 & $4.39 E+06$ & $7.08 \mathrm{E}+03$ & $1.14 \mathrm{E}+06$ & 165.87 & 365 & $\mathrm{~T}$ & 3600 & $1.13 \mathrm{E}+08$ \\
\hline D & B & 10teams & $1.02 E+07$ & $9.24 \mathrm{E}+02$ & $3.26 \mathrm{E}+05$ & 7.49 & 3 & $\mathrm{~T}$ & 3600.1 & $3.66 \mathrm{E}+08$ \\
\hline A & $\mathrm{M}$ & 10teams & $3.94 E+07$ & $9.24 \mathrm{E}+02$ & $1.44 \mathrm{E}+06$ & 0.41 & 3 & $\mathrm{~T}$ & 3600.1 & $2.54 \mathrm{E}+08$ \\
\hline D & $\mathrm{M}$ & 10teams & $1.11 \mathrm{E}+07$ & $9.24 \mathrm{E}+02$ & $3.02 E+05$ & 18.58 & 1 & $\mathrm{~T}$ & 3600.1 & $3.47 E+08$ \\
\hline A & B & 10teams & $2.22 \mathrm{E}+07$ & $9.24 \mathrm{E}+02$ & $6.12 \mathrm{E}+05$ & 1.62 & 3 & $\mathrm{~T}$ & 3600.1 & $1.08 \mathrm{E}+09$ \\
\hline $\mathrm{L}$ & $\mathrm{M}$ & 10teams & $2.99 \mathrm{E}+07$ & $9.26 \mathrm{E}+02$ & $1.10 \mathrm{E}+06$ & 32.79 & 3 & $\mathrm{~T}$ & 3600 & $3.15 E+08$ \\
\hline D & B & gt2 & $1.54 \mathrm{E}+06$ & $2.20 \mathrm{E}+04$ & $1.02 \mathrm{E}+06$ & 0.03 & 6 & $\mathrm{~T}$ & 3600.1 & $2.87 E+08$ \\
\hline A & $\mathrm{M}$ & gt2 & $5.12 \mathrm{E}+07$ & $2.23 E+04$ & $5.63 \mathrm{E}+07$ & 0.01 & 4 & $\mathrm{~T}$ & 3600 & $4.44 E+06$ \\
\hline D & $\mathrm{M}$ & gt2 & $1.09 E+08$ & $3.04 \mathrm{E}+04$ & $4.03 E+07$ & 1.19 & 8 & $\mathrm{~T}$ & 3600 & $4.08 \mathrm{E}+06$ \\
\hline A & B & gt2 & $3.84 E+06$ & $2.31 E+04$ & $1.39 \mathrm{E}+06$ & 0.03 & 3 & $\mathrm{~T}$ & 3600.1 & $8.53 E+08$ \\
\hline $\mathrm{L}$ & $\mathrm{M}$ & gt2 & $5.89 \mathrm{E}+07$ & $3.68 \mathrm{E}+04$ & $3.89 \mathrm{E}+07$ & 0.01 & 9 & $\mathrm{~T}$ & 3600 & $5.70 E+06$ \\
\hline
\end{tabular}




\begin{tabular}{|c|c|c|c|c|c|c|c|c|c|c|}
\hline VDS & NS & model & $\begin{array}{r}\text { simplex } \\
\text { it. }\end{array}$ & incu. Sol. & nodes & $\begin{array}{r}\text { 1st fea. } \\
\text { Time } \\
\end{array}$ & $\begin{array}{r}\text { fea. } \\
\text { nodes }\end{array}$ & $\begin{array}{l}\text { exit } \\
\text { code }\end{array}$ & time & memory \\
\hline D & $\mathrm{B}$ & sp150x300d & $3.22 \mathrm{E}+06$ & $\mathrm{~N}$ & $1.19 \mathrm{E}+06$ & 0 & 0 & $T$ & 3600.1 & $3.36 \mathrm{E}+08$ \\
\hline $\mathrm{A}$ & $\mathrm{M}$ & sp150x300d & $3.33 \mathrm{E}+06$ & $\mathrm{~N}$ & $1.82 \mathrm{E}+06$ & 0 & 0 & $\mathrm{~T}$ & 3600.1 & $4.84 \mathrm{E}+08$ \\
\hline D & $\mathrm{M}$ & $\mathrm{sp} 150 \times 300 \mathrm{~d}$ & $3.34 \mathrm{E}+06$ & $6.90 \mathrm{E}+01$ & $9.48 \mathrm{E}+05$ & 0.64 & 1 & $\mathrm{~T}$ & 3600 & $1.03 E+08$ \\
\hline A & B & sp150x300d & $3.48 \mathrm{E}+06$ & $6.90 \mathrm{E}+01$ & $1.76 \mathrm{E}+06$ & 0.01 & 1 & $\mathrm{~T}$ & 3600 & $4.77 \mathrm{E}+08$ \\
\hline D & B & comp07-2idx & $4.61 \mathrm{E}+05$ & $9.10 \mathrm{E}+01$ & $8.78 \mathrm{E}+03$ & 213.75 & 3 & $T$ & 3605.2 & $6.82 \mathrm{E}+07$ \\
\hline A & $\mathrm{M}$ & comp07-2idx & $3.61 \mathrm{E}+06$ & $\mathrm{~N}$ & $6.65 E+04$ & 0 & 0 & $\mathrm{~T}$ & 3604.8 & $2.60 \mathrm{E}+08$ \\
\hline D & $\mathrm{M}$ & comp07-2idx & $5.16 \mathrm{E}+05$ & $6.50 \mathrm{E}+01$ & $1.11 \mathrm{E}+04$ & 937.73 & 1 & $\mathrm{~T}$ & 3605 & $6.92 \mathrm{E}+07$ \\
\hline A & B & comp07-2idx & $3.14 E+06$ & $5.40 \mathrm{E}+01$ & $1.21 E+05$ & 19.25 & 7 & $T$ & 3604.8 & $7.04 E+08$ \\
\hline D & B & leo2 & $2.33 E+05$ & $4.47 E+08$ & $6.10 E+04$ & 733.33 & 3 & $\mathrm{~T}$ & 3600.5 & $1.00 E+08$ \\
\hline A & M & leo2 & $2.58 \mathrm{E}+06$ & $4.24 E+08$ & $2.88 \mathrm{E}+05$ & 1064.43 & 2 & $\mathrm{~T}$ & 3600.6 & $5.05 \mathrm{E}+09$ \\
\hline D & $M$ & leo2 & $4.15 E+05$ & $4.34 \mathrm{E}+08$ & $1.22 \mathrm{E}+05$ & 240.23 & 3 & $\mathrm{~T}$ & 3600.5 & $8.98 \mathrm{E}+08$ \\
\hline A & $\mathrm{B}$ & leo2 & $3.86 \mathrm{E}+06$ & $4.41 \mathrm{E}+08$ & $2.63 \mathrm{E}+05$ & 0.45 & 3 & $\mathrm{~T}$ & 3600.6 & $3.78 \mathrm{E}+09$ \\
\hline D & B & bppc4-08 & $1.17 E+07$ & $5.60 \mathrm{E}+01$ & $6.17 E+05$ & 0.51 & 11 & $\mathrm{~T}$ & 3600.1 & $7.69 \mathrm{E}+08$ \\
\hline A & M & bppc4-08 & $5.63 E+06$ & $5.70 \mathrm{E}+01$ & $6.10 E+05$ & 0.64 & 9 & $T$ & 3600 & $4.21 \mathrm{E}+08$ \\
\hline D & M & bppc4-08 & $6.19 E+06$ & $5.70 \mathrm{E}+01$ & 4.70E+05 & 0.82 & 7 & $\mathrm{~T}$ & 3600 & $5.01 E+08$ \\
\hline A & B & bppc4-08 & $2.20 \mathrm{E}+07$ & $5.50 \mathrm{E}+01$ & $5.42 \mathrm{E}+05$ & 0.07 & 25 & $\mathrm{~T}$ & 3600.1 & $1.27 \mathrm{E}+09$ \\
\hline D & B & $\begin{array}{l}\text { cmflsp50-24- } \\
8-8\end{array}$ & $4.51 E+05$ & $5.75 \mathrm{E}+07$ & $1.82 \mathrm{E}+04$ & 954.86 & 1 & $\mathrm{~T}$ & 3605.6 & $5.03 E+07$ \\
\hline A & $\mathrm{M}$ & $\begin{array}{l}\text { cmflsp50-24- } \\
8-8\end{array}$ & +06 & $\mathrm{~N}$ & $E+05$ & 0 & 0 & $\mathrm{~T}$ & 3605.5 & $2.20 \mathrm{E}+08$ \\
\hline D & M & $\begin{array}{l}\text { cmflsp50-24- } \\
8-8\end{array}$ & $E+06$ & $\mathrm{~N}$ & $42 \mathrm{E}+04$ & 0 & 0 & $\mathrm{~T}$ & 3605.5 & $8.94 \mathrm{E}+07$ \\
\hline $\mathrm{A}$ & B & $\begin{array}{l}\text { cmflsp50-24- } \\
8-8\end{array}$ & $5.74 \mathrm{E}+06$ & $\mathrm{~N}$ & $8.05 E+04$ & 0 & 0 & $\mathrm{~T}$ & 3605.5 & $1.71 \mathrm{E}+08$ \\
\hline $\mathrm{D}$ & $\mathrm{B}$ & uccase9 & $1.41 \mathrm{E}+05$ & $1.27 \mathrm{E}+04$ & $8.90 \mathrm{E}+03$ & 773.85 & 1 & $\mathrm{~T}$ & 3653.9 & $2.37 E+08$ \\
\hline $\mathrm{A}$ & $\mathrm{M}$ & uccase9 & $1.26 \mathrm{E}+06$ & $\mathrm{~N}$ & $7.58 \mathrm{E}+04$ & 0 & 0 & $\mathrm{~T}$ & 3653.8 & $2.16 \mathrm{E}+08$ \\
\hline $\mathrm{D}$ & $\mathrm{M}$ & uccase9 & $1.29 \mathrm{E}+05$ & $\mathrm{~N}$ & $7.37 E+03$ & 0 & 0 & $\mathrm{~T}$ & 3654.5 & $1.02 \mathrm{E}+08$ \\
\hline $\mathrm{A}$ & $\mathrm{B}$ & uccase9 & $1.15 \mathrm{E}+06$ & $1.26 \mathrm{E}+04$ & $6.76 \mathrm{E}+04$ & 91.37 & 2 & $\mathrm{~T}$ & 3653.9 & $1.40 \mathrm{E}+09$ \\
\hline D & B & unitcal_7 & $2.21 \mathrm{E}+05$ & $\mathrm{~N}$ & $7.27 E+03$ & 0 & 0 & $\mathrm{~T}$ & 3661.3 & $9.93 \mathrm{E}+07$ \\
\hline A & $\mathrm{M}$ & unitcal_7 & $2.06 \mathrm{E}+06$ & $1.97 \mathrm{E}+07$ & $5.13 E+04$ & 37.44 & 5 & $\mathrm{~T}$ & 3661.6 & $2.40 \mathrm{E}+08$ \\
\hline $\mathrm{D}$ & $\mathrm{M}$ & unitcal_7 & $1.96 \mathrm{E}+05$ & $1.97 \mathrm{E}+07$ & $1.06 \mathrm{E}+04$ & 371 & 11 & $\mathrm{~T}$ & 3662 & $9.96 \mathrm{E}+07$ \\
\hline A & B & unitcal_7 & $2.00 \mathrm{E}+06$ & $2.00 \mathrm{E}+07$ & $5.56 \mathrm{E}+04$ & 13.39 & 7 & $\mathrm{~T}$ & 3661.4 & $2.52 \mathrm{E}+08$ \\
\hline $\mathrm{D}$ & B & $\begin{array}{l}\text { supportcase1 } \\
8\end{array}$ & $1.42 \mathrm{E}+06$ & $5.10 \mathrm{E}+01$ & $5.39 \mathrm{E}+05$ & 0 & 0 & $\mathrm{~T}$ & 3600.1 & $3.89 \mathrm{E}+08$ \\
\hline A & $\mathrm{M}$ & $\begin{array}{l}\text { supportcase1 } \\
8\end{array}$ & $3.21 \mathrm{E}+06$ & $\mathrm{~N}$ & $9.54 \mathrm{E}+05$ & 0 & 0 & $\mathrm{~T}$ & 3600.2 & $2.12 \mathrm{E}+09$ \\
\hline D & $\mathrm{M}$ & $\begin{array}{l}\text { supportcase1 } \\
8\end{array}$ & $1.73 E+06$ & $\mathrm{~N}$ & $2.87 E+05$ & 0 & 0 & $\mathrm{~T}$ & 3600.1 & $4.82 \mathrm{E}+08$ \\
\hline A & $\mathrm{B}$ & $\begin{array}{l}\text { supportcase1 } \\
8\end{array}$ & $5.53 E+06$ & $5.70 \mathrm{E}+01$ & $1.34 \mathrm{E}+06$ & 0 & 0 & $\mathrm{~T}$ & 3600.3 & $3.94 \mathrm{E}+09$ \\
\hline D & $\mathrm{B}$ & $\mathrm{h} 80 \times 6320 \mathrm{~d}$ & $2.46 \mathrm{E}+05$ & $\mathrm{~N}$ & $2.03 E+05$ & 0 & 0 & $\mathrm{~T}$ & 3600.2 & $2.62 E+08$ \\
\hline $\mathrm{A}$ & $\mathrm{M}$ & $\mathrm{h} 80 \times 6320 \mathrm{~d}$ & $7.59 \mathrm{E}+05$ & $6.87 E+03$ & $3.11 \mathrm{E}+05$ & 0.45 & 62 & $\mathrm{~T}$ & 3600.2 & $6.93 \mathrm{E}+08$ \\
\hline D & M & $\mathrm{h} 80 \times 6320 \mathrm{~d}$ & $8.33 E+05$ & $\mathrm{~N}$ & $4.83 \mathrm{E}+05$ & 0 & 0 & $\mathrm{~T}$ & 3600.2 & $9.01 E+08$ \\
\hline
\end{tabular}




\begin{tabular}{|c|c|c|c|c|c|c|c|c|c|c|}
\hline VDS & NS & model & $\begin{array}{r}\text { simplex } \\
\text { it. }\end{array}$ & incu. Sol. & nodes & $\begin{array}{r}\text { 1st fea. } \\
\text { Time }\end{array}$ & $\begin{array}{r}\text { fea. } \\
\text { nodes }\end{array}$ & $\begin{array}{l}\text { exit } \\
\text { code }\end{array}$ & time & memory \\
\hline$A$ & B & h80x6320d & $6.48 \mathrm{E}+05$ & $7.40 \mathrm{E}+03$ & $9.17 E+05$ & 0.37 & 17 & $T$ & 3646.8 & $1.64 \mathrm{E}+10$ \\
\hline D & B & sct2 & $6.24 E+06$ & $-2.29 \mathrm{E}+02$ & $4.56 \mathrm{E}+05$ & 1.86 & 5 & $\mathrm{~T}$ & 3600.4 & $1.43 E+09$ \\
\hline$A$ & $\mathrm{M}$ & sct2 & $4.43 E+06$ & $-2.30 E+02$ & $7.83 E+05$ & 53.26 & 3 & $T$ & 3600.4 & $2.11 E+09$ \\
\hline D & $M$ & sct2 & $6.46 \mathrm{E}+06$ & $\mathrm{~N}$ & $5.28 \mathrm{E}+05$ & 0 & 0 & $T$ & 3600.3 & $2.98 \mathrm{E}+08$ \\
\hline A & $\mathrm{B}$ & sct2 & $1.19 E+07$ & $-2.27 E+02$ & $7.66 \mathrm{E}+05$ & 0.33 & 3 & $\mathrm{~T}$ & 3600.5 & $3.50 E+09$ \\
\hline D & B & swath3 & $2.80 E+06$ & $3.98 \mathrm{E}+02$ & $4.77 E+05$ & 0.44 & 13 & $T$ & 3600.4 & $1.30 \mathrm{E}+09$ \\
\hline A & $\mathrm{M}$ & swath3 & $7.48 \mathrm{E}+06$ & $3.98 \mathrm{E}+02$ & $1.01 E+06$ & 5.63 & 12 & $T$ & 3600.3 & $2.66 \mathrm{E}+08$ \\
\hline D & $\mathrm{M}$ & swath3 & $4.60 E+06$ & $3.98 \mathrm{E}+02$ & $6.70 E+05$ & 0.33 & 9 & $\mathrm{~T}$ & 3600.3 & $3.60 E+08$ \\
\hline A & $\mathrm{B}$ & swath3 & $3.70 E+06$ & $4.01 E+02$ & $4.77 E+05$ & 1.76 & 6 & $\mathrm{~T}$ & 3600.4 & $2.51 E+09$ \\
\hline D & $\mathrm{B}$ & $50 v-10$ & $4.45 E+06$ & $3.79 \mathrm{E}+03$ & $3.35 E+06$ & 0.72 & 15 & $\mathrm{~T}$ & 3600.2 & $1.87 \mathrm{E}+09$ \\
\hline $\mathrm{A}$ & $\mathrm{M}$ & $50 v-10$ & $6.10 E+06$ & $3.78 \mathrm{E}+03$ & $7.45 \mathrm{E}+05$ & 0.1 & 34 & $\mathrm{~T}$ & 3600.1 & $1.97 \mathrm{E}+09$ \\
\hline $\mathrm{D}$ & $\mathrm{M}$ & $50 v-10$ & $2.99 E+06$ & $3.45 E+03$ & $1.89 E+06$ & 3.73 & 25 & $\mathrm{~T}$ & 3600.1 & $1.41 \mathrm{E}+09$ \\
\hline $\mathrm{A}$ & B & $50 v-10$ & $1.29 E+07$ & $6.64 \mathrm{E}+03$ & $1.71 \mathrm{E}+06$ & 0.04 & 16 & $T$ & 3600.6 & $8.83 E+09$ \\
\hline $\mathrm{D}$ & B & enlight_hard & $1.67 E+06$ & $3.70 \mathrm{E}+01$ & $8.21 E+05$ & 1159.7 & 1 & $T$ & 3600.0 & $1.90 \mathrm{E}+08$ \\
\hline A & $M$ & enlight_hard & $1.64 E+06$ & $3.70 E+01$ & $7.67 E+05$ & 1.71 & 1 & $T$ & 3600.0 & $1.45 E+08$ \\
\hline $\mathrm{D}$ & $M$ & enlight_hard & $1.60 \mathrm{E}+06$ & $\mathrm{~N}$ & $7.46 \mathrm{E}+05$ & 0 & 0 & $\mathrm{~T}$ & 3600.0 & $1.62 E+08$ \\
\hline$A$ & B & enlight_hard & $1.40 E+06$ & $3.70 E+01$ & $7.13 E+05$ & 12.06 & 1 & $\mathrm{~T}$ & 3600.0 & $1.43 E+08$ \\
\hline $\mathrm{D}$ & B & gen-ip054 & $2.82 E+06$ & $6.85 E+03$ & $1.33 \mathrm{E}+06$ & 0 & 0 & $\mathrm{~T}$ & 3600.1 & $4.20 E+08$ \\
\hline A & $M$ & gen-ip054 & $1.78 \mathrm{E}+06$ & $6.85 E+03$ & $8.43 E+05$ & 0 & 6 & $\mathrm{~T}$ & 3600 & $2.47 E+08$ \\
\hline D & $M$ & gen-ip054 & $2.00 E+06$ & $6.85 \mathrm{E}+03$ & $7.39 E+05$ & 36.29 & 1 & $\mathrm{~T}$ & 3600 & $2.14 \mathrm{E}+08$ \\
\hline$A$ & B & gen-ip054 & $1.97 E+06$ & $6.84 \mathrm{E}+03$ & $9.29 E+05$ & 0.02 & 2 & $T$ & 3600 & $4.40 E+08$ \\
\hline D & B & $\begin{array}{l}\text { neos- } \\
5140963- \\
\text { mincio } \\
\end{array}$ & $3.33 \mathrm{E}+06$ & $1.44 \mathrm{E}+04$ & $8.83 E+05$ & 0.01 & 7 & $\mathrm{~T}$ & 3600 & $3.26 \mathrm{E}+08$ \\
\hline A & $\mathrm{M}$ & $\begin{array}{l}\text { neos- } \\
5140963- \\
\text { mincio }\end{array}$ & $2.55 E+06$ & $1.44 \mathrm{E}+04$ & $5.74 \mathrm{E}+05$ & 0.05 & 9 & T & 3600 & $2.26 \mathrm{E}+08$ \\
\hline D & $M$ & $\begin{array}{l}\text { neos- } \\
5140963- \\
\text { mincio }\end{array}$ & $2.54 \mathrm{E}+06$ & $1.44 \mathrm{E}+04$ & $5.04 \mathrm{E}+05$ & 1.33 & 6 & $\mathrm{~T}$ & 3600 & $1.81 E+08$ \\
\hline A & B & $\begin{array}{l}\text { neos- } \\
5140963- \\
\text { mincio }\end{array}$ & $2.49 E+06$ & $1.44 \mathrm{E}+04$ & $7.29 E+05$ & 0.11 & 5 & $\mathrm{~T}$ & 3600.1 & $3.59 E+08$ \\
\hline $\mathrm{D}$ & B & binkar10_1 & $5.52 E+06$ & $6.77 \mathrm{E}+03$ & $1.14 \mathrm{E}+06$ & 0.28 & 8 & $\mathrm{~T}$ & 3600.1 & $7.01 E+08$ \\
\hline A & $\mathrm{M}$ & binkar10_1 & $7.37 E+06$ & $\mathrm{~N}$ & $8.41 E+05$ & 0 & 0 & $T$ & 3600.1 & $7.05 E+08$ \\
\hline D & $\mathrm{M}$ & binkar10_1 & $3.92 E+06$ & $6.74 \mathrm{E}+03$ & $7.73 E+05$ & 176.71 & 5 & $T$ & 3600 & $3.89 E+08$ \\
\hline A & B & binkar10_1 & $1.39 \mathrm{E}+07$ & $7.39 \mathrm{E}+03$ & $1.54 \mathrm{E}+06$ & 24.91 & 8 & $\mathrm{~T}$ & 3600.2 & $1.46 \mathrm{E}+09$ \\
\hline $\mathrm{D}$ & B & $\begin{array}{l}\text { exp-1-500-5- } \\
5\end{array}$ & $4.74 E+06$ & $9.10 E+04$ & $2.93 E+06$ & 0.26 & 12 & $\mathrm{~T}$ & 3600.1 & $8.48 E+08$ \\
\hline A & $M$ & $\begin{array}{l}\text { exp-1-500-5- } \\
5\end{array}$ & $1.82 \mathrm{E}+06$ & $\mathrm{~N}$ & $1.02 E+06$ & 0 & 0 & $\mathrm{~T}$ & 3600 & $3.50 E+08$ \\
\hline D & $\mathrm{M}$ & $\begin{array}{l}\text { exp-1-500-5- } \\
5\end{array}$ & $4.02 E+06$ & $\mathrm{~N}$ & $2.35 E+06$ & 0 & 0 & $\mathrm{~T}$ & 3600.1 & $6.65 \mathrm{E}+08$ \\
\hline
\end{tabular}




\begin{tabular}{|c|c|c|c|c|c|c|c|c|c|c|}
\hline VDS & NS & model & $\begin{array}{r}\text { simplex } \\
\text { it. }\end{array}$ & incu. Sol. & nodes & $\begin{array}{r}\text { 1st fea. } \\
\text { Time }\end{array}$ & $\begin{array}{r}\text { fea. } \\
\text { nodes }\end{array}$ & $\begin{array}{l}\text { exit } \\
\text { code }\end{array}$ & time & memory \\
\hline $\mathrm{A}$ & B & $\begin{array}{l}\text { exp-1-500-5- } \\
5\end{array}$ & $8.30 \mathrm{E}+06$ & $1.45 \mathrm{E}+05$ & $2.49 \mathrm{E}+06$ & 0.03 & 33 & $\mathrm{~T}$ & 3600.1 & $1.15 \mathrm{E}+09$ \\
\hline D & B & beavma & $2.11 \mathrm{E}+06$ & $4.06 \mathrm{E}+05$ & $1.15 \mathrm{E}+06$ & 0.05 & 8 & $\mathrm{~T}$ & 3600.1 & $5.67 \mathrm{E}+08$ \\
\hline $\mathrm{A}$ & $M$ & beavma & $7.86 \mathrm{E}+05$ & $\mathrm{~N}$ & $7.19 E+05$ & 0 & 0 & $\mathrm{~T}$ & 3600 & $3.87 E+08$ \\
\hline $\mathrm{D}$ & $\mathrm{M}$ & beavma & $1.21 \mathrm{E}+06$ & $3.83 E+05$ & $5.10 \mathrm{E}+05$ & 0.08 & 9 & $\mathrm{~T}$ & 3600 & $1.57 \mathrm{E}+08$ \\
\hline $\mathrm{A}$ & B & beavma & $8.34 \mathrm{E}+05$ & $\mathrm{~N}$ & $6.39 \mathrm{E}+05$ & 0 & 0 & $\mathrm{~T}$ & 3600 & $3.29 E+08$ \\
\hline $\mathrm{D}$ & B & gen-ip021 & $2.83 E+06$ & $2.36 \mathrm{E}+03$ & $1.06 \mathrm{E}+06$ & 0 & 0 & $\mathrm{~T}$ & 3600 & $3.02 E+08$ \\
\hline $\mathrm{A}$ & $M$ & gen-ip021 & $2.04 \mathrm{E}+06$ & $2.36 \mathrm{E}+03$ & $6.89 \mathrm{E}+05$ & 0.1 & 2 & $\mathrm{~T}$ & 3600 & $2.53 \mathrm{E}+08$ \\
\hline $\mathrm{D}$ & $\mathrm{M}$ & gen-ip021 & $1.98 \mathrm{E}+06$ & $2.36 \mathrm{E}+03$ & $6.19 \mathrm{E}+05$ & 0 & 0 & $\mathrm{~T}$ & 3600 & $1.69 \mathrm{E}+08$ \\
\hline A & B & gen-ip021 & $2.33 \mathrm{E}+06$ & $2.36 \mathrm{E}+03$ & $8.85 \mathrm{E}+05$ & 0 & 0 & $\mathrm{~T}$ & 3600 & $3.88 \mathrm{E}+08$ \\
\hline $\mathrm{D}$ & B & $\mathrm{k} 16 \times 240 \mathrm{~b}$ & $6.19 E+06$ & $1.32 \mathrm{E}+04$ & $2.57 \mathrm{E}+06$ & 0.04 & 13 & $\mathrm{~T}$ & 3600.1 & $1.17 \mathrm{E}+09$ \\
\hline $\mathrm{A}$ & $M$ & $\mathrm{k} 16 \times 240 \mathrm{~b}$ & $1.45 \mathrm{E}+06$ & $1.20 \mathrm{E}+04$ & $6.99 \mathrm{E}+05$ & 0 & 9 & $\mathrm{~T}$ & 3600.1 & $2.01 E+09$ \\
\hline $\mathrm{D}$ & $\mathrm{M}$ & $\mathrm{k} 16 \times 240 \mathrm{~b}$ & $1.70 \mathrm{E}+06$ & $1.25 \mathrm{E}+04$ & $9.21 \mathrm{E}+05$ & 0.08 & 7 & $\mathrm{~T}$ & 3600 & $8.15 E+08$ \\
\hline A & B & $\mathrm{k} 16 \times 240 \mathrm{~b}$ & $3.18 \mathrm{E}+06$ & $1.21 \mathrm{E}+04$ & $1.16 \mathrm{E}+06$ & 0.01 & 4 & $\mathrm{~T}$ & 3600.2 & $2.39 \mathrm{E}+09$ \\
\hline $\mathrm{D}$ & B & $\operatorname{ran} 12 \times 21$ & $6.04 \mathrm{E}+06$ & $3.79 \mathrm{E}+03$ & $1.49 \mathrm{E}+06$ & 0.03 & 13 & $\mathrm{~T}$ & 3600.1 & $8.85 \mathrm{E}+08$ \\
\hline $\mathrm{A}$ & $\mathrm{M}$ & $\operatorname{ran} 12 \times 21$ & $3.77 \mathrm{E}+06$ & $3.68 \mathrm{E}+03$ & $6.09 \mathrm{E}+05$ & 0.01 & 10 & $\mathrm{~T}$ & 3600.1 & $8.15 \mathrm{E}+08$ \\
\hline $\mathrm{D}$ & $M$ & $\operatorname{ran} 12 \times 21$ & $3.22 \mathrm{E}+06$ & $3.72 \mathrm{E}+03$ & $6.99 \mathrm{E}+05$ & 0.06 & 7 & $\mathrm{~T}$ & 3600.1 & $7.18 \mathrm{E}+08$ \\
\hline $\mathrm{A}$ & $\mathrm{B}$ & $\operatorname{ran} 12 \times 21$ & $5.95 \mathrm{E}+06$ & $3.73 E+03$ & $1.03 E+06$ & 0.01 & 19 & $\mathrm{~T}$ & 3600.1 & $1.06 \mathrm{E}+09$ \\
\hline D & B & $\begin{array}{l}\text { nexp-50-20- } \\
1-1\end{array}$ & $7.14 \mathrm{E}+06$ & $3.00 \mathrm{E}+01$ & $2.40 \mathrm{E}+06$ & 0.04 & 4 & $\mathrm{~T}$ & 3600.1 & $7.09 \mathrm{E}+08$ \\
\hline A & $\mathrm{M}$ & $\begin{array}{l}\text { nexp-50-20- } \\
1-1\end{array}$ & $5 \mathrm{E}+06$ & $\mathrm{~N}$ & $44 \mathrm{E}+06$ & 0 & 0 & $\mathrm{~T}$ & 3600 & $4.29 \mathrm{E}+08$ \\
\hline D & $\mathrm{M}$ & $\begin{array}{l}\text { nexp-50-20- } \\
1-1\end{array}$ & $4.09 \mathrm{E}+06$ & $\mathrm{~N}$ & $1.58 \mathrm{E}+06$ & 0 & 0 & $\mathrm{~T}$ & 3600 & $5.09 \mathrm{E}+08$ \\
\hline $\mathrm{A}$ & B & $\begin{array}{l}\text { nexp-50-20- } \\
1-1\end{array}$ & $6.18 \mathrm{E}+06$ & $2.90 \mathrm{E}+01$ & $83 \mathrm{E}+06$ & 0.01 & 7 & $\mathrm{~T}$ & 3600.1 & $5.64 \mathrm{E}+08$ \\
\hline $\mathrm{D}$ & B & $\begin{array}{l}\text { neos- } \\
\text { 3072252-nete }\end{array}$ & $3.16 \mathrm{E}+06$ & $1.37 \mathrm{E}+07$ & $20 E+06$ & 0.11 & 12 & $\mathrm{~T}$ & 3600.3 & $6.00 \mathrm{E}+09$ \\
\hline $\mathrm{A}$ & $\mathrm{M}$ & $\begin{array}{l}\text { neos- } \\
\text { 3072252-nete }\end{array}$ & $4.68 \mathrm{E}+06$ & $1.27 \mathrm{E}+07$ & $2.44 \mathrm{E}+06$ & 0.01 & 117 & $\mathrm{~T}$ & 3600.2 & $5.07 \mathrm{E}+09$ \\
\hline $\mathrm{D}$ & $\mathrm{M}$ & $\begin{array}{l}\text { neos- } \\
\text { 3072252-nete }\end{array}$ & $4 \mathrm{E}+07$ & +07 & $1 \mathrm{E}+06$ & 0.08 & 62 & $\mathrm{~T}$ & 3600.1 & $.06 \mathrm{E}+09$ \\
\hline $\mathrm{A}$ & B & $\begin{array}{l}\text { neos- } \\
\text { 3072252-nete }\end{array}$ & $2.26 \mathrm{E}+07$ & $1.77 \mathrm{E}+07$ & $6.67 E+05$ & 0.01 & 13 & $\mathrm{~T}$ & 3600.1 & $9.46 \mathrm{E}+08$ \\
\hline $\mathrm{D}$ & B & $\begin{array}{l}\text { graphdraw- } \\
\text { gemcutter }\end{array}$ & $2.66 \mathrm{E}+06$ & $7.57 \mathrm{E}+03$ & $9.11 E+05$ & 0.07 & 9 & $\mathrm{~T}$ & 3600 & $5.73 \mathrm{E}+08$ \\
\hline A & $\mathrm{M}$ & $\begin{array}{l}\text { graphdraw- } \\
\text { gemcutter }\end{array}$ & $3.29 E+06$ & $7.58 \mathrm{E}+03$ & $7.00 \mathrm{E}+05$ & 0.25 & 22 & $\mathrm{~T}$ & 3600 & $5.75 \mathrm{E}+08$ \\
\hline $\mathrm{D}$ & $M$ & $\begin{array}{l}\text { graphdraw- } \\
\text { gemcutter }\end{array}$ & $2.47 E+06$ & $7.31 \mathrm{E}+03$ & $6.62 E+05$ & 1.28 & 10 & $\mathrm{~T}$ & 3600 & $3.70 \mathrm{E}+08$ \\
\hline $\mathrm{A}$ & B & $\begin{array}{l}\text { graphdraw- } \\
\text { gemcutter }\end{array}$ & $4.61 \mathrm{E}+06$ & $7.90 \mathrm{E}+03$ & $9.91 E+05$ & 0.03 & 9 & $\mathrm{~T}$ & 3600 & $8.95 \mathrm{E}+08$ \\
\hline $\mathrm{D}$ & $\mathrm{B}$ & $\mathrm{r} 50 \times 360$ & $1.04 \mathrm{E}+07$ & $2.52 \mathrm{E}+03$ & $3.54 \mathrm{E}+06$ & 0.15 & 9 & $\mathrm{~T}$ & 3600.2 & $1.12 \mathrm{E}+09$ \\
\hline $\mathrm{A}$ & $\mathrm{M}$ & $\mathrm{r} 50 \times 360$ & $2.58 \mathrm{E}+06$ & $1.79 \mathrm{E}+03$ & $1.43 \mathrm{E}+06$ & 0.3 & 18 & $\mathrm{~T}$ & 3600.1 & $2.53 \mathrm{E}+09$ \\
\hline $\mathrm{D}$ & $\mathrm{M}$ & $\mathrm{r} 50 \times 360$ & $5.71 \mathrm{E}+06$ & $1.77 \mathrm{E}+03$ & $1.61 \mathrm{E}+06$ & 0.85 & 15 & $\mathrm{~T}$ & 3600.1 & $1.15 \mathrm{E}+09$ \\
\hline A & B & $r 50 \times 360$ & $4.46 \mathrm{E}+06$ & $1.91 \mathrm{E}+03$ & $2.68 \mathrm{E}+06$ & 0.01 & 7 & $\mathrm{~T}$ & 3600.1 & $2.02 \mathrm{E}+09$ \\
\hline
\end{tabular}




\begin{tabular}{|c|r|l|r|r|r|r|r|r|r|r|}
\hline VDS & NS & model & $\begin{array}{r}\text { simplex } \\
\text { it. }\end{array}$ & incu. Sol. & nodes & $\begin{array}{r}\text { 1st fea. } \\
\text { Time }\end{array}$ & $\begin{array}{r}\text { fea. } \\
\text { nodes }\end{array}$ & $\begin{array}{r}\text { exit } \\
\text { code }\end{array}$ & time & memory \\
\hline D & $\mathrm{B}$ & $\begin{array}{l}\text { control30-3- } \\
\text { 2-3 }\end{array}$ & $3.38 \mathrm{E}+06$ & $1.69 \mathrm{E}+02$ & $2.09 \mathrm{E}+06$ & 0.05 & 28 & $\mathrm{~T}$ & 3600.1 & $1.54 \mathrm{E}+09$ \\
\hline $\mathrm{A}$ & $\mathrm{M}$ & $\begin{array}{l}\text { control30-3- } \\
2-3\end{array}$ & $2.13 \mathrm{E}+06$ & $\mathrm{~N}$ & $7.87 \mathrm{E}+05$ & 0 & 0 & $\mathrm{~T}$ & 3600 & $5.28 \mathrm{E}+08$ \\
\hline $\mathrm{D}$ & $\mathrm{M}$ & $\begin{array}{l}\text { control30-3- } \\
\text { 2-3 }\end{array}$ & $2.84 \mathrm{E}+07$ & $3.42 \mathrm{E}+01$ & $8.45 \mathrm{E}+06$ & 0.05 & 64 & $\mathrm{~T}$ & 3600 & $1.42 \mathrm{E}+06$ \\
\hline $\mathrm{A}$ & $\mathrm{B}$ & $\begin{array}{l}\text { control30-3- } \\
2-3\end{array}$ & $5.88 \mathrm{E}+06$ & $7.30 \mathrm{E}+00$ & $1.74 \mathrm{E}+06$ & 0.01 & 10 & $\mathrm{~T}$ & 3600.1 & $1.21 \mathrm{E}+09$ \\
\hline
\end{tabular}

Table B.3: List of MIP instances for which neither an integer-optimal solution nor an integer-feasible solution was found by any VDS / NS configuration

\begin{tabular}{|l|}
\hline ex9 \\
\hline neos16 \\
\hline neos-3381206-awhea \\
\hline berlin_5_8_0 \\
\hline nh97_tension \\
\hline csched008 \\
\hline railway_8_1_0 \\
\hline mik-250-1-100-1 \\
\hline momentum2 \\
\hline
\end{tabular}

